Mineração de fluxos contínuos de dados para jogos de computador

Rosane Maria Maffei Vallim 
SERVIÇO DE PÓS-GRADUAÇ̃̃O DO ICMC-USP

Data de Depósito:

Assinatura:

\title{
Mineração de fluxos contínuos de dados para jogos de computador
}

\author{
Rosane Maria Maffei Vallim
}

Orientador: Prof. Dr. André Carlos Ponce de Leon Ferreira de Carvalho

Coorientador: Prof. Dr. João Manuel Portela da Gama

Tese apresentada ao Instituto de Ciências Matemáticas e de Computação - ICMC-USP, como parte dos requisitos para obtenção do título de Doutor em Ciências - Ciências de Computação e Matemática Computacional. VERSÃO REVISADA 
Ficha catalográfica elaborada pela Biblioteca Prof. Achille Bassi e Seção Técnica de Informática, ICMC/USP, com os dados fornecidos pelo(a) autor(a)

Vallim, Rosane Maria Maffei

Mineração de fluxos contínuos de dados para jogos de computador / Rosane Maria Maffei Vallim;

orientador André Carlos Ponce de Leon Ferreira de Carvalho; co-orientador João Manuel Portela da Gama. -- São Carlos, 2013.

142 p.

Tese (Doutorado - Programa de Pós-Graduação em Ciências de Computação e Matemática Computacional) -Instituto de Ciências Matemáticas e de Computação, Universidade de São Paulo, 2013.

1. Jogos computacionais. 2. Modelagem de jogadores. 3. Detecção de mudanças. 4. Fluxos de dados. I. de Carvalho, André Carlos Ponce de Leon Ferreira, orient. II. da Gama, João Manuel Portela, ororient. III. Título. 


\section{Agradecimentos}

Gostaria aqui de expressar meus sinceros agradecimentos a todos aqueles que contribuíram para a realização deste trabalho.

Ao meu orientador, Prof. Dr. André Carlos Ponce de Leon Ferreira de Carvalho, pela sua orientação, apoio, incentivo e suporte durante todas as fases deste projeto de doutorado. Agradeço a confiança depositada pelo Prof. André durante todo o processo, a sua abertura para discutir as decisões tomadas e, principalmente, a sua amizade durante todos os anos que trabalhamos juntos.

Ao Prof. Dr. João Manuel Portela da Gama, meu co-orientador da Universidade do Porto, por sua dedicação ao meu projeto, sempre oferecendo sugestões pertinentes para a melhoria do trabalho.

Quero também agradecer especialmente ao Prof. Dr. Rodrigo Fernandes de Mello por sua contribuição na realização deste trabalho. Todas as discussões, ideias trocadas e auxílios oferecidos contribuíram imensamente para o desenvolvimento deste projeto de doutorado.

Ao Programa de Pós-graduação de Ciências de Computação e Matemática Computacional (PG-CCMC) do Instituto de Ciências Matemáticas e de Computação (ICMC), pela oportunidade concedida ao me aceitar no programa e pela estrutura oferecida durante todo o tempo que passei no ICMC. Agradeço sinceramente a todos os professores que participaram de minha formação e também aos funcionários que estavam sempre dispostos a nos auxiliar.

À Fundação de Amparo a Pesquisa do Estado de São Paulo (FAPESP) pela concessão da bolsa de doutorado e pelo apoio financeiro para realização deste trabalho (processo número 2010/11250-0).

Gostaria de agradecer aos amigos Carolina Evaristo Scarton, Debora Maria Rossi de Medeiros, Eduardo Alves da Silva Ticianelli, Jonathan Andrade Silva, José Augusto Andrade Filho, Paulo Henrique Ribeiro Gabriel e Thiago Ferreira Covões.

Ao Cleber Soares Mori, por sua paciência, dedicação, carinho e apoio durante boa parte deste doutorado.

Finalmente, agradeço aos meus pais, Célia de Assumpção Maffei Vallim e Juventino Araújo Vallim Filho, por terem me apoiado incondicionalmente em todos os passos da minha vida, sendo não somente pais, mas amigos, parceiros e exemplos de vida. 
Um dos desafios da Inteligência Artificial aplicada em jogos é o aprendizado de comportamento, em que o objetivo é utilizar estatísticas obtidas da interação entre jogador e jogo de modo a reconhecer características particulares de um jogador ou monitorar a evolução de seu comportamento no decorrer do tempo. A maior parte dos trabalhos na área emprega modelos previamente aprendidos, por meio da utilização de algoritmos de Aprendizado de Máquina. Entretanto, são poucos os trabalhos que consideram que o comportamento de um jogador pode evoluir no tempo e que, portanto, reconhecer quando essas mudanças ocorrem é o primeiro passo para produzir jogos que se adaptam automaticamente às capacidades do jogador. Para detectar variações comportamentais em um jogador, são necessários algoritmos que processem dados de modo incremental. Esse pré-requisito motiva o estudo de algoritmos para detecção de mudanças da área de Mineração em Fluxos Contínuos de Dados. Entretanto, algumas das características dos algoritmos disponíveis na literatura inviabilizam sua aplicação direta ao problema de detecção de mudança em jogos. Visando contornar essas dificuldades, esta tese propõe duas novas abordagens para detecção de mudanças de comportamento. A primeira abordagem é baseada em um algoritmo incremental de agrupamento e detecção de novidades que é independente do número e formato dos grupos presentes nos dados e que utiliza um mecanismo de janela deslizante para detecção de mudanças de comportamento. A segunda abordagem, por outro lado, é baseada na comparação de janelas de tempo consecutivas utilizando espectrogramas gerados a partir dos dados contidos em cada janela. Os resultados experimentais utilizando simulações e dados de jogos comerciais indicam a aplicabilidade dos algoritmos propostos na tarefa de detecção de mudanças de comportamento de um jogador, assim como mostram sua vantagem em relação a outros algoritmos para detecção de mudança disponíveis na literatura.

Palavras-chave: jogos computacionais, modelagem de jogadores, detecção de mudança de comportamento, fluxos de dados. 
One of the challenges of Artificial Intelligence applied to games is behavior learning, where the objective is to use statistics derived from the interaction between the player and the game environment in order to recognize particular player characteristics or to monitor the evolution of a player's behavior along time. The majority of work developed in this area applies models that were previously learned through the use of Machine Learning techniques. However, only a few pieces of work consider that the player's behavior can evolve over time and, therefore, recognizing when behavior changes happen is the first step towards the production of games that adapt to the player's needs. In order to detect changes in the behavior of a player, incremental algorithms are necessary, what motivates the study of change detection algorithms from the area of Data Stream Mining. However, some of the characteristics of the algorithms available in the literature make their application to the task of change detection in games unfeasible. To overcome these difficulties, this work proposes two new approaches for change detection. The first approach is based on an incremental clustering and novelty detection algorithm which is independent of the number and format of clusters and uses a mechanism for change detection based on sliding windows. The second approach, on the other hand, is based on the comparison of consecutive time windows using spectrograms created from the data inside each window. Experimental results using simulations and data from commercial games indicate the applicability of the proposed algorithms in the task of detecting a player's changing behavior, as well as present their advantage when compared to other change detection algorithms available in the literature.

Keywords: computer games, player modeling, behavior change detection, data streams. 


\section{Lista de Algoritmos}

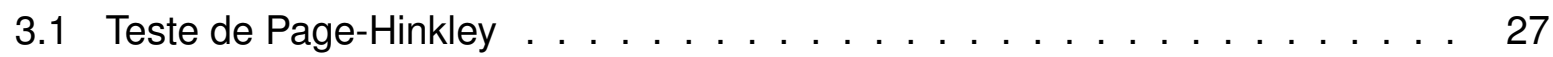

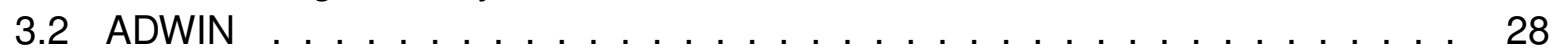

3.3 CluStream . . . . . . . . . . . . . . . . . . . . . . . . . . . . . 30

3.4 DenStream . . . . . . . . . . . . . . . . . . . . . 33

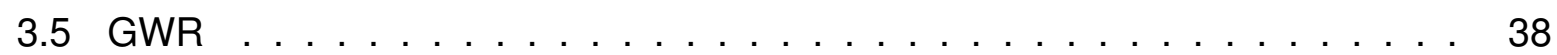

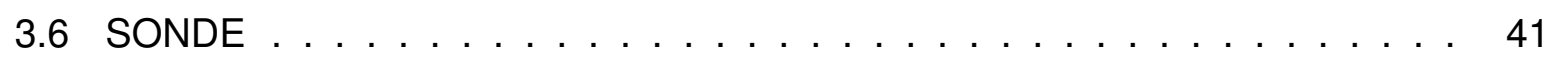

4.1 M-DBScan: etapa de agrupamento incremental por densidade . . . . . . . . 48

4.2 M-DBScan: etapa de detecção de novidades . . . . . . . . . . . . . . . . . 53

4.3 M-DBScan: etapa de detecção de mudança de comportamento . . . . . . . 55

4.4 M-DBScan V2: etapa de agrupamento incremental por densidade . . . . . . . . . 63

4.5 M-DBScan*: etapa de agrupamento incremental por densidade . . . . . . . . . 85

5.1 Windowing Specgram . . . . . . . . . . . . . . . . 108 
4.1 Exemplo de entropia de uma variável aleatória. Adaptado de Shannon (1948). 50

4.2 Dois estados consecutivos de uma CM e respectivos níveis de entropia. . . . 51

4.3 Distribuição de exemplos por grupo em dois instantes de tempo consecutivos com correspondentes valores de entropia. . . . . . . . . . . . . . . . . 53

4.4 Variação de entropia espacial, desvio padrão e detecção de novidades para o conjunto de dados FixedDenSpatial. . . . . . . . . . . . . . . . . . .

4.5 Variação de entropia espacial, desvio padrão móvel e detecção de novidades para o conjunto FixedDenSpatial: (a) utilizando M-DBScan; (b) utilizando M-DBScan V2. . . . . . . . . . . . . . . . . . . . .

4.6 Variação de entropia, desvio padrão móvel e detecção de novidades para o conjunto VarDenAddCluster: (a) utilizando M-DBScan V2; (b) utilizando MKMeans. . . . . . . . . . . . . . . . . .

4.7 Variação de entropia, desvio padrão móvel e detecção de novidades para a sexta simulação: (a) utilizando MSDR1; (b) utilizando MSDR1R2. . . . . . . .

4.8 Boxplots para os atrasos obtidos nas simulações de FPS por cada um dos algoritmos investigados.

4.9 Boxplots para os atrasos obtidos nos conjuntos de RTS por cada um dos algoritmos investigados.

5.1 Espectrograma gerado a partir de onda seno com frequência de $440 \mathrm{~Hz}$. . . 103

5.2 Espectrogramas gerados a partir de: (a) Onda seno com frequência de 440 $\mathrm{Hz}$. (b) Onda seno com frequência de $258 \mathrm{~Hz}$. (c) Concatenação das ondas de 440 e $258 \mathrm{~Hz}$, nessa ordem. (d) Concatenação das ondas de 258 e 440 $\mathrm{Hz}$, nessa ordem.

5.3 Espectrogramas gerados a partir de: (a) Concatenação das ondas de 440 e $258 \mathrm{~Hz}$, nessa ordem. (b) Concatenação das ondas de 258 e $440 \mathrm{~Hz}$, nessa ordem. (c ) Criação de matrizes bidimensionais com a primeira e segunda colunas contendo, respectivamente, as ondas seno de 440 e $258 \mathrm{~Hz}$. (d) Criação de matrizes bidimensionais com a primeira e segunda colunas contendo, respectivamente, as ondas seno de 258 e $440 \mathrm{~Hz}$. . . . . . . . . . 107

5.4 Gráfico com valores de NCD para duas ondas unidimensionais distintas. . . 109

5.5 Diferenças entre valores de NCD consecutivos para o algoritmo WS no sexto conjunto de dados de FPS. A linha vermelha representa o limiar $\eta=0,007$ utilizado para sinalizar uma mudança de comportamento. 
5.6 Diferenças entre valores de NCD consecutivos para o algoritmo ws no décimo primeiro conjunto de dados de RTS. A linha vermelha representa o limiar $\eta=0,0035$ utilizado para sinalizar uma mudança de comportamento. . . . .

5.7 Detecção de mudança de comportamento no primeiro conjunto de dados de FPS. A linha vermelha representa o limiar utilizado para sinalizar uma mudança de comportamento. (a) Diferença entre valores de NCD consecutivos para o algoritmo WS. (b) Diferença entre valores de NCD consecutivos para o algoritmo WSE. (c) Valores para a estatística calculada pelo PHT para o algoritmo WSE-PHT.

5.8 Boxplots para os atrasos obtidos nos conjuntos de dados de FPS por cada um dos algoritmos investigados. . . . . . . . . . . . . . . . .

5.9 Detecção de mudança de comportamento no décimo primeiro conjunto de dados de RTS. A linha vermelha representa o limiar utilizado para sinalizar uma mudança de comportamento. (a) Diferença entre valores de NCD consecutivos para o algoritmo WS. (b) Diferença entre valores de NCD consecutivos para o algoritmo WSE. (c) Valores para a estatística calculada pelo PHT para

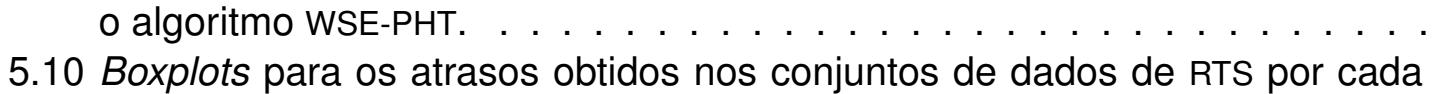
um dos algoritmos investigados. 


\section{Lista de Tabelas}

2.1 Principais características dos trabalhos apresentados nesta seção. . . . . . . 14

2.2 Principais características dos trabalhos apresentados nesta seção. . . . . . . 16

2.3 Principais características dos trabalhos apresentados nesta seção. . . . . . . 19

4.1 Características dos conjuntos de dados artificiais. . . . . . . . . . . . . . . 57

4.2 Valor do parâmetro $\epsilon$ utilizado em cada conjunto de dados. . . . . . . . . . . . 59

4.3 Resultados para a medida de entropia espacial utilizando M-DBScan. . . . . . 59

4.4 Resultados para a medida de entropia temporal utilizando M-DBScan. . . . . 60

4.5 Resultados para a medida de entropia espacial: comparação entre M-DBScan e M-DBScan V2 . . . . . . . . . . . . . . . . . . . . . . . . . . . . . 64

4.6 Resultados para a medida de entropia temporal: comparação entre M-DBScan e M-DBScan V2 . . . . . . . . . . . . . . . . . . . . . . . . . . 64

4.7 Resultados utilizando entropia espacial: comparação entre M-DBScan V2 e MK-Means. . . . . . . . . . . . . . . . . . . .

4.8 Atraso, em número de exemplos, para detecção de mudanças de comportamento com respeito à utilização da entropia espacial. C1, C2 e C3, representam, respectivamente, a primeira, segunda e terceira mudança ocorrendo nos dados. Uma linha tracejada representa a não detecção da respectiva mudança, enquanto que o sinal ${ }^{* * *}$ representa uma mudança que não se aplica ao respectivo conjunto de dados. . . . . . . . . . . . . . . . . .

4.9 Resultados utilizando entropia temporal: comparação entre M-DBScan V2 e MK-Means.

4.10 Atraso, em número de exemplos, para detecção de mudanças de comportamento com respeito à utilização da entropia temporal. C1, C2 e C3, representam, respectivamente, a primeira, segunda e terceira mudança ocorrendo nos dados. Uma linha tracejada representa a não detecção da respectiva mudança, enquanto que o sinal ${ }^{* *}$ representa uma mudança que não se aplica ao respectivo conjunto de dados. . . . . . . . . . . . . . . . .

4.11 Valores de VP, FP e F1 obtidos por M-DBScan V2 utilizando entropia espacial em cada uma das simulações.

4.12 Valores de VP, FP e F1 totais utilizando M-DBScan V2. A última coluna contém os atrasos médios para detecção de mudança, em número de exemplos, e respectivos desvios padrão.

4.13 Valores de VP, FP e F1 obtidos por M-DBScan V2 utilizando entropia temporal em cada uma das simulações. 
4.14 Valores de $F 1$ obtidos em cada uma das simulações para cada configuração do M-DBScan V2 estudada. . . . . . . . . . . . . . . . . . . .

4.15 Valores de VP, FP e $F 1$ totais utilizando diferentes configurações do M-DBScan V2. A última coluna contém os atrasos médios para detecção de mudança, em número de exemplos, e respectivos desvios padrão.

4.16 Testes de hipótese entre configurações considerando F1. O símbolo - é utilizado para comparações desconsideradas. O símbolo = representa igualdade estatística entre configurações consideradas. Os símbolos $\wedge$ e $<$ são utilizados para representar existência de diferença estatística entre os configurações consideradas e indicam, respectivamente, vantagem para a configuração da coluna e vantagem para a configuração da linha. . . . . . . . . .

4.17 Valores de F1 obtidos por M-DBScan* em cada uma das simulações para cada configuração estudada.

4.18 Valores de VP, FP e F1 totais utilizando diferentes configurações do M-DBScan*. A última coluna contém os atrasos médios para detecção de mudança, em número de exemplos, e respectivos desvios padrão. . . . . . . . . . . . . . .

4.19 Testes de hipótese entre Micro-Clustering DBScan Version 2 (M-DBScan V2) e M-DBScan*, utilizando as mesmas configurações, de acordo com os valores de F1 obtidos. O símbolo - é utilizado para comparações desconsideradas. O símbolo = representa igualdade estatística entre configurações consideradas. Os símbolos $\wedge \mathrm{e}<$ são utilizados para representar existência de diferença estatística entre os configurações consideradas e indicam, respectivamente, vantagem para a configuração da coluna e vantagem para a configuração da linha. . . . . . . . . . . . . . . . . . . . . .

4.20 F1 obtida pelos algoritmos PHT e ADWIN em cada um dos conjuntos de dados de FPS.

4.21 Valores de VP, FP e F1 totais obtidos por cada configuração do M-DBScan* e pelos algoritmos PHT e ADWIN. A última coluna contém os atrasos médios para detecção de mudança, em número de exemplos, e respectivos desvios padrão.

4.22 Testes de hipótese entre as configurações de M-DBScan*, PHT e ADWIN, de acordo com os valores de $F 1$ obtidos. O símbolo - é utilizado para comparações desconsideradas. O símbolo $=$ representa igualdade estatística entre configurações consideradas. Os símbolos $\wedge \mathrm{e}<$ são utilizados para representar existência de diferença estatística entre os configurações consideradas e indicam, respectivamente, vantagem para a configuração da coluna e vantagem para a configuração da linha.

4.23 Estatísticas sobre atrasos para detecção de mudanças nas simulações de FPS: mínimo, primeiro quartil, mediana, média com desvio padrão, terceiro quartil e máximo.

4.24 Características dos conjuntos de dados de RTS. . . . . . . . . . . . . . . . .

4.25 Valores de F1 obtidos em cada um dos conjuntos de dados de RTS utilizados para cada configuração estudada de M-DBScan* e para os algoritmos PHT e ADWIN.

4.26 Valores de VP, FP e F1 totais obtidos nos conjuntos de RTS por cada configuração do M-DBScan* e pelos algoritmos PHT e ADWIN. A última coluna contém os atrasos médios para detecção de mudança, em número de exemplos, e respectivos desvios padrão. 
4.27 Testes de hipótese entre as configurações de M-DBScan*, PHT e ADWIN, de acordo com os valores de F1 obtidos. O símbolo - é utilizado para comparações desconsideradas. O símbolo $=$ representa igualdade estatística entre configurações consideradas. Os símbolos $\wedge \mathrm{e}<$ são utilizados para representar existência de diferença estatística entre os configurações consideradas e indicam, respectivamente, vantagem para a configuração da coluna e vantagem para a configuração da linha. . . . . . . . . . . . . . .

4.28 Estatísticas sobre atrasos para detecção de mudanças nos conjuntos de RTS: mínimo, primeiro quartil, mediana, média com desvio padrão, terceiro quartil e máximo.

5.1 F1 obtida pelos algoritmos WS, PHT e ADWIN em cada um dos conjuntos de dados de FPS.

5.2 Valores de VP, FP e F1 totais obtidos nos conjuntos de dados de FPS. A última coluna contém os atrasos médios para detecção de mudança, em número de exemplos, e respectivos desvios padrão.

5.3 F1 obtida pelos algoritmos WS, PHT e ADWIN em cada um dos conjuntos de dados de RTS. . . . . . . . . . . . . . . . . . . . . . .

5.4 Valores de VP, FP e F1 totais obtidos nos conjuntos de dados de RTS. A última coluna contém os atrasos médios para detecção de mudança, em número de exemplos, e respectivos desvios padrão.

5.5 F1 obtida pelos algoritmos WS, WSE, WSE-PHT, PHT e ADWIN em cada um dos conjuntos de dados de FPS.

5.6 Valores de VP, FP e F1 totais obtidos nos conjuntos de dados de FPS. A última coluna contém os atrasos médios para detecção de mudança, em número de exemplos, e respectivos desvios padrão.

5.7 Testes de hipótese entre pares de algoritmos considerando $F 1$ nos conjuntos de dados de FPS. O símbolo - é utilizado para comparações desconsideradas. O símbolo = representa igualdade estatística entre os algoritmos considerados. Os símbolos $\wedge \mathrm{e}<$ são utilizados para representar existência de diferença estatística entre os algoritmos considerados e indicam, respectivamente, vantagem para o algoritmo da coluna e vantagem para o algoritmo da linha.

5.8 Estatísticas sobre atrasos para detecção de mudanças nos conjuntos de dados de FPS: mínimo, primeiro quartil, mediana, média com desvio padrão, terceiro quartil e máximo.

5.9 F1 obtida pelos algoritmos WS, WSE, WSE-PHT, PHT e ADWIN em cada um dos conjuntos de dados de RTS. . . . . . . . . . . . . . . . . . . .

5.10 Valores de VP, FP e F1 totais obtidos nos conjuntos de dados de RTS. A última coluna contém os atrasos médios para detecção de mudança, em número de exemplos, e respectivos desvios padrão.

5.11 Testes de hipótese entre pares de algoritmos considerando $F 1$ nos conjuntos de dados de RTS. O símbolo - é utilizado para comparações desconsideradas. O símbolo = representa igualdade estatística entre os algoritmos considerados. Os símbolos $\wedge \mathrm{e}<$ são utilizados para representar existência de diferença estatística entre os algoritmos considerados e indicam, respectivamente, vantagem para o algoritmo da coluna e vantagem para o algoritmo da linha. 
5.12 Estatísticas sobre atrasos para detecção de mudanças nos conjuntos de dados de RTS: mínimo, primeiro quartil, mediana, média com desvio padrão, terceiro quartil e máximo. . . . . . . . . . . . . . . . . . . . . 120 
$A D$

ADWIN

AG

AM

CM

CTF

DA

DFT

FAAD

FCWM

FFT

FP

FPS

GWR

IA

K-NN

M-DBScan

M-DBScan V2

M-DBScan*

MK-Means

MFCD
Árvore de Decisão

Adaptive Windowing

Algoritmo Genético

Aprendizado de Máquina

Cadeia de Markov

Capture the Flag

Detecção Atrasada

Discrete Fourier Transform

Floresta Aleatória de Árvores de Decisão

Fixed Cumulative Windows Model

Fast Fourier Transform

Falso Positivo

First Person Shooter

Grow When Required

Inteligência Artificial

K-Nearest Neighbors

Micro-Clustering DBScan

Micro-Clustering DBScan Version 2

Micro-Clustering DBScan*

Micro-Clustering K-Means

Mineração em Fluxos Contínuos de Dados 
MLP

NB

NCD

ND

NNge

OLINDDA

PHT

PM

RB

RNA

RSOM

RTS

SFS

SLC

SoM

SONDE

UT2004

VP

ws

WSE

WSE-PHT
Multi-Layer Perceptron

Naive-Bayes

Normalized Compressed Distance

Não Detecção

Non-Nested Generalized Exemplars

OnLIne Novelty and Drift Detection Algorithm

Page-Hinkley Test

Player Modeling

Redes Bayesianas

Rede Neural Artificial

Recurrent Self-Organizing Map

Real-Time Strategy

Sequential Forward Selection

Sequential Leader Clustering

Self-Organizing Map

Self-Organizing Novelty Detection Neural Network

Unreal Tournament 2004

Verdadeiro Positivo

Windowing Specgram

Windowing Specgram Extended

Windowing Specgram Extended with PHT 


\section{Lista de Símbolos}

$\delta_{P H T}$ Magnitude de mudanças que são permitidas no PHT

$\epsilon_{P H T}$ Limiar separador do PHT

$\delta_{A D W I N}$ Confiança do teste estatístico para o ADWIN

$\mu$ Peso mínimo de um micro-cluster

$\beta$ Limiar de outliers relativo a $p$-micro-clusters

$\lambda$ Parâmetro que controla o decaimento no peso dos micro-clusters

$\epsilon$ Limite máximo no raio de um micro-cluster

$\eta_{s}$ Fator de ponderação da entropia espacial

$\eta_{t}$ Fator de ponderação da entropia temporal

$\gamma$ Fator de ponderação da média móvel de entropias

$\delta$ Fator de ponderação do desvio padrão de entropias

$\theta$ Número de desvios padrão a partir da média em uma distribuição Normal

$k$ Tamanho da janela deslizante para detectar mudanças de comportamento

$l$ Tamanho da janela da restrição $\mathrm{R} 2$

minNovelties Número mínimo de novidades que devem ocorrer para que uma mudança de comportamento seja detectada

$\Phi$ Média móvel de valores de entropia

$\Omega$ Desvio padrão móvel de valores de entropia

$\tau$ Limiar dinâmico que separa eventos normais de novidades

$\mathbb{H}_{t}(\cdot)$ Valor de entropia no instante de tempo $t$

SamplingRate Número de exemplos por segundo

FrameSize Tamanho da janela da DFT 
$N$ Tamanho da janela de dados

$\eta$ Limiar separador entre valores de NCD para detecção de mudança

$\alpha$ Valor adicionado ao NCD 
1 Introdução 1

1.1 Contextualização e Motivação . . . . . . . . . . . . . . . . . . . . 1

1.2 Objetivo e Hipóteses . . . . . . . . . . . . . . . . . . . . . . 4

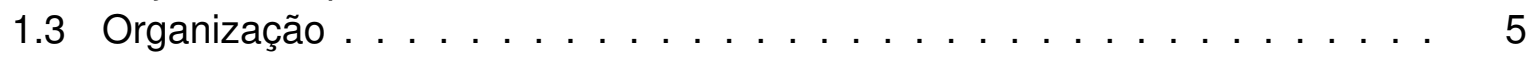

2 Modelagem Automática de Comportamento em Jogos Computacionais 7

2.1 Considerações Iniciais . . . . . . . . . . . . . . . . . . . . 7

2.2 Aprendizado de Comportamento a Partir de Dados de Jogadores . . . . . . 8

2.3 Utilização de Dados de Jogo para Verificação de Decisões de Projeto . . . . 14

2.4 Identificação de Características de Jogadores em Tempo de Execução . . . 17

2.5 Metodologias para Avaliação de Desempenho . . . . . . . . . . . . . 20

2.6 Considerações Finais . . . . . . . . . . . . . . . . . . . . . . . . . . . . . . 21

3 Detecção de Mudança de Comportamento em Fluxos de Dados 23

3.1 Considerações Iniciais . . . . . . . . . . . . . . . . . . . . . . . 23

3.2 Algoritmos Estatísticos . . . . . . . . . . . . . . . . . . . . . . . . . . . . . . . . . . . . . . 26

3.2.1 Page-Hinkley Test . . . . . . . . . . . . . . . . . . . . . . . . . . . 26

3.2.2 Adaptive Windowing . . . . . . . . . . . . . . . . . . . . . . . . 27

3.3 Algoritmos de Agrupamento . . . . . . . . . . . . . . . . . . . . . . . . . . . . . . 29

3.3 .1 CluStream . . . . . . . . . . . . . . . . . . . . . . 29

3.3 .2 DenStream . . . . . . . . . . . . . . . . . . . . . . . . . . . . . . . 32

3.4 Agrupamento e Detecção de Novidades . . . . . . . . . . . . . . . . . . . . 36

3.4.1 Rede Neural Grow When Required . . . . . . . . . . . . . . . . . 37

3.4.2 Self-Organizing Novelty Detection Neural Network . . . . . . . . . . 40

3.5 Considerações Finais . . . . . . . . . . . . . . . . . . . . . . . . 44

4 M-DBScan*: Uma Abordagem Incremental para Detecção de Mudanças de Comportamento $\quad 45$

4.1 Considerações Iniciais . . . . . . . . . . . . . . . . . . . . . . . . . . . . 45

4.2 Agrupamento Incremental por Densidade . . . . . . . . . . . . . . . . 47

4.3 Detecção de Novidade . . . . . . . . . . . . . . . . . . . . . . . . . . . . . . . . . . . . . . . . . . 40

4.3.1 Medida de Entropia Temporal . . . . . . . . . . . . . . . . . . . . 50

4.3 .2 Medida de Entropia Espacial . . . . . . . . . . . . . . . . . . . . 52

4.3.3 Usando Entropia para Detectar Novidades . . . . . . . . . . . . . . 52

4.4 Detecção de Mudança de Comportamento . . . . . . . . . . . . . . . . . . 54 
4.5 Experimentos Iniciais em Dados Artificiais . . . . . . . . . . . . . . . . . 54

4.5.1 Conjuntos de Dados . . . . . . . . . . . . . . . . . . . . . . . . 56

4.5 .2 Configuração dos experimentos . . . . . . . . . . . . . 58

4.5 .3 Resultados . . . . . . . . . . . . . . . . . . . 59

4.5 .4 Análise dos Resultados . . . . . . . . . . . . . . . . . . . . . . . . . . . . . . . . . . . . . . .

4.6 Redução de Falsos Positivos . . . . . . . . . . . . . . . . . . . . . . . . . . 61

4.6 .1 Modificação Proposta . . . . . . . . . . . . . . . . . . . . . . 61

4.6 .2 Experimentos e Resultados . . . . . . . . . . . . . . . . . . . . 62

4.7 Comparação com Abordagem por Proximidade . . . . . . . . . . . . . . . . 66

4.7.1 Abordagem de Agrupamento Utilizada . . . . . . . . . . . . . . . . . . . 66

4.7 .2 Experimentos e Resultados . . . . . . . . . . . . . . . . . . . . . . 67

4.8 Aplicação em Dados de Jogos . . . . . . . . . . . . . . . . . . . . . . . . 72

4.8 .1 Avaliação Inicial em Dados de FPS . . . . . . . . . . . . . . . . 72

4.8.2 Novas Medidas para Detecção de Novidades . . . . . . . . . . . . . 77

4.8.3 Redução de Atraso para Detecção . . . . . . . . . . . . . . . . . . . . . . . . . . . . 84

4.8 .4 Aplicação em Dados de RTS . . . . . . . . . . . . . . . . . . . . . . 92

4.9 Considerações Finais . . . . . . . . . . . . . . . . . . . . . . . . . . . . . . 98

5 WSE: Uma Abordagem Baseada em Janelas de Tempo para Detecção de Mudanças de Comportamento 101

5.1 Considerações Iniciais . . . . . . . . . . . . . . . . . . . . . . . . . 101

5.2 Geração de Espectrogramas . . . . . . . . . . . . . . . . . . . . . . . . 102

5.3 Detectando Mudanças Usando Espectrogramas . . . . . . . . . . . . . . . 104

5.3.1 Espectrogramas para Representar Comportamentos Variáveis . . . 104

5.3.2 Espectrogramas para Dados Multidimensionais . . . . . . . . . . . . . 106

5.3.3 Medida de Comparação entre Espectrogramas . . . . . . . . . . . . 106

5.3.4 Detectando Mudanças de Comportamento . . . . . . . . . . . . . . 108

5.4 Experimentos Iniciais em Jogos . . . . . . . . . . . . . . . . . . . . . . . . 110

5.4.1 Configuração dos Experimentos . . . . . . . . . . . . . . . . . . 110

5.4 .2 Resultados . . . . . . . . . . . . . . . . . . . . . 111

5.4.3 Análise dos Resultados . . . . . . . . . . . . . . . . . . . . . . . . 111

5.5 Detectando Comportamentos Similares . . . . . . . . . . . . . . . . . 114

5.6 Experimentos Adicionais . . . . . . . . . . . . . . . . . . . . . . 116

5.6.1 Configuração dos Experimentos . . . . . . . . . . . . . . . . . 116

5.6 .2 Resultados . . . . . . . . . . . . . . . . . . . . 116

5.6.3 Análise dos Resultados . . . . . . . . . . . . . . . . . . . . . . . 120

5.7 Considerações Finais . . . . . . . . . . . . . . . . . . . . . . . . . . 121

6 Conclusões 127

$\begin{array}{ll}\text { Referências } & 132\end{array}$

A Complexidade Computacional dos Algoritmos Propostos $\quad 139$

A.1 M-DBScan* . . . . . . . . . . . . . . . . . . . . . . . . 139

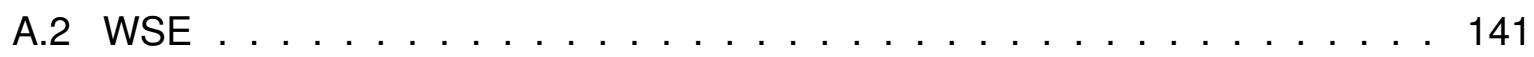




\subsection{Contextualização e Motivação}

Jogos eletrônicos são aplicações computacionais que movimentam bilhões de dólares por ano (LUCAS, 2009). Nas últimas décadas, essas aplicações contribuíram fortemente para a evolução de técnicas da Computação Gráfica e, atualmente, diversos jogos apresentam simulações com um elevado grau de realismo gráfico em ambientes bastante complexOS (FUNGE, 2004). Embora os jogos tenham evoluído aceleradamente em termos gráficos, o mesmo não foi observado em termos de Inteligência Artificial (IA). A IA de um jogo compreende, entre outras coisas, a resposta do ambiente de jogo a determinadas ações do jogador e o comportamento das personagens que interagem com este. Até recentemente, apenas uma pequena parcela do processador estava disponível para processamento das rotinas relacionadas a IA. Por isso, boa parte da IA era implementada utilizando-se técnicas simples, como Máquinas de Estado Finito e scripts de regras. A desvantagem na utilização dessas abordagens é que elas são naturalmente estáticas, ou seja, as respostas serão sempre as mesmas independente do jogador e de suas habilidades (BAKKES; SPRONCK; HERIK, 2009).

Com a evolução das plataformas utilizadas, algoritmos mais sofisticados podem ser implementados, conferindo assim respostas mais realistas para o jogador (FUNGE, 2004). Entretanto, muitos desenvolvedores ainda se mostram cautelosos quanto à inclusão de técnicas avançadas de IA em seus jogos, como por exemplo, algoritmos de Aprendizado de Máquina (AM). Isso se dá principalmente porque esses algoritmos necessitam de múltiplas avaliações dos dados e pelo fato de que alguns deles utilizam procedimentos estocásticos. 
Apesar da aparente cautela de grande parte dos desenvolvedores, por outro lado, grupos de pesquisa em Inteligência Computacional e AM têm utilizado com uma frequência cada vez maior plataformas de jogos computacionais em suas pesquisas. Esses pesquisadores utilizam o ambiente simulado dos jogos para avaliar algoritmos existentes e até mesmo propor novos algoritmos, mais adaptados ao ambiente complexo dessas aplicações, em que diversos fatores interagem ao mesmo tempo (LUCAS; KENDALL, 2006).

Uma linha de pesquisa particularmente interessante aplica algoritmos de AM a dados e estatísticas coletados a partir da interação jogador/jogo, com o objetivo de capturar as características, ou comportamento, de um determinado jogador. Essa abordagem é referenciada na literatura como Modelagem de Jogador (PM, do inglês Player Modeling). As aplicações de PM são variadas. Pode-se, por exemplo, aprender um modelo de jogador de modo offline e, posteriormente, utilizá-lo para controlar personagens do jogo (GALLI; LOIACONO; LANZI, 2009; WEBER; MATEAS, 2009; ZANETTI; RHALIBI, 2004). Uma outra possível aplicação é estudar, a partir dos dados coletados, como diferentes jogadores se comportam e se existem grupos ou padrões comportamentais mais comuns em determinadas situações (DRACHEN; CANOSSA; YANNAKAKIS, 2009).

Uma aplicação de PM que vem recebendo atenção de diversos pesquisadores é o reconhecimento do comportamento de um jogador de maneira online (YANNAKAKIS; MARAGOUDAKIS, 2005; MARTINEZ; HULLETT; YANNAKAKIS, 2010; YANNAKAKIS; HALLAM, 2009; DELALLEAU et al., 2011). Baseando-se num modelo construído de forma offline, determina-se qual o tipo de comportamento pré-aprendido é mais próximo do comportamento do jogador. Essa abordagem considera que o comportamento de um novo jogador deve se encaixar em um dos padrões de comportamento previamente aprendidos. Essa hipótese restringe a aplicabilidade da abordagem na prática, pois é praticamente impossível construir um modelo de decisão que reconheça todos os possíveis comportamentos que diferentes jogadores podem apresentar. Além disso, uma vez que um comportamento é selecionado como representativo das características do jogador, este é mantido até o final da interação. Nesse caso, mudanças comportamentais por parte do jogador no decorrer do tempo não são consideradas.

A possibilidade de detectar variações comportamentais de um jogador adiciona à IA de um jogo o potencial de se adaptar a cada jogador, proporcionando uma interação personalizada às suas características e habilidades. Além disso, adiciona-se muito mais credibilidade ao jogo, além de permitir ajuste automático de nível de dificuldade.

Por esses motivos, técnicas que monitoram a evolução das características do jogador de forma online e informam sobre possíveis mudanças comportamentais são necessárias, embora pouco exploradas. Alguns exemplos de trabalhos que abordam essas questões são os trabalhos de Hunicke e Chapman (2004) e de Thue et al. (2011).

Para lidar com esse problema, esta tese propõe o estudo de técnicas para detecção de variações comportamentais do jogador no decorrer de sua interação com o ambiente 
de jogo. Para tanto, são necessários algoritmos que processem os dados provenientes da interação jogador/jogo incrementalmente, atualizando seus modelos de decisão a medida que novos dados estejam disponíveis. Além desse pré-requisito, também é importante levar em consideração a característica mutável dos dados e, portanto, deve-se ser capaz de detectar se o comportamento atual dos dados difere do que vinha sendo observado. Essas restrições motivaram o estudo detalhado de técnicas para Mineração em Fluxos Contínuos de Dados (MFCD). Os algoritmos para MFCD são especialmente projetados para trabalhar incrementalmente, processando dados que estão constantemente evoluindo com o passar do tempo. A seguir, são sumarizadas as características dos algoritmos projetados para processar fluxos de dados (GAMA; RODRIGUES, 2009):

- Aprendizado incremental em tempo de execução;

- Utilização de tempo e memória constantes para processar cada exemplo;

- Processamento por simples varredura, i.e., processar os dados assim que se tornam disponíveis e, em seguida, descartá-los;

- Levar em consideração mudanças nos dados com o decorrer do tempo.

Como esses algoritmos consideram a não estacionariedade dos dados, diversos trabalhos em MFCD abordam especificamente a chamada detecção de mudança de conceito, que é a detecção de mudanças na distribuição dos dados com o passar do tempo (WIDMER; KUBAT, 1996; GAMA et al., 2004). Esses trabalhos são diretamente relevantes para o domínio desta tese, principalmente aqueles que abordam a o cenário não supervisionado.

A mudança de comportamento em fluxos de dados não-supervisionados pode ser abordada de diversas maneiras. Abordagens estatísticas monitoram a evolução dos dados, geralmente observando variações em valores médios, e podem ser incrementais ou utilizar janelas de tempo (BIFET; GAVALDÀ, 2007; PAGE, 1954). Quando a variação está acima de um dado limiar, uma mudança é detectada. A principal desvantagem desses algoritmos é que uma boa parte deles foi projetada para processar dados unidimensionais, sendo posteriormente estendidos para o cenário multidimensional. Quando aplicados ao cenário multidimensional uma série de restrições se aplicam quanto à definição dos valores dos parâmetros utilizados por esses algoritmos. Por outro lado, abordagens baseadas em agrupamento são, em geral, acopladas a um detector de novidades que monitora a evolução da estrutura de grupos no decorrer do tempo (MARSLAND; SHAPIRO; NEHMZOW, 2002; SPINOSA; CARVALHO; GAMA, 2007; ALBERTINI; MELLO, 2010). Esses algoritmos também detectam mudanças quando o nível de variação está acima de um dado limiar ou quando eventos novos acontecem como, por exemplo, quando um novo grupo é criado. Entretanto, a maior parte desses algoritmos considera um único evento novo como uma mudança de 
comportamento, o que é impraticável em muitos cenários onde a presença de outliers não pode ser descartada, como o caso dos jogos computacionais. Além disso, eles impõem restrições quanto ao número e forma dos grupos gerados, o que nem sempre é possível de se determinar a priori ou quando os dados evoluem no tempo.

Para detectar mudanças comportamentais em um jogador é necessário considerar diversos aspectos de sua interação com o ambiente de jogo. Também é necessário fazer o menor número de suposições prévias a respeito dos dados gerados a partir dessa interação, visto que cada jogador apresenta características e habilidades únicas. Finalmente, devido ao elevado grau de interação dessas aplicações, é preciso considerar a existência de exemplos outliers no fluxo de dados gerado. Esses exemplos outliers não indicam uma mudança real de comportamento do jogador e devem ser, portanto, desconsiderados.

Atender a todos esses requisitos inviabiliza a aplicação direta da maior parte dos algoritmos disponíveis na literatura. Portanto, para detectar mudanças de comportamento nesse domínio de aplicação, esta tese propõe dois novos algoritmos que atendem a todos os requisitos apontados.

O primeiro algoritmo proposto, Micro-Clustering DBScan* (M-DBScan*), é baseado em abordagens de agrupamento incremental e detecção de novidades e é independente do número e formato dos grupos, assim como considera uma sequência de novidades como uma mudança de comportamento. O segundo algoritmo, Windowing Specgram Extended (WSE), por outro lado, baseia-se em utilização de janelas de tempo para detecção de mudanças nos dados e na geração de espectrogramas a partir dos dados contidos em cada janela. Esses algoritmos, assim como resultados mostrando sua aplicabilidade à tarefa de monitorar o comportamento de um jogador no decorrer do tempo, são apresentados no decorrer desta tese.

\subsection{Objetivo e Hipóteses}

Ser capaz de monitorar o comportamento de um jogador durante sua interação com o jogo abre novas possibilidades na área de desenvolvimento de jogos, permitindo avanços em direção a jogos que se auto-adaptam às habilidades e características de cada jogador. Essa constatação motivou a hipótese desta tese, a qual é apresentada a seguir:

A modelagem online do comportamento de um jogador a partir de seus dados permite detectar eventuais mudanças de comportamento de modo eficaz e com um nível de atraso aceitável para esse domínio de aplicação.

Modelagem online do comportamento de um jogador a partir de seus dados se refere ao processo de descrever um determinado jogador em termos de dados coletados a partir de sua interação com o ambiente de jogo. Entende-se por mudança de comportamento 
uma alteração significativa dos dados gerados como reflexo de uma alteração nas características de jogo do jogador. A detecção de mudança de comportamento de modo eficaz se refere ao número de detecções corretas em comparação ao número de falsos alarmes, ou detecções incorretas. Finalmente, em aplicações fortemente interativas, como os jogos computacionais, é preciso que as detecções de mudanças ocorram dentro de um limite de atraso relativamente baixo, de modo que qualquer medida a ser tomada a partir do momento da detecção não leve muito tempo para ser implementada.

A definição da hipótese do trabalho permitiu, em seguida, a definição do objetivo desta tese de doutorado, que é o projeto de um algoritmo para monitoramento de características comportamentais de um jogador em tempo de execução, detectando e informando sempre que seu comportamento se alterar. Para atingir esse objetivo foram investigadas técnicas de MFCD, em particular aquelas projetadas para detectar mudanças nos dados. Visto que essas técnicas são incrementais, elas se tornam adequadas ao objetivo deste trabalho que visa a detecção de mudanças em tempo de execução.

Para aplicação no domínio de jogos proposto, o algoritmo para detecção de mudanças deve trabalhar com dados multidimensionais, que contêm informação sobre diferentes aspectos do jogador. Como cada jogador é único, o algoritmo utilizado deve fazer o menor número de suposições possíveis a respeito dos dados que serão gerados. Além disso, deve-se considerar a existência de outliers no fluxo de dados e, portanto, uma mudança de comportamento não deve ser baseada em um único evento novo. A definição desses requisitos tornou impraticável a utilização imediata de uma grande parte dos algoritmos disponíveis na literatura. Desse modo, para que o objetivo deste projeto de doutorado fosse satisfeito, foram propostos dois novos algoritmos para detecção de mudança de comportamento que levam em conta as características do cenário de aplicação, nesse caso, jogos computacionais. Cada algoritmo tomou como base uma linha de pesquisa em detecção de mudança de comportamento para fluxos de dados. Experimentos em simulações utilizando jogos comerciais permitiram mostrar a eficácia dos algoritmos propostos na tarefa de detecção de mudanças quando comparados a outros métodos da literatura, comprovando assim a hipótese desta tese.

O trabalho apresentado nesta tese para detecção de mudança de comportamento em jogos contribui para a disseminação da aplicação de técnicas de AM e MFCD no domínio dos jogos computacionais. Além disso, este projeto contribui para o avanço nas pesquisas em detecção de mudança em fluxos de dados.

\subsection{Organização}

O restante deste texto está organizado como segue. No Capítulo 2 são descritos trabalhos relacionados à modelagem de jogadores de acordo com sua aplicação. Em seguida, no Capítulo 3, é realizada uma revisão dos principais conceitos e algoritmos utilizados para 
detecção de mudança em fluxos de dados. A primeira abordagem proposta neste trabalho, M-DBScan*, baseada em um algoritmo de agrupamento incremental e detecção de novidades, é apresentada no Capítulo 4. No Capítulo 4 também são apresentados os experimentos e resultados em dois gêneros de jogos computacionais distintos, assim como comparações com outros algoritmos para detecção de mudança. O Capítulo 5 apresenta o segundo algoritmo proposto neste trabalho, WSE, baseado em utilização de janelas de tempo e geração de espectrogramas a partir dos dados contidos em cada janela. Experimentos e resultados utilizando esse algoritmo também são apresentados no Capítulo 5, juntamente com comparações com outras técnicas para detecção de mudanças. O Capítulo 6 descreve as considerações finais deste trabalho, sumariza as principais contribuições para a área de pesquisa e aponta direções para pesquisas futuras. No Apêndice A, apresenta-se uma análise da complexidade computacional dos algoritmos propostos nesta tese. 


\section{Modelagem Automática de Comportamento em Jogos Computacionais}

\subsection{Considerações Iniciais}

A modelagem automática de comportamento de jogadores em um cenário de jogo particular vem sendo estudada por diversos pesquisadores nos últimos anos (SMITH et al., 2011). Um dos primeiros trabalhos sobre modelagem de jogadores foi o de Houlette (2004), que define a tarefa de criar modelos representativos do jogador humano através do armazenamento de valores numéricos obtidos durante sessões de jogo, também denominados estatísticas de jogo. Esses modelos poderiam então ser utilizados, por exemplo, para possibilitar a adaptação das respostas do jogo à um respectivo jogador. Na mesma linha do trabalho de Houlette, o trabalho de Charles e Black (2004) discute a possibilidade de utilização de estatísticas de jogo de modo a permitir a evolução de jogos baseando-se nas características dos jogadores. $\mathrm{O}$ ato de armazenar estatísticas de jogo e, em seguida, utilizá-las para construir modelos de um dado jogador é, atualmente, referenciado na literatura como Modelagem de Jogador (PM, do inglês, Player Modeling) Smith et al. (2011). Apesar de PM ainda ser considerada uma linha de pesquisa recente na área de IA aplicada a jogos computacionais, a ideia de utilizar dados provenientes da interação de um usuário com um sistema computacional é abordada por diversos pesquisadores e conhecida como Modelagem de Usuário (do inglês, User Modeling). 
De modo geral, para construir os modelos de comportamento de jogadores, algoritmos de AM são empregados. Os tipos de modelos induzidos variam de acordo com o objetivo desejado, uma vez que o termo PM pode ser aplicado em diversas situações.

Geralmente, PM está associado a três grandes tarefas em jogos. A primeira delas é o aprendizado de estratégias. O objetivo nesse caso é utilizar estatísticas de jogo para construir comportamentos que serão utilizados por personagens controladas pelo motor do jogo. Ou seja, deseja-se aprender um determinado comportamento a partir do jogador humano (GALLI; LOIACONO; LANZI, 2009; WEBER; MATEAS, 2009; ZANETTI; RHALIBI, 2004). A segunda tarefa é utilizar dados e estatísticas armazenados após o lançamento de um jogo de modo a verificar se o design empregado é adequado, permitindo acomodar uma variedade de jogadores com estratégias e comportamentos distintos (DRACHEN; CANOSSA; YANNAKAKIS, 2009). O principal objetivo nesse caso é explorar os diferentes tipos de jogadores encontrados e utilizar essa informação de modo a propor melhorias e correções em próximos jogos ou versões de um jogo. Finalmente, a terceira tarefa com a qual PM está associado é a identificação de jogadores durante a interação com o jogo ou monitoramento da evolução comportamental do jogador (YANNAKAKIS; MARAGOUDAKIS, 2005; MARTINEZ; HULLETT; YANNAKAKIS, 2010; YANNAKAKIS; HALLAM, 2009; DELALLEAU et al., 2011; HUNICKE; CHAPMAN, 2004; THUE et al., 2007, 2011). Essa é, talvez, a aplicação mais interessante de estratégias de PM, permitindo reconhecer características de um jogador e utilizar essa informação para adaptar as respostas do sistema de acordo com as necessidades de cada jogador.

Neste capítulo serão abordados alguns trabalhos relacionados a PM. A revisão aqui realizada não tem por objetivo incluir todos os trabalhos na área, mas sim apresentar alguns trabalhos representativos das três tarefas associadas a PM. Dessa maneira, na Seção 2.2, apresentam-se alguns trabalhos que abordam PM sob a ótica do aprendizado de comportamento a partir de um jogador. Em seguida, na Seção 2.3, alguns trabalhos que constroem modelos de jogadores para verificação de design de jogo são apresentados. Os trabalhos que abordam a identificação de jogadores durante a interação com o jogo são apresentados na Seção 2.4. A Seção 2.5 aponta algumas das abordagens utilizadas para validar o desempenho de abordagens que utilizam PM. Finalmente, na Seção 2.6, são realizadas as considerações finais deste capítulo.

\subsection{Aprendizado de Comportamento a Partir de Dados de Jogadores}

Dados coletados a partir da interação de seres humanos com o sofware de jogo podem ser utilizados na construção automática de controladores de personagens que interagem com o jogador e que são controladas pelo motor do jogo. O intuito é automatizar o processo de 
geração dos controladores de comportamento e também permitir que esses controladores exibam características mais parecidas com a de um jogador humano. O escopo dos controladores gerados é variável, sendo que se pode aprender um controlador completo do comportamento de uma personagem, assim como um controlador parcial, que é responsável por uma parte do comportamento da personagem. Pode-se também criar controladores que decidem não apenas sobre uma única personagem, mas um grupo inteiro delas, sendo assim situados um nível acima na hierarquia de decisões dos componentes de IA do jogo e, portanto, responsáveis por tomadas de decisões estratégicas. Para construção dos controladores, algoritmos de AM supervisionados (GALLI; LOIACONO; LANZI, 2009; WEBER; MATEAS, 2009; ZANETTI; RHALIBI, 2004; HEFNY et al., 2008; THURAU; BAUCKHAGE; SAGERER, 2003) e baseados em algoritmos evolutivos (PRIESTERJAHN et al., 2005) são os mais empregados.

O trabalho de Galli, Loiacono e Lanzi (2009) empregou aprendizado supervisionado para criação de um sistema automático de troca de armas no Unreal Tournament III ${ }^{1}$, um jogo comercial do gênero FPS (do inglês, First-Person Shooter). Para tanto, os autores armazenaram diversas estatísticas de jogo sempre que o jogador trocou a arma que utilizava. Após pré-processamento, essas informações foram transformadas em um conjunto de dados apropriado para o processamento por um algoritmo de AM, contendo 31 atributos e um rótulo que indica a arma escolhida pelo jogador. Esses dados foram utilizados para treinar diversos classificadores, entre eles um classificador Naive-Bayes (NB), um algoritmo de indução de Árvores de Decisão (AD), uma Floresta Aleatória de Árvores de Decisão (FAAD) e uma Rede Neural Artificial (RNA) utilizando o algoritmo de backpropagation. Todos os classificadores foram gerados utilizando-se o software Weka (University of Waikato, 2012) sob configuração padrão. Referências para esses métodos de classificação podem ser encontradas em Tan, Steinbach e Kumar (2005) e Faceli et al. (2011). Os autores utilizaram uma metodologia de validação cruzada para treinar os classificadores, com a acurácia e o coeficiente de Cohen $(k)$ usados como medidas de desempenho dos modelos gerados. A medida de acurácia fornece um indicativo sobre o desempenho do modelo de classificação gerado, enquanto que o coeficiente de Cohen provê uma estimativa de quão significativos são os resultados obtidos.

Para obter melhores resultados, os autores também realizaram uma análise exploratória no conjunto de dados. Essa análise revelou um desbalanceamento nos dados quanto aos rótulos de classes existentes. Devido a essa constatação, um balanceamento do conjunto de dados foi realizado de modo a gerar um novo conjunto com uma distribuição uniforme de classes. Os algoritmos de aprendizado empregados anteriormente foram novamente utilizados, obtendo-se modelos com um desempenho preditivo superior.

Weber e Mateas (2009) utilizaram algoritmos de AM para modelar controladores de personagens no RTS (do inglês, Real-Time Strategy) StarCraft ${ }^{2}$. Estatísticas de jogos

\footnotetext{
${ }^{1}$ Epic Games/Valve Corporation

${ }^{2}$ Blizzard Entertainment
} 
foram coletadas e utilizadas na construção de conjuntos de dados onde cada exemplo representava uma partida entre dois jogadores. Cada exemplo foi constituído de atributos que representavam o momento em que um tipo de unidade era construída no jogo, pois, segundo os autores, essa é uma informação importante para tentar predizer a estratégia utilizada por um dado jogador. Os rótulos de cada exemplo, que representavam a estratégia utilizada pelo jogador $i$ na partida $j$, foram atribuídos a partir de um conjunto de regras construído utilizando-se conhecimento de domínio e análise de jogadores profissionais. A construção dos modelos se deu através da utilização dos algoritmos C4.5 (QUINLAN, 1993), K-NN (do inglês, K-Nearest Neighbors) (TAN; STEINBACH; KUMAR, 2005) e NNge (do inglês, Non-Nested Generalized Exemplars) (MARTIN, 1995). A metodologia de validação cruzada foi adotada no treinamento e teste dos classificadores construídos, utilizando a precisão como medida de desempenho.

Assim como no trabalho de Galli, Loiacono e Lanzi (2009), Weber e Mateas (2009) também realizaram uma análise exploratória nos conjuntos de dados gerados, com foco na distribuição temporal de diversos atributos. Como um atributo representava o tempo no jogo em que uma unidade em particular foi construída pela primeira vez, foi possível construir um gráfico com a distribuição temporal desse atributo no conjunto de dados. Essa informação foi utilizada para tentar prever o tempo de construção de cada unidade, que foi tratado como um problema de regressão pelos autores. Experimentos de regressão foram realizados para cada atributo individualmente, utilizando, entre outros, métodos de regressão linear e aditiva.

Os autores afirmaram que os modelos gerados pelos algoritmos de AM para predição da estratégia utilizada pelo oponente alcançaram bons resultados. Os algoritmos de regressão, entretanto, obtiveram resultados satisfatórios em apenas um sub-conjunto dos atributos.

Zanetti e Rhalibi (2004) propuseram a utilização de algoritmos de AM para criação de controladores de personagens para o FPS Quake III ${ }^{3}$. Para isso, estatísticas de jogo foram utilizadas para treinar RNAs. Os autores afirmam que comportamentos complexos podem ser observados e aprendidos mais facilmente se forem sub-divididos em ações mais simples. Desse modo, o comportamento do jogador foi dividido em três sub-comportamentos: movimentação durante batalha, busca por rotas no mapa quando não está em situação de batalha e, finalmente, escolha de uma arma. Esse último sub-comportamento compreendia tanto a escolha da arma a ser utilizada quanto as ações de mirar e atirar propriamente ditas. Exemplos foram armazenados para cada um dos três sub-comportamentos, sendo que os exemplos pertencentes à um sub-comportamento não necessariamente eram formados pelos mesmos atributos e rótulos de classe que os exemplos dos demais subcomportamentos.

Para aprender os comportamentos em cada um dos três grupos de exemplos, foram

\footnotetext{
${ }^{3}$ Id Software
} 
utilizadas RNAs do tipo Multi-Layer Perceptron (MLP) (HAYKIN, 1999) com um Algoritmo Genético (AG) (GOLDBERG, 2002) para evolução dos pesos da rede. O AG utilizou uma população de 30 cromossomos representando cada um uma configuração de pesos (mais o bias) de uma RNA. Embora os autores não mencionem como a aptidão de cada indivíduo foi calculada, acredita-se que essa tenha sido baseada em uma medida de desempenho, como a acurácia preditiva, no conjunto de exemplos de treinamento.

Para avaliação do método investigado, os autores apresentaram os resultados do treinamento de cada sub-comportamento separadamente. Assim, para cada sub-comportamento, foram apresentados os valores de aptidão em intervalos de 500 gerações. Por fim, os melhores modelos obtidos ao final do treinamento foram empregados como controladores de personagens do jogo. A análise realizada no trabalho, entretanto, foi puramente qualitativa. Não foi realizado nenhum tipo de análise seguindo alguma metodologia de teste do controlador obtido, de modo a poder comparar o método utilizado com outros no mesmo contexto.

O trabalho de Hefny et al. (2008) aplicou aprendizado supervisionado em um jogo do tipo Capture the Flag (CTF). Esse modo de jogo é bastante comum em jogos do genêro FPS e consiste em dois times formados por um número igual de personagens dispostos em duas bases. Na base de cada time existe um bandeira. Um time marca pontos se um dos membros do time conseguir capturar e trazer a bandeira do time adversário para sua própria base, ao mesmo tempo impedindo que o time adversário consiga capturar sua própria bandeira.

Os autores utilizaram RNAs do tipo MLP para controlar ações de baixo nível de uma dada personagem, sejam elas, mirar/atirar e movimentação em combate. Essas RNAs foram treinadas utilizando-se estatísticas obtidas a partir de partidas entre jogadores humanos. A metodologia empregada se baseia no trabalho de Zanetti e Rhalibi (2004). Entretanto, diferentemente de Zanetti e Rhalibi (2004), não foi empregada uma RNA para aprender a calcular rotas pelo mapa. Ao contrário, utilizou-se uma estratégia baseada em sistemas de waypoints para análise de mapa e planejamento de caminho. Um sistema de waypoints é um grafo $G=(W, E)$ onde cada nó $w_{i}$ em $W$ representa um waypoint em um local do mapa onde a personagem possa existir e cada aresta $(w 1, w 2)$ em $E$ indica um caminho entre os nós $w 1$ e $w 2$. Os autores utilizaram uma estratégia de análise de mapa para gerar o sistema de waypoints e o algoritmo A* (HART; NILSSON; RAPHAEL, 1968) para calcular rotas através de nós no grafo.

Os autores provêm comentários subjetivos quanto ao desempenho dos modelos obtidos através das RNAs, alegando um resultado adequado ao tentar imitar as estratégias de um jogador humano.

Thurau, Bauckhage e Sagerer (2003) empregaram RNAs do tipo Self-Organizing Map (SOM) (HAYKIN, 1999) e RNAs do tipo MLP para aprender comportamentos no FPS Quake 
$\mathbf{I I}^{4}$. Após coletar estatísticas de jogo, os autores empregaram uma SOM para agrupar os exemplos de treinamento. Em um segundo instante do treinamento, duas redes do tipo MLP foram associadas a cada grupo, uma para o ângulo de visão da personagem e outra para o ajuste de velocidade da personagem, que foram treinadas usando os dados no grupo correspondente. As redes MLPs foram utilizadas para mapear um vetor de entrada, com informações de estado do jogo, em um vetor de saída, que representa a reação do jogador. Para gerar a reação correspondente a uma dada situação $s_{t}$ (dada por um vetor de entrada), a rede MLP associada ao neurônio com maior valor de atividade na rede SOM foi selecionada.

A fim de avaliar o modelo gerado, foram utilizados dois conjuntos de treinamento e dois conjuntos de teste distintos. O primeiro par treinamento/teste continha exemplos de um jogador se movimentando pelo mapa e, portanto, o que se desejava aprender eram padrões de movimento. O segundo par de treinamento/teste continha exemplos de movimento e, adicionalmente, exemplos de um jogador mirando em seus oponentes. Os autores realizaram dois experimentos distintos, um com o primeiro par de treinamento/teste e outro com o segundo, utilizando como medida de desempenho dos modelos gerados o erro quadrático médio no conjunto de teste. Os resultados indicaram que, para o primeiro experimento, foi possível alcançar bons resultados com apenas um neurônio, pois todos os exemplos pertenciam a um mesmo comportamento (mover-se pelo mapa). Para o segundo experimento, dois neurônios correspondem ao número mínimo capaz de produzir resultados satisfatórios, uma vez que os exemplos de treinamento codificavam dois comportamentos.

A maioria dos trabalhos acima citados utilizou conjuntos de dados rotulados e algoritmos de AM supervisionados para a construção automática dos controladores. A exceção é o trabalho de Thurau, Bauckhage e Sagerer (2003), que utilizou, além da rede MLP supervisionada, uma rede SoM não supervisionada. Entretanto, como mencionado anteriormente, existem trabalhos que utilizam algoritmos evolutivos como parte do processo de aprendizado. Nesse caso, o objetivo é o mesmo: produzir controladores para personagens de modo automático, diminuindo, assim, o esforço por parte dos programadores e projetistas.

O trabalho de Priesterjahn et al. (2005) propôs um sistema para aprendizado de regras de comportamento baseado em algoritmos evolutivos e aplicado ao FPS Quake III.

O comportamento de cada personagem foi definido por um conjunto de regras na forma antecedente/consequente. $\mathrm{O}$ antecedente correspondia a uma matriz que representava $\mathrm{O}$ ambiente ao redor da personagem. O ambiente foi representado na forma de uma malha formada por regiões quadradas. Cada região na malha correspondia a uma posição na matriz. Cada posição dessa matriz recebeu um entre três valores, representando respectivamente uma região vazia no mapa, uma região ocupada (que podia ser pela própria personagem ou por algum objeto do cenário) e uma região ocupada por um oponente. $O$ consequente da regra foi representado por uma tupla contendo quatro valores que consti-

\footnotetext{
${ }^{4}$ Id Software/GT Interactive
} 
tuíam a ação a ser realizada pela personagem. Uma regra, portanto, mapeava uma representação das vizinhanças da personagem para uma correspondente ação.

Para gerar a base de regras iniciais, jogadores disputaram entre si e, a cada atualização lógica do jogo, armazenou-se uma regra representando sua vizinhança e ação correspondente. Para que uma personagem escolhesse a regra mais adequada para uma dada situação, foi preciso comparar diferentes malhas para encontrar a regra contendo a malha mais similar ao que é recebido como entrada. Assim, definiu-se uma medida de distância entre duas malhas baseada na distância euclidiana. A distância entre duas malhas $G$ e $G^{\prime}$ é dada pela distância euclidiana entre $G_{g}$ e $G^{\prime}$, onde $G_{g}$ denota o resultado de uma convolução de $G$ usando um filtro Gaussiano de raio $r$.

Durante a fase de otimização da abordagem proposta, a base de regras foi evoluída por uma adaptação da Estratégia Evolutiva do tipo $(\mu+\lambda)$. Dois indivíduos pais foram escolhidos segundo uma distribuição uniforme a partir da população atual. Sendo $R_{1}, \ldots, R_{k}$ e $R_{1}^{\prime}, \ldots, R_{k}^{\prime}$ os conjuntos de regras dos indivíduos pais, então para o conjunto de regras de um indivíduo filho $O_{1}, \ldots, O_{k}$, a regra $O_{i}$ foi aleatoriamente escolhida entre $R_{i}$ e $R_{i}^{\prime}$. Esse operador de cruzamento afetou, portanto, a estrutura do conjunto de regras. A mutação, por outro lado, afetou a estrutura das regras e foi aplicada tanto no antecedente quanto no consequente da regra segundo uma probabilidade $p_{m}$. A aptidão de um indivíduo foi calculada no ambiente do jogo, em uma partida com tempo fixo e levou em consideração o dano causado ao oponente e o dano sofrido. O método de seleção de indivíduos para a próxima geração considerou todos os indivíduos da geração atual e os novos indivíduos criados por cruzamento e mutação. Os melhores $\mu$ indivíduos foram selecionados para formar a próxima população.

Os experimentos conduzidos utilizaram como inimigo um oponente existente no jogo Quake III, denominado de oponente base. Em vez de armazenar dados de jogadores humanos para servir como conjunto de regras iniciais, esse oponente base foi colocado para jogar contra si próprio, armazenando-se os dados produzidos durante o jogo. Durante o processo evolutivo, os indivíduos com os conjuntos de regras a serem evoluídos jogaram cada um contra o oponente base.

Para avaliar o método de aprendizado, os autores apresentaram a progressão da aptidão média da população e do melhor indivíduo a cada geração. Os resultados demonstraram que as personagens evoluídas pelo método proposto obtiveram sucesso em imitar o comportamento do oponente base. Além disso, foi evidenciada melhoria desse comportamento através do processo evolutivo.

A Tabela 2.1 apresenta as principais características dos trabalhos apresentados nesta seção. 
Tabela 2.1: Principais características dos trabalhos apresentados nesta seção.

\begin{tabular}{llll}
\hline Trabalho & Tipo de Jogo & Paradigma de Aprendizado & Algoritmos avaliados \\
\hline Galli, Loiacono e Lanzi (2009) & FPS & Supervisionado & NB, AD, FAAD e MLP \\
Weber e Mateas (2009) & RTS & Supervisionado & AD, K-NN, NNge \\
Zanetti e Rhalibi (2004) & FPS & Supervisionado & MLP \\
Hefny et al. (2008) & FPS & Supervisionado & MLP \\
Thurau, Bauckhage e Sagerer (2003) & FPS & Supervisionado e Não-supervisionado & MLP e SOM \\
Priesterjahn et al. (2005) & FPS & Supervisionado e Evolutivo & Conjuntos de regras \\
\hline
\end{tabular}

\subsection{Utilização de Dados de Jogo para Verificação de De- cisões de Projeto}

Os projetistas de jogos para computadores costumam criar níveis nos jogos onde não existe uma única maneira de interação. Isso significa que, para chegar ao final de um nível, existem diversas possibilidades de interação com o ambiente. Essa opção por parte dos projetistas de jogos é proposital, uma vez que é sabido que jogadores humanos distintos compreendem e raciocinam sobre uma mesma situação de jogo de maneiras também distintas. Os diferentes comportamentos dos jogadores são chamados de estilos de jogo e, portanto, os jogos devem ser projetados de modo a acomodar de maneira igualitária esses estilos.

Algoritmos de AM podem então ser empregados para, a partir de estatísticas de jogo, analisar os diferentes estilos de jogadores. O paradigma de AM empregado é o nãosupervisionado, que não utiliza conhecimento de rótulos de classe associados aos exemplos. Sendo assim, a maior parte dos trabalhos nessa categoria utiliza algoritmos de agrupamento para encontrar possíveis grupos, ou padrões, de jogadores com características similares nos dados. Essa informação pode ser utilizada pelos projetistas de modo a verificar se o design criado é adequado para acomodar diferentes padrões de jogabilidade, assim como expor falhas de projeto não antes previstas.

O trabalho de Tychsen e Canossa (2008) é, talvez, um dos primeiros a propor a utilização de estatísticas de jogo para verificar a existência de diferentes padrões de jogadores. Os autores focaram principalmente em quais estatísticas utilizar, ou seja, na identificação dos vários componentes associados à personagem do jogador e como fragmentá-los em elementos que possam ser mensurados. Essas estatísticas podem ser armazenadas utilizando-se diferentes resoluções de tempo e espaço. Uma vez que as estatísticas estejam disponíveis, é possível utilizá-las para descobrir padrões de jogabilidade através da construção do que os autores chamam de play-personas, que são modelos que definem como um jogador interage com um determinado jogo. Segundo os autores, as estatísticas relacionadas ao jogador podem ser agrupadas em quatro categorias.

- Estatísticas de Navegação: são geralmente armazenadas continuamente, baseadas em uma frequência específica. Alguns exemplos incluem posição no espaço em 
coordenadas vetoriais, os ângulos de câmera, os modificadores de movimento (andando, correndo, pulando), entre outros.

- Estatísticas de Interação: são, em geral, baseadas em eventos e geradas por ações específicas da personagem. Alguns exemplos incluem número de vezes que a personagem utiliza uma arma, número de vezes que adquire um item de um determinado tipo, etc.

- Estatísticas de Narração: essas métricas se referem à história do jogo e como o jogador evolui por ela, por exemplo, ao tomar decisões que influenciam o prosseguimento do jogo.

- Estatísticas de Interface: são métricas que dizem respeito ao uso da interface gráfica, como menus de jogo.

Diferentes grupos de comportamentos de jogadores podem ser definidos para cada categoria. Assim, uma vez definidos os grupos existentes, pode-se definir, para cada categoria de estatísticas, a qual desses grupos um determinado jogador pertence. A união do resultado desse agrupamento, levando em conta todas as categorias, constitui o comportamento do jogador.

Para modelar comportamentos de diferentes jogadores e identificar padrões de jogabilidade, o trabalho de Drachen, Canossa e Yannakakis (2009) agrupou dados coletados do jogo Tomb Raider: Underworld ${ }^{5}$ utilizando som. Os dados coletados referem-se a 1365 jogadores que completaram o jogo. A partir dos dados de cada um dos jogadores, foram calculados 6 atributos que juntos expressavam o comportamento de um dado jogador.

Os atributos foram escolhidos de acordo com o impacto que causavam no processo de distinguir entre padrões de jogabilidade. Os atributos extraídos foram: três atributos que definem a porcentagem de mortes causadas respectivamente por oponentes, pelo ambiente e por quedas; o número total de mortes de cada jogador; o tempo que cada jogador levou para terminar o jogo; e o número de vezes que o jogador solicitou ajuda ao sistema de ajuda do jogo. Cada jogador foi então representado por um exemplo contendo os 6 atributos, calculados a partir das métricas coletadas enquanto jogava.

A partir do conjunto de dados gerado, uma SoM foi treinada para separar os dados em grupos. Para minimizar os efeitos causados pela seleção dos protótipos iniciais da rede, os autores repetiram o treinamento 20 vezes e avaliaram o desempenho de cada modelo gerado utilizando o erro de quantização médio. O erro topográfico também foi utilizado e foi calculado como a proporção de todos os exemplos de entrada para os quais o primeiro e segundo neurônios mais representativos não eram adjacentes.

A partir da melhor SOM obtida, os autores utilizaram as técnicas de visualização conhecidas como $U$-matrix e $P$-matrix para analisar os grupos formados e identificar os padrões

\footnotetext{
${ }^{5}$ Crystal Dynamics/Warner Bros. Games
} 
de jogo. Os resultados demonstraram a existência de 4 padrões diferentes entre os jogadores, cada qual com suas características próprias e utilizando opções de jogo distintas. $O$ algoritmo K-means (TAN; STEINBACH; KUMAR, 2005) e o método hierárquico de Ward (WARD, 1963) também foram utilizados, de modo a comparar o número de grupos obtidos por esses algoritmos com o número de grupos obtido pela SOM. Os resultados obtidos pelo K-means indicaram a existência de 3 ou 4 grupos e o algoritmo hierárquico indicou a existência de 2 grupos abrangentes que se subdividiam em outros 2 grupos.

Nas conclusões desse trabalho, os autores afirmam que a metodologia proposta pode ser utilizada para complementar os procedimentos de teste com usuários, que tem por principais objetivos avaliar se o design do jogo funciona como planejado e identificar falhas. A possibilidade de utilizar a informação sobre diferentes estilos ou tipos de jogadores de maneira online para alterar dinamicamente parâmetros do jogo, é apontada pelos autores como uma direção de pesquisas futuras.

Martinez, Hullett e Yannakakis (2010) também utilizaram soMs para modelar os possíveis grupos de jogadores num jogo do tipo predador/presa. Para tanto, foram armazenadas várias estatísticas para cada jogo que, em seguida, foram processadas por um algoritmo para seleção de atributos denominado Sequential Forward Selection (SFS), de modo a selecionar um subconjunto de atributos que melhore a qualidade do agrupamento. Cada vez que um novo subconjunto de atributos era selecionado pelo algoritmo SFS, a SOM foi treinada dez vezes de modo a considerar a característica não-determínistica do algoritmo. $O$ erro topográfico médio e o erro de quantização médio foram utilizados para medir a qualidade do agrupamento gerado por esse subconjunto de atributos. A cada iteração do SFS, o subconjunto que produziu o menor erro topográfico médio foi selecionado. O algoritmo SFS foi interrompido quando o erro de quantização médio se tornou maior que o erro topográfico médio. Através da U-matrix e $P$-matrix, observou-se a existência de 5 grupos de jogadores com características distintas.

A Tabela 2.2 apresenta as principais características dos trabalhos apresentados nesta seção.

Tabela 2.2: Principais características dos trabalhos apresentados nesta seção.

\begin{tabular}{llll}
\hline Trabalho & Tipo de Jogo & Paradigma de Aprendizado & Algoritmos avaliados \\
\hline Drachen, Canossa e Yannakakis (2009) & Aventura & Não-supervisionado & SOM, K-means, Método Hierárquico de Ward \\
Martinez, Hullett e Yannakakis (2010) & Predador/Presa & Não-supervisionado & som \\
\hline
\end{tabular}




\subsection{Identificação de Características de Jogadores em Tempo de Execução}

A última tarefa com a qual PM está associado é a identificação de jogadores durante a interação com o jogo. O reconhecimento, em tempo de execução, das características de comportamento permitem ao sistema se adequar às particularidades do jogador, proporcionando uma experiência de interação personalizada.

O trabalho de Yannakakis e Maragoudakis (2005) aplicou Redes Bayesianas (RB) treinadas utilizando dados de jogadores em um jogo do tipo predador/presa. As redes foram utilizadas na construção de modelos que inferiam o conjunto de parâmetros mais apropriado a ser utilizado por um mecanismo de adaptação online. Assim, baseando-se nas características de jogo de um conjunto de jogadores, os autores construíram um modelo que predizia o conjunto de parâmetros que gerasse jogos com maior valor de uma medida de interesse. Quanto maior o valor dessa medida, maior seria o interesse do jogador pelo jogo.

Em um trabalho posterior, Yannakakis e Hallam (2009) aplicaram RNAs para construir modelos de usuários que mapeavam características de jogabilidade individuais a valores de preferência. Os valores de preferência mediam o grau de entretenimento oferecido por um jogo e foram obtidos através de questionários preenchidos pelos próprios jogadores após jogarem uma série de partidas distintas. Os modelos foram construídos a partir de estatísticas de jogo obtidas utilizando a plataforma "Playware" e os correspondentes valores de preferência reportados em cada jogo. Em seguida, um mecanismo que atuava de forma online ajustava parâmetros do jogo de modo a aumentar o nível de entretenimento provido.

Como apresentado na Seção 2.3, Martinez, Hullett e Yannakakis (2010) utilizaram redes som para modelar possíveis grupos de jogadores em um jogo do tipo predador/presa. O agrupamento final produzido reportou a existência de cinco grupos, representando cinco grupos de jogadores com características distintas. Em uma próxima etapa do trabalho, os autores utilizaram o grupo ao qual um jogador foi associado como entrada para um preditor de preferências. Para tanto, os jogadores preencheram questionários reportando suas preferências em relação ao jogo. As métricas de jogo anteriormente coletadas foram novamente processadas pelo algoritmo SFS. Entretanto dessa vez o objetivo era encontrar um subconjunto de atributos que gerasse o melhor modelo de classificação das preferências dos jogadores. Assim, o classificador treinado utilizou o subconjunto de atributos selecionado e o modelo de jogador obtido pelo agrupador para predizer as preferências de um jogador. O classificador utilizado foi uma RNA do tipo Perceptron (HAYKIN, 1999) de uma única camada. O treinamento da rede foi realizado através da evolução de seus pesos sinápticos através de um AG geracional (GOLDBERG, 2002). O desempenho da rede foi 
mensurado atráves de experimentos de validação cruzada utilizando-se três partições.

Para comparar o desempenho da abordagem de predição de preferências utilizando o modelo de jogador gerado pelo agrupamento, os autores repetiram os experimentos não fornecendo ao classificador o modelo de jogador durante o treinamento. Análises da acurácia preditiva entre os dois métodos demonstraram que a inclusão de um modelo de jogador resultou em melhores resultados por parte do sistema de predição.

Recentemente, Delalleau et al. (2011) propuseram uma metodologia para combinar times de jogadores no FPS Ghost Recon Online ${ }^{6}$. A estratégia empregada utilizou RNAs do tipo MLP para predizer o time vencedor de uma partida e uma medida de entretenimento baseada em dados de jogadores. Os dados utilizados para treinamento foram obtidos a partir de uma série de jogos entre times de jogadores. Os modelos gerados foram então utilizados para predizer as melhores combinações de times dentre os jogadores disponíveis.

Os trabalhos de Yannakakis e Maragoudakis (2005), Yannakakis e Hallam (2009), Martinez, Hullett e Yannakakis (2010) e Delalleau et al. (2011) apresentam diferentes estratégias para reconhecer características de jogadores em tempo de execução, i.e., esses trabalhos utilizam uma fase offline de aprendizado de possíveis modelos de jogadores e tentam, em sua fase online, associar o comportamento observado do jogador atual com um dos modelos de jogadores pré-estabelecidos. A desvantagem dessa abordagem é que na prática, não é viável construir um modelo de decisão que reconheça todos os possíveis comportamentos que os jogadores podem apresentar. Além disso, após a associação de um tipo de comportamento ao jogador, essa decisão é mantida até o final do jogo. Não há, portanto, nenhuma forma de monitoramento das características do jogador de modo a reconhecer possíveis mudanças no decorrer do tempo.

Em uma linha diferente, Hunicke e Chapman (2004) propuseram o aprendizado em tempo de execução, de características de um jogador de modo a realizar ajuste automático de dificuldade no FPS Half Life ${ }^{7}$. O objetivo do trabalho era monitorar o jogador através de estatísticas enquanto este interagia com o jogo, de modo a detectar quando o jogador estava falhando em atingir seus objetivos. Para tanto, foi utilizada uma estimativa da distribuição de danos sofridos pelo jogador durante o tempo. Os momentos de falha foram então calculados em função da quantidade de pontos iniciais do jogador e da média (e desvio padrão) da perda de pontos no tempo. A partir da detecção desses momentos, ações corretivas podem ser colocadas em prática. Essas ações podem incluir manipulação direta das capacidades dos inimigos ou manipulação de quantidade e qualidade de itens disponíveis no cenário de jogo.

Alguns trabalhos na linha de Interactive Storytelling realizam, de certa forma, um monitoramento das ações do jogador de modo a influenciar as respostas do jogo. Nesse caso, o

\footnotetext{
${ }^{6}$ Ubisoft

${ }^{7}$ Valve Software
} 
objetivo é alterar a história do jogo no que diz respeito aos diálogos ocorrendo com as personagens presentes no ambiente. Thue et al. (2011) apresentaram uma abordagem para definir o tipo de interação que uma personagem terá com o jogador, baseado em um valor de afinidade armazenado por essa personagem. $O$ valor de afinidade foi representado por uma variável numérica no intervalo $[-1,1]$, onde o valor -1 indicava baixa afinidade da personagem para com o jogador e o valor 1 indicava alta afinidade. Essa variável de afinidade foi incrementada, ou decrementada, de acordo com as ações tomadas pelo jogador em interações com essa personagem. Assim, em próximas interações que viessem a ocorrer, esse valor era considerado para produzir a resposta da personagem.

Essa abordagem foi implementada em um sistema denominado PaSSAGE (THUE et al., 2007), que foi criado pelos próprios autores em um trabalho anterior e consistia, em linhas gerais, de um sistema que selecionava as sequências de encontros entre jogador e personagens que iriam ocorrer, baseando-se em um modelo de comportamento do jogador. A escolha do modelo de comportamento do jogador foi realizada durante a sua interação com o jogo da seguinte maneira. PaSSAGE considerava que existiam cinco tipos de comportamento diferentes e tentava associar o comportamento do jogador a um desses cinco tipos pré-estabelecidos. Para tanto, o sistema mantinha um vetor de pesos que indicava a influência de cada um dos cinco tipos no comportamento do jogador. A cada ação do jogador, um incremento era realizado no vetor de pesos, de acordo com um conjunto de regras que determinava qual posição do vetor deveria ser atualizada, i.e., as regras indicavam se o jogador estava apresentando ações relacionadas a um dos cinco comportamentos. Em seguida, baseando-se em um conjunto de regras também definido previamente, PaSSAGE escolhia qual o próximo encontro para o jogador de acordo com os pesos observados.

Essa abordagem apresenta duas desvantagens principais. A primeira é a suposição de que existe um número fixo e pré-determinado de possíveis comportamentos para um jogador. A segunda é o alto grau de trabalho manual por parte do projetista do jogo, que deve descrever todos os conjuntos de regras necessários para que a abordagem funcione.

A Tabela 2.3 apresenta as principais características dos trabalhos apresentados nesta seção.

Tabela 2.3: Principais características dos trabalhos apresentados nesta seção.

\begin{tabular}{llll}
\hline Trabalho & Tipo de Jogo & Paradigma de Aprendizado & Algoritmos avaliados \\
\hline Yannakakis e Maragoudakis (2005) & Predador/Presa & Supervisionado & RB \\
Yannakakis e Hallam (2009) & Plataforma Playware & Supervisionado & RNA \\
Delalleau et al. (2011) & FPS & Supervisionado & RNA \\
Hunicke e Chapman (2004) & FPS & Não-supervisionado & Cálculo de Estatísticas \\
Thue et al. (2011) & RTS & Baseado em Reforço & Conjuntos de Regras \\
\hline
\end{tabular}




\subsection{Metodologias para Avaliação de Desempenho}

Embora a metodologia para avaliação de algoritmos de aprendizado seja bastante consolidada na comunidade de pesquisa em AM tradicional, nos trabalhos que apresentam a aplicação de aprendizado em jogos ainda não se observa um consenso quanto à forma de avaliar as abordagens propostas. Isso resulta na dificuldade em conseguir comparar os resultados obtidos por diferentes trabalhos. Além disso, são poucos os trabalhos que demonstram preocupação em seguir uma metodologia de avaliação de resultados que leve em conta os trabalhos de outros autores em um mesmo domínio de aplicação. Apesar dessa observação, nesta sub-seção apresentam-se algumas das metodologias empregadas nos trabalhos investigados.

Dentre os trabalhos estudados, aqueles que apresentam uma metodologia para avaliação de desempenho mais fundamentada são os da Seção 2.2. A metodologia utilizada é a mesma já consolidada na comunidade de AM, que utiliza conjuntos de treinamento e teste distintos e medidas como acurácia e precisão. Técnicas de validação cruzada são, em geral, utilizadas para obter medidas de desempenho médias e mais próximas da realidade.

Ainda sobre os trabalhos apresentados na Seção 2.2, aqueles que utilizam algoritmos evolutivos como método de treinamento de RNAs ao invés do tradicional algoritmo backpropagation costumam apresentar os resultados em forma de gráficos que demonstram a aptidão média e a aptidão do melhor indivíduo durante a evolução. É importante notar que o cálculo da aptidão de um indivíduo é dependente do gênero de jogo sendo avaliado.

Os trabalhos apresentados na Seção 2.3, em geral, possuem por objetivo agrupar jogadores baseando-se em métricas de jogo obtidas da interação desses jogadores com um jogo em particular. Para tanto são aplicados algoritmos de agrupamento de dados. A metodologia para avaliação de resultados utiliza estratégias de análise de agrupamento formado, como análise de U-matrix e $P$-matrix, de modo a identificar padrões de jogo. Além disso, alguns trabalhos também utilizam mais de um algoritmo de agrupamento para comparar o número de grupos encontrados por cada um deles, uma vez que, a priori, o número de grupos é desconhecido.

Quando o objetivo é modelar o comportamento de modo a identificá-lo durante a execução (Seção 2.4), em geral compara-se o mecanismo de adaptação utilizado com e sem a utilização da informação fornecida pelo modelo de jogador. O objetivo é identificar se a inclusão dessa informação melhora a capacidade do mecanismo de adaptação em adequar o jogo ao jogador. Para medir se houve ou não melhora é possível utilizar a própria opinião dos jogadores em uma série de experimentos comparativos ou então definir alguma medida de qualidade em termos de estatísticas mensuráveis. 


\subsection{Considerações Finais}

Este capítulo apresentou alguns dos trabalhos encontrados na literatura que investigam a modelagem de comportamento em jogos computacionais. A área de PM tem atraído o interesse de diversos pesquisadores pois permite, por meio do uso de informações da interação do jogador com o ambiente de jogo, construir modelos de comportamento que definem características desse jogador. Esses modelos são utilizados com três objetivos gerais: (i) gerar controladores de personagens de maneira automática, aliviando o esforço por parte dos projetistas de jogos; (ii) identificar padrões de jogabilidade de modo a validar decisões de projeto e propor melhorias em versões futuras; (iii) identificar padrões de jogabilidade em tempo de execução e utilizar essa informação para adaptar as respostas do jogo ao jogador atual ou monitorar a evolução de seu comportamento no decorrer do tempo.

Independente do objetivo abordado, algoritmos de AM são empregados para obtenção dos modelos de comportamento. Em geral, o processo de aprendizagem dos modelos é realizado de maneira offline, i.e., utilizando dados obtidos de partidas ou sessões de jogos já finalizadas. Assim, após a obtenção de um modelo, esse pode ser utilizado para análise ou ser integrado para funcionamento online em novas sessões. Uma desvantagem é que, se o modelo for confrontado com dados muito distintos em relação aqueles presentes no treinamento, a qualidade das predições realizadas irá decair. Nesse caso, seria necessário coletar mais dados e treinar novamente o modelo. Essa desvantagem abre espaço para novas pesquisas na área de modelagem de jogador, onde os modelos sejam obtidos de modo incremental durante a interação jogador/jogo, como nos trabalhos de Hunicke e Chapman (2004) e Thue et al. (2011).

Seguindo na mesma linha proposta por Hunicke e Chapman (2004), este trabalho tem por objetivo modelar o comportamento de um jogador de modo online, permitindo a identificação dos momentos em que o jogador altera seu comportamento. Para atingir esse objetivo, foram estudados diversos algoritmos para detecção de mudança de comportamento da área de MFCD. Dessa maneira, no Capítulo 3 são apresentados alguns dos algoritmos para detecção de mudança mais investigados na literatura. 


\section{Detecção de Mudança de}

\section{Comportamento em Fluxos de Dados}

\subsection{Considerações Iniciais}

Muitas aplicações produzem uma série de dados contínua no tempo. Nesse cenário, o modelo de aprendizado em batch implementado por muitos algoritmos de AM não é apropriado, por ser impraticável, ou até mesmo impossível, armazenar todos os exemplos em memória (AGGARWAL et al., 2003). Essa alta produção e disponibilização de dados levou ao desenvolvimento de uma nova linha de pesquisa denominada MFCD (GAMA; RODRIGUES, 2009). Nessa linha, em oposição a Mineração de Dados tradicional, os algoritmos são projetados para aprender de modo online, processando os exemplos a medida que estes se tornam disponíveis e, em seguida, descartando-os (GAMA, 2010).

Uma importante distinção entre o cenário de aprendizado em fluxo de dados e o cenário de aprendizado estático é que, no primeiro, a distribuição que gera os dados pode se alterar com o passar do tempo. No cenário convencional, i.e. estático, os algoritmos usualmente supõem que os dados não se alteram com o tempo e, portanto, uma vez que um modelo de aprendizado foi induzido, não há necessidade de alterá-lo no futuro. Por outro lado, um algoritmo projetado para aprender em um fluxo de dados precisa considerar a natureza não estática dos dados. Assim, pode ser necessário induzir novamente modelos previamente construídos caso mudanças ocorram nas características dos dados.

A detecção de mudança nos dados é um importante aspecto da MFCD, sendo frequentemente abordada sob as nomenclaturas de detecção de mudança de comportamento e 
detecção de mudança de conceito (GAMA et al., 2004; GAMA; RODRIGUES, 2007). Para o aprendizado supervisionado, detectar mudanças no comportamento dos dados é crucial. Uma vez que a distribuição dos dados se torna diferente do que era no passado, o modelo preditivo, induzido a partir de dados antigos, terá sua capacidade preditiva prejudicada. No paradigma de aprendizado não supervisionado, os algoritmos devem ser capazes de introduzir novos dados no modelo atual, ao mesmo tempo que mantém em níveis apropriados, conhecimento prévio.

Este trabalho está focado no paradigma de deteção de mudança em dados não rotulados. Para isso, são investigados algoritmos não supervisionados. Detectar quando os dados em um fluxo estão mudando e, consequentemente, incorporar essas mudanças nos modelos gerados pelo aprendizado não é uma tarefa trivial (AGGARWAL et al., 2003). Por essa razão, diversas abordagens estão disponíveis na literatura para tentar solucionar o problema de detecção de mudança em fluxos de dados não supervisionados.

A primeira abordagem consiste em processar os dados de modo a construir ferramentas de visualização que auxiliem um profissional humano no processo de análise da evolução dos dados. Os trabalhos que seguem essa abordagem geralmente aplicam técnicas de visualização de dados em um horizonte definido pelo usuário, tornando possível para um profissional analisar a evolução dos dados e encontrar padrões particulares. Uma vez que o objetivo é prover ao usuário uma ferramenta visual para observação da evolução dos dados através do tempo, essa abordagem não é apropriada para detecção automática de mudanças de comportamento. O trabalho de Aggarwal (2003) é um exemplo dessa abordagem. Esse trabalho apresenta um framework para o diagnóstico de fluxos de dados multidimensionais que utiliza um conceito denominado de velocity density estimation. Baseado nesse conceito, dois tipos de perfis, um espacial e outro temporal, são gerados. Esses perfis podem, então, ser visualizados e analisados em um horizonte de tempo definido pelo usuário.

A segunda abordagem consiste em monitorar alguma estatística sobre os dados de modo a detectar mudanças. Essa abordagem pode ser implementada por algoritmos incrementais ou que utilizam janelas de tempo. Um exemplo de algoritmo incremental é o Page-Hinkley Test (PHT) (PAGE, 1954). O algoritmo PHT foi projetado para detectar mudanças na média de um sinal Gaussiano. Portanto, o PHT monitora a evolução no valor médio de um sinal e utiliza um limiar constante para reportar a ocorrência de mudanças. Algoritmos baseados em janelas, por outro lado, monitoram a distribuição dos dados dentro de janelas contendo os pontos mais recentes no fluxo, ou comparam janelas sucessivas de dados. Alguns exemplos são os algoritmos Adaptive Windowing (ADWIN) (BIFET; GAVALDÀ, 2007) e Fixed Cumulative Windows Model (FCWM) (SEBASTIãO et al., 2010). O algoritmo ADWIN, por exemplo, cria uma janela com os exemplos mais recentes e divide essa janela em subjanelas. As diferenças nos valores médios dentro das subjanelas são analisadas utilizando o limitante de Hoeffding (GAMA; FERNANDES; ROCHA, 2006). Quando essa di- 
ferença é considerada estatisticamente significativa, o algoritmo declara a ocorrência de mudança nos dados. A principal desvantagem desses algoritmos é que uma boa parte deles foi projetada para processar dados unidimensionais, sendo posteriormente estendidos para o cenário multidimensional. Quando aplicados ao cenário multidimensional uma série de restrições se aplicam quanto à definição dos valores dos parâmetros utilizados por esses algoritmos.

A terceira abordagem está relacionada à tarefa de agrupamento dos dados, onde o algoritmo é projetado de modo a acomodar naturalmente mudanças na estrutura de grupos sendo construída. Nesse caso, novos grupos podem ser criados para representar os novos dados chegando no fluxo, ou grupos pré-existentes podem ter suas características ajustadas de maneira incremental. Nessas situações, as mudanças nos dados estão sendo introduzidas no modelo, porém não há indicativo explícito de quando o comportamento dos dados está apresentando tais mudanças. Alguns exemplos de algoritmos de agrupamento que incrementalmente atualizam seus modelos de decisão baseado em novos dados são CluStream (AGGARWAL et al., 2003), DenStream (CAO et al., 2006), SOM (KOHONEN, 1997) e Recurrent Self-Organizing Map (RSOM) (VARSTA; MILLáN; HEIKKONEN, 1997).

Há ainda uma outra maneira de abordar mudanças no cenário de fluxos de dados, que inclui a utilização de algoritmos de agrupamento acoplados a um mecanismo detector de novidades. Assim, o objetivo não é mais somente atualizar a estrutura de grupos com os dados mais recentes, mas também reportar quando da ocorrência de eventos que causem uma variação na estrutura atual. O detector de novidades verifica qual o nível de mudança na estrutura de grupos com a chegada de um novo exemplo. Se o nível de mudança for maior que um limiar pré-estabelecido, esses algoritmos reportam uma novidade no fluxo de dados. Um aspecto importante é que esses algoritmos são detectores incrementais de novidades, i.e., consideram apenas o exemplo atual de modo a tomar decisões. Alguns algoritmos que se baseiam nessa ideia são Sequential Leader Clustering (SLC) (DUDA; HART; STORK, 2000), Grow When Required (GWR) (MARSLAND; SHAPIRO; NEHMZOW, 2002) e Self-Organizing Novelty Detection Neural Network (SONDE) (ALBERTINI; MELLO, 2010). O algoritmo OnLIne Novelty and Drift Detection Algorithm (OLINDDA) (SPINOSA; CARVALHO; GAMA, 2007) propõe a utilização de agrupamento baseado no $K$-means e uma estratégia de detecção de novidades que considera a diferenciação entre um conceito novo e uma mudança de um conceito pré-existente. Para tanto esse algoritmo busca inspiração em estratégias de classificação com uma única classe. Uma desvantagem dessa abordagem é que a maior parte dos algoritmos considera um único evento novo como uma mudança de comportamento, o que é impraticável em muitos cenários onde a presença de outliers não pode ser descartada, como o caso dos jogos computacionais. Além disso, eles impõem restrições quanto ao número e forma dos grupos gerados, o que nem sempre é possível de se determinar a priori ou quando os dados evoluem no tempo.

Neste capítulo serão apresentados alguns dos algoritmos citados. A escolha dos algo- 
ritmos se deu por sua representatividade na área de pesquisa, assim como sua utilização neste trabalho. Dessa maneira, na Seção 3.2 são apresentados os algoritmos estatísticos para detecção de mudanças PHT e ADWIN. Em seguida, na Seção 3.3, faz-se uma revisão dos algortimos para agrupamento incremental CluStream e DenStream. Os algoritmos GWR e SONDE, baseados em agrupamento e detecção de novidades, são revisados na Seção 3.4. Finalmente, na Seção 3.5 são apontadas as considerações finais deste capítulo.

\subsection{Algoritmos Estatísticos}

Os algoritmos estatísticos para detecção de mudanças podem ser divididos, de modo geral, em duas categorias. A primeira consiste em abordagens que monitoram a evolução das características dos dados de modo incremental, utilizando, por exemplo, a média dos valores observados no tempo. A segunda categoria abrange algoritmos que monitoram a distribuição dos dados em duas janelas de tempo distintas. Na primeira janela estão contidos dados que, geralmente, sumarizam informação passada do fluxo, enquanto que a segunda janela contém os dados mais recentes. A seguir, são apresentados dois algoritmos estatísticos para detecção de mudanças, o teste incremental de PHT (PAGE, 1954) e a abordagem utilizando janelas de tempo ADWIN (BIFET; GAVALDÀ, 2007).

\subsubsection{Page-Hinkley Test}

O PHT (PAGE, 1954) é uma técnica de análise sequencial muito utilizada em processamento de sinais para monitoramento e detecção de possíveis mudanças. Esse teste monitora a média de um sinal Gaussiano, sinalizando mudanças abruptas. Um sinal pode ser visto como um fluxo de dados unidimensional. Assim, um exemplo chegando no instante de tempo $t$ pode ser visto como uma observação do sinal em $t$. O Algoritmo 3.1 sumariza, em forma de pseudocódigo, o funcionamento do PHT para um fluxo de dados unidimensional $X$.

O PHT considera uma variável cumulativa $m_{t}$, definida na Equação 3.1, que representa a diferença acumulada entre os valores $x_{i}$ observados do fluxo e sua média $\bar{x}_{t}$ até o presente momento, onde $\bar{x}_{t}$ é dada pela Equação 3.2.

$$
\begin{gathered}
m_{t}=\sum_{i=1}^{t}\left(x_{i}-\bar{x}_{t}-\delta_{P H T}\right) \\
\bar{x}_{t}=\frac{1}{T} \sum_{i=1}^{t} x_{i}
\end{gathered}
$$

Na Equação 3.1, $\delta_{P H T}$ corresponde a magnitude de mudanças que são permitidas. $O$ teste também utiliza o menor valor observado da variável $m_{t}$, dado por $M_{t}=\min \left(m_{i}, i=\right.$ 


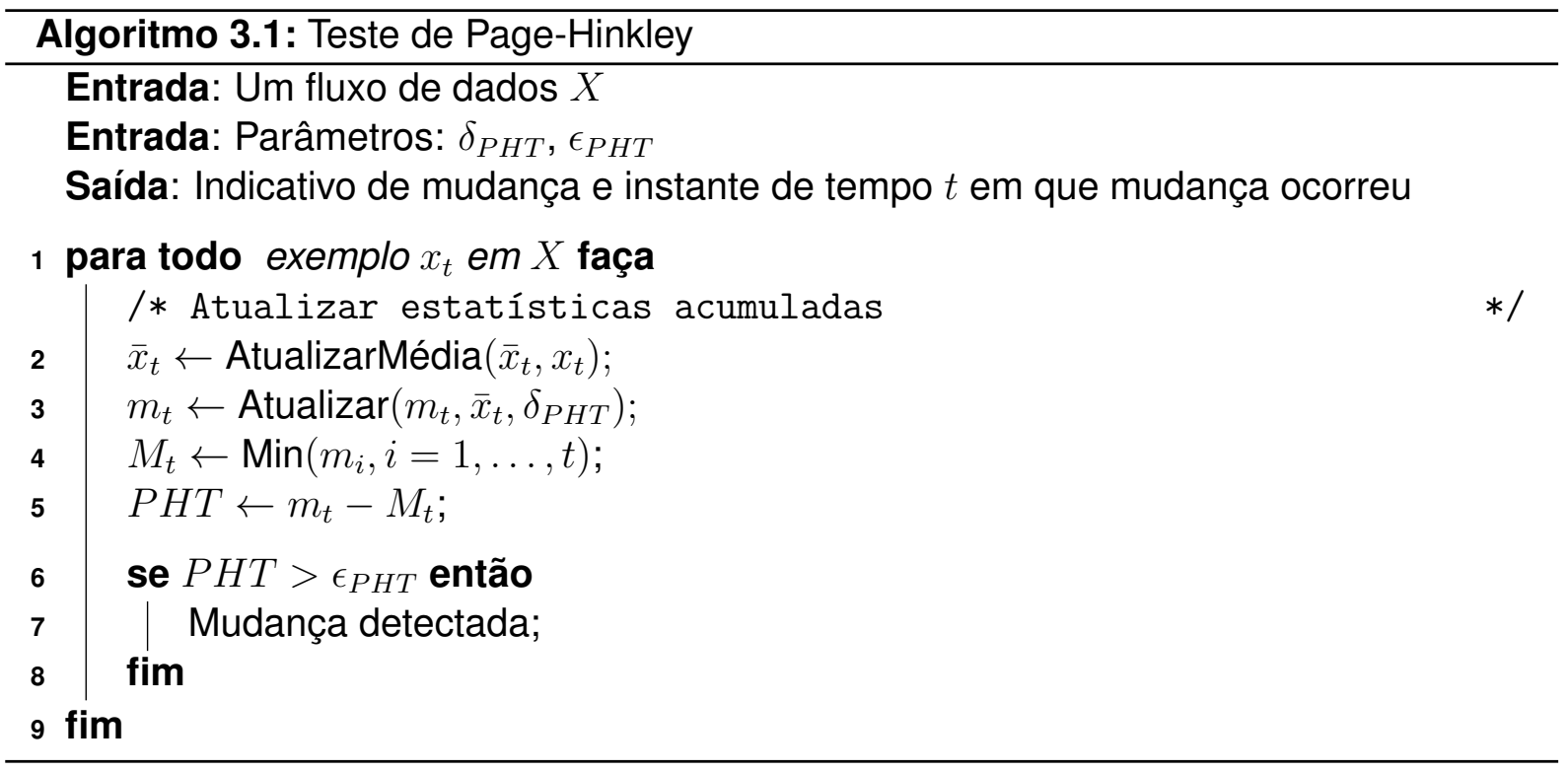

$1, \ldots, t)$. Assim, o PHT verifica a diferença entre $m_{t}$ e $M_{t}$. Se essa diferença for maior que um limiar $\epsilon_{P H T}$, o teste indica a ocorrência de uma mudança. Sempre que uma mudança for detectada, o PHT reinicializa os valores de suas variáveis acumuladas para zero.

$O$ limiar $\epsilon_{P H T}$ tem influência direta na taxa de falsos positivos do algoritmo. Ao aumentar $\epsilon_{P H T}$ diminui-se a ocorrência de falsos positivos, ao custo da não detecção de possíveis mudanças verdadeiras.

Para que o PHT seja aplicado em fluxos de dados contendo multidimensionais, isto é, cada exemplo $x_{t}$ no fluxo de dados $X$ é representado por um vetor $\overrightarrow{x_{t}}$ contendo $d$ dimensões, é necessário aplicar o teste separadamente para cada uma das $d$ dimensões presentes nos dados.

\subsubsection{Adaptive Windowing}

Assim como o PHT, a proposta original do algoritmo ADWIN (BIFET; GAVALDÀ, 2007) considera fluxos de dados unidimensionais. O ADWIN mantém uma janela $W$ contendo os exemplos $x_{t}$ mais recentes do fluxo. Seja $n$ o tamanho da janela $W$ e $\hat{\mu}_{W}$ a média observada dos valores em $W$. A ideia básica é a de que sempre que duas subjanelas de $W$ exibirem tamanhos e médias suficientemente distintas, pode-se concluir que a distribuição de valores esperada em cada subjanela é diferente e, portanto, a porção mais antiga da janela pode ser descartada. Assim, ADWIN verifica para cada divisão possível de $W$ em duas subjanelas $W_{1}$ e $W_{2}$ se a diferença entre as médias dos valores nas subjanelas, denotados por $\hat{\mu}_{W_{1}}$ e $\hat{\mu}_{W_{2}}$, é maior do que $\epsilon_{A D W I N}$. Ou seja, se $\left|\hat{\mu}_{W_{1}}-\hat{\mu}_{W_{2}}\right| \geqslant \epsilon_{A D W I N}$, então uma mudança é detectada, os dados correspondentes à primeira subjanela são descartados e o processo se repete. O Algoritmo 3.2 sumariza, em forma de pseudocódigo, o funcionamento do ADWIN para um fluxo de dados unidimensional.

O valor de $\epsilon_{A D W I N}$ para uma partição de $W$ em duas subjanelas $W_{1}$ e $W_{2}$ é calculado 


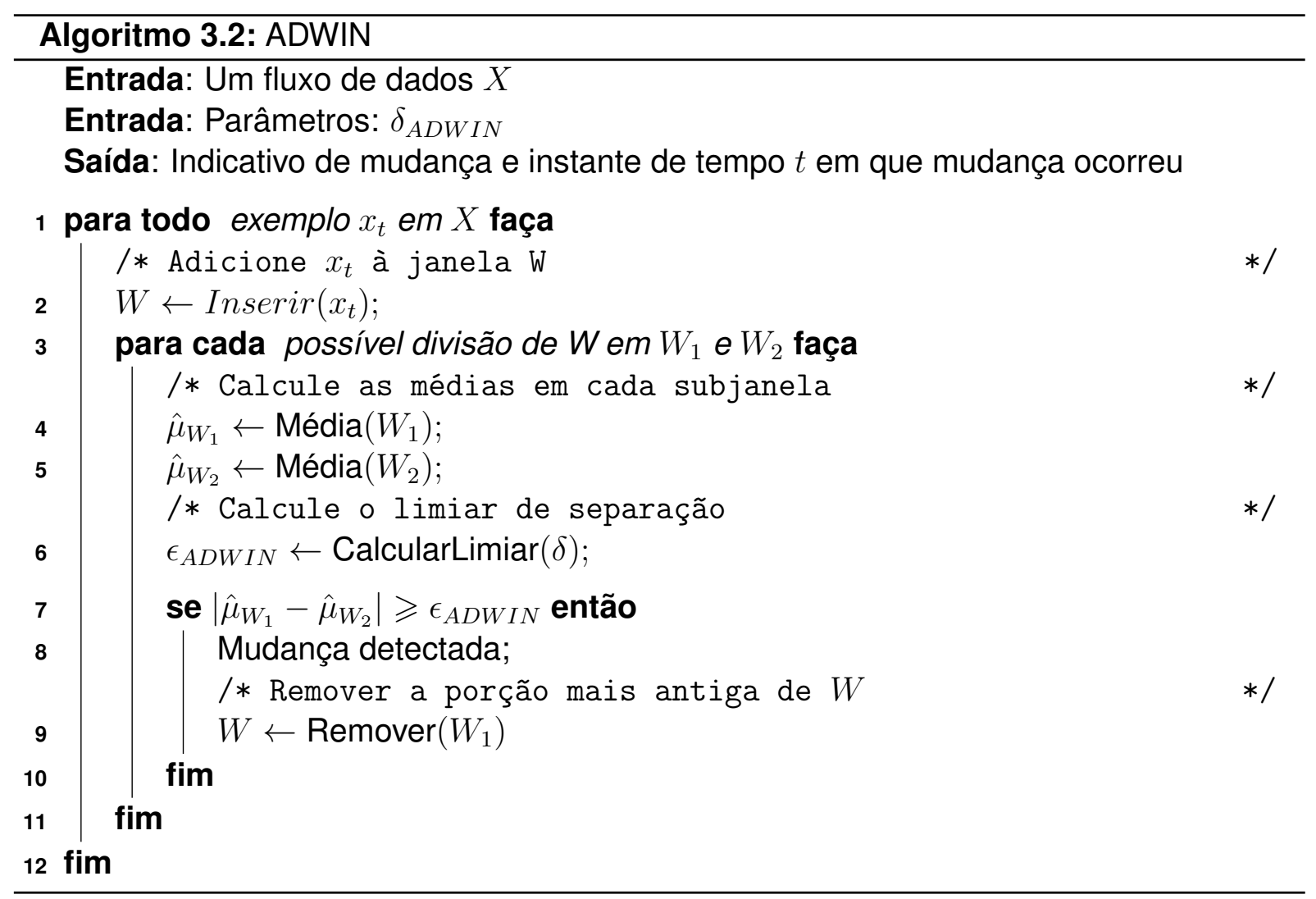

da seguinte maneira. Sejam $n_{1}$ e $n_{2}$ os tamanhos de $W_{1}$ e $W_{2}$, respectivamente, e $n$ o tamanho de $W$. O valor de $\epsilon_{A D W I N}$ é dado pela Equação 3.3, onde os valores de $m$ e $\delta^{\prime}$ são dados, respectivamente, pelas Equações 3.4 e 3.5 , e $\sigma_{W}^{2}$ representa a variância calculada a partir dos dados contidos em $W$.

$$
\begin{gathered}
\epsilon_{A D W I N}=\sqrt{\frac{2}{m} \cdot \sigma_{W}^{2} \cdot \ln \frac{2}{\delta^{\prime}}}+\frac{2}{3 m} \cdot \ln \frac{2}{\delta^{\prime}} \\
m=\frac{1}{\frac{1}{n_{1}}+\frac{1}{n_{2}}} \\
\delta^{\prime}=\frac{\delta_{A D W I N}}{n}
\end{gathered}
$$

O papel de $\delta_{A D W I N}$ é o de impor um limite sobre a taxa de falsos positivos detectados. Assim, se a média $\mu_{t}$ se mantém constante ao longo da janela de tamanho $W$, então a probabilidade de que o ADWIN irá detectar uma mudança e, consequentemente, diminuir o tamanho da janela nesse instante de tempo, é no máximo $\delta_{A D W I N}$.

Como o ADWIN foi criado para processar dados unidimensionais, sua aplicação em um cenário multidimensional requer múltiplas execuções do algoritmo, i.e., o ADWIN deve ser aplicado, separadamente, em cada uma das $d$ dimensões presentes nos dados. 


\subsection{Algoritmos de Agrupamento}

A mudança de comportamento nos dados chegando em um fluxo é também abordada, embora indiretamente, por diversos algoritmos de agrupamento em fluxos de dados. Esses algoritmos consideram que as características dos dados podem se alterar com o passar do tempo, de modo que o agrupamento gerado deve ser modificado, refletindo esse novo comportamento dos dados. Dessa maneira, uma boa parte dos algoritmos de agrupamento aplicáveis ao cenário de fluxos de dados trabalha incrementalmente, adicionando novos dados aos grupos pré-existentes, ou criando novos grupos, a medida que os dados se tornam disponíveis. Esses algoritmos são projetados de modo a considerar as possíveis mudanças dos dados e, automaticamente, inserir esses novos dados nos modelos sendo construídos, sempre mantendo um balanço entre informação passada e nova. Embora esses algoritmos considerem a possível ocorrência de mudanças e atualizem a estrutura de grupos formada, eles não informam quando as mudanças estão ocorrendo. A seguir, são apresentados os algoritmos para agrupamento incremental CluStream (AGGARWAL et al., 2003) e DenStream (CAO et al., 2006).

\subsubsection{CluStream}

O algoritmo para agrupamento em um fluxo de dados CluStream (AGGARWAL et al., 2003) foi proposto de modo a superar a deficiência de algoritmos anteriores que não consideravam o comportamento variável de um fluxo de dados no tempo. O algoritmo CluStream é dividido em uma fase online de microagrupamento e uma fase offline de macroagrupamento. A fase de microagrupamento requer um processo eficiente de armazenamento de estatísticas sumarizadas a respeito dos dados chegando no fluxo. O componente offline, então, utiliza essas estatísticas em conjunto com entradas fornecidas pelo usuário, como o número de grupos, de modo a prover o usuário com um rápido entendimento dos grupos formados sempre que necessário. O Algoritmo 3.3 apresenta, em forma de pseudocódigo, o funcionamento do CluStream.

Durante sua fase de microagrupamento, o algoritmo CluStream utiliza o conceito de micro-clusters. Um micro-cluster para um conjunto de $n$ exemplos contendo $d$ dimensões $\overrightarrow{x_{1}} \ldots \overrightarrow{x_{n}}$ com marcadores de tempo $T_{1} \ldots T_{n}$ é definido pela tupla de dimensão $(2 . d+3)$, $\left(\overrightarrow{C F 1^{x}}, \overrightarrow{C F 2^{x}}, C F 1^{t}, C F 2^{t}, n\right)$, onde $\overrightarrow{C F 1^{x}}$ e $\overrightarrow{C F 2^{x}}$ correspondem a vetores contendo $d$ dimensões. A definição de cada um desses componentes é dada por:

- Para cada dimensão, a soma dos valores dos exemplos é mantida em $\overrightarrow{C F 1^{x}}$. Desse modo, $\overrightarrow{C F 1^{x}}$ contém $d$ valores e a p-ésima entrada de $\overrightarrow{C F 1^{x}}$ é igual a $\sum_{i=1}^{n} x_{i}^{p}$, onde $x_{i}^{p}$ corresponde à p-ésima dimensão do i-ésimo exemplo.

- Para cada dimensão, a soma dos quadrados dos valores é mantida em $\overrightarrow{C F 2^{x}}$. Desse modo, $\overrightarrow{C F 2^{x}}$ contém $d$ valores e a p-ésima entrada de $\overrightarrow{C F 2^{x}}$ é igual a $\sum_{i=1}^{n}\left(x_{i}^{p}\right)^{2}$. 


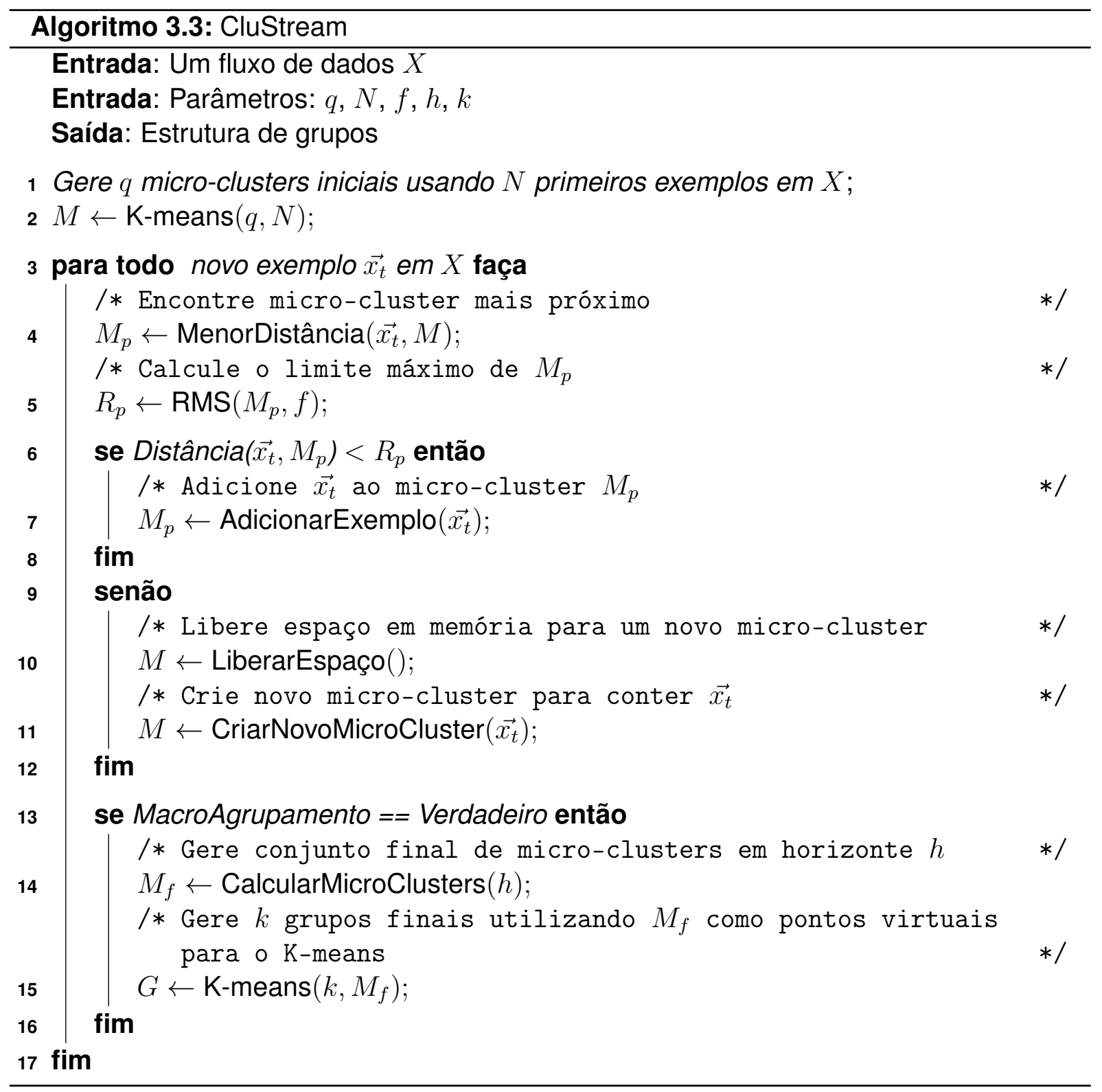


- A soma dos marcadores de tempo $T_{1} \ldots T_{n}$ é mantida em $C F 1^{t}$.

- A soma dos quadrados dos marcadores de tempo $T_{1} \ldots T_{n}$ é mantida em $C F 2^{t}$.

- O último componente representa o número de exemplos $n$.

A definição de micro-cluster é uma extensão temporal direta do vetor Cluster Feature utilizado pelo algoritmo BIRCH (ZHANG; RAMAKRISHNAN; LIVNY, 1996). Nessa fase, o objetivo é manter estatísticas em um nível suficiente de granularidade de modo a prover informação suficiente para o passo seguinte de macroagrupamento. Essas estatísticas são armazenadas pelos micro-clusters. O algoritmo supõe que podem ser mantidos em memória principal um total de $q$ micro-clusters. Esses micro-clusters são representados por $M_{1} \ldots M_{q}$ e representam o estado atual de agrupamento do fluxo. $O$ estado dos microclusters é armazenado em memória secundária em instantes de tempo calculados a partir de parâmetros fornecidos pelo usuário.

Para criar os $q$ micro-clusters iniciais, o algoritmo K-means é aplicado aos $N$ primeiros exemplos provenientes do fluxo. O valor de $N$ é escolhido de modo a ser tão grande quanto o permitido pela complexidade computacional do K-means criando $q$ grupos.

Uma vez criados os micro-clusters iniciais, o algoritmo procede à fase de manutenção online de micro-clusters. Sempre que um novo exemplo $x_{t}$ esteja disponível, os microclusters são atualizados de modo a refletir a chegada desse novo exemplo. Cada exemplo deve ser absorvido por um micro-cluster existente ou por um novo micro-cluster criado para contê-lo. O algoritmo incialmente encontra a distância de $\overrightarrow{x_{t}}$ aos centroides dos microclusters $M_{1} \ldots M_{q}$. Desse modo, é possível definir o micro-cluster $M_{p}$ mais próximo ao novo exemplo e também verificar se $\overrightarrow{x_{t}}$ recai sobre o limite máximo do grupo, definido como um fator $f$ do desvio RMS dos pontos em $M_{p}$ ao centroide de $M_{p}$. Se $\overrightarrow{x_{t}}$ recai dentro do limite máximo do grupo, então esse exemplo é absorvido por $M_{p}$. Caso contrário, um novo micro-cluster deve ser criado para acomodar $\overrightarrow{x_{t}}$.

Entretanto, para criar um novo micro-cluster, é preciso liberar espaço em memória principal removendo um micro-cluster antigo ou unindo dois micro-clusters. O algoritmo inicialmente verifica se é seguro remover um micro-cluster. Para tanto, calcula-se uma estimativa do tempo de chegada médio dos últimos $m$ exemplos em um micro-cluster $M_{k}$, utilizando os marcadores de tempo sumarizados no próprio micro-cluster, de modo a obter uma medida de quão relevantes são os micro-clusters em relação a chegada de exemplos no tempo. O micro-cluster menos relevante é comparado a um limiar $\delta$, definido pelo usuário, de modo que se a estimativa de relevância desse micro-cluster for menor do que $\delta$, esse micro-cluster é removido pelo algoritmo. Entretanto, em alguns casos nenhum micro-cluster pode ser removido. Nesses casos, os dois micro-clusters mais próximos são unidos, formando um único micro-cluster.

$\mathrm{Na}$ fase seguinte de macroagrupamento o algoritmo utiliza duas informações providas pelo usuário, o horizonte $h$ no qual deseja-se realizar o agrupamento e o número de gru- 
pos $k$. Utilizando a propriedade de subtração dos micro-clusters, é possível encontrar os micro-clusters pertencentes a um horizonte de tempo específico. Considere a situação em que o tempo atual é definido por $t_{c}$ e o usuário deseja encontrar grupos em um horizonte de tempo passado definido por $h$. O algoritmo recupera os conjuntos de micro-clusters armazenados no disco para os instantes de tempo $t_{c}$ e $t_{c}-h$, definidos por $S\left(t_{c}\right)$ e $S\left(t_{c}-h\right)$, e subtrai as estatísticas de cada micro-cluster correspondente, criando um único conjunto de micro-clusters. Esse conjunto final de micro-clusters é submetido a uma versão modificada do algoritmo K-means para geração do agrupamento final. Essa versão modificada utiliza os micro-clusters como pseudo-exemplos que devem ser agrupados de modo a determinar grupos de mais alto nível. Como pseudo-exemplos são utilizados, a versão modificada do K-means utilizada pelo CluStream considera que:

- Na fase de inicialização, os protótipos não são mais escolhidos aleatoriamente, mas sim amostrados com uma probabilidade proporcional ao número de exemplos em cada micro-cluster. O protótipo correspondente é o centroide desse micro-cluster.

- Na fase de particionamento, a distância de um protótipo a um dado pseudo-exemplo (ou micro-cluster) é igual a distância do protótipo ao centroide desse micro-cluster.

- Na fase de ajuste de protótipos, um novo protótipo é definido como o centroide ponderado dos micro-clusters nesta partição.

A principal vantagem do CluStream está em permitir ao usuário realizar o agrupamento utilizando diferentes horizontes de tempo e diferentes granularidades através dos parâmetros de entrada $h$ e $k$. Entretanto, por utilizar um algoritmo baseado em proximidade em sua fase de agrupamento offline, este algoritmo sempre irá retornar grupos de formato hiper-esférico, o que pode representar uma desvantagem em aplicações reais.

\subsubsection{DenStream}

Baseado no paradigma de agrupamento por densidade, o algoritmo DenStream (CAO et al., 2006), assim como o CluStream, também é dividido em uma fase online de sumarização dos dados que chegam no fluxo, também denominada de microagrupamento, e uma fase offline, ou de macroagrupamento. O algoritmo propõe uma estratégia para encontrar grupos de formato arbitrário sem que haja a necessidade de informar o número de grupos a priori. Além disso, conta com uma estratégia para distinguir exemplos outliers de exemplos pertencentes a novos grupos em formação. O Algoritmo 3.4 apresenta o pseudocódigo para o DenStream.

Em sua fase online o DenStream utiliza o conceito de core-micro-clusters. As seguintes definições e propriedades foram extraídas de Cao et al. (2006) 


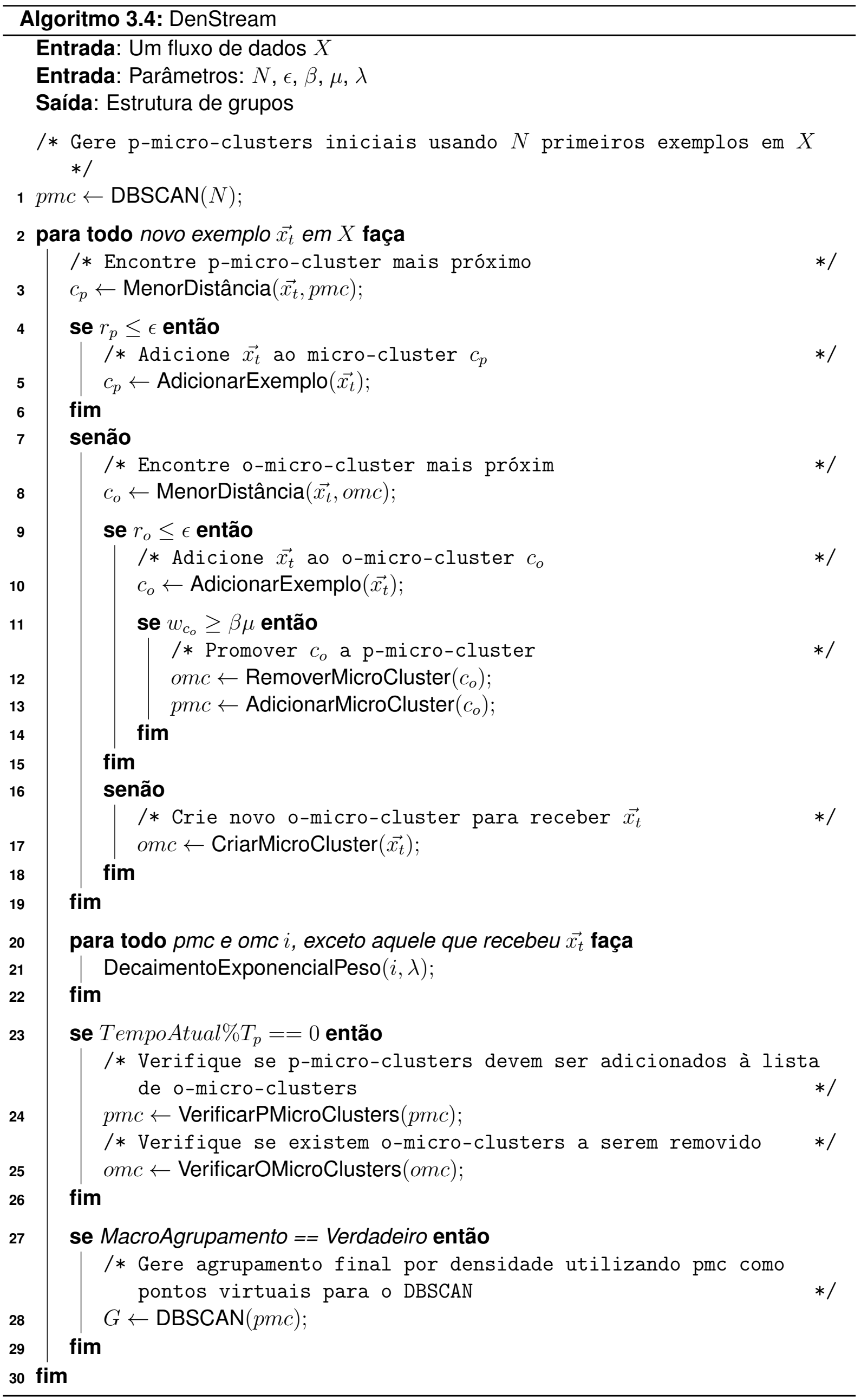


Definição 3.3.2.1 (core-micro-cluster) Um core-micro-cluster, abreviação c-micro-cluster, no instante de tempo $t$ é definido como $C M C(w, \vec{c}, r)$ para um grupo de $n$ exemplos próximos contendo $d$ dimensões $\overrightarrow{x_{1}}, \ldots, \overrightarrow{x_{n}}$ com marcadores de tempo $T_{1}, \ldots, T_{n}$, onde $w=$ $\sum_{i=1}^{n} f\left(t-T_{i}\right), w>\mu$, é o peso; $\vec{c}=\frac{\sum_{i=1}^{n} f\left(t-T_{i}\right) \cdot \overrightarrow{x_{i}}}{w}$ é o centro; $r=\frac{\sum_{i=1}^{n} f\left(t-T_{i}\right) \cdot \operatorname{dist}\left(\overrightarrow{x_{i}, \vec{c}}\right)}{w}$, $r<\epsilon$, é o raio e $\operatorname{dist}\left(\overrightarrow{x_{i}}, \vec{c}\right)$ denota a distância Euclidiana entre o exemplo $\overrightarrow{x_{i}}$ e o centro $\vec{c}$.

Em um fluxo de dados evoluindo no tempo, os papéis de grupos e ouliers muitas vezes se invertem. Para lidar com tal situação, o algoritmo utiliza ainda os conceitos de potencial c-micro-cluster e outlier c-micro-cluster. A principal diferença entre ambos é a restrição sobre o peso $w$.

Definição 3.3.2.2 (potencial c-micro-cluster) Um potencial c-micro-cluster, abreviação p-micro-cluster, no instante de tempo $t$ para um grupo de exemplos próximos $\overrightarrow{x_{1}}, \ldots, \overrightarrow{x_{n}}$ com marcadores de tempo $T_{1}, \ldots, T_{n}$ é definido como $\left(\overrightarrow{C F^{1}}, \overrightarrow{C F^{2}}, w\right)$, onde $w=\sum_{i=1}^{n} f\left(t-T_{i}\right)$, $w>\beta \mu$, é o peso; $\beta, 0<\beta \leq 1$, é o parâmetro para determinar o limiar de ouliers em relação a c-micro-clusters; $\overrightarrow{C F^{1}}=\sum_{i=1}^{n} f\left(t-T_{i}\right) \cdot \overrightarrow{x_{i}}$ é um vetor contendo a soma ponderada dos exemplos por dimensão; $\overrightarrow{C F^{2}}=\sum_{i=1}^{n} f\left(t-T_{i}\right) \cdot{\overrightarrow{x_{i}}}^{2}$ é um vetor contendo a soma ponderada quadrática dos exemplos por dimensão. O centro de um $p$-micro-cluster é dado por $\vec{c}=\frac{\overrightarrow{C F^{1}}}{w}$ e o raio é dado por $r=\sqrt{\frac{\overrightarrow{C F^{2}}}{w}-\left(\frac{\overrightarrow{C F}}{w}\right)^{2}}, r \leq \epsilon$.

Definição 3.3.2.3 (outlier c-micro-cluster) Um outlier c-micro-cluster, abreviação omicro-cluster, no instante de tempo $t$ para um grupo de exemplos próximos $\overrightarrow{x_{1}}, \ldots, \overrightarrow{x_{n}}$ com marcadores de tempo $T_{1}, \ldots, T_{n}$ é definido como $\left(\overrightarrow{C F^{1}}, \overrightarrow{C F^{2}}, w, t_{0}\right)$. As definições de $w$, $\overrightarrow{C F^{1}}, \overrightarrow{C F^{2}}$, centro e raio são as mesmas que um $p$-micro-cluster; $t_{0}=T_{1}$ denota o tempo de criação do o-micro-cluster e é utilizado para determinar seu tempo de vida. Entretanto, $w<\beta \mu$. Isso é, como o peso está abaixo do limiar de outliers, esse micro-cluster correponde a exemplos outliers.

Propriedade 3.3.2.1 p-micro-clusters e o-micro-clusters podem ser mantidos incrementalmente.

Prova: Considere um p-micro-cluster $c_{p}=\left(\overrightarrow{C F^{2}}, \overrightarrow{C F^{1}}, w\right)$. Se nenhum exemplo é adicionado à $c_{p}$ no intervalo de tempo $\delta t, c_{p}=\left(2^{-\lambda \delta t} \cdot \overrightarrow{C F^{2}}, 2^{-\lambda \delta t} \cdot \overrightarrow{C F^{1}}, 2^{-\lambda \delta t} \cdot w\right)$. Se o exemplo $p$ é absorvido por $c_{p}, c_{p}=\left(\overrightarrow{C F^{2}}+p^{2}, \overrightarrow{C F^{1}}+p, w+1\right)$. O mesmo é válido para o-micro-clusters.

Para descobrir os grupos em um fluxo de dados, o algoritmo mantém um conjunto de p-micro-clusters e o-micro-clusters em sua fase online. Os o-micro-clusters são mantidos em um espaço de memória separado denominado buffer de outliers. O primeiro passo do algoritmo consiste, portanto, em gerar um conjunto de $p$-micro-cluster iniciais. Para tanto, 
o algoritmo DBSCAN (ESTER et al., 1996) é aplicado aos $N$ primeiros exemplos disponíveis no fluxo. Em seguida, durante a fase de manutenção online, quando um novo exemplo $\overrightarrow{x_{t}}$ chega no fluxo, o algoritmo procede como abaixo:

- Primeiramente, tenta-se colocar $\overrightarrow{x_{t}}$ no $p$-micro-cluster $c_{p}$ mais próximo. Se $r_{p}$, o novo raio de $c_{p}$ for menor ou igual a $\epsilon, \overrightarrow{x_{t}}$ é inserido em $c_{p}$. A inserção de um novo exemplo segue a propriedade incremental dos micro-clusters.

- Senão, tenta-se colocar $\overrightarrow{x_{t}}$ no o-micro-cluster $c_{o}$ mais próximo. Se $r_{o}$, o novo raio de $c_{o}$ for menor ou igual a $\epsilon, \overrightarrow{x_{t}}$ é inserido em $c_{o}$. Em seguida, verifica-se $w$, o novo peso de $c_{o}$. Se $w>\beta \mu, c_{o}$ deve ser promovido a $p$-micro-cluster. Assim, $c_{o}$ é removido do buffer de outliers e um novo $p$-micro-cluster é criado para acomodar $c_{o}$.

- Se $\overrightarrow{x_{t}}$ não pode ser inserido em um o-micro-cluster, um novo o-micro-cluster $c_{o}$ é criado para receber $\overrightarrow{x_{t}}$ e $c_{o}$ é inserido no buffer de outliers.

Para cada $p$-micro-cluster $c_{p}$ existente, se nenhum novo exemplo é adicionado, a informação em $c_{p}$ irá decair gradualmente com o tempo segundo uma função de esquecimento exponencial $f(t)=2^{-\lambda \cdot t}$, onde $\lambda>0$. Se o peso de $c_{p}$ for menor que $\beta \mu, c_{p}$ se tornou um outlier e deve ser removido e seu espaço em memória liberado para novos $p$ micro-clusters. Assim, verifica-se o peso de cada $p$-micro-cluster periodicamente. Cada p-micro-cluster é verificado a cada $T_{p}$ intervalos de tempo, onde $T_{p}$ é dado pela equação 4.1

$$
T_{p}=\left\lceil\frac{1}{\lambda} \log \left(\frac{\beta \mu}{\beta \mu-1}\right)\right\rceil
$$

Os o-micro-clusters são também verificados de modo a remover aqueles o-micro-clusters que não apresentam potencial de crescer e se tornar um p-micro-cluster. Cada o-microcluster é verificado a cada $T_{p}$ intervalos de tempo, seguindo a equação 4.1. Nesses intervalos de tempo, o peso do o-micro-cluster é comparado com o seu limite mínimo de peso, denotado por $\xi$. Se o peso do o-micro-cluster for menor que $\xi$, então esse o-microcluster é removido do buffer de outliers. O limite mínimo de peso $\xi$ é dado pela equação 4.2 .

$$
\xi\left(t_{c}, t_{o}\right)=\frac{2^{-\lambda\left(t_{c}-t_{o}+T_{p}\right)}-1}{2^{-\lambda T_{p}}-1}
$$

O limite mínimo de peso é uma função de $t_{c}$ (i.e., instante de tempo atual) e $t_{o}$ (i.e., tempo de criação do o-micro-cluster). Quando $t_{c}=t_{o}$, isto é, no instante de criação do omicro-cluster, $\xi=1$. Com o passar do tempo, $\xi$ aumenta e $\lim _{t_{c} \rightarrow \infty} \xi\left(t_{c}\right)=\frac{1}{1-2^{-\lambda T_{p}}}=\beta \mu$.

Em sua fase offline, sempre que uma requisição de agrupamento é recebida, o algoritmo DenStream utiliza a informação sumarizada nos $p$-micro-clusters para realizar um 
agrupamento superior baseado no algoritmo DBSCAN. Cada p-micro-cluster $c_{p}$ é considerado como um exemplo virtual localizado no centro de $c_{p}$ e cujo peso é igual a $w$. A variante do DBSCAN implementada no DenStream utiliza os parâmetros $\epsilon$ e $\mu$. O conceito de conexão por densidade é utilizado, i.e., todos os exemplos conectados por densidade formam um grupo.

Definição 3.3.2.4 (diretamente alcançável por densidade) Um p-micro-cluster $c_{p}$ é diretamente alcançável por densidade a um p-micro-cluster $c_{q}$, com relação a $\epsilon \mathrm{e} \mu$, se o peso de $c_{q}$ é maior do que $\mu$ e $\operatorname{dist}\left(c_{p}, c_{q}\right) \leq 2 \cdot \epsilon$, onde $\operatorname{dist}\left(c_{p}, c_{q}\right)$ é a distância entre os centros de $c_{p}$ e $c_{q}$.

Definição 3.3.2.5 (alcançável por densidade) Um p-micro-cluster $c_{p}$ é alcançavel por densidade a um p-micro-cluster $c_{q}$, com relação a $\epsilon$ e $\mu$, se existe uma cadeia de $p$-microclusters $c_{1}, \ldots, c_{n}, c_{1}=c_{q}, c_{n}=c_{p}$ de tal modo que $c_{i+1}$ é diretamente alcançável por densidade a partir de $c_{i}$.

Definição 3.3.2.6 (conectado por densidade) Um p-micro-cluster $c_{p}$ é conectado por densidade a um p-micro-cluster $c_{q}$, com relação a $\epsilon$ e $\mu$, se existir um p-micro-cluster $c_{m}$ de tal modo que ambos $c_{p}$ e $c_{q}$ sejam alcançáveis por densidade a partir de $c_{m}$, com relação a $\epsilon$ e $\mu$.

O algoritmo DenStream possui diversas vantagens em relação a outros algoritmos para agrupamento em fluxos de dados. Em primeiro lugar, o DenStream não faz nenhuma suposição a priori a respeito do número de grupos existentes no fluxo. Devido à utilização de um algoritmo baseado no paradigma de agrupamento por densidade em sua etapa de macroagrupamento, o DenStream é capaz de encontrar grupos de formatos arbitrários. Além disso, o DenStream implementa um processo de filtragem de exemplos outliers que eventualmente possam existir no fluxo de dados, melhorando a qualidade do agrupamento final obtido.

\subsection{Agrupamento e Detecção de Novidades}

Além de atualizar a estrutura de grupos sempre que os dados se alterarem, pode ser necessário informar os instantes em que as mudanças são detectadas nos dados, i.e., informar sobre a ocorrência de eventos que causem uma variação na estrutura atual de grupos. Uma forma de realizar essa tarefa é acoplar um detector de novidades ao algoritmo de agrupamento. O detector de novidades é responsável por verificar qual o nível de mudança na estrutura de grupos com a chegada de um novo exemplo. Se o nível de mudança exceder um limiar pré-estabelecido, uma novidade é reportada e considera-se 
que os dados estão sofrendo mudanças. Nesta seção, são apresentados o algoritmos GWR (MARSLAND, 2002) e SONDE (ALBERTINI; MELLO, 2010), baseados em RNAs.

\subsubsection{Rede Neural Grow When Required}

A habilidade de adicionar novos nós é uma característica interessante para RNA autoorganizáveis. Uma rede que adiciona nós em sua estrutura é capaz de aproximar o espaço de entrada de maneira mais acurada do que uma rede com estrutura e tamanho pré-definidos. Além disso, redes que crescem são capazes de se ajustar e lidar com distribuições de entrada dinâmicas.

Uma boa parte das redes que crescem propostas na literatura adicionam novos nós para auxiliar o nó com maior erro acumulado durante iterações passadas na rede. Isso significa que novos nó são adicionados quando o número de iterações é um inteiro múltiplo de uma constante pré-definida pelo usuário.

A rede GWR (MARSLAND, 2002), utiliza um critério diferente para adicionar novos nós em sua estrutura. No algoritmo da GWR, nós são adicionados sempre que a entrada atual não é absorvida por nenhum dos nós já existentes na rede. Dessa forma, o novo nó adicionado é inicializado para reconhecer a entrada atual. Essa estratégia possui o benefício de que, uma vez que o espaço de entrada é mapeado pela rede apresentando um limite bem definido de erro, a rede pára de crescer. O Algoritmo 3.5 apresenta o pseudocódigo para a GWR.

O algoritmo da GWR é definido utilizando conceitos de nós e arestas. Sejam $C$ o conjunto de nós da rede e $A \subset C \times C$ o conjunto de arestas conectando esses nós. Seja a distribuição de entrada $p(x)$, para entradas $\overrightarrow{x_{i}}$, contendo $d$ dimensões. Define-se $\overrightarrow{w_{n}}$ como o vetor de pesos do nó $n$.

Na fase de inicialização, são criados dois nós no conjunto $C$, dados por $C=\left\{n_{1}, n_{2}\right\}$, com $n_{1}, n_{2}$ inicializados aleatoriamente a partir de $p(x)$. O conjunto $A$ de arestas é definido como o conjunto vazio $C=\varnothing$.

A cada novo exemplo $\overrightarrow{x_{i}}$, o algoritmo calcula a distância de $\overrightarrow{x_{i}}$ à cada nó $j$ da rede, dada por $\left\|\overrightarrow{x_{i}}-\overrightarrow{w_{j}}\right\|$. Em seguida, selecionam-se o neurônio que melhor representa a entrada atual e o segundo melhor, isto é, os nós $s, t \in C$ de modo que

$$
\begin{gathered}
s=\arg \min _{n \in C}\left\|\overrightarrow{x_{i}}-\overrightarrow{w_{n}}\right\| \\
t=\arg \min _{n \in C /\{s\}}\left\|\overrightarrow{x_{i}}-\overrightarrow{w_{n}}\right\|
\end{gathered}
$$

onde $\overrightarrow{w_{n}}$ é o vetor de pesos do nó $n$. Caso não exista uma aresta entre $s$ e $t$, ela é criada.

Caso a aresta já exista, o marcador de idade dessa conexão é atualizado para 0 . Em 


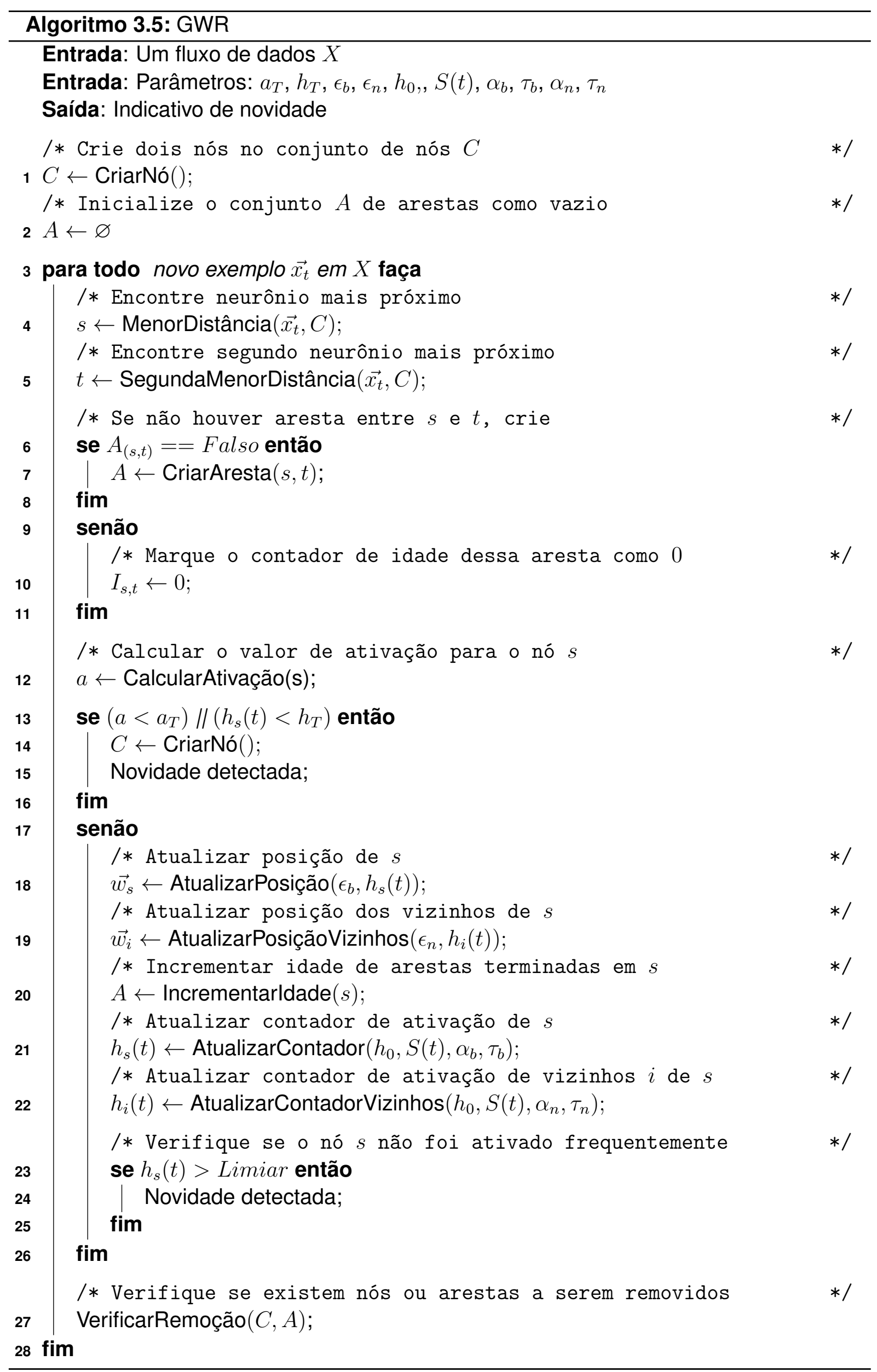


seguida, o valor de ativação do neurônio que melhor representa a entrada, dado pela Equação 3.10, é calculado.

$$
a=\exp \left(-\left\|\overrightarrow{x_{i}}-\overrightarrow{w_{s}}\right\|\right)
$$

Se a ativação $a$ for menor que o limiar de ativação $a_{T}$ e o contador de ativação do nó for menor que o respectivo limiar $h_{T}$, então um novo nó $r$ deve ser criado entre os dois neurônios que melhor representam a entrada ( $s$ e $t$ ). Nesse caso, um novo vetor de pesos é criado inicializando os pesos como a média entre o peso do neurônio que melhor representa a entrada e a própria entrada. Além disso, a aresta conectando $s$ e $t$ é removida e duas novas arestas são inseridas entre $r$ e $s$ e entre $r$ e $t$.

Caso um novo nó não tenha sido adicionado à rede, a posição do neurônio que melhor representa a entrada, $\vec{w}_{s}$, é ajustada de acordo com a Equação 3.11. As posições dos nós aos quais este neurônio está conectado, denominados de neurônios vizinhos $\left(\vec{w}_{i}\right)$, também são atualizadas de acordo com a Equação 3.12.

$$
\begin{gathered}
\Delta \vec{w}_{s}=\epsilon_{b} \times h_{s}(t) \times\left(\overrightarrow{x_{i}}-\vec{w}_{s}\right) \\
\Delta \vec{w}_{i}=\epsilon_{n} \times h_{i}(t) \times\left(\overrightarrow{x_{i}}-\vec{w}_{i}\right)
\end{gathered}
$$

onde $0<\epsilon_{n}<\epsilon_{b}<1$ e $h_{s}(t)$ é o valor do contador de ativação para o nó $s$.

Em seguida, o algoritmo procede incrementando a idade das arestas terminadas em $s$. O contador que mede quão frequentemente o nó $s$ foi ativado é reduzido de acordo com a Equação 3.13, e os contadores de seus $i$ vizinhos são reduzidos de acordo com a Equação 3.14 .

$$
\begin{aligned}
& h_{s}(t)=h_{0}-\frac{S(t)}{\alpha_{b}}\left(1-e^{-\alpha_{b} t / \tau_{b}}\right) \\
& h_{i}(t)=h_{0}-\frac{S(t)}{\alpha_{n}}\left(1-e^{-\alpha_{n} t / \tau_{n}}\right)
\end{aligned}
$$

onde $h_{i} t$ é o valor do contador de ativação para o nó $i, h_{0}$ é força inicial e $S(t)$ é a força do estímulo, usualmente 1. $\alpha_{n}, \alpha_{b}$ e $\tau_{n}, \tau_{b}$ são constantes que controlam o comportamento da curva. O contador de ativação do neurônio que melhor representa a entrada reduz mais rapidamente do que o de seus vizinhos.

O passo final da GWR verifica se existem nós ou arestas a serem removidas, i.e., se existem nós que não possuem vizinhos ou arestas que sejam mais antigas do que o limite de idade estabelecido.

A rede GWR é frequentemente utilizada como um filtro detector de novidades, utilizando para isso o contador de ativação presente em cada nó da rede. Se o nó que é ativado nunca foi ativado antes (ou seja, é um novo nó que está sendo adicionado à rede) ou se 
o nó não foi ativado muito frequentemente, considera-se que um evento novo ocorreu. A desvantagem de se utilizar a GWR para detecção de mudança nos dados é que este algoritmo considera apenas a saída do detector de novidades, i.e., qualquer novidade será imediatamente considerada como uma mudança de comportamento, a não ser que um novo mecanismo detector de mudanças seja adicionalmente implementado no algoritmo original. Sendo assim, eventos isolados, como a ocorrência de outliers, serão automaticamente considerados como uma mudança de comportamento, levando a uma alta taxa de falsos positivos.

\subsubsection{Self-Organizing Novelty Detection Neural Network}

A SONDE (ALBERTINI; MELLO, 2010) é uma técnica para agrupamento e detecção de novidades incremental que, ao contrário de outras técnicas também incrementais para detecção de novidades, atualiza os limiares que diferenciam eventos normais de novidades reais. A informação acumulada pela SONDE pode ser utilizada para detectar novidades temporais e não-temporais assim como quantificar o nível de novidade.

A SONDE, assim como a GWR, utiliza neurônios como unidades básicas para representar conhecimento acumulado. Esses neurônios se adaptam continuamente para melhor representar variações presentes nos exemplos. A arquitetura dessa rede neural é composta por 3 camadas.

- Camada de entrada: essa é uma camada de pré-processamento que pode, opcionalmente, realizar a normalização dos padrões de entrada.

- Camada de neurônios: camada que acomoda os neurônios representando o conhecimento acumulado a partir dos exemplos de entrada.

- Camada competitiva: nesta camada é realizada a escolha do neurônio mais representativo (também denominado de Best-Matching Unit - BMU) para um dado exemplo de entrada.

O Algoritmo 3.6 apresenta o pseudocódigo para a SONDE.

A primeira camada da SONDE é responsável por, opcionalmente, normalizar cada exemplo de entrada. A segunda camada calcula a distância do exemplo $\overrightarrow{x_{t}}$ a cada neurônio $c$. Para tanto, são considerados três componentes de um neurônio:

1. o protótipo $\vec{w}_{c}$ representa a tendência dos padrões de entrada que foram classificados pelo neurônio $c$.

2. o raio médio $\operatorname{rad}_{c}$ mede a dispersão dos padrões de entrada ao redor do protóripo $\vec{w}_{c}$. 


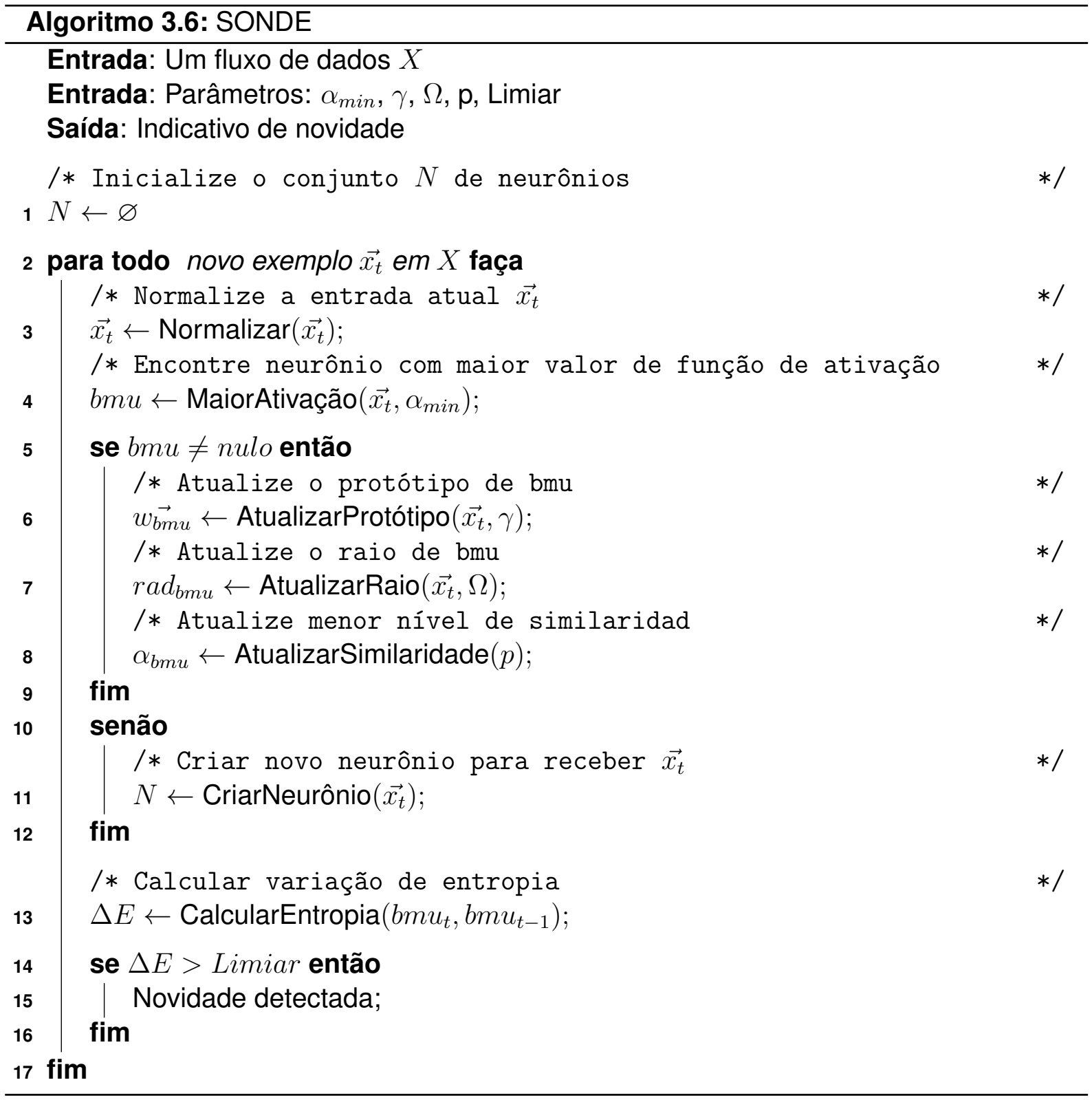


3. o menor nível de similaridade $\alpha_{c}$ representa o menor limiar de ativação para a aceitação de padrões de entrada em um dado neurônio.

$\mathrm{Na}$ terceira camada da arquitetura da SONDE, os neurônios competem para decidir qual deles representará a entrada $\overrightarrow{x_{t}}$. O neurônio com maior valor de ativação para a entrada atual, dada pela equação 3.15, e que respeite o menor nível de similaridade $\alpha_{\min }$ é selecionado como BMU.

$$
\alpha_{c}=\exp \left(-\left\|\overrightarrow{x_{t}}-\overrightarrow{w_{c}}\right\|\right)
$$

Assim que o neurônio mais representativo (BMU) é selecionado, os componentes desse neurônio são atualizados de modo a representar o conhecimento mais recente representado pelos exemplos de entrada. As equações 3.16 e 3.17 são responsáveis por atualizar, respectivamente, o protótipo e o raio médio.

$$
\begin{gathered}
w_{B \vec{M} U, t}=(1-\gamma) w_{B M U, t-1}+\gamma \overrightarrow{x_{t}} \\
\operatorname{rad}_{B M U, t}=(1-\Omega) \operatorname{rad}_{B M U, t-1}+\Omega\left\|w_{B M U, t}-\overrightarrow{x_{t}}\right\|
\end{gathered}
$$

As equações de adaptação 3.16 e 3.17 seguem médias móveis exponenciais ponderadas, que permitem a atualização incremental de acordo com novas entradas. As equações utilizam as taxas de aprendizado $\gamma \in[0,1]$ e $\Omega \in[0,1]$. Quanto maior o valor dessas taxas, mais a rede esquecerá exemplos observados no passado.

O menor nível de similaridade $\alpha_{c}$ é adaptado de acordo com a equação 3.19 , onde $p$ é a taxa de modificação relativa do raio médio $\operatorname{rad}_{B M U}$.

$$
\begin{gathered}
p=\frac{\left\|\operatorname{rad}_{B M U, t}-\operatorname{rad}_{B M U, t-1}\right\|}{\left\|\max \left(\operatorname{rad}_{B M U, t}, \operatorname{rad}_{B M U, t-1}\right)\right\|} \\
\alpha_{B M U, t}=\min \left((1+p) \alpha_{B M U, t-1}, \exp ^{-(1+p) \operatorname{rad}_{B M U, t}}\right)
\end{gathered}
$$

Se nenhum neurônio foi selecionado para representar o exemplo de entrada atual, um novo neurônio é criado. O protótipo do novo neurônio, $w_{n e w}$ é inicializado com os valores dos atributos do exemplo de entrada. O menor nível de similaridade, $\alpha_{\text {new }}$ é definido de acordo com uma constante $\alpha_{0}$ e o raio médio inicial, $\operatorname{rad}_{\text {new }}$ é igual a $-\ln (\alpha 0)$.

Para detectar novidades em fluxos de dados contínuos, o algoritmo da SONDE é aplicado gerando agrupamentos que são, em seguida, utilizados para estimar cadeias de Markov. Uma cadeia de Markov pode ser representada por uma matriz de transições $M$ (Equação 3.20), em que cada elemento da matriz representa uma transição de um estado $i$ para um estado $j$ da cadeia. 


$$
M=\left(\begin{array}{ccc}
p_{0,0} & \cdots & p_{0, j} \\
\vdots & & \vdots \\
p_{i, 0} & \cdots & p_{i, j}
\end{array}\right)
$$

A SONDE estima cadeias de Markov através da contagem do número de transições entre BMU consecutivos após a classificação de cada exemplo de entrada. A matriz de transições $M$ sumariza o número de ativações do neurônio $i$ seguida pela ativação do neurônio $j$ ocorridas, definido pelo elemento $L(i, j)$ na matriz $L$ (Equação 3.21

$$
L=\left(\begin{array}{ccc}
L_{0,0} & \cdots & L_{0, j} \\
\vdots & & \vdots \\
L_{i, 0} & \cdots & L_{i, j}
\end{array}\right)
$$

Cada elemento da matriz $M$ é estimado pela divisão de $L(i, j)$ pela soma $s(i)$ de todas as transições que partem do estado $i$ (Equação 3.22). Como a SONDE é um algoritmo incremental, a matriz de transições $M$ é computada a cada novo exemplo de entrada no instante $t$, denotada por $M_{t}$.

Em seguida, métricas de variação de informação são utilizadas para quantificar o nível de novidade introduzido pelo $t$-ésimo exemplo no modelo de aprendizado $M_{t-1}$. A SONDE aplica uma medida baseada em entropia para medir o nível de novidade dada pela Equação 3.24, onde $E(t)$ é a entropia média no instante $t$, definida na Equação 3.23. $M_{t}$ é a matriz de transições entre estados e $n_{t}$ é o número de estados no instante $t$.

$$
\begin{gathered}
s(i)=\sum_{j=0}^{n-1} L(i, j) \\
E(t)=\frac{-\sum_{i}^{n_{t}} \sum_{j}^{n_{t}} M_{t}(i, j) \log \left(M_{t}(i, j)\right)}{n_{t}} \\
\Delta E(t)=|E(t)-E(t-1)|
\end{gathered}
$$

Entretanto, a abordagem para atualização de $L$ baseada simplesmente em contagem do número de transições entre BMUs consecutivos pode levar a variações muito pequenas de entropia quando o número de exemplos processados é muito grande. Uma alternativa proposta pela SONDE para minimizar esse problema é utilizar uma média móvel exponencial ponderada para atualizar os valores na matriz $L$, com um fator de ponderação $\eta_{t} \in[0,1]$. O fator de ponderação possui uma influência de controle nas probabilidades de transição da cadeia. Quanto maior o valor de $\eta_{t}$, mais as probabilidades de transição são afetadas por atualizações que estejam ocorrendo. Por outro lado, se um valor pequeno de $\eta_{t}$ é utilizado, as probabildades se alterarão de modo mais gradual, dando maior peso ao passado histórico da cadeia. 
Se a diferença expressa na Equação 3.24 for maior que um limiar pré-estabelecido, considera-se que um evento novo está ocorrendo na rede. A aplicação da SONDE ao cenário de mudança de comportamento possui a mesma desvantagem apontada na rede GWR.

\subsection{Considerações Finais}

A mudança no comportamento dos dados é uma característica importante de muitas aplicações reais. Nesse cenário, é importante considerar a evolução dos dados no decorrer do tempo e que essa evolução pode acarretar mudanças que necessitam ser introduzidas nos modelos de aprendizado sendo induzidos. Assim, garante-se que os modelos utilizados representam a informação mais atual do fluxo de dados, ou seja, o comportamento mais recente do sistema gerando os dados, sempre mantendo um equilíbrio entre informação passada e informação recente.

Existem várias alternativas para se tratar mudanças de comportamento em fluxos de dados. Neste capítulo, foram apresentadas algumas abordagens relacionadas ao paradigma não-supervisionado de aprendizado. As abordagens estatísticas utilizam apenas as características dos dados para detectar mudanças, podendo ser incrementais ou trabalhar com janelas de tempo. Algoritmos de agrupamento para fluxos de dados também consideram a ocorrência de mudança de comportamento, atualizando a estrutura de grupos sempre que novos dados estejam presentes. Embora esses algoritmos não informem os momentos em que as mudanças estão ocorrendo, eles automaticamente introduzem informação nova em seus modelos, atualizando a estrutura de grupos sempre que ocorrerem mudanças nos dados. Para ser possível informar sobre a ocorrência de mudanças, um mecanismo de detecção de novidades pode ser adicionado ao algoritmo de agrupamento de dados. Essa abordagem é utilizada por alguns algoritmos de agrupamento baseados em RNAs, de modo que, sempre que uma alteração na estrutura de grupos for percebida pelo detector de novidades, considera-se que uma mudança está ocorrendo.

As abordagens apresentadas neste capítulo serviram como base para o estudo e desenvolvimento de dois novos algoritmos para detecção de mudanças de comportamento em fluxos de dados. Esses algoritmos foram aplicados a simulações com jogos computacionais modernos, que simulam ambientes altamente complexos de interação entre usuários e sistema. Assim, no Capítulo 4 é apresentado um algoritmo incremental baseado em agrupamento e detecção de novidades, assim como os resultados de experimentos realizados e comparação com outros algoritmos para detecção de mudança de comportamento. Em seguida, o Capítulo 5 apresenta um algoritmo baseado em janelas de tempo que utiliza espectrogramas para representar os dados dentro de uma janela. 


\section{M-DBScan*: Uma Abordagem Incremental para Detecção de Mudanças de Comportamento}

\subsection{Considerações Iniciais}

A primeira abordagem investigada neste trabalho para monitorar o comportamento de um jogador e detectar eventuais mudanças constrói, de maneira incremental, um modelo que represente o comportamento do jogador durante sua interação com o jogo. Esse modelo é atualizado a partir de dados não rotulados, de modo a refletir o comportamento mais recente do jogador. A monitoração do modelo permite detectar alterações comportamentais por parte do jogador, pois, uma vez que o jogador altere seu comportamento, o modelo gerado a partir de seus dados será automaticamente alterado.

Dessa maneira, neste Capítulo é apresentado um algoritmo denominado de MicroClustering DBScan* (M-DBScan*). Como outros algoritmos previamente propostos para detectar mudanças de comportamento em cenários não-supervisionados, M-DBScan* utiliza um algoritmo de agrupamento incremental, seguido de um passo de detecção de novidades para indicar mudanças. Entretanto, diferentemente de outros algoritmos na mesma linha como OLINDDA, GWR e SONDE, o M-DBScan* foi projetado de modo a satisfazer todas as três seguintes restrições:

1. O número de grupos no fluxo é desconhecido: uma vez que em um fluxo de dados os exemplos chegam continuamente, é, em geral, impossível determinar a 
priori o número de grupos existentes nos dados. Essa hipótese requer a aplicação de algoritmos de agrupamento que estimam o número de grupos automaticamente;

2. O formato dos grupos é arbitrário: para muitos fluxos de dados não é possível assumir que os grupos terão um formato espacial fixo e bem conhecido, especialmente quando os dados podem sofrer alterações no tempo. Essa restrição favorece a utilização de algoritmos que não assumem um formato específico de grupo;

3. Outliers podem ocorrer no fluxo e não refletem uma mudança real: exemplos que diferem significativamente dos demais podem ocorrer em um fluxo de dados como resultado de, por exemplo, ruído no processo de coleta dos dados; neste trabaIho, assume-se que esses exemplos não são um indicativo de uma mudança efetiva de comportamento, uma vez que constituem eventos isolados. Dessa forma, uma mudança de comportamento é aqui considerada como uma sequência de novidades ocorrendo em um deteminado intervalo de tempo.

Para satisfazer as duas primeiras restrições, o algoritmo de agrupamento utilizado pelo M-DBScan* é baseado no DenStream. Um detector de novidades baseado no algoritmo SONDE detecta alterações no agrupamento de dados gerado utilizando medidas de entropia. A deteç̧ão final de mudança de comportamento utiliza janelas de tempo deslizantes que captura sequências de novidades detectadas, reduzindo a ocorrência de falsos positivos e satisfazendo a terceira restrição. Neste trabalho, foram realizados experimentos considerando cinco configurações possíveis para detecção de novidades e mudanças de comportamento, denominadas MSDR1, MSDR1R2, ISDR1, ISDR1R2 e IPHT. Essas configurações são explicadas com detalhes no decorrer deste capítulo.

A organização deste capítulo foi definida como segue. Inicialmente, as Seções 4.2, 4.3 e 4.4 explicam em detalhes, a primeira versão do algoritmo, denominada de Micro-Clustering DBScan (M-DBScan). Os primeiros experimentos com o M-DBScan levaram em conta conjuntos de dados artificiais. Esses experimentos e seus resultados são apresentados na Seção 4.5. A partir dos resultados desses experimentos, uma modificação foi proposta na etapa de agrupamento do M-DBScan. Essa versão modificada do algoritmo, denominada de Micro-Clustering DBScan Version 2 (M-DBScan V2), é apresentada na Seção 4.6, assim como os resultados de novos experimentos realizados nos mesmos conjuntos de dados artificiais. A Seção 4.7 compara os resultados obtidos por M-DBScan V2 com um algoritmo que utiliza a mesma estratégia para detecção de mudanças de comportamento, porém realizando agrupamento baseado em proximidade através da aplicação do algoritmo $K$ means. O objetivo dessa comparação é validar a hipótese de que a estratégia baseada em densidade utilizada por M-DBScan V2 é mais eficaz em detectar possíveis mudanças de comportamento do que uma estratégia baseada em algoritmos de agrupamento que constroem grupos de formato hiperesféricos. A Seção 4.8 traz os experimentos e resultados 
da aplicação de M-DBScan V2 em simulações realizadas em ambientes de jogos. A partir dos primeiros resultados obtidos utilizando-se o FPS Unreal Tournament 2004 (UT2004) (Epic Games, Digital Extremes, 2004) foram propostas novas configurações para o detector de novidades do M-DBScan V2, assim como uma nova abordagem para detecção de mudanças que utiliza o algoritmo PHT. Nessa seção é ainda apresentada a última versão do algoritmo aqui proposto, denominado M-DBScan*, que visa reduzir o atraso para detecção de mudanças apresentado por M-DBScan V2, assim como resultados de novos experimentos no RTS Starcraft e comparações com outros algoritmos para detecção de mudanças. Finalmente, na Seção 4.9 são realizadas as últimas considerações deste capítulo.

\subsection{Agrupamento Incremental por Densidade}

A fase de agrupamento do algoritmo M-DBScan é baseada no algoritmo de agrupamento por densidade DenStream. Por isso, os conceitos de $p$-micro-clusters e o-micro-clusters são utilizados, armazenando as mesmas informações que o algoritmo DenStream original, i.e., $\overrightarrow{C F^{1}}, \overrightarrow{C F^{2}}$ e $w$. O Algoritmo 4.1 apresenta o funcionamento da etapa de agrupamento implementada pelo M-DBScan.

O Algoritmo 4.1 utiliza os parâmetros de entrada $\mu, \beta, \epsilon$ e $\lambda$, onde $\mu$ é o peso mínimo de um micro-cluster, $\beta \in[0,1]$ é o limiar de outliers relativo a $p$-micro-clusters, $\epsilon$ é o limite máximo no raio de um micro-cluster e, finalmente, $\lambda \in[0,1]$ é o parâmetro que controla o decaimento no peso dos micro-clusters com o passar do tempo. Na fase de inicialização do algoritmo de agrupamento, não há p-micro-clusters e o-micro-clusters criados previamente. Os primeiros exemplos no fluxo irão formar o-micro-clusters no buffer de outliers. A medida que novos exemplos são adicionados aos o-micro-clusters, aqueles cujos pesos sejam maiores que $\beta \mu$ são incrementalmente removidos do buffer de outliers, tornando-se $p$ micro-clusters.

A manutenção online de micro-clusters com a chegada de um novo exemplo $\overrightarrow{x_{t}}$ é como segue. Essa fase de microagrupamento é idêntica ao algoritmo DenStream.

1. Tente adicionar $\overrightarrow{x_{t}}$ ao seu p-micro-cluster $c_{p}$ mais próximo. Se $r_{p}$, o novo raio de $c_{p}$, for menor ou igual a $\epsilon, \overrightarrow{x_{t}}$ é inserido em $c_{p}$ (linhas 2 a 8 do Algoritmo 4.1.). A informação em $c_{p}$ é atualizada como $c_{p}=\left(\overrightarrow{C F^{1}}+\overrightarrow{x_{t}}, \overrightarrow{C F^{2}}+{\overrightarrow{x_{t}}}^{2}, w+1\right)$.

2. Caso contrário, tente adicionar $\overrightarrow{x_{t}}$ em seu o-micro-cluster mais próximo. Se $r_{o}, o$ novo raio de $c_{o}$, for menor ou igual a $\epsilon, \overrightarrow{x_{t}}$ é inserido em $c_{o}$. A informação em $c_{o}$ é atualizada como $c_{o}=\left(\overrightarrow{C F^{1}}+\overrightarrow{x_{t}}, \overrightarrow{C F^{2}}+\vec{x}_{t}^{2}, w+1\right)$. Em seguida, verifique se $w$, o novo peso de $c_{o}$, é maior que $\beta \mu$. Em caso afirmativo, $c_{o}$ tem potencial de se tornar um p-micro-cluster. Assim, $c_{o}$ é removido do buffer de outliers e um novo $p$-micro-cluster é criado a partir de $c_{o}$ (linhas 9 a 20 do Algoritmo 4.1). 


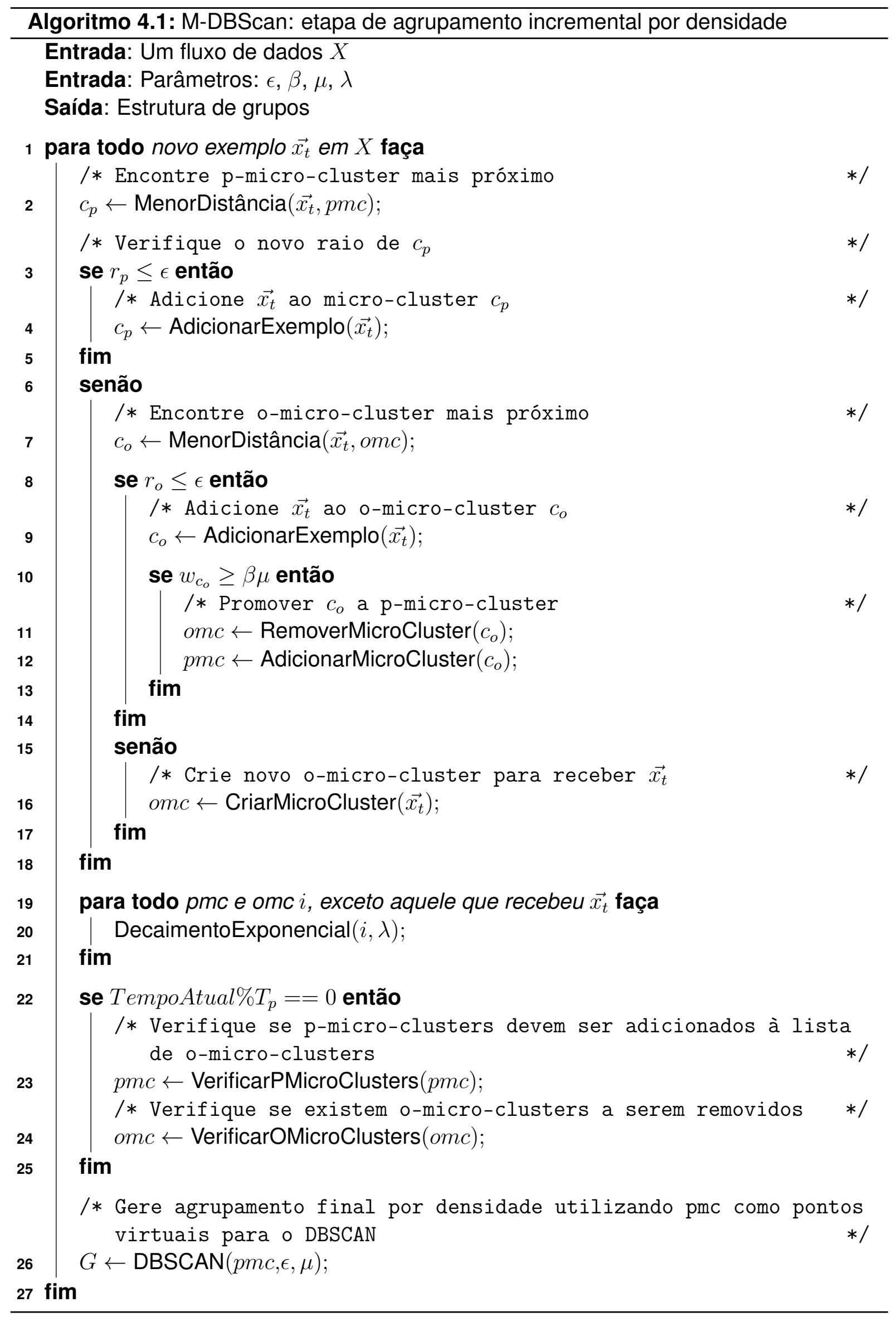


3. Em caso negativo, crie um novo o-micro-cluster no buffer de outliers para receber $\overrightarrow{x_{t}}$, com peso inicial $w=1$ (linhas 21 a 25 do Algoritmo 4.1).

4. Todos os micro-clusters, com exceção daquele que recebeu $\overrightarrow{x_{t}}$, sofrem um decaimento exponencial em suas informações (linhas 26 a 28 do Algoritmo 4.1), i.e, para cada micro-cluster $c$, se nenhum exemplo foi adicionado a $c$ no intervalo de tempo $\delta t, c=\left(2^{-\lambda \delta t} \cdot \overrightarrow{C F^{1}}, 2^{-\lambda \delta t} \cdot \overrightarrow{C F^{2}}, 2^{-\lambda \delta t} \cdot w\right)$.

5. Se o resto da divisão de $T_{p}$ por $t_{c}$ for nula, onde $t_{c}$ é o instante de tempo atual e $T_{p}$, dado pela Equação 4.1, é o mínimo intervalo de tempo necessário para um $p$ micro-cluster se tornar um outlier, verifique todos os $p$-micro-clusters e remova todos aqueles cujos pesos $w$ forem menores do que $\beta \mu$. Verifique também todos os $o$ micro-clusters e remova aqueles cujos pesos forem menores do que o limite inferior de peso, denotado por $\xi$ (linhas 29 a 34 do Algoritmo 4.1). O limite inferior de peso é dado pela Equação 4.2, onde $t_{o}$ é o instante de criação do o-micro-cluster. Quando $t_{c}=t_{o}$, i.e., no instante da criação do o-micro-cluster, $\xi=1$. Com o passar do tempo, $\xi$ aumenta e $\lim _{t_{c} \rightarrow \infty} \xi\left(t_{c}\right)=\beta \mu$.

$$
\begin{gathered}
T_{p}=\left\lceil\frac{1}{\lambda} \log \left(\frac{\beta \mu}{\beta \mu-1}\right)\right\rceil \\
\xi\left(t_{c}, t_{o}\right)=\frac{2^{-\lambda\left(t_{c}-t_{o}+T_{p}\right)}-1}{2^{-\lambda T_{p}}-1}
\end{gathered}
$$

A fase posterior de macroagrupamento aplica o algoritmo DBSCAN utilizando os $p$ micro-clusters como exemplos virtuais, assim como no DenStream (Seção 3.3.2). Entretanto, diferentemente do DenStream, o procedimento de macroagrupamento é realizado a cada novo exemplo inserido na estrutura de microagrupamento (linhas 35 e 36 do Algoritmo 4.1). No algoritmo DenStream, a fase de macroagrupamento é realizada em intervalos de tempo definidos pelo usuário. No caso do algoritmo M-DBScan, o macroagrupamento por densidade deve ser realizado a cada exemplo processado pois a fase seguinte, de detecção de novidades, necessita da informação do grupo final ao qual o exemplo foi associado.

\subsection{Detecção de Novidade}

Uma medida de entropia é uma medida de incerteza associada a uma variável aleatória. Quanto maior o valor da medida de entropia, maior a incerteza sobre o resultado dessa variável, enquanto que valores pequenos de entropia significam graus mais elevados de 
certeza (SHANNON, 1948). Como exemplo, considere a Figura 4.1, onde $H(X)$ representa a entropia associada ao ato de lançar uma moeda e $P(X=1)$ é a probabilidade da variável aleatória $X$ assumir valor um. Nesse exemplo, $X$ é o resultado obtido ao lançar uma moeda e pode, portanto, assumir dois valores. O valor 0 indica "coroa", enquanto que um valor 1 indica "cara". Se a moeda é justa, a probabilidade do resultado ser "cara" é igual a 0,5 , levando ao maior valor de incerteza relacionada ao resultado de um lançamento da moeda. Por outro lado, se a moeda é viesada e, por exemplo, sempre resulta em "cara", a probabilidade $P(X=1)$ é igual a 1 e o valor da entropia é nulo, significando total certeza em relação ao resultado do lançamento da moeda.

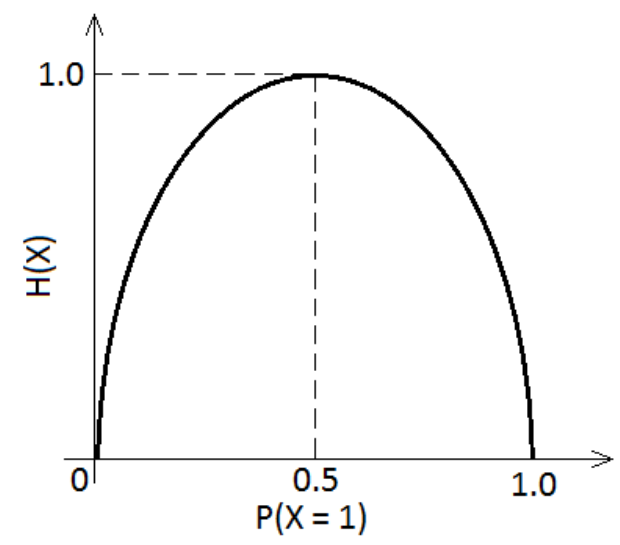

Figura 4.1: Exemplo de entropia de uma variável aleatória. Adaptado de Shannon (1948).

Este trabalho propõe o uso de duas medidas de entropia distintas, uma com um viés temporal e outra com um viés espacial. A primeira medida é baseada na medida de entropia utilizada pelo algoritmo SONDE. A segunda medida, por sua vez, é baseada na pureza de diferentes conjuntos como, por exemplo, a pureza de nós folhas em uma árvore de decisão. Ambas as medidas consideram os grupos presentes nos dados no instante atual de tempo $t$.

\subsubsection{Medida de Entropia Temporal}

Essa medida estima uma Cadeia de Markov (CM) (SENETA, 2006) a partir dos grupos encontrados nos dados no instante de tempo $t$. Cada grupo é considerado um estado na $\mathrm{CM}$. As probabilidades de transição entre estados são atualizadas de acordo com o grupo que foi selecionado para receber o exemplo no instante anterior de tempo e o grupo que foi selecionado para receber o exemplo no instante atual.

Seja $M$ uma CM com $N$ estados e $p_{i, j}$ a probabilidade de transição entre os estados $i$ e $j$. O estado $i$ representa o grupo escolhido para receber o exemplo no instante de tempo $t-1$, enquanto que o estado $j$ representa o grupo escolhido no instante de tempo atual $t$.

Neste trabalho, as probabilidades de transição da cadeia são estimadas através de uma média móvel exponencial ponderada, com um fator de ponderação $\eta_{t} \in[0,1]$. Como 

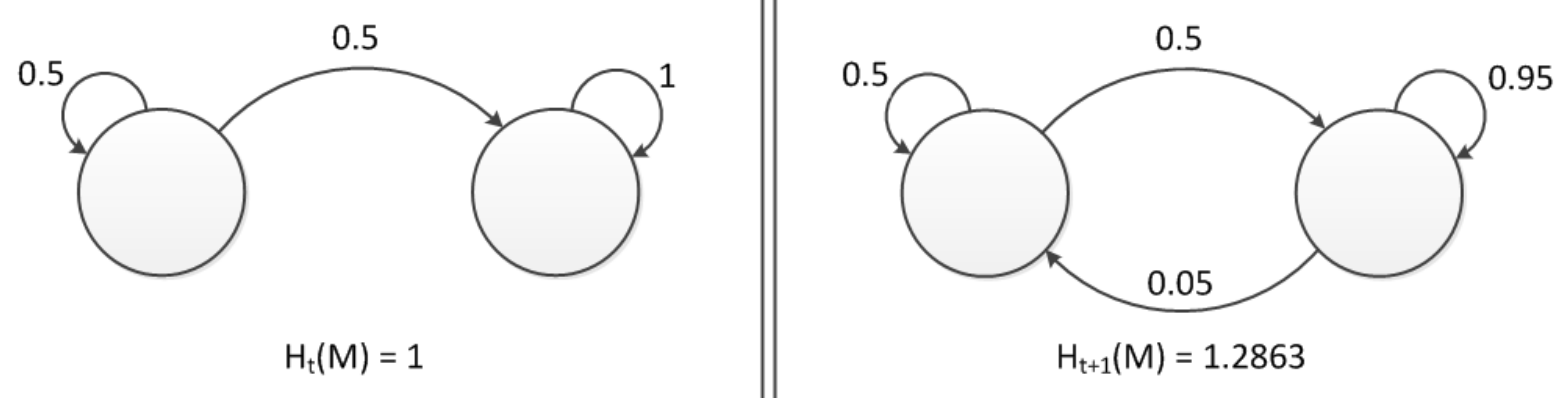

Figura 4.2: Dois estados consecutivos de uma CM e respectivos níveis de entropia.

explicado na descrição do algoritmo SONDE, o fator de ponderação possui uma influência de controle nas probabilidades de transição da cadeia. Quanto maior o valor de $\eta_{t}$, mais as probabilidades de transição são afetadas por atualizações que estejam ocorrendo. Por outro lado, se um valor pequeno de $\eta_{t}$ é utilizado, as probabildades se alterarão de modo mais gradual, dando maior peso ao passado histórico da cadeia. A transição correspondente aos estados $i$ e $j$ na cadeia é atualizada de acordo com a Equação 4.3.

$$
p_{i, j}=\frac{\left(1-\eta_{t}\right) \cdot p_{i, j}+\eta_{t}}{\sum_{k=0}^{N} p_{i, k}}
$$

Todas as demais transições $\{a, b\} \neq\{i, j\}$ no instante de tempo $t$ são atualizadas como na Equação 4.4.

$$
p_{a, b}=\frac{\left(1-\eta_{t}\right) \cdot p_{a, b}}{\sum_{k=0}^{N} p_{a, k}}
$$

O nível de entropia da cadeia é calculado usando as probabilidades de transição atualizadas. Esse nível de entropia é baseado na entropia de Shannon (SHANNON, 1948) (Equação 4.5).

$$
\mathbb{H}(M)=-\sum_{i=0}^{N} \sum_{j=0}^{N} p_{i, j} \cdot \log _{2}\left(p_{i, j}\right)
$$

Como exemplo, considere a Figura 4.2, onde uma CM é representada nos instantes de tempo $t$ e $t+1$. Nesse exemplo, $\eta_{t}$ é igual a 0.05 . Cada círculo, ou estado, na Figura 4.2 representa um grupo. Suponha que o exemplo que chegou no fluxo de dados no instante $t$ foi adicionado ao grupo da direita. O exemplo no instante $t+1$ foi adicionado ao grupo da esquerda, levando à criação de uma nova transição que tem como ponto de partida o grupo mais a direita e terminando no grupo mais a esquerda. Todas as demais transições são atualizadas de modo a refletir a mudança. A entropia da cadeia é modificada como consequência da atualização das probabilidades de transição.

Uma vez que o nível de entropia da cadeia é calculado utilizando as probabilidades de transição, essa entropia possui um viés temporal, i.e., a medida é sensível a mudanças 
na ordem de ocorrência de eventos. Portanto, a utilização dessa medida permite detectar relações temporais entre exemplos consecutivos em um fluxo de dados.

\subsubsection{Medida de Entropia Espacial}

A segunda medida de entropia considera a distribuição espacial dos dados em grupos e estima o número de exemplos pertencentes a cada grupo durante o processamento do fluxo. O número de exemplos em um grupo $i$, denotado por $P_{i}$, é atualizado toda vez que um novo exemplo é inserido no grupo $i$. Isso pode ser feito simplesmente atualizando-se um contador que guarda o número de exemplos em um dado grupo. Entretanto, quando o número de exemplos por grupo aumenta significativamente, a adição de um novo grupo não produz uma modificação expressiva na medida de entropia. Para solucionar esse problema, recorreu-se à mesma solução empregada na entropia temporal. Assim, uma estimativa do número de exemplos por grupo, utilizando uma média móvel exponencial ponderada, foi utilizada. O grupo $i$ que recebe o exemplo no instante de tempo $t$ tem seu número de exemplos atualizado como na Equação 4.6, onde $\eta_{s} \in(0,1)$ é o fator de ponderação para a média móvel.

$$
P_{i}=\left(1-\eta_{s}\right) \cdot P_{i}+\eta_{s}
$$

Todos os demais grupos tem seus valores atualizados como na Equação 4.7, onde $j \neq i$ representa o índice do grupo.

$$
P_{j}=\left(1-\eta_{s}\right) \cdot P_{j}
$$

Em seguida, a entropia é calculada como na Equação 4.8

$$
\mathbb{H}(G)=-\sum_{i=0}^{N} P_{i} \cdot \log _{2}\left(P_{i}\right)
$$

onde $G$ é o conjunto de grupos no instante de tempo atual e $N$ é o número total de grupos.

A Figura 4.3 apresenta um exemplo onde o número estimado de exemplos por grupo no instante de tempo $t$ é diferente do número no instante $t+1$, consequentemente modificando o valor da entropia. Nesse exemplo, um valor de $\eta_{s}=0.05$ é considerado.

Diferentemente da entropia temporal, a medida de entropia espacial não considera dependências temporais que possam estar presentes nos dados.

\subsubsection{Usando Entropia para Detectar Novidades}

Independente da medida de entropia considerada (temporal ou espacial), níveis de entropia são utilizados neste trabalho para decidir se a chegada de um novo exemplo produz 

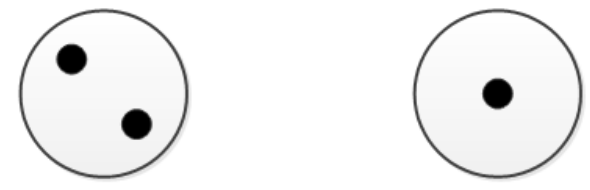

$H_{t}(M)=0.5340$
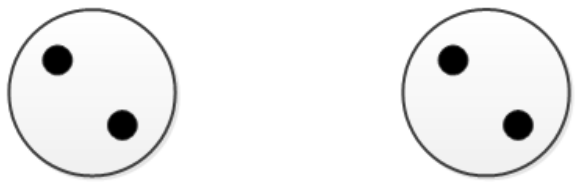

$\mathrm{H}_{\mathrm{t}+1}(\mathrm{M})=0.5298$

Figura 4.3: Distribuição de exemplos por grupo em dois instantes de tempo consecutivos com correspondentes valores de entropia.

uma variação significativa na estrutura de grupos formada. O Algoritmo 4.2 expressa o pseudocódigo para a etapa de detecção de novidades.

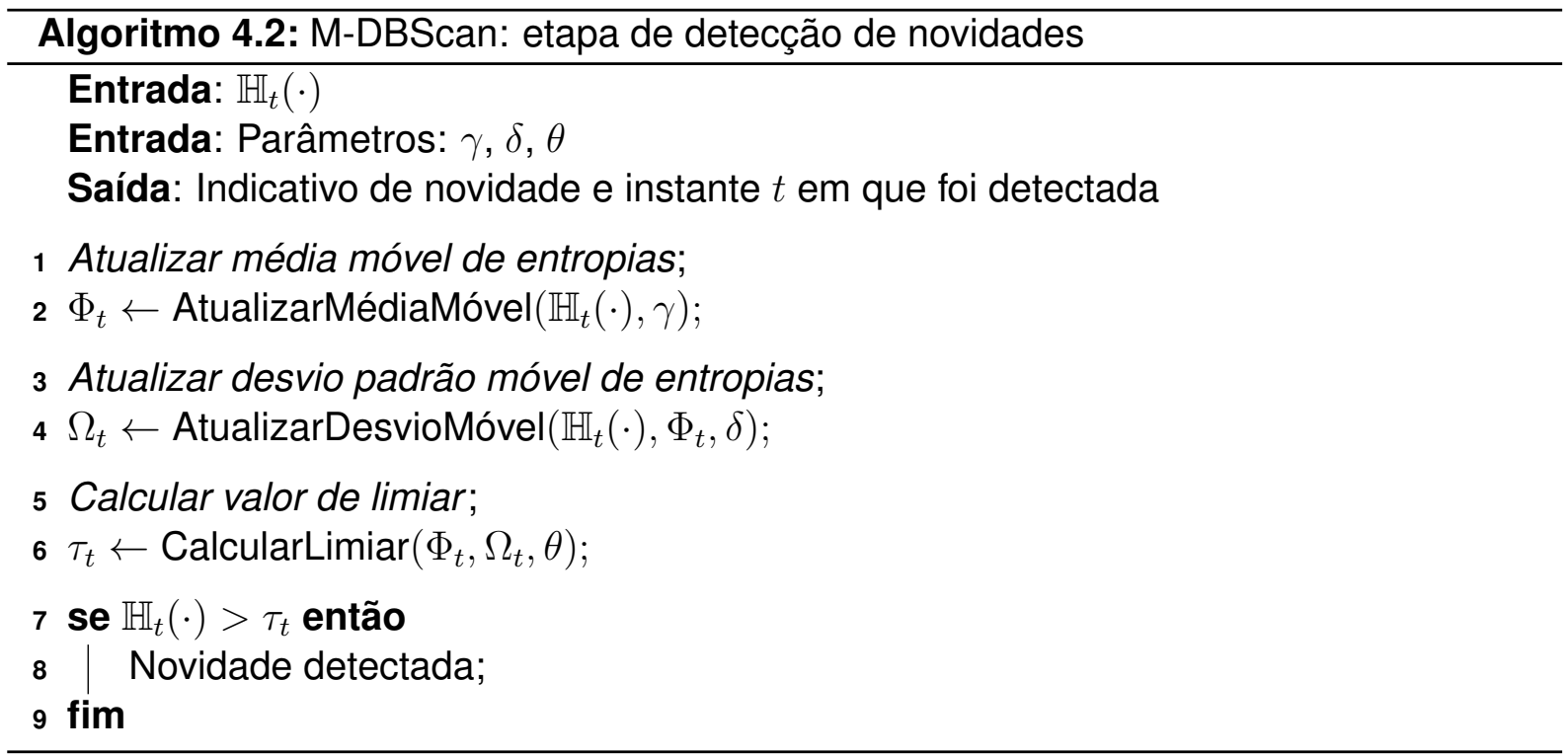

A entropia calculada no instante de tempo $t$, expressa como $\mathbb{H}_{t}(\cdot)$, é comparada com um limiar $\tau_{t}$ calculado dinamicamente. Para definir o valor de $\tau_{t}$, uma média móvel $\Phi_{t}$ sobre os valores passados de entropia (Equação 4.9), e um desvio padrão móvel $\Omega_{t}$ (Equação 4.10) são calculados, onde $\gamma$ e $\delta \in[0,1]$ são fatores de ponderação.

$$
\begin{gathered}
\Phi_{t}=(1-\gamma) \cdot \Phi_{t-1}+\gamma \cdot \mathbb{H}_{t}(\cdot) \\
\Omega_{t}=(1-\delta) \cdot \Omega_{t-1}+\delta \cdot\left|\mathbb{H}_{t}(\cdot)-\Phi_{t}\right|
\end{gathered}
$$

Para estimar $\tau$, assume-se uma distribuição Normal de valores de entropia. Portanto, um parâmetro constante $\theta$, que representa o número de desvios padrão a partir da média, é adicionado à definição do limiar. A Equação 4.11 apresenta o cálculo final de $\tau_{t}$. 


$$
\tau_{t}=\Phi_{t}+\left(\Omega_{t} \cdot \theta\right)
$$

Se $\mathbb{H}_{t}(\cdot)>\tau_{t}$, então o nível de entropia $\mathbb{H}_{t}(\cdot)$ no instante de tempo $t$ é considerado divergente da média de entropia observada, indicando a ocorrência de uma novidade.

Esse procedimento para detecção de novidades automaticamente ajusta o limiar separando eventos normais de novidades durante o processamento do fluxo de dados. Como consequência, é mais apropriado para a detecção de novidades em fluxos de dados que se alteram no tempo do que outras abordagens que assumem um limiar constante e prédefinido pelo usuário.

\subsection{Detecção de Mudança de Comportamento}

Este trabalho considera que, para que uma mudança de comportamento seja detectada, é necessário que uma sequência de novidades ocorra dentro de um intervalo de tempo. Para determinar esse intervalo de tempo, o conceito de janelas de tempo foi aplicado. $O$ Algoritmo 4.3 apresenta a etapa de detecção de mudança de comportamento do M-DBScan.

Uma vez que uma novidade é detectada no instante de tempo $t$, inicializa-se uma janela deslizante de tamanho $k$. Essa janela conterá a saída do detector de novidades no intervalo $[t+1, \cdots, t+k]$. Se, durante a existência da janela, no mínimo minNovelties ocorrerem, então uma mudança de comportamento é declarada no instante $t+n$, onde $n$ é o momento de detecção da novidade mais recente. Nesse caso, a janela desliza, i.e., a janela é atualizada de modo a conter o novo intervalo $[t+n+1, \cdots,(t+n+1)+k]$. A partir desse ponto, cada nova novidade que venha a ocorrer é descartada e a janela desliza novamente a cada ocorrência. Esse processo tem por objetivo descartar novidades que constituem a mesma mudança de comportamento. O processo continua até que nenhuma novidade ocorra durante a duração da janela. Se o limite imposto por minNovelties não é atingido dentro da janela, então nenhuma mudança de comportamento é declarada.

\subsection{Experimentos Iniciais em Dados Artificiais}

Inicialmente, foram realizados alguns experimentos aplicando o algoritmo M-DBScan a dados artificiais. Esses experimentos foram realizados por dois motivos. Primeiro, havia a necessidade de avaliar o comportamento do algoritmo proposto em um cenário mais controlado. Os dados coletados diretamente de um ambiente de jogo são muito mais variáveis e complexos do que dados artificiais. Dessa maneira, é importante avaliar o desempenho do algoritmo em dados com características mais bem comportadas de modo a permitir avaliar possíveis limitações e propor melhorias. Segundo, como cada conjunto de dados artificial utilizado possui características particulares, também foi possível avaliar o desem- 


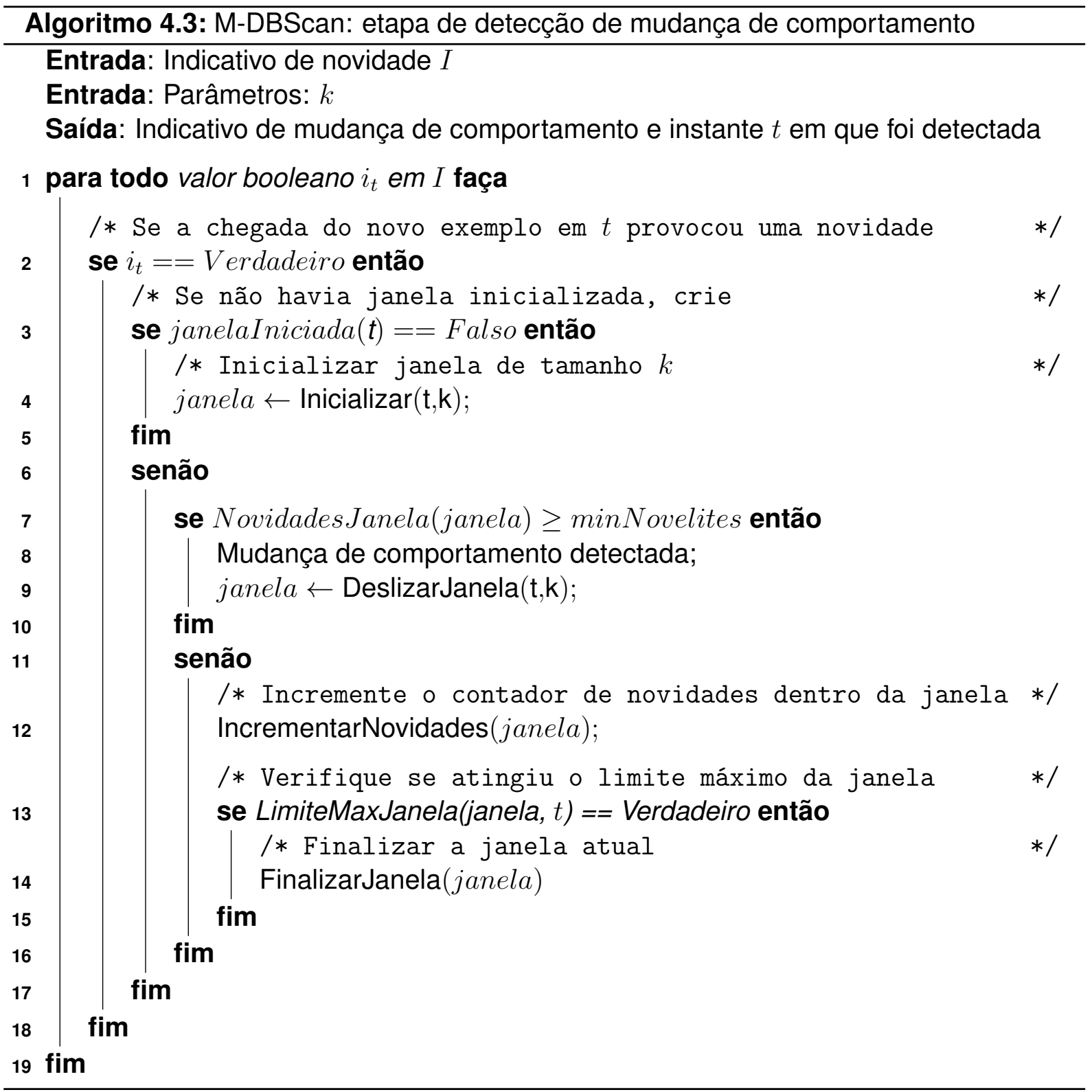


penho de cada uma das duas medidas de entropia estudadas neste trabalho.

Esta seção apresenta os conjuntos de dados utilizados, a configuração dos experimentos realizados, assim como os resultados e conclusões obtidas.

\subsubsection{Conjuntos de Dados}

Oito conjuntos de dados artificiais foram construídos para testar o desempenho da abordagem proposta. Cada um desses conjuntos possui dois atributos numéricos e representam fluxos de dados que evoluem no tempo. Assim, cada conjunto possui três mudanças de comportamento, ocorrendo respectivamente aos exemplos de índice 1000, 2000 e 3000. Os conjuntos foram contruídos de forma a representar várias possíveis formas de se organizar os dados em grupos, assim como diferentes maneiras desses grupos evoluírem no tempo. Nós acreditamos que esses conjuntos são apropriados para avaliar o desempenho de um algoritmo para detecção de mudanças, pois é possível saber exatamente como os dados estão evoluindo. Esses conjuntos também são apropriados para avaliar como as duas medidas de entropia utilizadas se comportam frente a diferentes situações como, por exemplo, quando grupos são criados ou removidos com o passar do tempo. A seguir são apresentadas as características de cada conjunto.

1. FixedDenSpatial: apresenta quatro grupos de formatos arbitrários do começo ao fim do fluxo. As mudanças são do tipo estrutural, modificando a proporção de exemplos por grupo e os formatos dos grupos.

2. FixedDenTemporal: apresenta quatro grupos de formatos arbitrários do começo ao fim do fluxo. As mudanças são do tipo temporal, modificando a ordem de chegada de exemplos a grupos existentes.

3. FixedSphericalSpatial: apresenta quatro grupos de formato esférico do começo ao fim do fluxo. As mudanças são do tipo estrutural e modificam a proporção de exemplos por grupo e o raio da esfera que forma cada grupo.

4. FixedSphericalTemporal: apresenta quatro grupos de formato esférico do começo ao fim do fluxo. As mudanças são do tipo temporal e modificam a ordem de chegada de exemplos a grupos existentes.

5. VarDenAddCluster: apresenta um número variável de grupos com formatos arbitrários. As mudanças são do tipo estrutural e modificam o número de grupos através da adição de novos grupos. O número de grupos inicial é igual a quatro. Um novo grupo aparece no fluxo a cada mudança de comportamento. Assim, no final do fluxo existem sete grupos presentes nos dados. 
6. VarDenMergeCluster: apresenta um número variável de grupos com formatos arbitrários. As mudanças são do tipo estrutural e modificam o número de grupos através da união de dois grupos existentes, provocando a redução no número total de grupos. O número de grupos inicial é igual a cinco. Dois grupos se unem a cada mudança de comportamento. Assim, no final do fluxo existem 2 grupos presentes nos dados.

7. VarSphericalAddCluster: apresenta um número variável de grupos com formato esférico. As mudanças são do tipo estrutural e modificam o número de grupos. Esse conjunto possui as mesmas características do conjunto VarDenAddCluster, com exceção ao formato dos grupos.

8. VarSphericalAddSubCluster: apresenta um número variável de grupos com formato esférico. As mudanças são do tipo estrutural e modificam o número de grupos através da adição de um novo grupo seguida da remoção de um grupo existente. $O$ número de grupos inicial é igual a quatro.

A Tabela 4.1 sumariza as principais características de cada conjunto de dados, onde: \#Ex representa o número total de exemplos nesse conjunto; \#Dim representa o número de dimensões (atributos) presentes; \#Grupos representa o número de grupos, podendo ser fixo ou variável durante a evolução do fluxo; Formato representa o formato dos grupos presentes no conjunto; Tipo de mudança representa se as mudanças ocorridas no conjunto são do tipo estrutural ou temporal; e, finalmente, \#Mudanças representa o número de mudanças presentes no conjunto de dados.

A coluna \#Grupos pode apresentar um único valor, por exemplo 4, ou múltiplos valores, por exemplo 4 a 7 . A existência de um valor único indica que o conjunto possui o respectivo número de grupos do início ao fim do fluxo. Por outro lado, a existência de múltiplos valores pode ser representada na forma crescente ou decrescente, por exemplo, 4 a 7 ou 5 a 2. Essa representação indica que o conjunto possui número de grupos variável no tempo. Se a representação crescente for utilizada, o número de grupos cresce no tempo através da adição de novos grupos. Caso contrário, se a representação decrescente é utilizada, o número de grupos diminui no tempo através da união ou remoção de grupos.

Tabela 4.1: Características dos conjuntos de dados artificiais.

\begin{tabular}{lrrrlrl}
\hline Nome & \#Ex & \#Dim & \#Grupos & Formato & \#Mudanças & Tipo de Mudança \\
\hline FixedDenSpatial & 4000 & 2 & 4 & Arbitrário & 3 & Estrutural \\
FixedDenTemporal & 4000 & 2 & 4 & Arbitrário & 3 & Temporal \\
FixedSphericalSpatial & 4000 & 2 & 4 & Esférico & 3 & Estrutural \\
FixedSphericalTemporal & 4000 & 2 & 4 & Esférico & 3 & Temporal \\
VarDenAddCluster & 4000 & 2 & 4 a 7 & Arbitrário & 3 & Estrutural \\
VarDenMergeCluster & 4000 & 2 & 5 a 2 & Arbitrário & 3 & Estrutural \\
VarSphericalAddCluster & 4000 & 2 & 4 a 7 & Esférico & 3 & Estrutural \\
VarSphericalAddSubCluster & 4000 & 2 & 4 a 6 & Esférico & 3 & Estrutural \\
\hline
\end{tabular}




\subsubsection{Configuração dos experimentos}

Para avaliar o desempenho da abordagem proposta na detecção de diferentes tipos de mudanças, experimentos foram conduzidos utilizando essa abordagem nos oito conjuntos de dados artificiais criados. O primeiro experimento utilizou a medida de entropia espacial e o segundo utilizou a medida de entropia temporal. Para tanto, os valores de parâmetros utilizados pela etapa de agrupamento do M-DBScan foram $\mu=10, \beta=0,105$ and $\lambda=$ 0,03 . Esses valores configuram o algoritmo para promover 0 -micro-clusters à $p$-microclusters quando o respectivo o-micro-cluster contiver mais de um exemplo. Eles também estabelecem que, a cada 102 exemplos, o algorimo irá verificar e possivelmente remover p-micro-clusters e o-micro-clusters. O valor do parâmetro $\epsilon$, que define um limiar máximo para os micro-clusters, foi definido separadamente para cada conjunto de dados utilizado e é expresso na Tabela 4.2. Esses valores foram estabelecidos empiricamente para cada conjunto de dados.

Para os experimentos usando a medida de entropia espacial os valores $\eta_{s}=0,005$, $\gamma=0,05, \delta=0,02$ e $\theta=3$ foram utilizados. Os experimentos com a medida de entropia temporal utilizaram $\eta_{t}=0,005, \gamma=0,05, \delta=0,002$ e $\theta=3$. Esses valores foram escolhidos de modo a aplicar uma abordagem mais conservadora para detecção de novidades, onde a história passada de eventos possui uma maior influência na definição do limiar que separa eventos normais de novidades. Em todos os experimentos, considerou-se que os exemplos se tornavam disponíveis no fluxo a cada 1 segundo. Para detectar mudanças de comportamento, o valor da janela utilizada foi de $k=20$ exemplos. O número mínimo de novidades dentro dessa janela até indicar uma mudança de comportamento foi minNovelties $=2$.

Para avaliar os resultados obtidos, três medidas foram utilizadas. A primeira medida considera o número de vezes que uma mudança foi detectada quando na verdade não havia mudança ocorrendo nos dados (Falso Positivo (FP)). A segunda considera o número de vezes que uma mudança real foi detectada, porém com atraso significativo (Detecção Atrasada (DA)). Um mudança é considerada atrasada, se o atraso para detecção for maior do que 100 e inferior a 300 exemplos. Finalmente, a terceira medida considera o número de vezes que uma mudança não foi detectada (Não Detecção (ND)). Essa medida inclui as mudanças que simplesmente não foram detectadas, assim como as mudanças que foram detectadas com atraso superior a 300 exemplos. Quanto menor o valor de cada uma dessas medidas, melhor o resultado. 
Tabela 4.2: Valor do parâmetro $\epsilon$ utilizado em cada conjunto de dados.

\begin{tabular}{lr}
\hline Conjunto de dados & $\epsilon$ \\
\hline FixedDenSpatial & 80 \\
FixedDenTemporal & 80 \\
FixedSphericalSpatial & 100 \\
FixedSphericalTemporal & 100 \\
VarDenAddCluster & 60 \\
VarDenMergeCluster & 80 \\
VarSphericalAddCluster & 35 \\
VarSphericalAddSubCluster & 35 \\
\hline
\end{tabular}

\subsubsection{Resultados}

Os resultados do experimento utilizando a medida de entropia espacial são apresentados na Tabela 4.3.

Tabela 4.3: Resultados para a medida de entropia espacial utilizando M-DBScan.

\begin{tabular}{l|rrr}
\hline \multirow{2}{*}{ Conjunto de dados } & \multicolumn{3}{|c}{ M-DBScan } \\
\cline { 2 - 4 } & & & \\
& FP & DA & ND \\
\hline FixedDenSpatial & 20 & 0 & 0 \\
FixedDenTemporal & 14 & 2 & 0 \\
FixedSphericalSpatial & 8 & 2 & 1 \\
FixedSphericalTemporal & 12 & 2 & 0 \\
VarDenAddCluster & 12 & 1 & 2 \\
VarDenMergeCluster & 2 & 0 & 3 \\
VarSphericalAddCluster & 14 & 1 & 0 \\
VarSphericalAddSubCluster & 11 & 1 & 0 \\
\hline Total & $\mathbf{9 3}$ & $\mathbf{9}$ & $\mathbf{6}$ \\
\hline
\end{tabular}

A Tabela 4.3 permite observar que, embora uma boa parte das mudanças $(75 \%)$ tenham sido detectadas, o número de FPs ocorridos foi bastante elevado. Além disso, uma boa parte das detecções ocorridas foram atrasadas. Os resultados também demonstraram que a medida de entropia espacial obteve pior desempenho, em termos de ND, nos conjuntos onde os formatos dos grupos são arbitrários e o número de grupos varia no tempo, como é o caso dos conjuntos VarDenAddCluster e VarDenMergeCluster. Os resultados obtidos no experimento utilizando a medida de entropia temporal são apresentados na Tabela 4.4.

Os resultados na Tabela 4.4 apontam para um desempenho levemente superior por parte da utilização da entropia temporal em relação à entropia espacial. O número de NDs foi praticamente o mesmo para ambas as entropias. Já os números de DAs e FPs foram inferiores para a entropia temporal. Entretanto, o número de FPs ainda foi bastante 
Tabela 4.4: Resultados para a medida de entropia temporal utilizando M-DBScan.

\begin{tabular}{l|rrr}
\hline \multirow{3}{*}{ Conjunto de dados } & \multicolumn{3}{|c}{ M-DBScan } \\
\cline { 2 - 4 } & FP & DA & ND \\
\hline FixedDenSpatial & 11 & 0 & 0 \\
FixedDenTemporal & 5 & 1 & 1 \\
FixedSphericalSpatial & 8 & 1 & 1 \\
FixedSphericalTemporal & 7 & 0 & 0 \\
VarDenAddCluster & 8 & 1 & 2 \\
VarDenMergeCluster & 3 & 0 & 0 \\
VarSphericalAddCluster & 11 & 2 & 0 \\
VarSphericalAddSubCluster & 6 & 0 & 1 \\
\hline Total & $\mathbf{5 9}$ & $\mathbf{5}$ & $\mathbf{5}$ \\
\hline
\end{tabular}

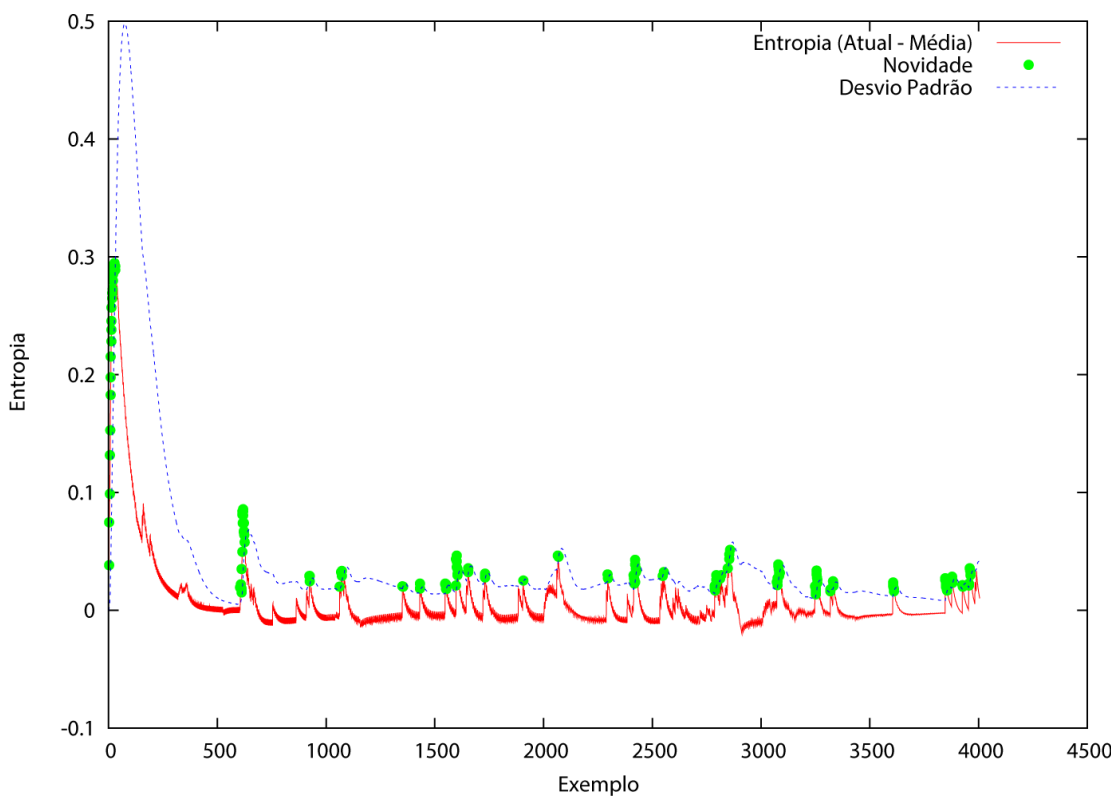

Figura 4.4: Variação de entropia espacial, desvio padrão e detecção de novidades para o conjunto de dados FixedDenSpatial.

elevado quando consideramos que os conjuntos de dados utilizados contém mudanças bem definidas e razoavelmente bem separadas no tempo.

A Figura 4.4 ilustra um exemplo de como a média móvel dos valores de entropia $\left(\Phi_{t}\right)$ e o desvio padrão móvel $\left(\Omega_{t}\right)$ estão sendo utilizados na definição do limiar $\tau$ que separa eventos normais de novidades.

\subsubsection{Análise dos Resultados}

A partir dos resultados desses experimentos, concluiu-se que para que M-DBScan possa ser utilizado na prática, é necessário reduzir consideravelmente a incidência de FPs em ambas as medidas de entropia.

Uma análise mais minusciosa desses resultados permitiu concluir que a ocorrência de FPs se deu devido a grandes variações no nível de entropia. Isso foi observado para ambas as medidas estudadas. Como as medidas de entropia são baseadas na forma 
como os exemplos são adicionados aos grupos, a hipótese sugerida é que modificações intermediárias na estrutura de grupos gerada no decorrer do tempo estariam introduzindo erros nas medidas de entropia utilizadas. Mais especificamente, surgiu a suspeita de que o processo de remoção de $p$-micro-clusters estivesse produzindo pequenas alterações no agrupamento superior em determinados instantes de tempo. Essas alterações estariam provocando alterações nos níveis de entropia levando à detecção de FPs.

Para verificar essa hipótese, uma nova versão do algoritmo foi implementada onde não há remoção de p-micro-clusters. Essa nova versão, assim como os resultados obtidos e comparação com os resultados atuais, são apresentados na Seção 4.6.

\subsection{Redução de Falsos Positivos}

Pode-se observar pelos resultados apresentados na Seção 4.5 que o algoritmo proposto detectou a maior parte das reais mudanças de comportamento ocorridas nos dados, para ambas as medidas de entropia. Entretanto, observa-se uma elevada ocorrência de FPs, isto é, indicativos de mudança de comportamento onde estas não estão verdadeiramente ocorrendo. Uma explicação para esse fato está na forma como as medidas de entropia são calculadas. Para que as medidas de entropia funcionem, é preciso fornecer, a cada novo exemplo processado, o grupo ao qual esse foi associado. Entretanto, o algoritmo M-DBScan possui um fator de decaimento associado a cada micro-cluster, de modo a remover microcluster que não estejam sendo utilizados. Dessa forma, micro-clusters que não tenham sido atualizados recentemente, podem, e de fato irão deixar de existir. Em certos casos, micro-clusters podem deixar de existir não porque os grupos aos quais pertençam estejam deixando de existir nos dados, mas simplesmente devido à aleatoriedade na chegada de exemplos aos micro-clusters. Quando micro-clusters deixam de existir, o macro agrupamento realizado pode também sofrer alterações. Essas alterações provocam variações de entropia, levando a detecções de novidade onde estas não estão de fato ocorrendo.

Para verificar a hipótese de que a remoção de micro-clusters aplicada pelo algoritmo M-DBScan estaria causando modificações momentâneas na estrutura de grupos que, em seguida, são refletidas nas medidas de entropia, uma nova abordagem sem esquecimento de p-micro-clusters foi implementada. Nessa seção é descrita essa abordagem, assim como resultados de novos experimentos realizados e comparação com os resultados anteriormente obtidos.

\subsubsection{Modificação Proposta}

Tendo como base os algoritmos GWR e SONDE, uma modificação no algoritmo M-DBScan foi implementada. Essa nova versão será, de agora em diante, referenciada como MicroClustering DBScan Version 2 (M-DBScan V2) (para indicar a segunda versão do algoritmo 
de agrupamento).

Originalmente, M-DBScan utiliza o algoritmo DenStream em sua fase de agrupamento. O DenStream aplica um decaimento nos pesos dos micro-clusters, de modo a remover aqueles que não tenham sido atualizados recentemente. Neste trabalho, foi avaliada uma versão modificada do DenStream em que não há poda de p-micro-clusters. Assim, não há mais o fator de decaimento aplicado aos $p$-micro-clusters. Os o-micro-clusters, por outro lado, continuam sofrendo decaimento em suas características e podem ser removidos caso não haja potencial de se tornarem p-micro-clusters. O Algoritmo 4.4 apresenta a nova versão da etapa de agrupamento do M-DBScan, implementando a modificação proposta.

É importante ressaltar que a modificação implementada por M-DBScan V2 possui a desvantagem de que a qualidade do agrupamento em si consequentemente será inferior caso grupos estejam aparecendo e desaparecendo do fluxo. Assim, se o objetivo for agrupar dados da melhor maneira possível em um fluxo de dados, a alternativa mais viável é utilizar o algoritmo DenStream da maneira original como foi concebido.

\subsubsection{Experimentos e Resultados}

\section{Configuração dos Experimentos}

Para avaliar se M-DBScan V2 é eficaz em reduzir a taxa de FPs detectados, os mesmos experimentos apresentados na Seção 4.5.2 foram novamente conduzidos, mantendo-se os mesmos valores de parâmetros de modo a realizar uma comparação justa de resultados. Os resultados são apresentados separadamente para cada medida de entropia estudada.

\section{Resultados}

A Tabela 4.5 apresenta os resultados de M-DBScan V2 utilizando a entropia espacial. Para facilitar a comparação de resultados, a Tabela 4.5 contém também os resultados previamente observados para M-DBScan.

Observa-se na Tabela 4.5 que houve uma considerável melhora nos resultados obtidos pela entropia espacial em termos de FPs e DAs. Entretanto, ND ainda foi considerado alto. A maioria das não detecções aconteceu em conjuntos de dados contendo mudanças do tipo temporal ou mudanças no formato dos grupos. Com relação aos conjuntos de dados que apresentam mudanças temporais, esse resultado já era esperado, visto que a medida de entropia espacial não captura mudanças na ordem de chegada dos exemplos. Para os conjuntos de dados contendo mudanças no formato dos grupos existentes, observou-se que a ocorrência de NDs estava relacionada ao processo de microagrupamento. Uma vez que a criação dos micro-clusters depende do parâmetro $\epsilon$, é possível que exemplos sejam 


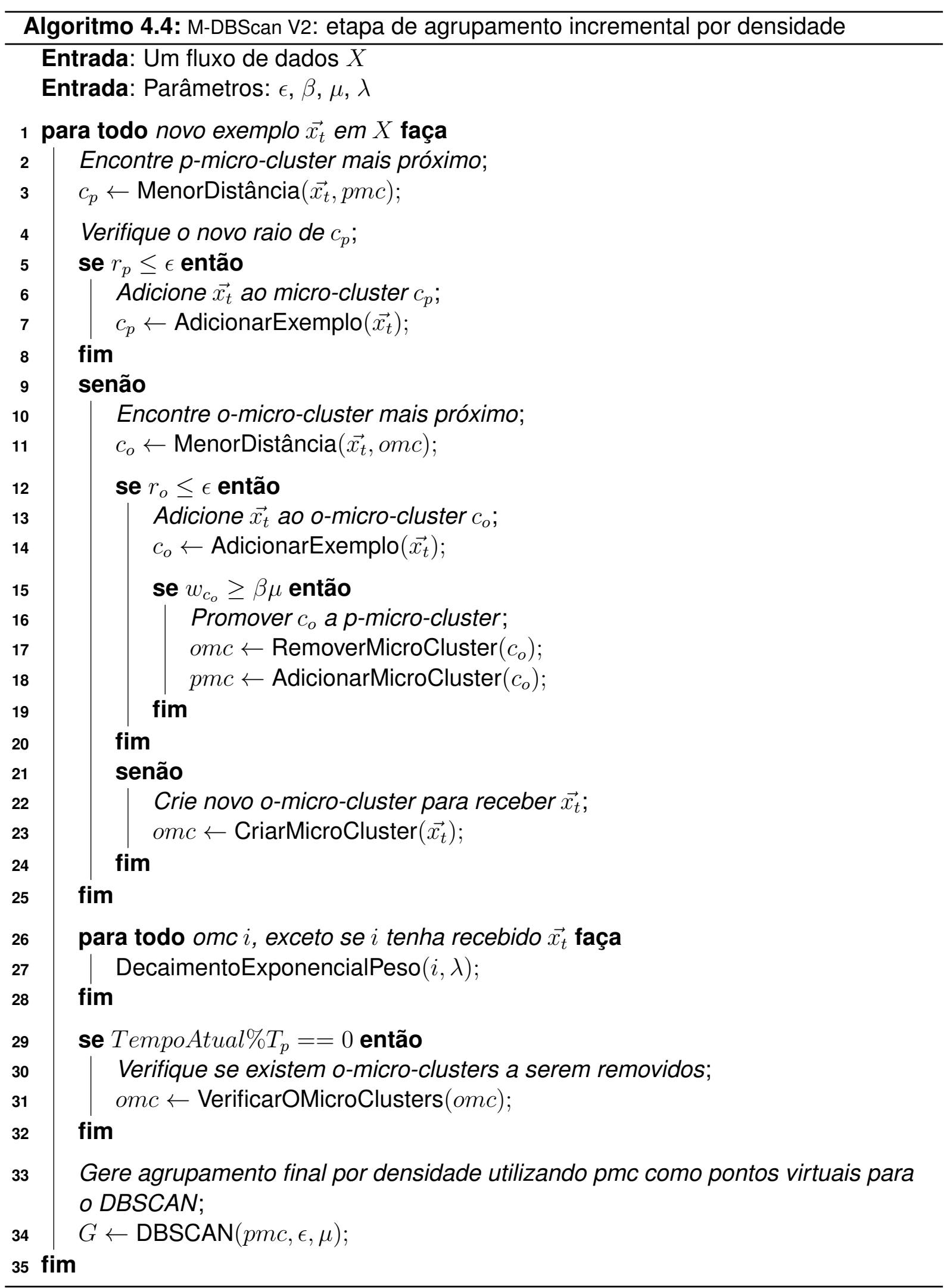


Tabela 4.5: Resultados para a medida de entropia espacial: comparação entre M-DBScan e M-DBScan V2

\begin{tabular}{l|rrr|rrr}
\hline \multirow{2}{*}{ Conjunto de Dados } & \multicolumn{3}{|c|}{ M-DBScan } & \multicolumn{3}{c}{ M-DBScan V2 } \\
\cline { 2 - 7 } & FP & DA & ND & FP & DA & ND \\
\hline FixedDenSpatial & 20 & 0 & 0 & 0 & 0 & 2 \\
FixedDenTemporal & 14 & 2 & 0 & 0 & 0 & 3 \\
FixedSphericalSpatial & 8 & 2 & 1 & 0 & 0 & 1 \\
FixedSphericalTemporal & 12 & 2 & 0 & 0 & 0 & 3 \\
VarDenAddCluster & 12 & 1 & 2 & 0 & 0 & 0 \\
VarDenMergeCluster & 2 & 0 & 3 & 2 & 0 & 1 \\
VarSphericalAddCluster & 14 & 1 & 0 & 0 & 0 & 0 \\
VarSphericalAddSubCluster & 11 & 1 & 0 & 0 & 0 & 0 \\
\hline Total & $\mathbf{9 3}$ & $\mathbf{9}$ & $\mathbf{6}$ & $\mathbf{3}$ & $\mathbf{0}$ & $\mathbf{1 0}$ \\
\hline
\end{tabular}

adicionados à grupos de maneira equivocada se o valor de $\epsilon$ não for apropriado. Isso ocorre porque $\epsilon$ define um limiar máximo para o raio dos micro-clusters. Erros decorrentes do processo de microagrupamento propagam para a fase de macroagrupamento, resultando em um agrupamento final diferente do ideal. Esses erros podem fazer com que a entropia espacial não detecte variações nas proporções de exemplos por grupo, perdendo assim algumas das mudanças. A medida de entropia espacial, entretanto, foi capaz de detectar a maior parte das mudanças no número de grupos ocorrendo nos conjuntos de dados utilizados.

A Tabela 4.6 apresenta os resultados após a modificação proposta utilizando a entropia temporal. Para facilitar a comparação de resultados, a Tabela 4.6 contém também os resultados previamente obtidos por M-DBScan.

Tabela 4.6: Resultados para a medida de entropia temporal: comparação entre M-DBScan e M-DBScan V2

\begin{tabular}{|c|c|c|c|c|c|c|}
\hline \multirow{2}{*}{ Conjunto de Dados } & \multicolumn{3}{|c|}{ M-DBScan } & \multicolumn{3}{|c|}{ M-DBScan V2 } \\
\hline & FP & DA & ND & FP & DA & ND \\
\hline FixedDenSpatial & 11 & 0 & 0 & 0 & 0 & 0 \\
\hline FixedDenTemporal & 5 & 1 & 1 & 0 & 0 & 0 \\
\hline FixedSphericalSpatial & 8 & 1 & 1 & 1 & 0 & 0 \\
\hline FixedSphericalTemporal & 7 & 0 & 0 & 0 & 0 & 0 \\
\hline VarDenAddCluster & 8 & 1 & 2 & 3 & 0 & 0 \\
\hline VarDenMergeCluster & 3 & 0 & 0 & 1 & 0 & 0 \\
\hline VarSphericalAddCluster & 11 & 2 & 0 & 2 & 0 & 0 \\
\hline VarSphericalAddSubCluster & 6 & 0 & 1 & 0 & 0 & 0 \\
\hline Total & 59 & 5 & 5 & 8 & 0 & 0 \\
\hline
\end{tabular}

Os resultados na Tabela 4.6 mostram que a modificação proposta proporcionou melhores resultados, em todas as medidas estudadas, quando utilizamos a medida de entropia temporal. Além disso, os resultados utilizando a medida de entropia temporal demonstraram que essa medida é mais apropriada para detectar os tipos de mudança em que a entropia espacial falhou. Isso se dá porque essas mudanças causam uma modificação 
quase instantânea nas probabilidades de transição da CM, mesmo em alguns casos onde a estrutura de grupos não é ótima. Modificações na CM refletem diretamente na medida de entropia, produzindo diferenças significativas nos níveis de entropia e, consequentemente, levando à detecção de novidades. A medida de entropia temporal, entretanto, se mostrou menos conservadora em detectar novidades, apresentando maior valor de FPSs.

Como exemplo, as Figuras 4.5 (a) e 4.5 (b) demonstram a variação de entropia $\left(\Phi_{t}\right)$ e desvio padrão móvel $\left(\Omega_{t}\right)$ na detecção de novidades utilizando o conjunto de dados FixedDenSpatial, respectivamente para M-DBScan e M-DBScan V2.

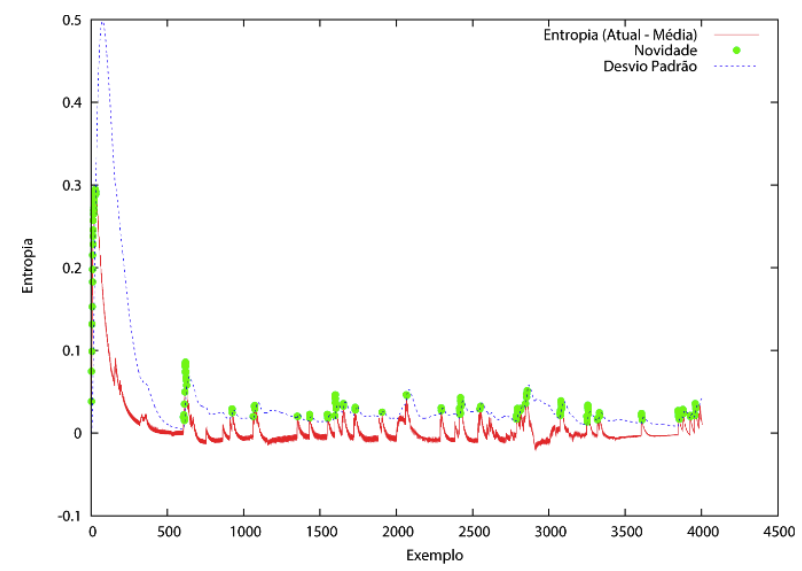

(a)

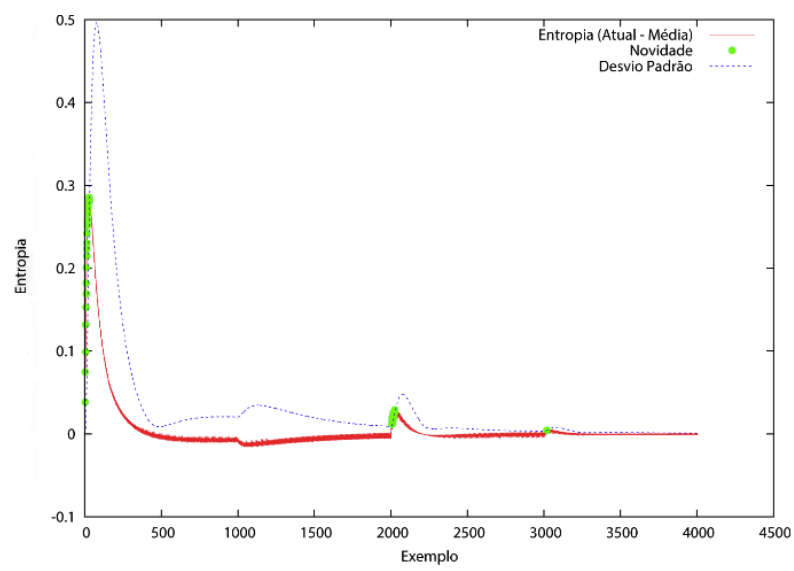

(b)

Figura 4.5: Variação de entropia espacial, desvio padrão móvel e detecção de novidades para o conjunto FixedDenSpatial: (a) utilizando M-DBScan; (b) utilizando M-DBScan V2.

\section{Análise dos Resultados}

Os resultados obtidos pela modificação proposta, onde não há esquecimento de p-microclusters, permitiram verificar a hipótese de que o processo de remoção de $p$-micro-clusters induz a detecção de FPs nas medidas de entropia estudadas. A modificação proposta nesta seção permitiu reduzir consideravelmente a ocorrência de FPs em todos os conjuntos de dados, para ambas as medidas de entropia.

Pode-se também verificar que, como já era esperado, a medida de entropia espacial não é adequada para detectar mudanças do tipo temporal. Além disso, a entropia espacial requer a observação de um número maior de exemplos para que uma variação significativa no nível de entropia seja produzido, sendo, portanto, menos afetada por FPs. A entropia temporal, por outro lado, é menos conservadora em detectar novidades, sendo capaz de detectar um maior número de mudanças verdadeiras. Entretanto, por ser mais sensível a pequenas alterações nos dados, a medida de entropia temporal também é mais afetada por FPs. 


\subsection{Comparação com Abordagem por Proximidade}

O algoritmo M-DBScan V2 utiliza uma fase de agrupamento incremental que é baseada no algoritmo DenStream. Portanto, em sua fase de macroagrupamento, um algoritmo de agrupamento de dados baseado em densidade é aplicado. Esse algoritmo é uma variação do $D B S C A N$ que utiliza os centros dos p-micro-clusters, construídos na fase anterior de microagrupamento, como pontos virtuais que serão divididos em grupos. A primeira hipótese avaliada nesta seção é que utilizar um algoritmo de agrupamento baseado em densidade no estágio final de agrupamento irá produzir melhores resultados, em termos de detecção de mudanças, quando os dados apresentam grupos de formatos arbitrários. Para avaliar essa hipótese, foi implementado outro algoritmo de agrupamento para o M-DBScan V2 que é baseado em proximidade, i.e., constrói grupos de formatos hiperesféricos.

A abordagem de agrupamento por densidade utilizada pelo M-DBScan V2 possui também a vantagem de estimar automaticamente o número de grupos presentes nos dados. A segunda hipótese a ser verificada nesta seção é a de que M-DBScan V2 é mais apropriado à tarefa de detecção de mudanças do que uma abordagem que utiliza número de grupos fixo, quando os dados apresentam variação no número de grupos. O algoritmo por proximidade implementado para verificar a primeira hipótese utiliza número fixo de grupos. Assim, esse algoritmo mostrou-se adequado para verificar também a segunda hipótese aqui discutida.

Nesta seção é apresentado o algoritmo por proximidade implementado, os experimentos realizados para comparar ambas abordagens, i.e., densidade e proximidade, assim como os resultados obtidos.

\subsubsection{Abordagem de Agrupamento Utilizada}

A abordagem de agrupamento baseada em proximidade utilizada funciona da seguinte forma. Ao invés de aplicar o DBSCAN ao conjunto de $p$-micro-clusters, foi aplicado o algoritmo K-Means (HARTIGAN; WONG, 1979). O algoritmo K-Means é um algoritmo bastante conhecido na área de agrupamento de dados, sendo frequentemente utilizado como referência. Os exemplos submetidos ao K-Means são pontos virtuais representados pelos centros dos $p$-micro-clusters. Uma vez que cada $p$-micro-cluster $c_{p}$ possui um centro e um peso $w_{c_{p}}$ correspondente, foram criados $N_{c_{p}}$ cópias do exemplo que representa $c_{p}$. $\mathrm{O}$ número de cópias de $c_{p}$ adicionadas ao conjunto de pontos virtuais é calculado como na Equação 4.12, onde $c$ é uma constante inteira.

$$
N_{c_{p}}=\left\lceil w_{c_{p}}\right\rceil * c
$$

Nos experimentos realizados, a constante $c$ foi fixada com o mesmo valor de $k$, onde $k$ é o parâmetro que define o número de grupos do $K$-Means. Todos os exemplos no conjunto de pontos virtuais são normalizados no intervalo $[0,1]$ antes de serem processados pelo $K$ - 
Means, de modo a reduzir problemas relacionados à escala de diferentes atributos. Com relação à inicialização dos centroides do algoritmo K-Means, na primeira execução do algoritmo, são selecionados aleatóriamente $k$ pontos no intervalo [0,1]. Esses centroides iniciais são então armazenados de modo a inicializar os centroides sempre nas mesmas posições todas as vezes que o K-Means for executado.

É importante ressaltar que essa implementação permite realizar uma comparação justa entre abordagem por densidade e abordagem por proximidade, uma vez que ambas são baseadas no mesmo processo de microagrupamento. Além disso, todo o processo de deteção de novidades e mudança de comportamento continua inalterado. Portanto, diferenças entre abordagens resultam somente do processo de macroagrupamento. A abordagem que utiliza o algoritmo K-Means no processo de macroagrupamento será referenciada neste texto como Micro-Clustering K-Means (MK-Means).

\subsubsection{Experimentos e Resultados}

Para validar as hipóteses que M-DBScan V2 é mais apropriado do que MK-Means para detectar mudanças em grupos de formato arbitrário e em fluxos com número variável de grupos, foram conduzidos novamente experimentos utilizando os mesmos conjuntos de dados artificiais avaliados em experimentos anteriores nesta tese. Um novo conjunto de dados, construído a partir da partição $10 \%$ do conjunto KDD99, contendo dados de intrusão em redes, foi adicionado aos novos experimentos. Esse conjunto de dados, denominado StreamKDD99, foi construído utilizando dados de três diferentes ataques a redes de computadores contidos no conjunto original KDD99. Os ataques escolhidos foram Satan (Probe attack), Smurf (DOS attack) e Neptune (DOS attack). O conjunto de dados criado contém 3000 exemplos, divididos em sub-conjuntos de 1000 exemplos, cada qual contendo dados de um dos tipos de ataque. Portanto, o conjunto StreamKDD99 possui duas mudanças de comportamento, ocorrendo nos exemplos de índice 1000 e 2000. Além disso, os dados utilizados foram pré-processados de modo a remover todos os atributos categóricos presentes e, portanto, os exemplos contém 34 atributos dos tipos numérico e binário.

Os experimentos realizados compararam o desempenho dos algoritmos M-DBScan V2 e MK-Means nos nove conjuntos de dados.

\section{Configuração dos Experimentos}

Nos experimentos utilizando o algoritmo M-DBScan V2 todos os parâmetros utilizados na Seção 4.6 foram mantidos. O valor de $\epsilon$ utilizado no novo conjunto StreamKDD99 foi fixado como 120.

Para o algoritmo MK-Means, o número de grupos $k$ foi escolhido como igual ao número de grupos inicialmente presente em cada conjunto de dados, com exceção do conjunto StreamKDD99, no qual $k=4$. 
Os resultados foram analisados considerando-se as mesmas três medidas apresentadas, i.e., número de FPs, DAs e NDs. Além disso, são também apresentados os atrasos observados para detecção de mudanças.

As hipóteses que se pretende verificar são as de que o algoritmo M-DBScan V2 é capaz de produzir melhores resultados, em termos de detecção de mudança, do que MK-Means naqueles conjuntos de dados contendo grupos de formatos arbitrários e naqueles em que há alteração no número de grupos.

\section{Resultados}

O primeiro experimento compara M-DBScan V2 com MK-Means utilizando a medida de entropia espacial. Os resultados obtidos por ambos os algoritmos são apresentados na Tabela 4.7. A Tabela 4.8 apresenta o atraso para detecção de cada uma das mudanças de comportamento.

Tabela 4.7: Resultados utilizando entropia espacial: comparação entre M-DBScan V2 e MKMeans.

\begin{tabular}{l|rrr|rrr}
\hline \multirow{2}{*}{ Conjunto de Dados } & \multicolumn{3}{|c|}{ M-DBScan V2 } & \multicolumn{3}{c}{ MK-Means } \\
\cline { 2 - 7 } & & & & & & \\
& FP & DA & ND & FP & DA & ND \\
\hline FixedDenSpatial & 0 & 0 & 1 & 2 & 0 & 2 \\
FixedDenTemporal & 0 & 0 & 3 & 0 & 0 & 3 \\
FixedSphericalSpatial & 0 & 0 & 1 & 0 & 0 & 1 \\
FixedSphericalTemporal & 0 & 0 & 3 & 0 & 0 & 3 \\
VarDenAddCluster & 0 & 0 & 0 & 1 & 0 & 3 \\
VarDenMergeCluster & 2 & 0 & 1 & 4 & 1 & 1 \\
VarSphericalAddCluster & 0 & 0 & 0 & 3 & 0 & 2 \\
VarSphericalAddSubCluster & 0 & 0 & 0 & 3 & 0 & 1 \\
StreamKDD99 & 1 & 0 & 0 & 1 & 0 & 0 \\
\hline Total & $\mathbf{3}$ & $\mathbf{0}$ & $\mathbf{9}$ & $\mathbf{1 4}$ & $\mathbf{1}$ & $\mathbf{1 6}$ \\
\hline
\end{tabular}

Os resultados na Tabela 4.7 sugerem que boa parte das mudanças não foram detectadas por ambos algoritmos (ND). Entretanto, esses resultados permitem tirar importantes conclusões sobre o funcionamento da entropia espacial. Em primeiro lugar, os resultados utilizando ambos os algoritmos indicam que a entropia espacial não é apropriada quando a mudança presente nos dados é do tipo temporal. Esse fato já havia sido observado para M-DBScan V2 e se repetiu ao utilizar a abordagem MK-Means. Esse resultado era esperado, uma vez que a entropia espacial não considera a ordem de chegada de exemplos aos seus respectivos grupos. Observou-se também que a medida de entropia espacial é bastante sensível à criação de novos grupos, produzindo uma grande variação nos níveis de entropia e, portanto, indicando mudanças.

Mesmo não sendo capazes de detectar uma boa parte das mudanças ocorridas, os resultados nos conjuntos de dados contendo grupos de formato arbitrário permitem verificar 
que M-DBScan V2 foi, de fato, mais eficaz do que MK-Means, detectando maior número de mudanças. Os resultados nos conjuntos de dados com um número crescente de grupos sugerem que o desempenho da abordagem MK-Means foi inferior à M-DBScan V2. Enquanto M-DBScan V2 detectou a maioria das mudanças nesses conjuntos de dados, MK-Means ou não detectou ou detectou mudanças com atraso significativo, como pode ser observado na Tabela 4.8. Além disso, a abordagem MK-Means apresentou alta taxa de FPs.

Para o conjunto de dados StreamKDD99 ambos os algoritmos foram capazes de detectar as duas mudanças de comportamento existentes. Isso se dá pois os dados representando um ataque em particular são razoavelmente bem definidos, apresentando pequena variação. Além disso, ataques distintos produzem dados que diferem significativamente entre si. Dessa forma, mesmo a abordagem MK-Means ainda é capaz de diferenciar entre os ataques existentes no conjunto de dados em questão. Com relação aos FPs, M-DBScan V2 detectou a ocorrência de um FP no meio dos dados representando o primeiro ataque (Satan). Ao observar os resultados obtidos, foi constatado que esse FP era, na verdade, uma variação do mesmo ataque, com características diferentes do que havia sido observado até então nos dados do fluxo. Dessa maneira, a detecção desse evento seria, na verdade, desejável uma vez que constitui uma variação de comportamento do mesmo tipo de intrusão.

Tabela 4.8: Atraso, em número de exemplos, para detecção de mudanças de comportamento com respeito à utilização da entropia espacial. C1, C2 e C3, representam, respectivamente, a primeira, segunda e terceira mudança ocorrendo nos dados. Uma linha tracejada representa a não detecção da respectiva mudança, enquanto que o sinal *** representa uma mudança que não se aplica ao respectivo conjunto de dados.

\begin{tabular}{l|rrr|rrr}
\hline \multirow{2}{*}{ Conjunto de Dados } & \multicolumn{3}{|c|}{ M-DBScan V2 } & \multicolumn{3}{|c}{ MK-Means } \\
\cline { 2 - 7 } & C1 & C2 & C3 & C1 & C2 & C3 \\
\hline FixedDenSpatial & - & 4 & 21 & - & - & - \\
FixedDenTemporal & - & - & - & - & - & - \\
FixedSphericalSpatial & - & 4 & 9 & - & 9 & 9 \\
FixedSphericalTemporal & - & - & - & - & - & - \\
VarDenAddCluster & 44 & 58 & 20 & - & 951 & - \\
VarDenMergeCluster & - & 8 & 16 & - & 258 & 25 \\
VarSphericalAddCluster & 19 & 40 & 20 & 14 & 413 & 480 \\
VarSphericalAddSubCluster & 15 & 23 & 14 & 15 & - & 8 \\
StreamKDD99 & 12 & 0 & $* * *$ & 12 & 0 & $* * *$ \\
\hline
\end{tabular}

O segundo experimento compara M-DBScan V2 com MK-Means usando a medida de entropia temporal. A Tabela 4.9 sumariza os resultados desse experimento. Os resultados mostram que MK-Means não foi capaz de detectar 4 das 26 mudanças de comportamento existentes, enquanto que M-DBScan V2 detectou todas as mudanças. Foi também observado durante os experimentos que M-DBScan V2 foi capaz de encontrar um agrupamento 
dos dados muito mais estável e perto do ideal para vários conjuntos de dados. Isso ocorreu porque M-DBScan V2 consegue encontrar um número arbitrário de grupos, enquanto que MK-Means produziu um número fixo de grupos durante todo o processamento do fluxo. Esse fato foi particularmente notável quando o número de grupos no fluxo estava variando, o que se reflete nos resultados em termos de NDs para MK-Means, onde todas as não detecções ocorreram em conjuntos de dados com um número variável de grupos.

Construir um agrupamento mais estável durante o processamento do fluxo também significa construir uma CM mais estável durante o tempo, o que está diretamente relacionado à ocorrência de FPs. Se a estrutura de grupos é pobre, haverá uma grande probabilidade de que transições errôneas ocorram na cadeia. Essas transições resultarão em falsas novidades temporais. Esse fato pode ser percebido, em especial, quando o formato dos grupos é arbitrário. Como pode ser observado nos resultados da Tabela 4.9, M-DBScan V2 produziu uma quantidade relativamente inferior de FPs do que MK-Means.

Para o conjunto StreamKDD99, novamente ambos os algoritmos obtiveram desempenho similar. A mesma conclusão obtida utilizando a entropia espacial se aplica à entropia temporal.

Tabela 4.9: Resultados utilizando entropia temporal: comparação entre M-DBScan V2 e MKMeans.

\begin{tabular}{|c|c|c|c|c|c|c|}
\hline \multirow{2}{*}{ Conjunto de dados } & \multicolumn{3}{|c|}{ M-DBScan V2 } & \multicolumn{3}{|c|}{ MK-Means } \\
\hline & FP & DA & ND & FP & DA & ND \\
\hline FixedDenSpatial & 0 & 0 & 0 & 10 & 0 & 0 \\
\hline FixedDenTemporal & 0 & 0 & 0 & 3 & 0 & 0 \\
\hline FixedSphericalSpatial & 1 & 0 & 0 & 0 & 0 & 0 \\
\hline FixedSphericalTemporal & 0 & 0 & 0 & 0 & 0 & 0 \\
\hline VarDenAddCluster & 3 & 0 & 0 & 1 & 0 & 2 \\
\hline VarDenMergeCluster & 1 & 0 & 0 & 5 & 0 & 0 \\
\hline VarSphericalAddCluster & 2 & 0 & 0 & 1 & 0 & 1 \\
\hline VarSphericalAddSubCluster & 0 & 0 & 0 & 0 & 0 & 1 \\
\hline StreamKDD99 & 1 & 0 & 0 & 0 & 0 & 0 \\
\hline Total & 8 & 0 & 0 & 20 & 0 & 4 \\
\hline
\end{tabular}

Os atrasos para detecção de cada uma das mudanças de comportamento são apresentados na Tabela 4.10. Além de ter detectado mais mudanças de comportamento, M-DBScan V2 também apresentou atrasos similares aos de MK-Means.

As Figuras 4.6 (a) e 4.6 (b) apresentam exemplos de variação de entropia e detecção de novidades, respectivamente, para os algoritmos M-DBScan V2 e MK-Means. 
Tabela 4.10: Atraso, em número de exemplos, para detecção de mudanças de comportamento com respeito à utilização da entropia temporal. C1, C2 e C3, representam, respectivamente, a primeira, segunda e terceira mudança ocorrendo nos dados. Uma linha tracejada representa a não detecção da respectiva mudança, enquanto que o sinal ${ }^{* * *}$ representa uma mudança que não se aplica ao respectivo conjunto de dados.

\begin{tabular}{l|rrr|rrr}
\hline \multirow{2}{*}{ Conjunto de dados } & \multicolumn{3}{|c|}{ M-DBScan V2 } & \multicolumn{3}{|c}{ MK-Means } \\
\cline { 2 - 7 } & C1 & C2 & C3 & C1 & C2 & C3 \\
\hline FixedDenSpatial & 4 & 3 & 9 & 10 & 3 & 9 \\
FixedDenTemporal & 0 & 8 & 6 & 1 & 4 & 8 \\
FixedSphericalSpatial & 4 & 3 & 9 & 4 & 3 & 9 \\
FixedSphericalTemporal & 0 & 1 & 3 & 0 & 1 & 3 \\
VarDenAddCluster & 10 & 11 & 20 & 14 & - & - \\
VarDenMergeCluster & 5 & 33 & 16 & 19 & 25 & 26 \\
VarSphericalAddCluster & 5 & 10 & 13 & - & 10 & 14 \\
VarSphericalAddSubCluster & 3 & 7 & 13 & - & 7 & 14 \\
StreamKDD99 & 12 & 1 & $* * *$ & 12 & 1 & $* \star *$ \\
\hline
\end{tabular}

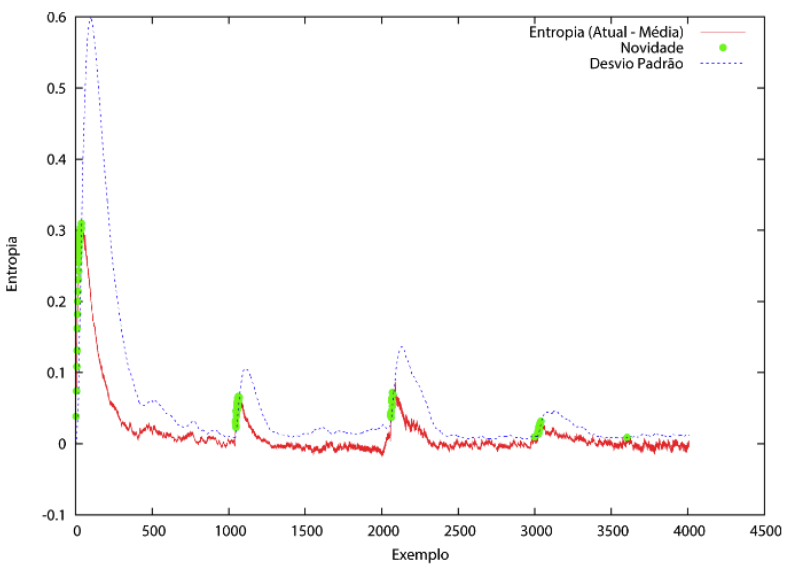

(a)

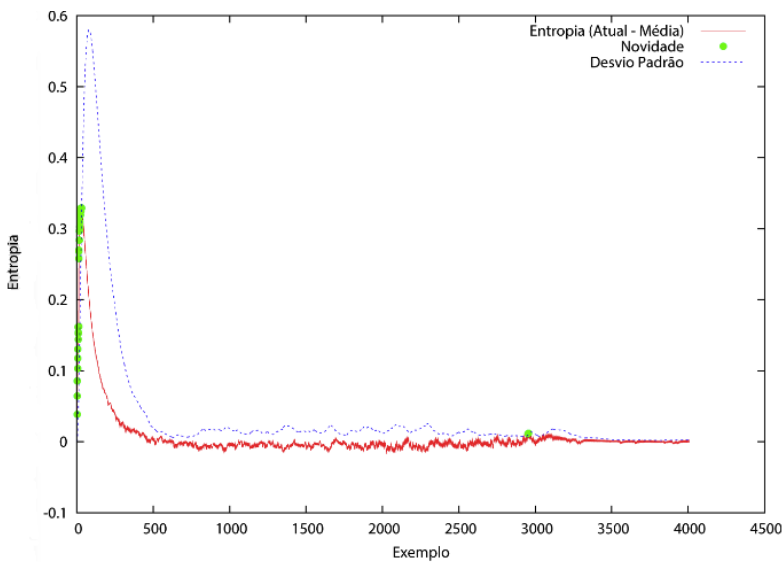

(b)

Figura 4.6: Variação de entropia, desvio padrão móvel e detecção de novidades para o conjunto VarDenAddCluster: (a) utilizando M-DBScan V2; (b) utilizando MK-Means.

\section{Análise dos Resultados}

Os resultados obtidos nos experimentos realizados permitiram validar ambas as hipóteses levantadas nesta seção. Em primeiro lugar, M-DBScan V2 demonstrou ser mais apropriado que MK-Means, em ambas as medidas de entropia, quando o formato dos grupos presentes nos dados é arbitrário. Nesse caso, M-DBScan V2 detectou um maior número de mudanças, assim como um menor número de FPs. Isso ocorreu pois M-DBScan V2 segue uma abordagem baseada em agrupamento por densidade e, portanto, consegue capturar com mais precisão grupos que apresentam formatos diferentes. Em segundo lugar, M-DBScan V2 também mostrou ser mais adequado, em ambas as entropias, para detectar mudanças quando o número de exemplos no fluxo se altera. Como esse algoritmo constrói grupos por densidade, não é necessário informar a priori o número de grupos existentes nos dados. Dessa maneira, a abordagem implementada por M-DBScan V2 consegue alcançar melhores resultados quando o número de grupos varia durante o tempo do que uma abordagem que 
utiliza número de grupos fixo.

\subsection{Aplicação em Dados de Jogos}

Este trabalho tem por objetivo modelar o comportamento de um jogador de maneira online, de modo a ser capaz de informar ao sistema de jogo sempre que mudanças comportamentais ocorram. Para atingir esse objetivo, será investigada a utilização da abordagem proposta M-DBScan V2.

Um conjunto de atributos, que medem características particulares do jogador, são verificados em intervalos de tempo fixo. Ou seja, em um dado intervalo de tempo, estatísticas que resumem o comportamento do jogador nesse intervalo são coletadas. Ao chegar ao término desse intervalo, essas estatísticas, também denominadas de métricas de jogo, são representadas por um vetor, formando um exemplo que é então encaminhado ao algoritmo de aprendizado para processamento. O algoritmo, nesse caso M-DBScan V2, adiciona o novo exemplo à sua estrutura atual, atualizando o modelo induzido com a chegada dessa nova informação.

Desse modo, quando mudanças ocorrem no comportamento do jogador, consequentemente as estatísticas sendo coletadas também irão se alterar. A hipótese deste trabalho é que o algoritmo M-DBScan V2 será capaz de detectar esses momentos de mudança de comportamento utilizando as métricas de jogo coletadas.

As próximas sub-seções descrevem o ambiente de jogo utilizado para realização de experimentos com o M-DBScan V2, assim como os primeiros resultados obtidos.

\subsubsection{Avaliação Inicial em Dados de FPS}

A seguir são descritos os primeiros experimentos aplicando M-DBScan V2 ao FPS UT2004 (Epic Games, Digital Extremes, 2004).

\section{Ambiente Utilizado}

Para avaliar a aplicação do algoritmo M-DBScan V2 ao cenário de jogos, um conjunto de experimentos foi realizado utilizando o jogo UT2004. O UT2004 é um jogo do gênero FPS que simula de modo bastante realista um ambiente de guerra. Por meio da utilização da IDE Pogamut (GEMROT et al., 2009), que permite o acesso à algumas funcionalidades do motor de jogo do UT2004, foram criadas diferentes simulações para testar a aplicabilidade da abordagem proposta neste trabalho em detectar mudanças de comportamento no agente interagindo com o jogo.

Essas simulações foram criadas da seguinte maneira. Em primeiro lugar, foi implementado um agente no UT2004 que apresenta comportamento variável no tempo. Esse agente altera entre quatro possíveis comportamentos e é utilizado para representar um jogador 
interagindo com o jogo. Optou-se por implementar esse agente, ao invés de utilizar um jogador humano, pois esse processo automatiza os experimentos e facilita a reprodução de resultados. O agente foi implementado utilizando uma Máquina de Estados Finita que possibilita a alternância entre comportamentos em momentos fixos no tempo. O primeiro comportamento do agente (A) simula um comportamento agressivo, onde o agente ataca todo inimigo avistado e persegue aqueles inimigos que por ventura tenham saído de seu campo de visão. O segundo comportamento (B) é uma variação do comportamento $A$ onde o agente não mais persegue inimigos que saiam de sua área de visão, decidindo por coletar itens no cenário. O comportamento $C$ é uma variação de $B$ onde o agente não é capaz de acionar a arma e se mover ao mesmo tempo, i.e., o agente apenas acionará a arma parado. Finalmente, o quarto comportamento (D) simula um jogador amador, onde o agente apenas coleta itens pelo cenário e não é capaz de atirar nos inimigos encontrados.

É também importante notar que os comportamento $A, B$ e $C$ são bastante parecidos entre si. Apenas o comportamento $D$ difere significativamente dos demais. Essa configuração foi proposital, uma vez que alterações entre comportamentos parecidos são mais difíceis de serem detectadas.

Uma simulação consiste em uma partida entre o agente jogador de comportamento variável, no modo de jogo DeathMatch, contra um inimigo que implementa um único comportamento. Em todas as simulações realizadas o inimigo implementou sempre o comportamento A. A simulação durou quatro horas, durante a qual o agente jogador mudou de seu comportamento atual para o próximo a cada uma hora, i.e., todos os quatro comportamentos foram executados durante a partida. O mapa utilizado nos experimentos realizados foi o DMTrainingDay devido a sua simplicidade e garantia de que o agente jogador e o inimigo iriam se encontrar diversas vezes durante a simulação. De modo a considerar o efeito da ordem de execução de diferentes comportamentos, todas as permutações possíveis de comportamento do agente jogador foram executadas, resultando, portanto, em vinte e quatro simulações distintas.

\section{Dados Coletados}

Uma vez que o interesse é modelar o agente jogador, algumas métricas de jogo foram coletadas em intervalos fixos de tempo em cada simulação realizada. O intervalo de tempo deve ser pequeno o suficiente de modo que, quando o jogador mude de comportamento, essa mudança seja percebida o mais rápido possível. Entretanto, intervalos muito pequenos podem não conter informação suficiente para modelar o jogador. O intervalo de tempo utilizado neste trabalho para coleta das métricas foi de quinze segundos.

Essas métricas compõem um vetor, que é um novo exemplo a ser enviado ao M-DBScan V2. O exemplo formado contém nove atributos, que são: o número de trocas de armas, número de tiros disparados, frequência de utilização do primeiro modo de tiro, frequência de utilização do segundo modo de tiro, número de vezes que a arma foi acionada com 
o agente parado, número de mortes do agente, número de inimigos mortos pelo agente, velocidade média de movimentação (medida em unidades de jogo) e, finalmente, distância média entre jogadores (medida em unidades de jogo).

Todos os exemplos gerados foram também armazenados em conjuntos de dados representando cada simulação. Dessa maneira, esses dados podem ser utilizados futuramente por outras pesquisas, sem a necessidade de se realizar as simulações novamente.

\section{Configuração dos Experimentos}

Para as vinte e quatro simulações realizadas, as seguintes configurações foram utilizadas pelo algoritmo M-DBScan V2. Os valores dos parâmetros utilizados na fase de agrupamento foram $\mu=10, \lambda=0,006, \beta=0,305$ e $\epsilon=2$. Esses valores configuram o algoritmo para promover o-micro-cluster à $p$-micro-clusters quando o o-micro-cluster contiver mais do que três exemplos. Essa configuração de parâmetros também estabelece que o algoritmo irá verificar a possível remoção de o-micro-clusters a cada 67 exemplos (aproximadamente 16,7 minutos de jogo).

Para a fase de deteçcão de novidades e mudança de comportamento foram utilizados $\eta_{s}=0,005, \eta_{t}=0,005, \gamma=0,05, \delta=0,03, \theta=2, k=15$ e minNovelties $=2$. Com relação aos parâmetros $\eta_{s}, \eta_{t}, \gamma$ e $\delta$, os valores foram escolhidos de modo a aplicar uma abordagem mais conservadora para detecção de novidades, onde a história passada de eventos tem uma forte influência na definição do limiar $\tau$.

Os experimentos conduzidos tem por objetivo avaliar o desempenho de M-DBScan V2 na tarefa de detectar as mudanças de comportamento do agente jogador. Para tanto, utilizouse o número de VPs e FPs ocorridos. Para cálculo do número de VPs e FPs considerou-se o atraso para detecção $d$, em número de exemplos, e o intervalo $L$ entre duas mudanças consecutivas, também em número de exemplos. Uma mudança detectada com um atraso $d$, onde $d \in[0, \ldots, L / 2]$, é considerada um verdadeiro positivo (VP), se $d$ for a primeira mudança detectada no intervalo $[0, \ldots, L / 2]$. Caso uma outra mudança já tenha sido detectada previamente nesse intervalo, $d$ é considerada como falso positivo (FP). Por outro lado, uma mudança detectada com um atraso $d$, onde $d \in(L / 2, \ldots, L]$, é considerada um FP pois o atraso $d$ é muito grande.

Os resultados obtidos são apresentados em termos do caso especial da medida $F$ measure denominada de $F 1$, calculada como na Equação 4.15. As medidas Precisão e Revocação, necessárias para cálculo da medida $F 1$, são dadas, respectivamente, pelas Equações 4.14 e 4.13.Optou-se por utilizar a medida $F 1$ pois essa facilita a análise dos resultados em relação as medidas anteriormente utilizadas e definidas na Seção 4.5.2.

$$
\text { Revocação }=\frac{V P}{P}
$$




$$
\begin{gathered}
\text { Precisão }=\frac{V P}{V P+F P} \\
F 1=2 \cdot\left(\frac{\text { Precision } \cdot \text { Recall }}{\text { Precision }+ \text { Recall }}\right)
\end{gathered}
$$

$\mathrm{Na}$ Equação 4.13, P significa o número total de eventos positivos, i.e., o número de possíveis mudanças de comportamento. As medidas acima foram calculadas para cada uma das simulações separadamente. Um valor de $F 1$ total também foi calculado somandose os valores de VP e FP em todas as simulações. Nesse caso, como cada simulação apresenta 3 mudanças de comportamento, então $P=72$ (24 simulações $\times 3$ mudanças).

O atraso médio para detecção de mudanças, calculado a partir dos atrasos observados nas detecções dos VPs, também foi analisado.

\section{Resultados}

Os valores de VP, FP e F1 obtidos utilizando a entropia espacial em cada uma das simulações realizadas são apresentados na Tabela 4.11. Na Tabela 4.12 são apresentados VP, FP e $F 1$ totais, considerando todas as simulações, e o atraso médio total observado para detecção de mudanças.

Tabela 4.11: Valores de VP, FP e F1 obtidos por M-DBScan V2 utilizando entropia espacial em cada uma das simulações.

\begin{tabular}{lrrr}
\hline Simulação & VP & FP & F1 \\
\hline 1 & 3 & 0 & 1 \\
2 & 3 & 0 & 1 \\
3 & 3 & 0 & 1 \\
4 & 2 & 0 & 0,8 \\
5 & 2 & 0 & 0,8 \\
6 & 2 & 0 & 0,8 \\
7 & 1 & 0 & 0,5 \\
8 & 1 & 0 & 0,5 \\
9 & 2 & 0 & 0,8 \\
10 & 1 & 0 & 0,5 \\
11 & 2 & 0 & 0,8 \\
12 & 2 & 0 & 0,8 \\
13 & 3 & 1 & 0,86 \\
14 & 3 & 1 & 0,86 \\
15 & 2 & 0 & 0,8 \\
16 & 2 & 0 & 0,8 \\
17 & 1 & 0 & 0,5 \\
18 & 2 & 0 & 0,8 \\
19 & 1 & 0 & 0,5 \\
20 & 1 & 0 & 0,5 \\
21 & 1 & 0 & 0,5 \\
22 & 1 & 0 & 0,5 \\
23 & 2 & 1 & 0,66 \\
24 & 2 & 0 & 0,8 \\
\hline & & &
\end{tabular}


Tabela 4.12: Valores de VP, FP e F1 totais utilizando M-DBScan V2. A última coluna contém os atrasos médios para detecção de mudança, em número de exemplos, e respectivos desvios padrão.

\begin{tabular}{lrrrr}
\hline & VP & FP & F1 & Atraso Médio \\
\hline Entropia espacial & 45 & 3 & 0,75 & $44,53(27,8)$ \\
Entropia temporal & 47 & 29 & 0,63 & $48,38(30,9)$ \\
\hline
\end{tabular}

Em seguida, repetiu-se os mesmos experimentos, porém utilizando a medida de entropia temporal para detectar novidades. A Tabela 4.13 apresenta os valores de VP, FP e F1 obtidos utilizando a entropia temporal em cada uma das simulações. Na Tabela 4.12 são apresentados VP, FP e F1 totais e o atraso médio total para detecção de mudanças.

Tabela 4.13: Valores de VP, FP e F1 obtidos por M-DBScan V2 utilizando entropia temporal em cada uma das simulações.

\begin{tabular}{lrrr}
\hline Simulação & VP & FP & F1 \\
\hline 1 & 3 & 2 & 0,75 \\
2 & 2 & 0 & 0,8 \\
3 & 3 & 2 & 0,75 \\
4 & 2 & 3 & 0,5 \\
5 & 1 & 1 & 0,4 \\
6 & 2 & 0 & 0,8 \\
7 & 1 & 0 & 0,5 \\
8 & 1 & 1 & 0,4 \\
9 & 2 & 0 & 0,8 \\
10 & 1 & 0 & 0,5 \\
11 & 3 & 1 & 0,86 \\
12 & 3 & 1 & 0,86 \\
13 & 3 & 1 & 0,86 \\
14 & 3 & 3 & 0,66 \\
15 & 2 & 0 & 0,8 \\
16 & 3 & 1 & 0,86 \\
17 & 2 & 0 & 0,8 \\
18 & 2 & 1 & 0,66 \\
19 & 0 & 1 & 0 \\
20 & 1 & 3 & 0,28 \\
21 & 1 & 1 & 0,4 \\
22 & 2 & 3 & 0,5 \\
23 & 2 & 2 & 0,57 \\
24 & 2 & 2 & 0,57 \\
\hline
\end{tabular}

\section{Análise dos Resultados}

Os primeiros resultados obtidos ao utilizar o ambiente de jogos mostraram que as entropias espacial e temporal detectaram praticamente a mesma quantidade de mudanças de comportamento, com a entropia espacial obtendo uma Revocação total de 0,625 e a espacial de 0,65 . Entretanto, a Precisão da medida de entropia espacial foi superior à da medida de entropia temporal, pois a entropia temporal detectou muito mais FPs. Consequentemente, a medida $F 1$ total foi melhor para a entropia espacial do que para a temporal, com a primeira obtendo $F 1$ total de 0,75 enquanto que a segunda obteve 0,63 . 
Como já havia sido observado nos experimentos com conjuntos de dados artificiais, a entropia temporal é, de fato, menos conservadora ao detectar novidades. Em um cenário onde vários fatores interagem entre si, é comum que, em determinados instantes de tempo, alguns exemplos diferentes sejam gerados. Entretanto, esses exemplos não são diferentes o suficiente para levar à criação de um novo micro-cluster, que nesse caso seria um omicro-cluster e não provocaria alterações de entropia. O que ocorre nesses casos é a alteração da ordem de chegada de exemplos aos grupos. Quando isso ocorre, o nível de entropia temporal se altera, gerando detecções de novidade que não correspondem a reais mudanças de comportamento. É por esse fato que a entropia temporal apresentou um número elevado de FPs.

Por outro lado, a entropia espacial não observa a ordem de chegada de exemplos aos grupos. Além disso, essa medida de entropia se altera quando a proporção de exemplos por grupo começa a se alterar, ou quando novos grupos são criados. Isso implica em um maior conservadorismo por parte da medida de entropia espacial, pois esta somente indica novidades quando alterações mais severas na estrutura de agrupamento ocorrem.

O atraso médio observado, parecido para ambas as entropias, foi de aproximadamente 12 minutos de jogo.

A conclusão obtida através da análise dos resultados é a de que, como a entropia temporal apresenta um número muito mais elevado de FPs com aproximadamente a mesma taxa de VPs que a entropia espacial, não é viável, nesse cenário, considerar mudanças na ordem de chegada dos exemplos. Concluiu-se, portanto, que a entropia espacial é mais adequada para detectar mudanças de comportamento em cenários onde há uma alta taxa de interação entre diversos fatores, como é o caso das simulações utilizando jogos aqui apresentadas.

\subsubsection{Novas Medidas para Detecção de Novidades}

Como os resultados utilizando a medida de entropia espacial se mostraram promissores, foram também estudadas neste trabalho outras formas de detecção de novidades e mudanças de comportamento a partir dessa medida de entropia. Primeiramente, estudou-se a inclusão de uma nova restrição para ocorrência de novidade, adicional àquela já existente que utiliza o limiar $\tau$ para declarar eventos novos. Essa nova restrição tem por objetivo aumentar a capacidade do algoritmo em detectar mudanças de comportamento. Em seguida, uma nova abordagem para estimar $\tau$ foi proposta, com a vantagem de necessitar de um parâmetro a menos que a abordagem original para estimação desse limiar. Além disso, uma abordagem para detecção de mudanças de comportamento que utiliza a entropia espacial e o algoritmo para detecção de mudanças PHT foi também implementada.

Esta seção apresenta, separadamente, cada uma dessas novas abordagens. Em seguida, foram conduzidos experimentos utilizando cada uma delas no cenário de jogo apre- 
sentado. Os resultados obtidos por cada abordagem foram comparados entre si e com os resultados obtidos anteriormente. Esses resultados são apresentados nesta seção, assim como as conclusões obtidas.

\section{Nova Restrição para Ocorrência de Novidade}

Originalmente o algoritmo M-DBScan V2 declara a ocorrência de uma novidade quando $\mathbb{H}_{t}(\cdot)>\tau$. É possível reescrever $\mathbb{H}_{t}(\cdot)>\tau$ como na Equação 4.16 .

$$
\mathbb{H}_{t}(\cdot)-\Phi_{t}>\Omega_{t} \cdot \theta
$$

Por simplicidade, vamos referenciar $\mathbb{H}_{t}(\cdot)-\Phi_{t}$ como $\Delta \mathbb{H}_{t}(\cdot)$ e, dessa maneira, a Equação 4.16 pode ser reescrita como na Equação 4.17.

$$
\Delta \mathbb{H}_{t}(\cdot)>\Omega_{t} \cdot \theta
$$

A Equação 4.17 representa a primeira restrição para declarar um evento como novo, e será referenciada como Restrição 1 (R1). Essa restrição, entretanto, implica que a diferença $\Delta \mathbb{H}_{t}(\cdot)$ pode se tornar negativa quando os dados permanecem estáveis por um período de tempo razoável. Como o desvio padrão é sempre positivo, se $\Delta \mathbb{H}_{t}(\cdot)$ se tornar negativa o desvio começará a aumentar, podendo atrasar, ou até mesmo desconsiderar, a detecção de mudanças de comportamento quando a diferença $\Delta \mathbb{H}_{t}(\cdot)$ voltar a se tornar positiva.

Para solucionar este problema sem alterar a propriedade do desvio padrão positivo, foi adicionada uma segunda restrição, denominada Restrição 2 (R2), que também considera a diferença $\Delta \mathbb{H}_{t}(\cdot)$. Existem três afirmações que devem ser verificadas para que R2 ocorra. Primeiro, $\Delta \mathbb{H}_{t}(\cdot) \geq 0$. Segundo, pelo menos $\Delta \mathbb{H}_{t-1}(\cdot)<0$ e $\Delta \mathbb{H}_{t-2}(\cdot)<0$. E terceiro, os valores de entropia no intervalo $\left[\Delta \mathbb{H}_{t+1}(\cdot), \cdots, \Delta \mathbb{H}_{t+l}(\cdot)\right]$ devem ser positivos, onde $l$ é um parâmetro que define o tamanho do intervalo.

A restrição $\mathrm{R} 2$ tenta, portanto, capturar a tendência de $\Delta \mathbb{H}_{t}(\cdot)$ através do tempo. $\mathrm{A}$ restrição é completamente satisfeita se $\Delta \mathbb{H}_{t}(\cdot)$ muda de uma tendência negativa para positiva, mantendo essa tendência por um intervalo fixo de tempo. Quando isso ocorre, uma novidade é declarada. Sempre que uma novidade detectada pela restrição R2 ocorrer, automaticamente é também declarada uma mudança de comportamento. Mesmo assim, o mecanismo de janela deslizante utilizado para declarar mudanças de comportamento continua sendo utilizado, criando-se a janela a partir do exemplo que provocou a novidade do tipo R2. Entretanto, como a ocorrência de uma única novidade do tipo R2 já é suficiente para declarar uma mudança de comportamento, esse mecanismo é utilizado apenas para desconsiderar possíveis outras novidades subsequentes do tipo R1 que ocorram, diminuindo assim FPs que possam vir a ocorrer da interação entre as duas restrições. 


\section{Novo Cálculo de Limiar Dinâmico}

A nova abordagem estudada para estimar $\tau$ considera a mesma média móvel de valores passados de entropia calculada na Equação 4.9. A diferença está no cálculo do desvio padrão. A abordagem original considera um desvio padrão móvel que usa um fator de ponderação $\delta \in[0,1]$ que controla o balanço entre informação mais antiga e mais recente. A nova abordagem proposta utiliza um desvio padrão incremental, ao invés do desvio móvel. Para calcular o desvio incremental, recorreu-se ao algoritmo de Knuth (KNUTH, 1998). Esse algoritmo primeiro atualiza a média de uma sequência de valores com a chegada de um novo elemento. A média, no exemplo de índice $n$, é calculada como na Equação 4.18.

$$
\bar{x}_{n}=\bar{x}_{n-1}+\frac{x_{n}-\bar{x}_{n-1}}{n}
$$

Em seguida, o desvio padrão é incrementalmente atualizado como na Equação 4.19

$$
\Omega_{n}=\sqrt{\frac{M_{n}}{n-1}}
$$

onde $M_{n}$ é soma dos quadrados das diferenças a partir da média atual. O cálculo de $M_{n}$ é definido na Equação 4.20.

$$
M_{n}=M_{n-1}+\left(x_{n}-\bar{x}_{n}\right) \cdot\left(x_{n}-\bar{x}_{n-1}\right)
$$

O limiar $\tau$ é calculado como na Equação 4.11, exatamente como na proposta original do M-DBScan, com a exceção de que agora $\Omega$ é calculado como descrito nesta seção. Esse algoritmo para cálculo do desvio padrão é uma boa aproximação para o desvio padrão verdadeiro, calculado através do armazenamento de todos os exemplos. Além disso, o algoritmo é independente de parametrização, diferente do desvio padrão móvel que necessita do fator de ponderação $\delta$.

\section{Detecção de Mudança Usando PHT}

Estudou-se também uma abordagem para detecção de mudança de comportamento utilizando o algoritmo PHT. Essa abordagem consiste em aplicar o algoritmo PHT aos valores de $\mathbb{H}_{t}(\cdot)$ produzidos pelo algoritmo M-DBScan V2. Como o PHT é um algoritmo incremental, cada novo valor $\mathbb{H}_{t}(\cdot)$ gerado é repassado ao PHT para atualização das suas estatísticas. O PHT necessita de dois parâmetros. O primeiro é a magnitude de mudanças que são permitidas, $\delta_{P H T}$, e o segundo é o limiar que define uma mudança, $\epsilon_{P H T}$. 


\section{Experimentos}

Os experimentos conduzidos nesta seção comparam cinco possíveis configurações do algoritmo M-DBScan V2, dependendo do mecanismso de detecção de novidade ou detecção de mudanças empregado. As cinco configurações possíveis são listadas abaixo:

1. Desvio Padrão Móvel com Restrição R1(MSDR1): essa configuração utiliza o desvio padrão móvel para definir $\tau$ e considera apenas R1 para diferenciar entre eventos normais e novidades. Os valores de parâmetros utilizados foram: $\eta_{s}=0,005, \gamma=$ $0,05, \delta=0,03, \theta=2, k=15$ e minNovelties $=2$; Note que esta é exatamente a configuração utilizada nos experimentos da Seção 4.8.1.

2. Desvio Padrão Móvel com Restrições R1 e R2 (MSDR1R2): essa configuração é a mesma que MSDR1, exceto que considera tanto a restrição do tipo R1 quanto R2 para diferenciar entre eventos normais e novidades. Os valores de parâmetros utilizados foram: $\eta_{s}=0,005, \gamma=0,05, \delta=0,03, \theta=2, k=15, l=15$ e minNovelties $=2$;

3. Desvio Padrão Incremental com Restrição R1 (ISDR1): essa configuração utiliza o desvio padrão incremental para definir $\tau$ e considera apenas $\mathrm{R} 1$ para diferenciar entre eventos normais e novidades. Os valores de parâmetros utilizados foram: $\eta_{s}=0,005$, $\gamma=0,05, \theta=1, k=15$ e minNovelties $=2$;

4. Desvio Padrão Incremental com Restrições R1 e R2 (ISDR1R2): essa configuração é a mesma que ISDR1, exceto que considera tanto a restrição do tipo R1 quanto R2 para diferenciar entre eventos normais e novidades. Os valores de parâmetros utilizados foram: $\eta_{s}=0,005, \gamma=0,05, \theta=1, k=15, l=15$ e minNovelties $=2$.

5. Utilização de teste PHT (IPHT): essa configuração utiliza o algoritmo PHT aplicado aos valores de entropia para definir mudanças de comportamento. Os valores de parâmetros utilizados foram: $\eta_{s}=0,005, \delta_{P H T}=0,01$ e $\epsilon_{P H T}=10$.

A fase de agrupamento do M-DBScan V2 é a mesma, independente da configuração anterior escolhida. Portanto, os parâmetros correspondentes a fase de agrupamento do algoritmo são os mesmos para todas as configurações utilizadas. Os valores adotados nesses experimentos foram: $\mu=10, \lambda=0,006, \beta=0,305, \epsilon=2$. Essa é a mesma configuração utilizada na Seção 4.8.1.

Todos os parâmetros utilizados foram obtidos através de avaliações empíricas, de modo que os valores aqui apresentados aqueles que resultaram em melhor desempenho de cada uma das configurações do M-DBScan V2.

Foram conduzidas as mesmas simulações apresentas na Seção 4.8.1, variando a configuração do algoritmo M-DBScan V2 utilizada. Os resultados para cada uma das cinco configurações foram avaliados em termos da $F 1$ obtida por cada algoritmo em cada simulação, 
além da $F 1$ total de cada algoritmo e do atraso para detecção de mudanças. O objetivo desses experimentos foi avaliar se: (a) a adição da segunda restrição (R2) melhora a capacidade do algoritmo em detectar mudanças verdadeiras; (b) avaliar se existe uma vantagem de uma abordagem para cálculo do desvio padrão em relação à outra; (c) a utilização do algoritmo PHT produz melhores resultados em termos de detecção de mudanças. As conclusões obtidas a partir desses experimentos permitem definir qual das configurações do algoritmo M-DBScan V2 é mais apropriada ao cenário de jogos estudado.

\section{Resultados}

A Tabela 4.14 apresenta os valores de $F 1$ obtidos em cada simulação, para cada uma das configurações do algoritmo M-DBScan V2 avaliadas. Os valores de VP, FP e F1 totais para cada configuração, assim como os atrasos obtidos, são apresentados na Tabela 4.15.

Tabela 4.14: Valores de F1 obtidos em cada uma das simulações para cada configuração do M-DBScan V2 estudada.

\begin{tabular}{lrrrrr}
\hline Simulação & MSDR1 & MSDR1R2 & ISDR1 & ISDR1R2 & IPHT \\
\hline 1 & 1 & 1 & 0,86 & 0,86 & 0,57 \\
2 & 1 & 1 & 0,86 & 0,75 & 0,57 \\
3 & 1 & 1 & 1 & 0,86 & 0,57 \\
4 & 0,8 & 0,66 & 0,8 & 0,66 & 0,66 \\
5 & 0,8 & 0,8 & 0,8 & 0,8 & 0,66 \\
6 & 0,8 & 0,57 & 1 & 0,75 & 0,66 \\
7 & 0,5 & 1 & 0,5 & 1 & 0 \\
8 & 0,5 & 0,66 & 0,5 & 0,86 & 0,4 \\
9 & 0,8 & 1 & 0,66 & 0,75 & 0,86 \\
10 & 0,5 & 0,8 & 0,8 & 1 & 0,57 \\
11 & 0,8 & 1 & 0,8 & 1 & 0,33 \\
12 & 0,8 & 0,86 & 0,8 & 0,86 & 0,28 \\
13 & 0,86 & 0,75 & 0,75 & 0,6 & 0,66 \\
14 & 0,86 & 0,75 & 0,86 & 0,75 & 0,57 \\
15 & 0,8 & 1 & 0,8 & 1 & 0,66 \\
16 & 0,8 & 0,8 & 0,5 & 1 & 0,33 \\
17 & 0,5 & 0,5 & 0,5 & 0,5 & 0,33 \\
18 & 0,8 & 0,66 & 0,5 & 0,8 & 0,28 \\
19 & 0,5 & 0,5 & 0,5 & 0,5 & 0,33 \\
20 & 0,5 & 0,8 & 0,5 & 0,66 & 0,57 \\
21 & 0,5 & 0,8 & 0,5 & 0,8 & 0,66 \\
22 & 0,5 & 0,66 & 0,5 & 0,66 & 0,33 \\
23 & 0,66 & 0,5 & 0,5 & 0,57 & 0,33 \\
24 & 0,8 & 0,66 & 0,66 & 0,57 & 0,86 \\
\hline
\end{tabular}

Para melhor avaliar as diferenças entre as configurações estudadas, foram realizados testes estatísticos considerando os valores de $F 1$ obtidos em cada simulação. Embora a situação ideal para a realização de um teste de hipótese seja a utilização de pelo menos 30 amostras de cada algoritmo estudado, decidiu-se, mesmo assim, realizar os testes utilizando as 24 amostras disponíveis para cada configuração do M-DBScan V2 (Tabela 4.14). 
Tabela 4.15: Valores de VP, FP e F1 totais utilizando diferentes configurações do M-DBScan V2. A última coluna contém os atrasos médios para detecção de mudança, em número de exemplos, e respectivos desvios padrão.

\begin{tabular}{lrrrr}
\hline & VP & FP & F1 & Atraso Médio \\
\hline MSDR1 & 45 & 3 & 0,75 & $44,53(27,80)$ \\
MSDR1R2 & 56 & 15 & 0,78 & $36,93(23,89)$ \\
ISDR1 & 44 & 7 & 0,71 & $43,45(28,16)$ \\
ISDR1R2 & 60 & 23 & 0,77 & $36,40(23,39)$ \\
IPHT & 39 & 41 & 0,51 & $67,13(28,64)$ \\
\hline
\end{tabular}

Seguindo os princípios estabelecidos por Demsar (2006), o teste de Friedman para múltiplas comparações foi escolhido para comparar essas configurações. No caso de o teste de Friedman rejeitar a hipótese nula de desempenho similar entre os algoritmos comparados, o teste de Nemenyi foi aplicado para descobrir quais pares de algoritmos diferem entre si. Em todos os testes realizados, um nível de confiança no teste igual a $95 \%$ foi empregado. A Tabela 4.16 apresenta os resultados obtidos com a aplicação final do teste de Nemenyi. Como o teste de hipóteses é simétrico, a Tabela 4.16 apresenta apenas a metade superior.

Tabela 4.16: Testes de hipótese entre configurações considerando F1. O símbolo - é utilizado para comparações desconsideradas. O símbolo $=$ representa igualdade estatística entre configurações consideradas. Os símbolos $\wedge \mathrm{e}<$ são utilizados para representar existência de diferença estatística entre os configurações consideradas e indicam, respectivamente, vantagem para a configuração da coluna e vantagem para a configuração da linha.

\begin{tabular}{llllll}
\hline & MSDR1 & MSDR1R2 & ISDR1 & ISDR1R2 & IPHT \\
\hline MSDR1 & - & $=$ & $=$ & $=$ & $<$ \\
MSDR1R2 & - & $=$ & $=$ & $<$ \\
ISDR1 & & & - & $=$ & $<$ \\
ISDR1R2 & & & & - & $<$ \\
IPHT & & & & & - \\
\hline
\end{tabular}

\section{Análise dos Resultados}

Os resultados nas Tabelas 4.14 e 4.15 indicam melhores resultados, em termos de $F 1$, por parte das configurações MSDR1R2 e ISDR1R2. A adição da restrição R2 aumentou o número de mudanças detectadas. Embora os algoritmos utilizando essa restrição também tenham sofrido um aumento no número de FPs, o aumento obtido no número de VPs foi significativo, aumentando assim o valor de F1 obtido. Além disso, pode-se observar que tanto MSDR1R2 quanto ISDR1R2 obtiveram menores atrasos médios quando comparados aos algoritmos utilizando apenas uma restrição (MSDR1 e ISDR1). O atraso para detecção quando incluímos a restrição $\mathrm{R} 2$ foi menor pois o tamanho da janela utilizada permitiu detectar mudanças antes de $\mathrm{R} 1$, i.e., antes que $\mathbb{H}_{t}(\cdot)>\tau$, nos casos em que $\mathbb{H}_{t}(\cdot)$ havia 
se tornado negativo. Como exemplo, considere a Figura 4.7 que representa a detecção de novidade para a sétima simulação utilizando as configurações MSDR1 e MSDR1R2, respectivamente. Observa-se pelas Figura 4.7 que a adição de R2 em MSDR1R2 induz a detecção de duas mudanças de comportamento não detectadas por MSDR1, representadas respectivamente pelos dois pontos verdes no gráfico próximos aos valores 240 e 480 no eixo x. Além disso, observa-se que a terceira mudança é detectada com menor atraso por MSDR1R2.

É importante ressaltar que o atraso observado pela restrição R2 é dependente do tamanho de intervalo utilizado, $l$. Quanto menor o valor de $l$, menor será o atraso para detecção de mudanças verdadeiras. Porém, maior será a incidência de FPs. Por outro lado, quanto maior o valor de $l$, o algoritmo se tornará mais conservador ao detectar mudanças, com consequente aumento no atraso para detecção e redução no número de FPs.

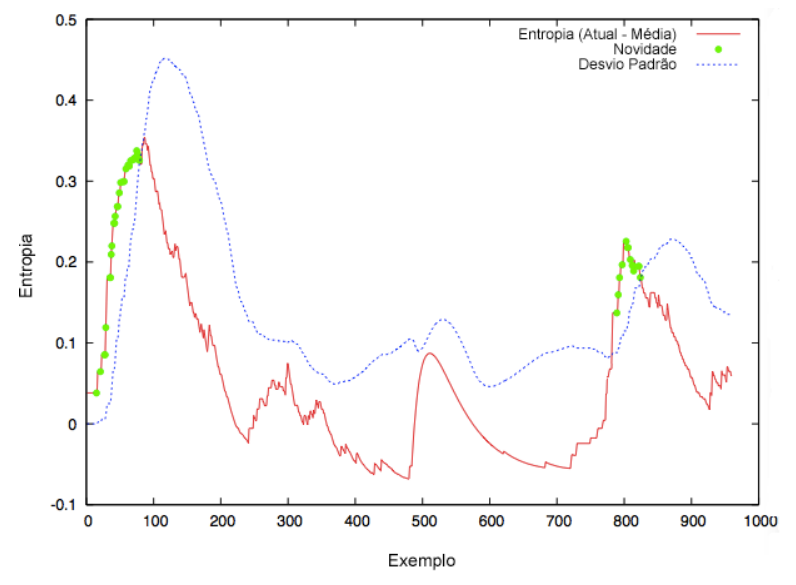

(a)

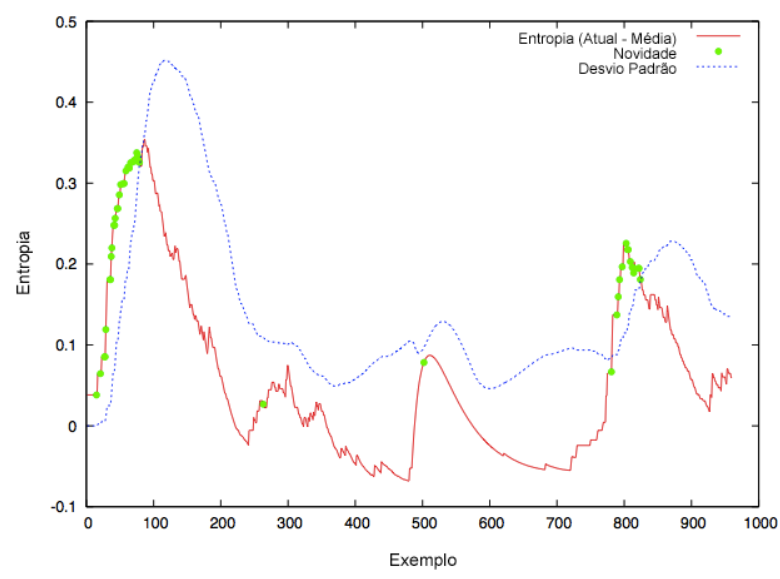

(b)

Figura 4.7: Variação de entropia, desvio padrão móvel e detecção de novidades para a sexta simulação: (a) utilizando MSDR1; (b) utilizando MSDR1R2.

Embora os resultados nas Tabelas 4.14 e 4.15 indiquem melhores resultados em termos de $F 1$ para as configurações MSDR1R2 e ISDR1R2 quando comparados às demais configurações, os testes de hipóteses indicaram diferença estatística significativa apenas entre essas configurações e IPHT. Os resultados obtidos por IPHT foram os piores observados entre todas as configurações do M-DBScan V2 tanto em termos de $F 1$ quanto em termos de atraso médio. Os resultados inferiores dessa abordagem podem ser explicados pelo limiar fixo utilizado pelo algoritmo PHT para detectar mudanças, enquanto que as demais configurações aqui estudadas utilizam um mecanismo de ajuste desse limiar no decorrer do tempo.

Como não há diferença estatística entre as configurações MSDR1, MSDR1R2, ISDR1 e ISDR1R2, concluiu-se que, para esses experimentos, a melhor configuração a ser utilizada foi ISDR1R2. Embora não seja observada diferença estatística significativa entre essa configuração e as demais citadas, ISDR1R2 obteve melhor F1 total que MSDR1 e ISDR1. Além disso, ISDR1R2 obteve resultado similar a MSDR1R2, com a vantagem de necessitar 
de menos ajustes de parâmetros. Por fim, ISDR1R2 foi uma das configurações com menor atraso médio observado, correspondendo a aproximadamente 8,5 minutos de jogo.

\subsubsection{Redução de Atraso para Detecção}

Embora os resultados apresentados na Seção 4.8.2 tenham mostrado que o algoritmo MDBScan V2, principalmente sob as configurações MSDR1R2 e ISDR1R2, conseguiu obter valores razoáveis em termos de $F 1$ no cenário de jogos estudado, para que sua aplicação prática seja viável ainda é necessário reduzir o atraso para detecções de mudanças. $O$ atraso é decorrente de uma série de fatores. A existência de um buffer de outliers na fase de microagrupamento para absorver pontos distintos introduz atraso para percepção de uma sequência de exemplos novos como novidades de fato. Dessa maneira, quanto maiores os valores dos parâmetros $\beta$ e $\mu$, mais tempo o detector de novidades levará para perceber alguma mudança, pois exemplos associados a micro-clusters outliers não são considerados no cálculo de entropia. O detector de novidades em si também introduz atrasos, uma vez que os parâmetros minNovelties da restrição $\mathrm{R} 1$ e $k$ da restrição $R 2$, representam um balanço entre atraso para detecção e ocorrência de FPs. Quanto menores os valores desses parâmetros, menos conservador será o detector de mudanças.

Porém é interessante lembrar que o algoritmo proposto utiliza uma janela deslizante de tamanho $l$, que é iniciada sempre que uma novidade do tipo R1 ou R2 é verificada. Essa janela tem por objetivo desconsiderar novidades decorrentes da mesma mudança de comportamento que ainda está em curso. Dessa forma, o mecanismo de janela é, por si só, um filtro de FPs. Portanto, visto que o mecanismo de janela já filtra FPs, e existe um número mínimo de novidades (minNovelties) que devem ocorrer para que uma mudança de comportamento seja aceita, hipotetiza-se que o filtro de outliers implementado na fase de microagrupamento é desnecessário e introduz atraso na detecção de mudanças que poderia ser evitado.

Assim, nesta seção, propõe-se uma nova versão para a fase de agrupamento do $M$ DBScan V2 onde não há buffer de outliers. A seguir, é apresentado o novo algoritmo de agrupamento. Em seguida, experimentos comparando o M-DBScan V2 com sua nova versão são apresentados, demonstrando a redução no atraso para detecção, sem perda de eficácia em detecção de mudanças.

\section{Modificação Proposta}

A nova versão do algoritmo de agrupamento utilizado é apresentada no Algoritmo 4.5. Com essa versão é a última apresentada nesta tese, ela será referenciada como MicroClustering DBScan* (M-DBScan*). Note que M-DBScan* consiste em uma modificação a partir da versão anterior (M-DBScan V2). A modificação realizada diz respeito à fase de microagrupamento somente e não interfere na forma como a fase de macroagrupamento é realizada. 


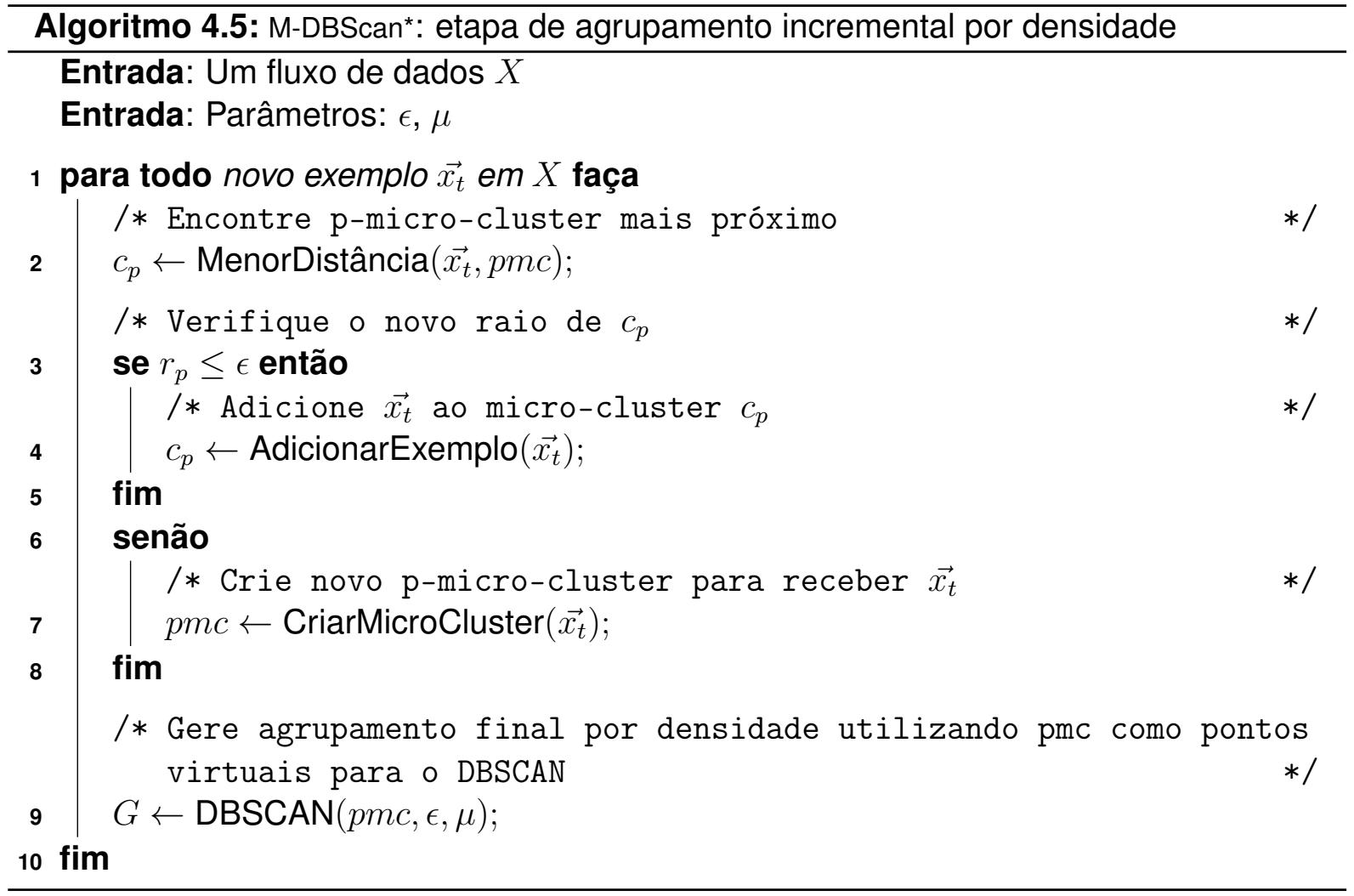

Os conceitos utilizados continuam os mesmos, com exceção de que, agora, não há mais o conceito de o-micro-cluster, somente existindo p-micro-clusters. A manutenção online de $p$-micro-clusters com a chegada de um novo exemplo $\overrightarrow{x_{t}}$ ocorre como segue.

1. Tente adicionar $\overrightarrow{x_{t}}$ ao seu $p$-micro-cluster $c_{p}$ mais próximo. Se $r_{p}$, o novo raio de $c_{p}$, for menor ou igual a $\epsilon, \overrightarrow{x_{t}}$ é inserido em $c_{p}$.

2. Caso contrário, crie um novo $p$-micro-cluster centrado em $p$, com peso inicial $w=1$, para receber $\overrightarrow{x_{t}}$.

Assim, se o novo exemplo $\overrightarrow{x_{t}}$ for um outlier, um novo $p$-micro-cluster será criado para recebê-lo, i.e., $\overrightarrow{x_{t}}$ não mais será filtrado por um o-micro-cluster. A hipótese levantada é que, mesmo sem o filtro implementado pelos o-micro-clusters, o algoritmo não sofrerá aumento no número de FPs detectados pois conta com o mecanismo subsequente de janela deslizante. Além disso, o atraso para detecção de mudanças será reduzido.

\section{Experimentos}

Para verificar se M-DBScan* reduz o atraso médio para detecção de mudanças, sem prejuízo em termos de $F 1$, todas as configurações (MSDR1, MSDR1R2, ISDR1, ISDR1R2 e IPHT) para detecção de mudança de comportamento foram novamente avaliadas. Todos os parâmetros utilizados na Seção 4.8 .2 foram mantidos. 
Também foram conduzidas as mesmas simulações, porém utilizando os algoritmos para detecção de mudança PHT e ADWIN, de modo a poder avaliar a qualidade dos resultados obtidos por M-DBScan*.

As implementações de PHT e ADWIN utilizadas consideram a aplicação desses algoritmos no cenário multidimensional, onde o algoritmo deve ser re-executado para cada dimensão. Neste trabalho optou-se por manter a mesma configuração de parâmetros em todas as dimensões. A saída final do algoritmo é, portanto, a união das mudanças detectadas em cada uma das dimensões. Na implementação utilizada neste trabalho, se uma mesma mudança for detectada no mesmo instante $t$ em mais de uma dimensão, essa mudança será considerada uma única vez.

O PHT utilizou $\delta_{P H T}=0,01$ e $\epsilon_{P H T}=100$. O algoritmo ADWIN necessita apenas do valor de confiança do teste estatístico $\delta_{A D W I N}$. O valor escolhido nesses experimentos foi $\delta_{A D W I N}=98 \%$.

Todos os parâmetros utilizados foram obtidos através de avaliações empíricas, de modo que os valores aqui apresentados são as configurações que resultaram em melhor desempenho de cada um dos algoritmos investigados.

\section{Resultados}

A Tabela 4.17 apresenta os valores de $F 1$ obtidos em cada simulação, para cada uma das configurações do algoritmo M-DBScan* avaliadas. Os valores de VP, FP e F1 totais para cada configuração, assim como os atrasos obtidos, são apresentados na Tabela 4.18.

Tabela 4.17: Valores de F1 obtidos por M-DBScan* em cada uma das simulações para cada configuração estudada.

\begin{tabular}{lrrrrr}
\hline Simulação & MSDR1 & MSDR1R2 & ISDR1 & ISDR1R2 & IPHT \\
\hline 1 & 1 & 0,86 & 1 & 0,86 & 0,86 \\
2 & 1 & 1 & 0,86 & 0,75 & 0,66 \\
3 & 1 & 0,86 & 0,86 & 0,75 & 1 \\
4 & 0,8 & 0,66 & 0,8 & 0,66 & 0,66 \\
5 & 0,8 & 0,66 & 0,8 & 0,66 & 0,4 \\
6 & 0,5 & 0,86 & 0,5 & 0,86 & 0,4 \\
7 & 0,8 & 1 & 1 & 1 & 0,66 \\
8 & 1 & 1 & 1 & 1 & 0,86 \\
9 & 1 & 1 & 1 & 1 & 0,86 \\
10 & 0,8 & 0,66 & 0,8 & 0,66 & 0,57 \\
11 & 0,5 & 0,8 & 0,8 & 0,8 & 0,4 \\
12 & 0,5 & 1 & 0,8 & 1 & 0,4 \\
13 & 1 & 0,86 & 1 & 0,86 & 0,75 \\
14 & 0,8 & 0,8 & 0,8 & 0,8 & 0,57 \\
15 & 1 & 1 & 1 & 1 & 0,66 \\
16 & 0,8 & 0,8 & 0,8 & 0,8 & 0,66 \\
17 & 0,4 & 0,4 & 0,5 & 0,4 & 0,33 \\
18 & 0,4 & 0,66 & 0,5 & 0,66 & 0,33 \\
19 & 0,5 & 0,5 & 0,5 & 0,5 & 0 \\
20 & 0 & 0,8 & 0 & 0,8 & 0 \\
21 & 0,5 & 0,5 & 0,5 & 0,5 & 0 \\
22 & 0,5 & 0,8 & 0 & 0,8 & 0 \\
23 & 0 & 0,8 & 0 & 0,8 & 0 \\
24 & 0 & 0,8 & 0 & 0,8 & 0 \\
\hline
\end{tabular}


Tabela 4.18: Valores de VP, FP e $F 1$ totais utilizando diferentes configurações do M-DBScan*. A última coluna contém os atrasos médios para detecção de mudança, em número de exemplos, e respectivos desvios padrão.

\begin{tabular}{lrrrr}
\hline & VP & FP & F1 Total & Atraso Médio \\
\hline MSDR1 & 41 & 2 & 0,71 & $12,46(12,81)$ \\
MSDR1R2 & 55 & 9 & 0,81 & $14,29(10,80)$ \\
ISDR1 & 43 & 2 & 0,73 & $15(12,52))$ \\
ISDR1R2 & 55 & 12 & 0,79 & $15,74(9,71)$ \\
IPHT & 35 & 34 & 0,50 & $49(15,23)$ \\
\hline
\end{tabular}

Os resultados na Tabela 4.17 foram comparados aos resultados obtidos por M-DBScan V2 (Tabela 4.14) por meio da aplicação de testes de hipótese aos valores de $F 1$ obtidos. Os testes realizados compararam M-DBScan V2 e M-DBScan* em uma mesma configuração, ou seja, o objetivo é comparar o desempenho obtido por ambas versões do algoritmo de acordo com cada configuração. Dessa forma, apenas comparações entre mesmas configurações são realizadas. A Tabela 4.19 contém os resultados dos testes de hipótese realizados.

Tabela 4.19: Testes de hipótese entre M-DBScan V2 e M-DBScan*, utilizando as mesmas configurações, de acordo com os valores de F1 obtidos. O símbolo - é utilizado para comparações desconsideradas. O símbolo = representa igualdade estatística entre configurações consideradas. Os símbolos $\wedge \mathrm{e}<$ são utilizados para representar existência de diferença estatística entre os configurações consideradas e indicam, respectivamente, vantagem para a configuração da coluna e vantagem para a configuração da linha.

\begin{tabular}{lrrrrr}
\hline & M-DBScan* MSDR1 & M-DBScan* MSDR1R2 & M-DBScan* ISDR1 & M-DBScan* ISDR1R2 & M-DBScan* IPHT \\
\hline M-DBScan V2 MSDR1 & $=$ & - & - & - & - \\
M-DBScan V2 MSDR1R2 & & - & - & - & - \\
M-DBScan V2 ISDR1 & & & - & - & - \\
M-DBScan V2 ISDR1R2 & & & & - \\
M-DBScan V2 IPHT & & & - \\
\hline
\end{tabular}

Para analisar o desempenho final obtido pelo algoritmo M-DBScan*, foram utilizados também os algoritmos PHT e ADWIN aplicados diretamente aos dados. A Tabela 4.20 apresenta os valores de F1 obtidos por esses algoritmos. Em seguida, a Tabela 4.21 apresenta os valores de VP, FP e F1 totais para os algoritmos PHT e ADWIN. Para facilitar a comparação, essa tabela apresenta novamente os resultados obtidos por M-DBScan* nas mesmas simulações. 
Tabela 4.20: F1 obtida pelos algoritmos PHT e ADWIN em cada um dos conjuntos de dados de FPS.

\begin{tabular}{lrr}
\hline Conjunto & PHT & ADWIN \\
\hline 1 & 0,46 & 0,22 \\
2 & 0,33 & 0,26 \\
3 & 0,4 & 0,24 \\
4 & 0,4 & 0,25 \\
5 & 0,5 & 0,25 \\
6 & 0,31 & 0,21 \\
7 & 0,4 & 0,22 \\
8 & 0,28 & 0,22 \\
9 & 0,375 & 0,22 \\
10 & 0,46 & 0,21 \\
11 & 0,28 & 0,23 \\
12 & 0,375 & 0,26 \\
13 & 0,33 & 0,26 \\
14 & 0,25 & 0,24 \\
15 & 0,33 & 0,21 \\
16 & 0,21 & 0,24 \\
17 & 0,54 & 0,21 \\
18 & 0,31 & 0,25 \\
19 & 0,57 & 0,19 \\
20 & 0,44 & 0,19 \\
21 & 0,28 & 0,23 \\
22 & 0,44 & 0,24 \\
23 & 0,54 & 0,21 \\
24 & 0,5 & 0,20 \\
\hline & &
\end{tabular}

Tabela 4.21: Valores de VP, FP e F1 totais obtidos por cada configuração do M-DBScan* e pelos algoritmos PHT e ADWIN. A última coluna contém os atrasos médios para detecção de mudança, em número de exemplos, e respectivos desvios padrão.

\begin{tabular}{lrrrr}
\hline & VP & FP & F1 & Atraso Médio \\
\hline MSDR1 & 41 & 2 & 0,71 & $12,46(12,81)$ \\
MSDR1R2 & 55 & 9 & 0,81 & $14,29(10,80)$ \\
ISDR1 & 43 & 2 & 0,73 & $15(12,52)$ \\
ISDR1R2 & 55 & 12 & 0,79 & $15,74(9,71)$ \\
IPHT & 35 & 34 & 0,50 & $49(15,23)$ \\
PHT & 59 & 183 & 0,37 & $36,93(28,5)$ \\
ADWIN & 72 & 490 & 0,23 & $5,65(4,34)$ \\
\hline
\end{tabular}


Foram também conduzidos testes de hipóteses comparando os resultados obtidos por cada um dos algoritmos utilizados. A Tabela 4.22 apresenta os resultados do teste de hipóteses em termos de $F 1$.

Tabela 4.22: Testes de hipótese entre as configurações de M-DBScan*, PHT e ADWIN, de acordo com os valores de $F 1$ obtidos. O símbolo - é utilizado para comparações desconsideradas. O símbolo = representa igualdade estatística entre configurações consideradas. Os símbolos $\wedge \mathrm{e}<$ são utilizados para representar existência de diferença estatística entre os configurações consideradas e indicam, respectivamente, vantagem para a configuração da coluna e vantagem para a configuração da linha.

\begin{tabular}{lrrrrrrr}
\hline & MSDR1 & MSDR1R2 & ISDR1 & ISDR1R2 & IPHT & PHT & ADWIN \\
\hline MSDR1 & - & $=$ & $=$ & $=$ & $<$ & $<$ & $<$ \\
MSDR1R2 & & - & $=$ & $=$ & $<$ & $<$ & $<$ \\
ISDR1 & & - & $=$ & $<$ & $<$ & $<$ \\
ISDR1R2 & & & & - & $<$ & $<$ & $<$ \\
IPHT & & & & & - & $=$ & $<$ \\
PHT & & & & & & - & $=$ \\
ADWIN & & & & & & & - \\
\hline
\end{tabular}

A Tabela 4.23 apresenta estatísticas relacionadas aos atrasos obtidos. Para cálculo dessas estatísticas foram considerados apenas os VPs. Em seguida, na Figura 4.8, podese observar os boxplots para os atrasos obtidos por cada algoritmo investigado.

Tabela 4.23: Estatísticas sobre atrasos para detecção de mudanças nas simulações de FPS: mínimo, primeiro quartil, mediana, média com desvio padrão, terceiro quartil e máximo.

\begin{tabular}{lrrrrrr}
\hline Algoritmo & Mínimo & Primeiro Quartil & Mediana & Média & Terceiro Quartil & Máximo \\
\hline MSDR1 & 5 & 7 & 10 & $12,46(12,81)$ & 12 & 86 \\
MSDR1R2 & 5 & 8 & 12 & $14,29(10,80)$ & 17 & 69 \\
ISDR1 & 6 & 11 & 13 & $15(12,52)$ & 15 & 85 \\
ISDR1R2 & 6 & 12 & 14 & $15,74(9,71)$ & 17 & 66 \\
IPHT & 29 & 37 & 46 & $49(15,23)$ & 59 & 92 \\
PHT & 7 & 15 & 27 & $36,93(28,5)$ & 41 & 111 \\
ADWIN & 1 & 2 & 5 & $5,65(4,34)$ & 7 & 18 \\
\hline
\end{tabular}

\section{Análise dos Resultados}

Os resultados expressos na Tabela 4.19 mostram que M-DBScan* alcançou resultados estatisticamente iguais àqueles obtidos por M-DBScan V2, i.e., a modificação proposta não 

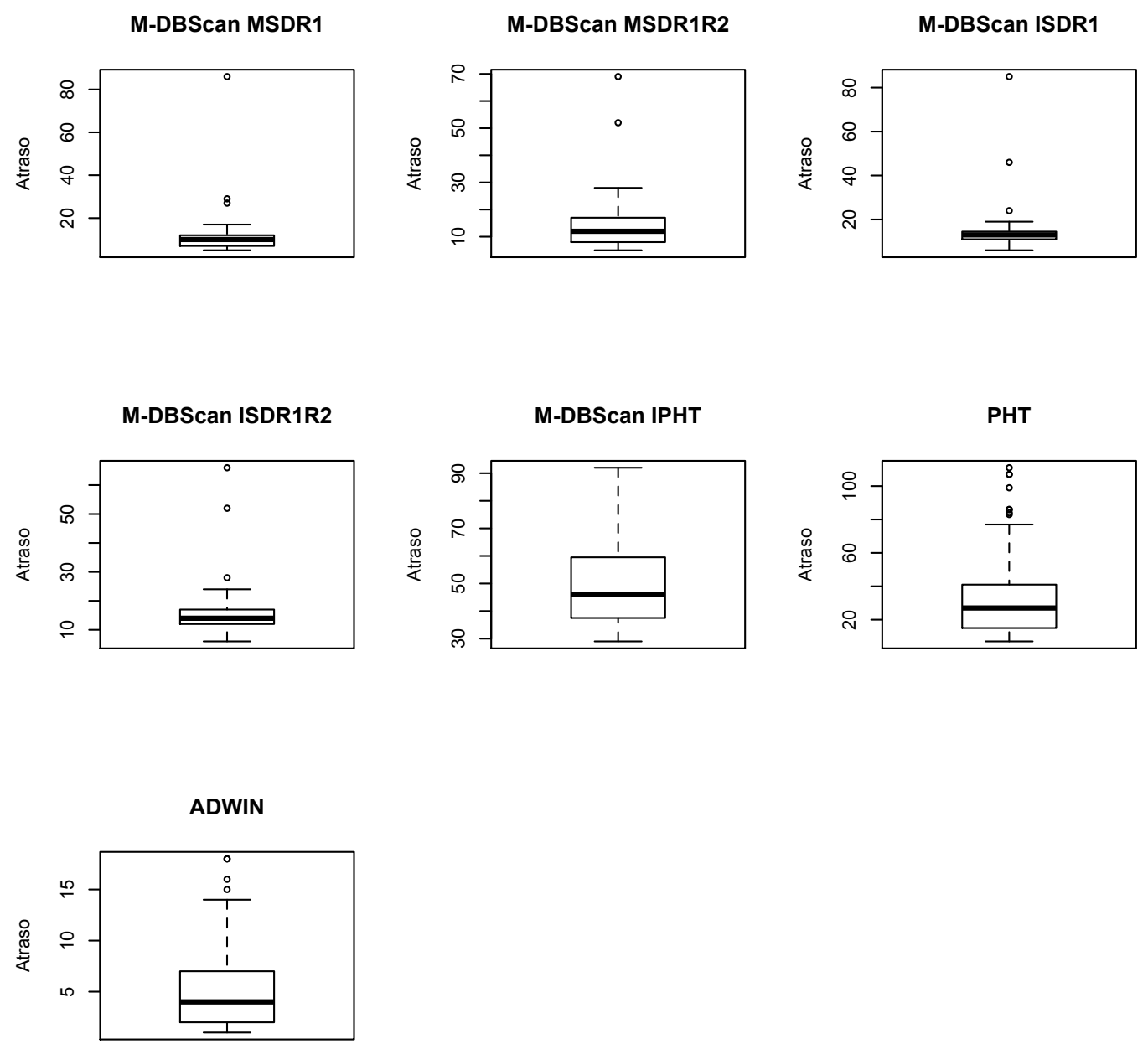

Figura 4.8: Boxplots para os atrasos obtidos nas simulações de FPS por cada um dos algoritmos investigados.

acarretou desempenho inferior do algoritmo em termos da capacidade de detecção de mudanças de comportamento. Isso é válido para todas as configurações avaliadas. Já em relação ao atraso, M-DBScan* apresentou melhores resultados do que M-DBScan V2, atingindo o objetivo proposto.

Esses resultados confirmam a hipótese de que a remoção do buffer de outliers de fato reduz 0 atraso médio para detecções de mudança, sem perda da capacidade de detecção correta de mudanças de comportamento. Dessa maneira, o buffer de outliers se torna desnecessário ao bom funcionamento do algoritmo, uma vez que, para se obter menor atraso, é necessário baixar ao mínimo possível os valores dos parâmetros $\beta$ e $\mu$, de modo que o-micro-clusters sejam promovidos à p-micro-clusters mais rapidamente. Entretanto, baixar esse limiar para valores muito pequenos representa, na prática, o mesmo que não utilizar o buffer de outliers.

A partir dos resultados na Tabela 4.18 notou-se que, novamente, as configurações de 
M-DBScan* com melhor desempenho em termos de F1 foram MSDR1R2 e ISDR1R2. Mais uma vez observou-se que a configuração IPHT não apresentou bons resultados quando comparada às demais configurações. Além disso, os resultados na Tabela 4.22 mostram que, de fato, M-DBScan* nas configurações MSDR1, MSDR1R2, ISDR1 e ISDR1R2 apresentou melhores resultados, em termos de $F 1$, do que os algoritmos PHT e ADWIN. O fato de quatro das configurações propostas neste trabalho para o algoritmo M-DBScan* apresentarem desempenho superior ao obtido por PHT e ADWIN se deve ao algoritmo M-DBScan* transformar uma série de exemplos multidimensionais em uma série unidimensional, por meio de sua estratégia de agrupamento e detecção de novidade através de medidas de entropia. Essa sequência pode ser vista como uma série temporal unidimensional que resume o comportamento de um sistema e, dessa forma, o problema de detectar mudanças de comportamento resume-se a uma única dimensão.

Por outro lado, tanto o algoritmo PHT quanto o ADWIN devem ser aplicados por dimensão. Assim, se uma mudança for detectada no mesmo instante de tempo $t$ em mais de uma dimensão, essa mudança será considerada apenas uma vez. Entretanto, se uma mudança for detectada no instante $t$ em uma dimensão e no instante $t+1$ em outra, então a mudança detectada no instante $t+1$ será contabilizada como um FP. Esse fato foi observado nos resultados de ambos os algoritmos, contribuindo para o elevado número de FPSs ocorridos. Para que isso não ocorra, seria necessário propor um mecanismo extra na fase de detecção de mudanças desses algoritmos.

Existe ainda um outro problema associado à estratégia implementada por PHT e ADWIN no cenário multidimensional: a definição dos valores de parâmetros a serem utilizados em cada dimensão. Nesse caso, existem duas opções: utilizar os mesmos valores em todas as dimensões ou utilizar valores distintos por dimensão. Neste trabalho, optou-se pela primeira opção. O problema com essa solução é que dimensões distintas podem necessitar de valores de parâmetros distintos. Entretanto, a estratégia alternativa de aplicar um limiar específico para cada dimensão também não é uma alternativa viável, pois ajustar um limiar distinto por dimensão é um problema bem mais difícil que ajustar um único limiar.

Em termos de atraso, todas as configurações de M-DBScan* utilizadas produziram atrasos parecidos, com exceção da configuração IPHT que produziu atrasos superiores às demais configurações. O atraso médio da configuração MSDR1R2, por exemplo, foi de 14.29 exemplos, o que equivale a, aproximadamente, 4 minutos de jogo. O algoritmo que apresentou o menor atraso médio para detecção foi o ADWIN. É importante comentar alguns dos resultados em termos de atraso obtidos por ADWIN. As estatísticas apresentadas na Tabela 4.23 consideram apenas os VPs detectados. O menor atraso observado para a detecção de um VP pelo algoritmo ADWIN foi igual a 1 exemplo. Esse resultado não é condizente com o esperado, mesmo quando consideramos a capacidade do ADWIN de detectar mudanças abruptas com baixo atraso (BIFET; GAVALDÀ, 2007). Analisando melhor estes resultados, observou-se que os VPs detectados com atraso inferior a 5 exemplos eram, 
na verdade, a detecção da mudança anterior de comportamento atrasada em uma das dimensões. Assim, essa detecção foi contabilizada como um VP por ter ocorrido, coincidentemente, ao mesmo tempo em que uma nova mudança se iniciava. Aproximadamente $30 \%$ dos VPs contabilizados pelo ADWIN recaíram nessa situação. Se não contabilizarmos esses VPs no total de detecções corretas do ADWIN, conclui-se que esse algoritmo detectou 48 das 72 mudanças ocorridas. Mesmo com essa consideração, observou-se que, em média, o atraso do ADWIN foi de aproximadamente 6 exemplos, o que o mantém como o algoritmo com menor atraso médio observado nesses experimentos.

A partir dos resultados observados para as configurações do algoritmo M-DBScan*, concluiu-se que a configuração ISDR1R2 é a mais adequada para detectar mudanças de comportamento em jogos, pois necessita de menos parametrização do que a configuração MSDR1R2, sem perda significativa em termos de $F 1$ e do atraso para detecção de mudanças. Essa conclusão está de acordo com a obtida na Seção 4.8.2.

\subsubsection{Aplicação em Dados de RTS}

Além dos resultados apresentados neste capítulo utilizando um jogo do gênero FPS, aplicouse o algoritmo M-DBScan* em dados de um jogo do gênero RTS. Esses dados foram coletados por Weber e Mateas (2009) e são relativos ao jogo Starcraft. Nesse jogo, o jogador pode escolher representar uma entre três raças, sejam elas: Terran, Protoss e Zerg. Os autores que coletaram esses dados procederam da seguinte maneira. Partidas entre dois jogadores, cada qual representando uma raça, foram realizadas. Cada jogador podia utilizar uma entre um conjunto de estratégias associadas com a sua raça. O jogador deveria manter a estratégia escolhida durante toda a partida. Ao final de uma partida, as estatísticas coletadas foram transformadas em um exemplo que representa um sumário da partida entre jogador $A$ e jogador $B$, onde jogador $A$ utilizou a estratégia $A_{i}$. A partir de cada uma das partidas foram então criados conjuntos de dados, com cada exemplo representando uma partida e contendo um rótulo de classe que indica a estratégia utilizada.

Embora esses exemplos representem uma partida já finalizada, esses dados foram utilizados neste trabalho com o intuito de verificar se o algoritmo M-DBScan* é aplicável na tarefa de reconhecer se um jogador altera sua estratégia entre partidas. Assim, nesta seção, são apresentados os dados selecionados para realização de experimentos utilizando o M-DBScan*, em todas as configurações de detecção de mudança estudadas neste trabaIho. Além disso, os algoritmos PHT e ADWIN foram novamente utilizados para analisar de forma comparativa o desempenho do M-DBScan*.

\section{Dados Utilizados}

Os dados gerados por Weber e Mateas (2009) foram utilizados para criação de 12 novos conjuntos de dados. Cada conjunto de dados possui exemplos de partidas entre dois joga- 
dores, $A$ e $B$, cada qual representando uma raça. Cada conjunto possui 3 mudanças de comportamento. Uma mudança de comportamento é representada por uma mudança na estratégia utilizada pelo jogador $A$. O jogador $B$ nunca muda sua estratégia. A Tabela 4.24 sumariza as características de cada conjunto criado. A coluna \#Nome representa o nome do conjunto de dados e indica as raças dos jogadores $A$ e $B$ e a ordem de estratégias utilizadas pelo jogador $A$. Por exemplo, o conjunto TP123 contém dados de um jogador $A$ utilizando a raça Terran contra um jogador $B$ utilizando a raça Protoss, onde $A$ alterna entre três estratégias com índices 1, 2 e 3 nesta ordem. A coluna \#Ex contém o número de exemplos no conjunto, enquanto que a coluna \#Dim apresenta o número de dimensões de cada exemplo. O número de estratégias utilizadas pelo jogador $A$ é expresso na coluna \#Estratégias. Já o número de exemplos pertencentes a cada uma dessas estratégias é apresentado na coluna \#Ex. por Estratégia.

Tabela 4.24: Características dos conjuntos de dados de RTS.

\begin{tabular}{lrrrr}
\hline Nome & \#Ex & \#Dim & \#Estratégias & \#Ex. por Estratégia \\
\hline TP123 & 600 & 51 & 3 & 200 \\
TP132 & 600 & 51 & 3 & 200 \\
TP213 & 600 & 51 & 3 & 200 \\
TP231 & 600 & 51 & 3 & 200 \\
TP312 & 600 & 51 & 3 & 200 \\
TP321 & 600 & 51 & 3 & 200 \\
ZT123 & 540 & 48 & 3 & 180 \\
ZT132 & 540 & 48 & 3 & 180 \\
ZT213 & 540 & 48 & 3 & 180 \\
ZT231 & 540 & 48 & 3 & 180 \\
ZT312 & 540 & 48 & 3 & 180 \\
ZT321 & 540 & 48 & 3 & 180 \\
\hline
\end{tabular}

Em todos os conjuntos criados, foram removidos o rótulo de classe contido nos exemplos originais. Além disso, todos os exemplos foram normalizados no intervalo $[0,1]$. Essa normalização se fez necessária, pois ao criar os conjuntos originais de dados, os autores tinham objetivos distintos dos avaliados neste trabalho e, portanto, utilizaram atributos com escalas bastante distintas, o que prejudica diversas estratégias de agrupamento de dados. Estratégias para normalização de fluxos são motivo de investigação na área de MFCD. Entretanto, este tema está fora do escopo de pesquisa deste trabalho e não será investigado no decorrer desta tese.

\section{Experimentos}

Para avaliar o desempenho do algoritmo M-DBScan* nos dados de RTS, novos experimentos foram conduzidos utilizando as cinco possíveis configurações do algoritmo. As configurações do M-DBScan* utilizadas foram: 
1. Desvio Padrão Móvel com Restrição R1(MSDR1): essa configuração utiliza o desvio padrão móvel para definir $\tau$ e considera apenas R1 para diferenciar entre eventos normais e novidades. Os valores de parâmetros utilizados foram: $\eta_{s}=0,005, \gamma=$ $0,05, \delta=0,03, \theta=2, k=10$ e minNovelties $=2$;

2. Desvio Padrão Móvel com Restrições R1 e R2 (MSDR1R2): essa configuração é a mesma que MSDR1, exceto que considera tanto a restrição do tipo R1 quanto R2 para diferenciar entre eventos normais e novidades. Os valores de parâmetros utilizados foram: $\eta_{s}=0,005, \gamma=0,05, \delta=0,03, \theta=2, k=10, l=15$ e minNovelties $=2$;

3. Desvio Padrão Incremental com Restrição R1 (ISDR1): essa configuração utiliza o desvio padrão incremental para definir $\tau$ e considera apenas $\mathrm{R} 1$ para diferenciar entre eventos normais e novidades. Os valores de parâmetros utilizados foram: $\eta_{s}=0,005$, $\gamma=0,05, \theta=1, k=10$ e e minNovelties $=2$;

4. Desvio Padrão Incremental com Restrições R1 e R2 (ISDR1R2): essa configuração é a mesma que ISDR1, exceto que considera tanto a restrição do tipo R1 quanto R2 para diferenciar entre eventos normais e novidades. Os valores de parâmetros utilizados foram: $\eta_{s}=0,005, \gamma=0,05, \theta=1, k=10, l=15$ e minNovelties $=2$.

5. Utilização de teste PHT (IPHT): essa configuração utiliza o algoritmo PHT aplicado aos valores de entropia para definir mudanças de comportamento. Os valores de parâmetros utilizados foram: $\eta_{s}=0,005, \delta_{P H T}=0,01$ e $\epsilon_{P H T}=10$.

A fase de agrupamento do M-DBScan* é a mesma, independente da configuração acima escolhida. Portanto, os parâmetros correspondentes a fase de agrupamento do algoritmo são os mesmos para todas as configurações utilizadas. Os valores adotados nesses experimentos foram: $\mu=10$ e $\epsilon=0,6$.

Foram conduzidos experimentos utilizando cada uma das cinco configurações acima. Os resultados para cada uma das cinco configurações foram avaliados em termos da $F 1$ obtida por cada algoritmo em cada conjunto de dados, além da $F 1$ total para cada algoritmo e do atraso para detecção de mudanças. Além disso, foram também avaliados o desempenho em termos de $F 1$, nesses conjuntos de dados, dos algoritmos PHT e ADWIN, de modo a poder comparar os resultados. O PHT aplicado diretamente aos dados utilizou, para os 6 primeiros conjuntos de dados, $\delta_{P H T}=0,02$ e $\epsilon_{P H T}=13$. Para os 6 conjuntos restantes, os valores utilizados foram $\delta_{P H T}=0,03$ e $\epsilon_{P H T}=11$. O nível de confiança empregado pelo algoritmo ADWIN foi de $\delta_{A D W I N}=98 \%$.

Todos os parâmetros utilizados foram obtidos através de avaliações empíricas, de modo que os valores aqui apresentados são as configurações que resultaram em melhor desempenho de cada um dos algoritmos investigados. 
O objetivo desses experimentos foi verificar se: o algoritmo M-DBScan* é aplicável a dados de um gênero de jogo diferente, mesmo que esses dados não tenham sido coletados de modo a favorecer um melhor desempenho do algoritmo; alguma das configurações do M-DBScan* é mais favorável do que as demais nos dados utilizados; verificar se o algoritmo proposto neste trabalho, M-DBScan*, é mais favorável para detectar mudanças de comportamento nos dados utilizados do que as estratégias implementadas por PHT e ADWIN.

\section{Resultados}

A Tabela 4.25 apresenta os valores de $F 1$ obtidos em cada conjunto de dados, para cada uma das configurações do algoritmo M-DBScan* avaliadas e para os algoritmos PHT e ADWIN. Os valores de VP, FP e F1 totais são apresentados na Tabela 4.26.

Tabela 4.25: Valores de F1 obtidos em cada um dos conjuntos de dados de RTS utilizados para cada configuração estudada de M-DBScan* e para os algoritmos PHT e ADWIN.

\begin{tabular}{lrrrrrrr}
\hline Conjunto & MSDR1 & MSDR1R2 & ISDR1 & ISDR1R2 & IPHT & PHT & ADWIN \\
\hline TP123 & 0.8 & 0,66 & 0,8 & 0,57 & 0 & 0,66 & 0,33 \\
TP132 & 0.66 & 0,5 & 0,5 & 0,4 & 0,66 & 0,66 & 0,66 \\
TP213 & 0.5 & 0,8 & 0,5 & 0,66 & 0 & 0,4 & 0,28 \\
TP231 & 0,5 & 0,5 & 0,66 & 0,66 & 0,66 & 0,8 & 0,33 \\
TP312 & 0 & 0 & 0 & 0 & 0 & 0 & 0,66 \\
TP321 & 0 & 0,5 & 0 & 0,5 & 0 & 0 & 0,33 \\
ZT123 & 1 & 1 & 0,66 & 0,66 & 0,5 & 0,5 & 0,44 \\
ZT132 & 0,66 & 0,66 & 0,66 & 0,66 & 0,5 & 0 & 0,28 \\
ZT213 & 1 & 0,80 & 0,66 & 1 & 0,5 & 0,66 & 0,33 \\
ZT231 & 1 & 1 & 0,66 & 1 & 0,5 & 0,66 & 0,33 \\
ZT312 & 0 & 0,66 & 0 & 0,66 & 0 & 0,5 & 0,4 \\
ZT321 & 0 & 0,66 & 0 & 0,66 & 0 & 0 & 0,44 \\
\hline
\end{tabular}

Tabela 4.26: Valores de VP, FP e F1 totais obtidos nos conjuntos de RTS por cada configuração do M-DBScan* e pelos algoritmos PHT e ADWIN. A última coluna contém os atrasos médios para detecção de mudança, em número de exemplos, e respectivos desvios padrão.

\begin{tabular}{lrrrr}
\hline & VP & FP & F1 & Atraso Médio \\
\hline MSDR1 & 12 & 4 & 0,60 & $24,58(15,32)$ \\
MSDR1R2 & 16 & 7 & 0,68 & $24(13,48)$ \\
ISDR1 & 9 & 3 & 0,49 & $23,33(8,81)$ \\
ISDR1R2 & 15 & 8 & 0,65 & $22,6(9,73)$ \\
IPHT & 6 & 8 & 0,32 & $64,33(19,46)$ \\
PHT & 9 & 10 & 0,42 & $65,10(24,69)$ \\
ADWIN & 16 & 39 & 0,40 & $57,93(26,15)$ \\
\hline
\end{tabular}

Novamente foram conduzidos testes de hipótese para verificar a existência de diferenças estatísticas entre os resultados. A Tabela 4.27 apresenta os resultados dos testes em termos de F1. 
Tabela 4.27: Testes de hipótese entre as configurações de M-DBScan*, PHT e ADWIN, de acordo com os valores de F1 obtidos. O símbolo - é utilizado para comparações desconsideradas. $O$ símbolo $=$ representa igualdade estatística entre configurações consideradas. Os símbolos $\wedge \mathrm{e}<$ são utilizados para representar existência de diferença estatística entre os configurações consideradas e indicam, respectivamente, vantagem para a configuração da coluna e vantagem para a configuração da linha.

\begin{tabular}{lrrrrrrr}
\hline & MSDR1 & MSDR1R2 & ISDR1 & ISDR1R2 & IPHT & PHT & ADWIN \\
\hline MSDR1 & - & $=$ & $=$ & $=$ & $=$ & $=$ & $=$ \\
MSDR1R2 & & - & $=$ & $=$ & $<$ & $=$ & $=$ \\
ISDR1 & & - & $=$ & $=$ & $=$ & $=$ \\
ISDR1R2 & & & - & $<$ & $=$ & $=$ \\
IPHT & & & & & - & $=$ & $=$ \\
PHT & & & & & & - & $=$ \\
ADWIN & & & & & & & - \\
\hline
\end{tabular}

A Tabela 4.28 apresenta estatísticas relacionadas aos atrasos obtidos. Para cálculo dessas estatísticas foram considerados apenas os VPs. Em seguida, na Figura 4.9, podese observar os boxplots para os atrasos obtidos por cada algoritmo investigado.

Tabela 4.28: Estatísticas sobre atrasos para detecção de mudanças nos conjuntos de RTS: mínimo, primeiro quartil, mediana, média com desvio padrão, terceiro quartil e máximo.

\begin{tabular}{lrrrrrr}
\hline Algoritmo & Mínimo & Primeiro Quartil & Mediana & Média & Terceiro Quartil & Máximo \\
\hline MSDR1 & 8 & 17 & 21 & $24,58(15,32)$ & 28 & 63 \\
MSDR1R2 & 8 & 16 & 21 & $24(13,48)$ & 30 & 63 \\
ISDR1 & 10 & 18 & 20 & $23,33(8,81)$ & 32 & 36 \\
ISDR1R2 & 10 & 16 & 18 & $22,6(9,73)$ & 28 & 48 \\
IPHT & 45 & 48 & 62 & $64,33(19,46)$ & 74 & 95 \\
PHT & 27 & 46 & 74 & $65,10(24,69)$ & 82 & 97 \\
ADWIN & 3 & 42 & 57 & $57,93(26,15)$ & 80 & 92 \\
\hline
\end{tabular}

\section{Análise dos Resultados}

Os resultados dos testes estatísticos apresentados na Tabela 4.27 não indicaram diferença entre os resultados obtidos pelas configurações MSDR1, MSDR1R2, ISDR1e ISDR1R2 de M-DBScan*. Entretanto, houve diferença significativa entre os resultados dessas configurações e IPHT, com essa última obtendo o pior desempenho em termos de $F 1$. Como não foi observada diferença entre os resultados de MSDR1R2 e ISDR1R2, concluiu-se que ISDR1R2 foi a configuração mais adequada para detecção de mudanças nos experimentos realizados, pois essa utiliza um parâmetro a menos que MSDR1R2. Essa conclusão está de acordo com os resultados observados nas simulações de FPS.

Também não foi observada diferença estatística entre os resultados alcançados por MDBScan* nas configurações MSDR1, MSDR1R2, ISDR1e ISDR1R2 quando comparado aos 

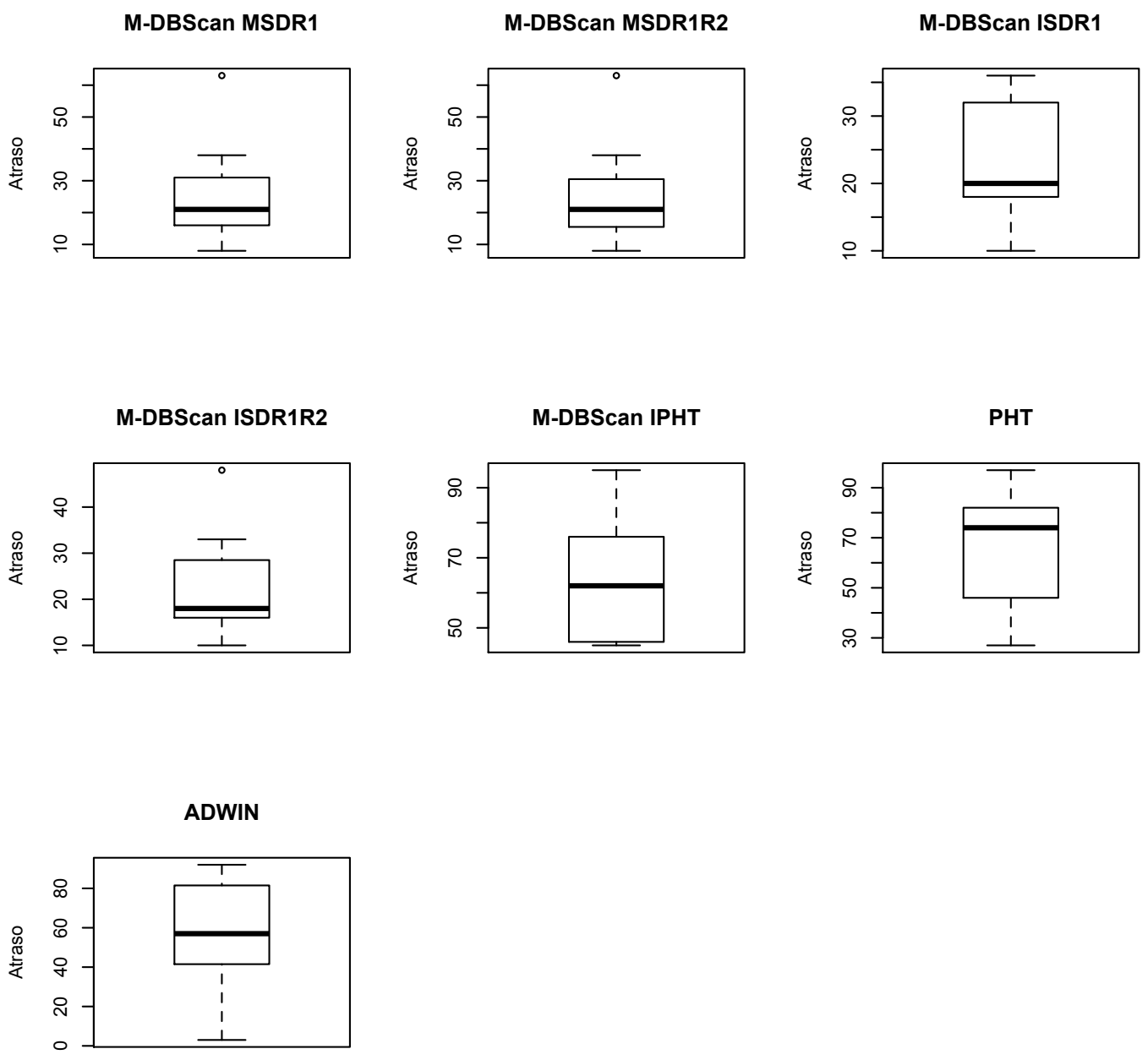

Figura 4.9: Boxplots para os atrasos obtidos nos conjuntos de RTS por cada um dos algoritmos investigados.

algoritmos PHT e ADWIN. Uma explicação para os testes não terem indicado uma diferença significativa entre as médias está no tamanho da amostra utilizada, que contém apenas doze valores para cada algoritmo estudado. Entretanto, as configurações do algoritmo $\mathrm{M}$ DBScan* obtiveram melhores resultados para a medida $F 1$, principalmente devido a baixa taxa de VPs do PHT e a elevada taxa de FPs do ADWIN. Com relação aos resultados de PHT e ADWIN, as mesmas conclusões obtidas nas simulações com o FPS UT2004 foram novamente observadas.

Quando comparados aos resultados obtidos nas simulações de FPS, observa-se que M-DBScan* não alcançou o mesmo desempenho nos dados de RTS estudados. Isso ocorreu porque esses dados foram criados com um objetivo totalmente distinto do objetivo deste trabalho. É importante ressaltar, a partir desses resultados, a importância da escolha dos atributos a serem considerados para formação de exemplos a serem processados pelo $\mathrm{M}$ DBScan*. Alguns atributos capturam melhor o comportamento de um jogador do que outros 
e, portanto, uma escolha mais acertada sobre quais conjuntos de atributos utilizar leva a uma melhora no desempenho final do algoritmo. Essa escolha pode ser feita, por exemplo, através da aplicação de conhecimento de domínio de projetistas de jogos. Entretanto, mesmo com essa limitação, o algoritmo ainda foi capaz de detectar uma boa parte das mudanças de comportamento nos dados de RTS.

Em termos de atraso para detecção, os resultados indicaram menores atrasos observados nas configurações MSDR1, MSDR1R2, ISDR1 e ISDR1R2 de M-DBScan* quando comparados à configuração IPHT e aos algoritmos PHT e ADWIN. Para a configuração ISDR1R2, por exemplo, observou-se uma atraso médio igual a 22,6 exemplos, equivalendo a, aproximadamente, 23 partidas realizadas.

\subsection{Considerações Finais}

Neste capítulo foi apresentado o algoritmo incremental M-DBScan* para detecção de mudanças de comportamento em fluxos de dados. O objetivo final era aplicar esse algoritmo à dados provenientes de um jogo comercial de modo a ser capaz de informar sobre mudanças comportamentais de um jogador durante sua interação com o software de jogo. Assim, este algoritmo considera todos os requisitos para detecção de mudanças relativos ao domínio dos jogos computacionais: trabalha com dados multidimensionais, não realiza suposições prévias a respeito dos dados e, finalmente, considera uma sequência de eventos novos para detecção de mudanças de comportamento.

Por meio de simulações realizadas no FPS UT2004 pôde-se observar que o algoritmo proposto apresentou bons resultados em termos de detecção de mudanças, principalmente se considerar o fato de que $3 / 4$ dos comportamentos implementados eram bastante similares. Várias configurações do detector de novidades foram avaliadas e concluiu-se que as configurações MSDR1R2 e ISDR1R2 foram as que obtiveram melhores desempenhos, em termos da medida $F 1$.

Quando comparado com os algoritmos PHT e ADWIN, M-DBScan* ISDR1R2 obteve desempenho consideravelmente superior em termos de $F 1$. O melhor desempenho de MDBScan* reside no fato de esse algoritmo transformar os dados originais, multidimensionais, em uma série unidimensional de valores de entropia. Em seguida, o algoritmo monitora essa série em busca de alterações que possam ser decorrentes de uma mudança de comportamento presente nos dados originais. Essa transformação permite que a decisão entre comportamento normal e comportamento novo seja tomada em apenas uma dimensão, ao contrário dos demais algoritmos investigados.

Com relação aos atrasos para detecção de mudanças, o algoritmo com menor atraso médio foi o ADWIN. Entretanto, esse também foi o algoritmo mais influenciado pela ocorrência de FPs.

Como os testes estatísticos realizados não apontaram diferenças entre as duas melho- 
res configurações de M-DBScan* (MSDR1R2 e ISDR1R2) e, como os atrasos observados por essas configurações são bastante parecidos, concluiu-se que a configuração mais adequada nesses experimentos foi ISDR1R2, por necessitar de menos parametrização.

Nos conjuntos de dados do RTS Starcraft observou-se um desempenho inferior do algoritmo M-DBScan*, independente de configuração, quando comparado aos resultados obtidos nos dados de FPS. Isso ocorreu porque esses dados foram criados por outros pesquisadores com um objetivo totalmente distinto do objetivo deste trabalho. Esses resultados apontam para a necessidade de se escolher atributos adequados para conseguir modelar as características de um jogador. Apesar disso, o M-DBScan* ainda foi capaz de detectar aproximadamente $67 \%$ das mudanças na configuração ISDR1R2.

Novamente observou-se um melhor desempenho em termos de $F 1$ por parte do MDBScan* ISDR1R2 quando comparado aos algoritmos PHT e ADWIN. Além disso, o M-DBScan* apresentou os menores atrasos para detecção de mudanças entre todos os algoritmos investigados.

Da mesma forma que nos experimentos com o FPS UT2004, concluiu-se que a configuração ISDR1R2 foi a mais adequada para o algoritmo M-DBScan*. 


\section{WSE: Uma Abordagem Baseada em Janelas de Tempo para Detecção de Mudanças de Comportamento}

\subsection{Considerações Iniciais}

Uma possível maneira de se detectar mudanças no comportamento de um fluxo de dados é realizar comparações entre duas janelas, cada qual contendo porções de dados consecutivas do fluxo. Ao utilizar janelas de dados, uma medida de comparação entre os dados presentes em cada janela deve ser definida. A partir do monitoramento dessa medida, é possível indicar se há uma mudança ocorrendo ou não nos dados que chegam no fluxo. Uma possível medida de comparação entre janelas é a diferença entre as médias observadas dos valores em cada janela. Essa é a estratégia empregada, por exemplo, pelo algoritmo para deteç̧ão de mudanças ADWIN (BIFET; GAVALDÀ, 2007). A abordagem utilizando janelas naturalmente descarta outliers que possam ocorrer no fluxo de dados.

Neste capítulo será abordada uma nova estratégia para detectar mudanças de comportamento em um fluxo de dados utilizando janelas, com o objetivo de detectar mudanças de comportamento em jogos. $\mathrm{O}$ algoritmo proposto é baseado na utilização de janelas fixas de dados, a partir das quais são gerados espectrogramas. Um espectrograma é gerado a partir de uma transformação dos dados para um novo domínio e é, portanto, livre de suposições prévias a respeito dos dados. Os espectrogramas gerados para duas janelas consecutivas são, em seguida, comparados por uma medida de similaridade. A partir 
dessa medida, uma abordagem para deteção de mudança de comportamento é definida.

Este capítulo está organizado como segue. Inicialmente, na Seção 5.2, é realizada uma breve introdução ao conceito de espectrograma e como ele pode ser gerado. A Seção 5.3 descreve como espectrogramas podem ser utilizados para diferenciar entre comportamentos e, em seguida, define a primeira versão do algoritmo para detecção de mudança de comportamento denominado de Windowing Specgram (WS) . Na Seção 5.4 são apresentados os primeiros experimentos com o algoritmo ws no domínio dos jogos computacionais. A partir dos resultados obtidos, duas modificações de WS, denominadas respectivamente de Windowing Specgram Extended (WSE) e Windowing Specgram Extended with PHT (WSE-PHT), são propostas na Seção 5.5, em uma tentativa de melhorar o desempenho da abordagem ws especificamente para os dados de jogos. Os experimentos adicionais avaliando o desempenho de WSE e WSE-PHT são apresentados na Seção 5.6, assim como os resultados obtidos e comparação com outros algoritmos para detecção de mudança de comportamento. Por fim, na Seção 5.7, são apresentadas as considerações finais deste capítulo.

\subsection{Geração de Espectrogramas}

Um espectrograma (HAYKIN, 1991) é uma representação de um espectro de frequências no tempo. O formato mais comum de um espectrograma é um gráfico em duas dimensões onde, no eixo horizontal, representa-se o tempo, enquanto que no eixo vertical representamse as frequências. Uma terceira dimensão, indicando a amplitude de uma dada frequência em um dado instante de tempo, é representada pela intensidade das cores com que os pontos no gráfico são apresentados. Como exemplo, a Figura 5.1 apresenta um espectrograma que foi gerado a partir de uma onda seno oscilando em frequência de $440 \mathrm{~Hz}$.

Uma das maneiras de se gerar um espectrograma é aplicar a Discrete Fourier Transform (DFT) (BRACEWELL, 2000; BOASHASH, 2003; JAMES, 2011) ao sinal. A terminologia sinal vem da área de processamento de sinais, porém é bastante fácil relacionar um sinal, que é representado por uma sequência de valores no tempo, com um fluxo de dados unidimensional. Nesse caso, o exemplo chegando no instante de tempo $t$ pode ser visto como uma observação do sinal no instante $t$.

O processo de geração de um espectrograma divide o sinal em intervalos. A DFT é aplicada a cada intervalo, transformando o sinal de seu domínio original para um domínio de frequências.

A DFT para uma sequência de valores $\left\{x_{n}\right\}_{n=0}^{N-1}$, na forma $x_{0}, \ldots, x_{N-1}$, é dada pelos coeficientes $X_{k}$, como na Equação 5.1.

$$
\operatorname{DFT}\left(\left\{x_{n}\right\}_{n=0}^{N-1}\right)=\left\{X_{k}\right\}_{k=0}^{N-1}=X_{0}, \ldots, X_{N-1}
$$




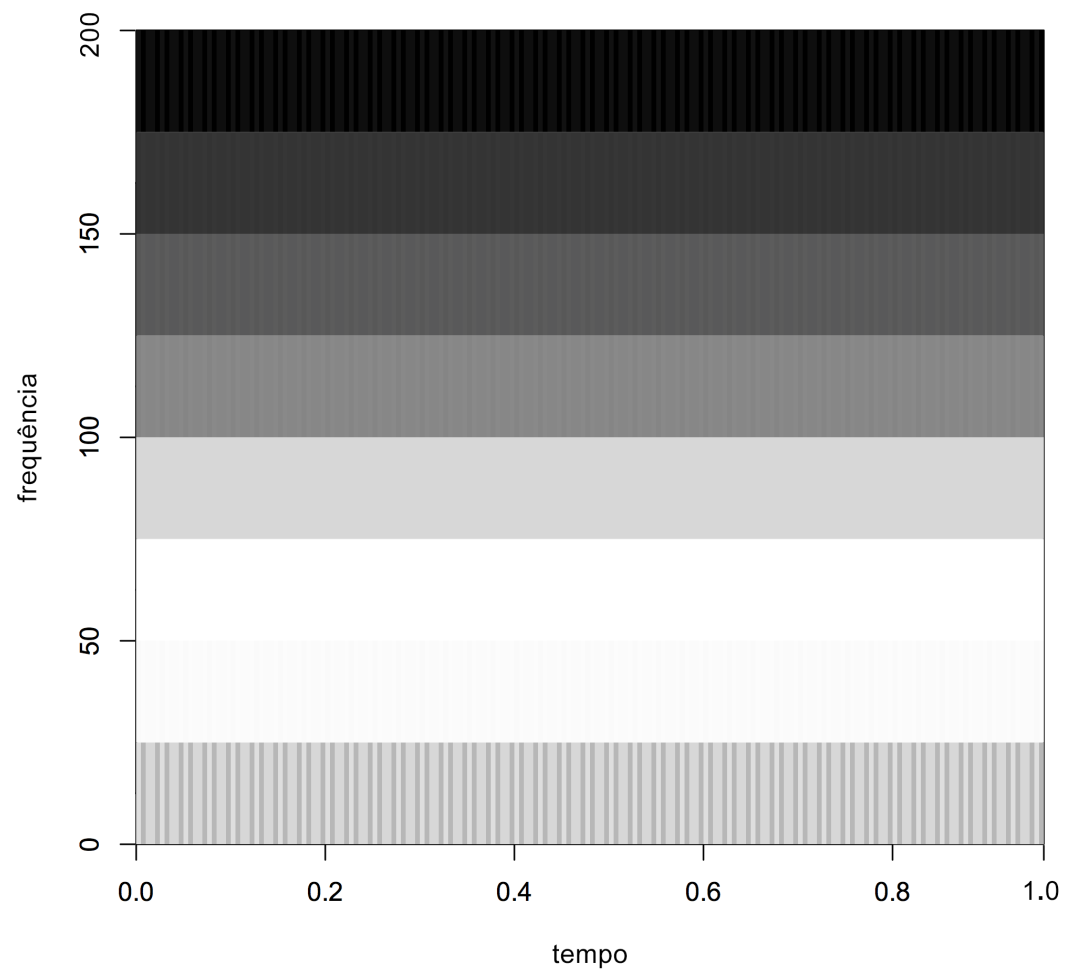

Figura 5.1: Espectrograma gerado a partir de onda seno com frequência de $440 \mathrm{~Hz}$.

Os coeficientes $\left\{X_{k}\right\}_{k=0}^{N-1}$ são conhecidos como coeficientes de Fourier e cada $X_{k}$ é obtido como na Equação 5.2.

$$
X_{k}=\sum_{n=0}^{N-1} x_{n} \cdot e^{-i\left(\frac{2 \pi k n}{N}\right)}
$$

Entretanto, calcular a DFT de um sinal diretamente a partir da definição acima resulta em um algoritmo de complexidade $O\left(n^{2}\right)$, onde $n$ é o número de observações, tornandose impraticável em muitas aplicações reais. Por isso, utiliza-se um algoritmo denominado Fast Fourier Transform (FFT) (BRIGHAM, 2002) para o cálculo da DFT. O algoritmo FFT utiliza uma estratégia de divisão e conquista de modo a realizar o cálculo da DFT com uma complexidade $O(n \cdot \log (n))$.

Para gerar o espectrograma, a magnitude dos coeficientes de Fourier é utilizada. Observe que, como explicado anteriormente, para obter o espectrograma completo de um sinal é necessário aplicar a DFT para cada um dos intervalos em que os dados foram divididos.

Alguns parâmetros influenciam o espectrograma a ser gerado. Esses parâmetros controlam como os dados serão divididos em intervalos, assim como a frequência máxima que pode ser representada em um dado espectrograma. O primeiro parâmetro é a frequência de amostragem, ou Sampling Rate, que define o número de observações por segundo. O 
segundo é o tamanho da janela da DFT, ou Frame Size, que define qual será o tamanho da janela de dados passados para a DFT. Ou seja, o Frame Size é o tamanho do intervalo em que dividimos os dados, de modo que a DFT seja aplicada a cada intervalo gerado.

O parâmetro Sampling Rate é utilizado para obter o intervalo de frequências do espectrograma (eixo y no gráfico). O espectrograma representa frequências no intervalo de 1 $\mathrm{Hz}$ a um valor de frequência denominado Frequência Nyquist. A Frequência Nyquist representa a máxima frequência que pode ser representada a partir de um dado valor de Sampling Rate e é definida na Equação 5.3.

$$
\text { Frequência Nyquist }=\frac{\text { Sampling Rate }}{2}
$$

O valor de Frame Size também é utilizado para definir o número de intervalos, ou bins, de frequência de acordo com a Equação 5.4.

$$
\text { Número de bins }=\frac{\text { Frame Size }}{2}
$$

A partir da Frequência Nyquist e do número de bins, obtém-se a largura de cada bin como na Equação 5.5 .

$$
\text { Largura do bin }=\frac{\text { Frequência Nyquist }}{\text { Número de bins }}
$$

A influência desses parâmetros no espectrograma final produzido pode ser observada no exemplo da Figura 5.1. O espectrograma da Figura 5.1 foi gerado a partir de uma onda seno de frequência $440 \mathrm{~Hz}$, utilizando-se um Sampling Rate igual a 400 exemplos por segundo e um Frame Size igual a 16 exemplos. Observe que a Frequência Nyquist nesse caso é igual a $200 \mathrm{~Hz}$ e, portanto, o espectrograma na Figura 5.1 representa frequências entre 1 e $200 \mathrm{~Hz}$. Como o Frame Size utilizado é igual a 16, o espectrograma apresenta 8 intervalos de frequência.

Alterando-se os valores de Sampling Rate e de Frame Size, espectrogramas diferentes são gerados. Ao alterar o valor de Sampling Rate, produz-se espectrogramas que representam uma faixa maior ou menor de frequências. Quanto maior o valor de Sampling Rate, maior a faixa de frequências representada. Quanto ao valor de Frame Size, ao alterá-lo produz-se uma diferente quantidade de bins no espectrograma, assim como altera-se a largura de cada bin. Quanto maior o Frame Size, maior também o número de bins criados.

\subsection{Detectando Mudanças Usando Espectrogramas}

\subsubsection{Espectrogramas para Representar Comportamentos Variáveis}

Um espectrograma de um sinal cujo comportamento é variável também deve apresentar diferentes representações em termos de frequências com o decorrer do tempo. Para 


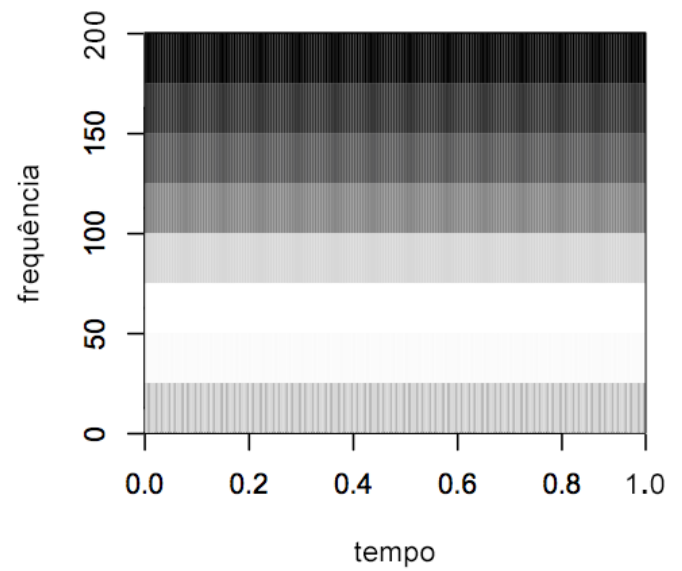

(a)

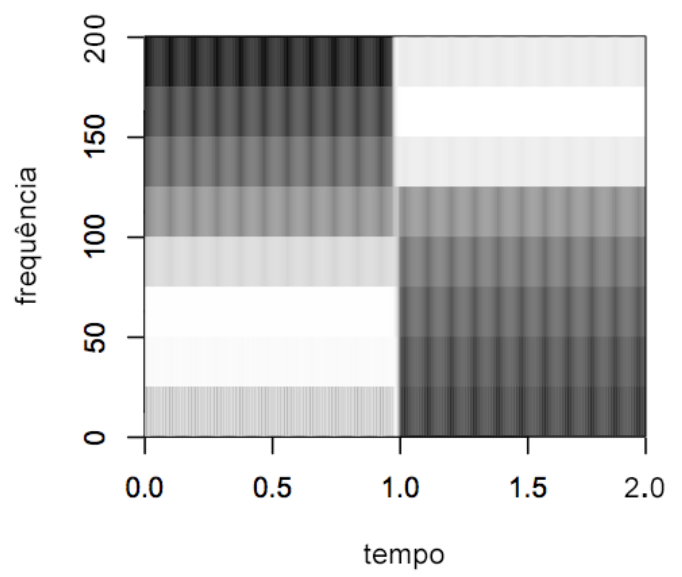

(c)

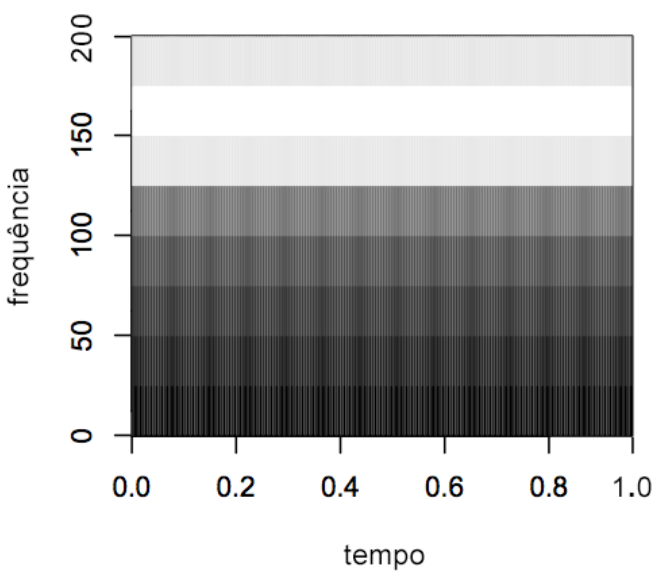

(b)

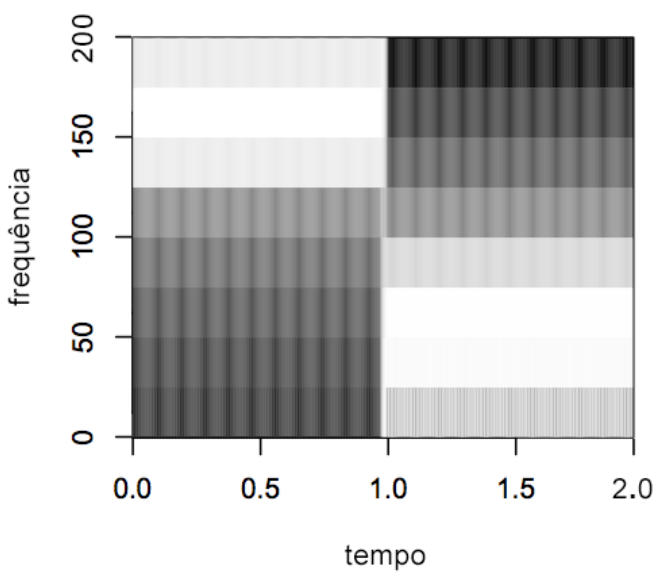

(d)

Figura 5.2: Espectrogramas gerados a partir de: (a) Onda seno com frequência de 440 $\mathrm{Hz}$. (b) Onda seno com frequência de $258 \mathrm{~Hz}$. (c) Concatenação das ondas de 440 e 258 $\mathrm{Hz}$, nessa ordem. (d) Concatenação das ondas de 258 e $440 \mathrm{~Hz}$, nessa ordem.

demonstrar essa hipótese, seja o seguinte exemplo. Sejam duas ondas seno, com frequências de 440 e $258 \mathrm{~Hz}$, respectivamente. Cada onda foi gerada utilizando-se um Sampling Rate igual a 400 exemplos por segundo. A partir dessas ondas, duas novas ondas foram criadas a partir, respectivamente, da concatenação da onda seno de $258 \mathrm{~Hz}$ ao final da onda seno de $440 \mathrm{~Hz}$ e da concatenação da onda seno de $440 \mathrm{~Hz}$ ao final da onda de 258 $\mathrm{Hz}$. Em seguida, foram gerados espectrogramas referentes a cada uma das quatro ondas descritas, utilizando-se SamplingRate $=400$ e FrameSize $=16$. Os espectrogramas gerados são apresentados na Figura 5.2.

Observa-se nas Figuras 5.2 (c) e 5.2 (d) que existem duas porções distintas nos gráficos dos espectrogramas que representam os dois senos concatenados. Essas porções distintas são relativas aos dados pertinentes à cada onda seno, seja ela a onda com 
frequência de $440 \mathrm{~Hz}$ ou de $258 \mathrm{~Hz}$. Dessa maneira pode-se perceber que um sinal que apresenta comportamento variável resultará em um espectrograma também variando no tempo.

\subsubsection{Espectrogramas para Dados Multidimensionais}

A Seção 5.3.1 apresentou um exemplo de como um espectrograma representa sinais variando no tempo. Entretanto, para os objetivos deste trabalho, é necessário criar espectrogramas a partir de dados multidimensionais. No cenário multidimensional, uma possível solução é aplicar a DFT para cada dimensão dos dados. Esse processo é equivalente a transformar a matriz de dados em um vetor, por meio da concatenação dos valores contidos em cada dimensão, uma após a outra. Essa abordagem é utilizada, por exemplo, pela linguagem para computação estatística $\mathrm{R}^{1}$.

Seja o seguinte exemplo. As ondas seno com frequências de 440 e de $258 \mathrm{~Hz}$, utilizadas anteriormente, foram armazenadas em uma matriz de modo que, na primeira coluna, foram armazenados os valores referentes a onda seno de $440 \mathrm{~Hz}$, enquanto que na segunda coluna foram armazenados os dados relativos a onda seno de $258 \mathrm{~Hz}$. Dessa forma, obteve-se um conjunto de dados contendo duas dimensões. O inverso também foi realizado, i.e., uma segunda matriz foi criada porém com as colunas em ordem inversa. Em seguida foram criados os espectrogramas para cada uma dessas matrizes de acordo com a metodologia descrita anteriormente. A Figura 5.3 apresenta quatro gráficos. Os dois gráficos superiores são os mesmos espectrogramas apresentados, respectivamente, nas Figuras 5.2 (c) e 5.2 (d). Os dois gráficos inferiores representam os espectrogramas obtidos a partir das duas matrizes geradas.

Observa-se que os gráficos superior e inferior esquerdos são idênticos, assim como os gráficos superior e inferior direitos. Isso demonstra que, para o caso das matrizes, o espectrograma foi gerado tomando cada dimensão da matriz separadamente.

\subsubsection{Medida de Comparação entre Espectrogramas}

Este trabalho propõe a comparação de dois espectrogramas distintos por meio da utilização de uma medida de distância denominada Normalized Compressed Distance (NCD) (ClLIBRASI; VITÁNYI, 2005). A medida NCD é utilizada para agrupar objetos similares, e é baseada em teorias de complexidade algorítmica desenvolvidas por Kolmogorov.

A medida NCD toma dois argumentos (objetos) e avalia uma fórmula expressa em termos das versões comprimidas desses objetos. Portanto, essa medida é parametrizada pelo algoritmo compressor utilizado. Se $x$ e $y$ são dois objetos e $C(x)$ é o tamanho da versão comprimida de $x$ usando o algoritmo de compressão $C, C(y)$ é o tamanho da versão

\footnotetext{
${ }^{1}$ A função para geração de espectrogramas disponível no R está implementada no pacote signal.
} 


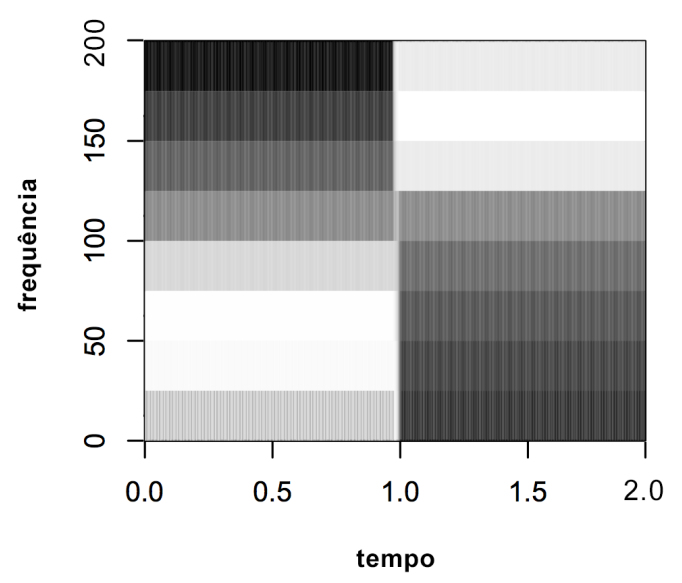

(a)

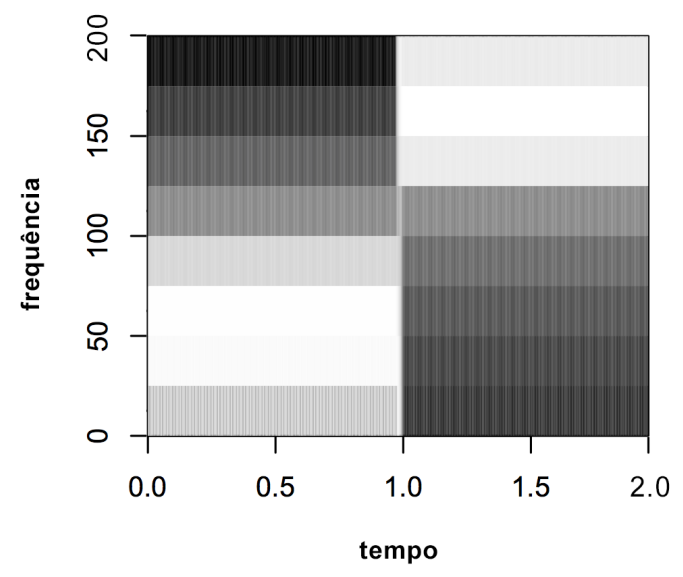

(c)

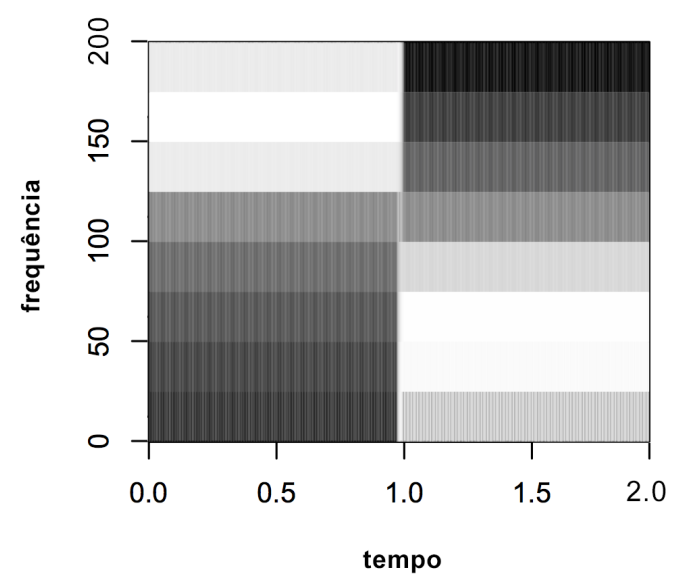

(b)

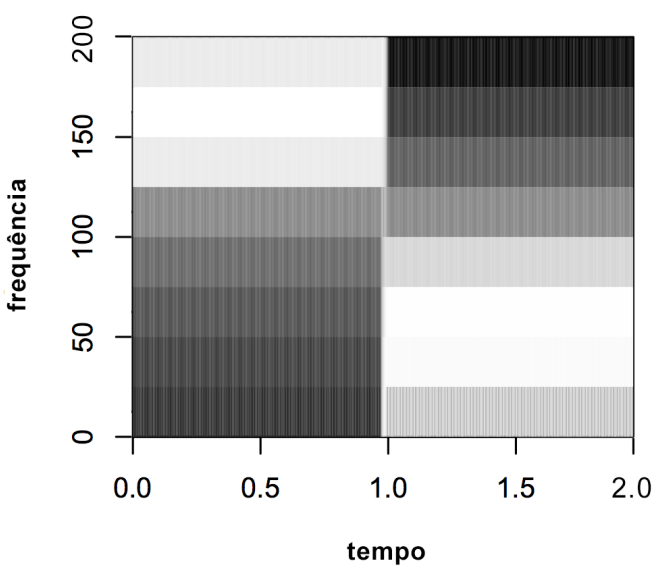

(d)

Figura 5.3: Espectrogramas gerados a partir de: (a) Concatenação das ondas de 440 e $258 \mathrm{~Hz}$, nessa ordem. (b) Concatenação das ondas de 258 e $440 \mathrm{~Hz}$, nessa ordem. (c ) Criação de matrizes bidimensionais com a primeira e segunda colunas contendo, respectivamente, as ondas seno de 440 e $258 \mathrm{~Hz}$. (d) Criação de matrizes bidimensionais com a primeira e segunda colunas contendo, respectivamente, as ondas seno de 258 e $440 \mathrm{~Hz}$. 
comprimida de $y$ usando $C$ e $C(x y)$ é o tamanho da versão comprimida contendo $x$ e $y$ usando $C$, então a medida NCD pode ser expressa como na Equação 5.6.

$$
N C D(x, y)=\frac{C(x y)-\min \{C(x), C(y)\}}{\max \{C(x), C(y)\}}
$$

Portanto, a função de distância NCD nada mais é do que o tamanho da versão comprida contendo $x$ e $y$, normalizado no intervalo $[0,1]$.

Dados dois espectrogramas $e_{1}$ e $e_{2}$, pode-se obter $N C D\left(e_{1}, e_{2}\right)$ através da compressão, utilizando um algoritmo compressor $C$, de dois arquivos $a_{1}$ e $a_{2}$, onde $a_{1}$ e $a_{2}$ contêm, respectivamente, as matrizes de dados que representam os espectrogramas $e_{1} \mathrm{e} e_{2}$.

\subsubsection{Detectando Mudanças de Comportamento}

Nesta seção será apresentado o algoritmo ws que utiliza espectrogramas para detectar mudanças de comportamento em dados não rotulados. Esse algoritmo utiliza janelas de dados de tamanho $N$ e é sumarizado, em forma de pseudocódigo, no Algoritmo 5.1.

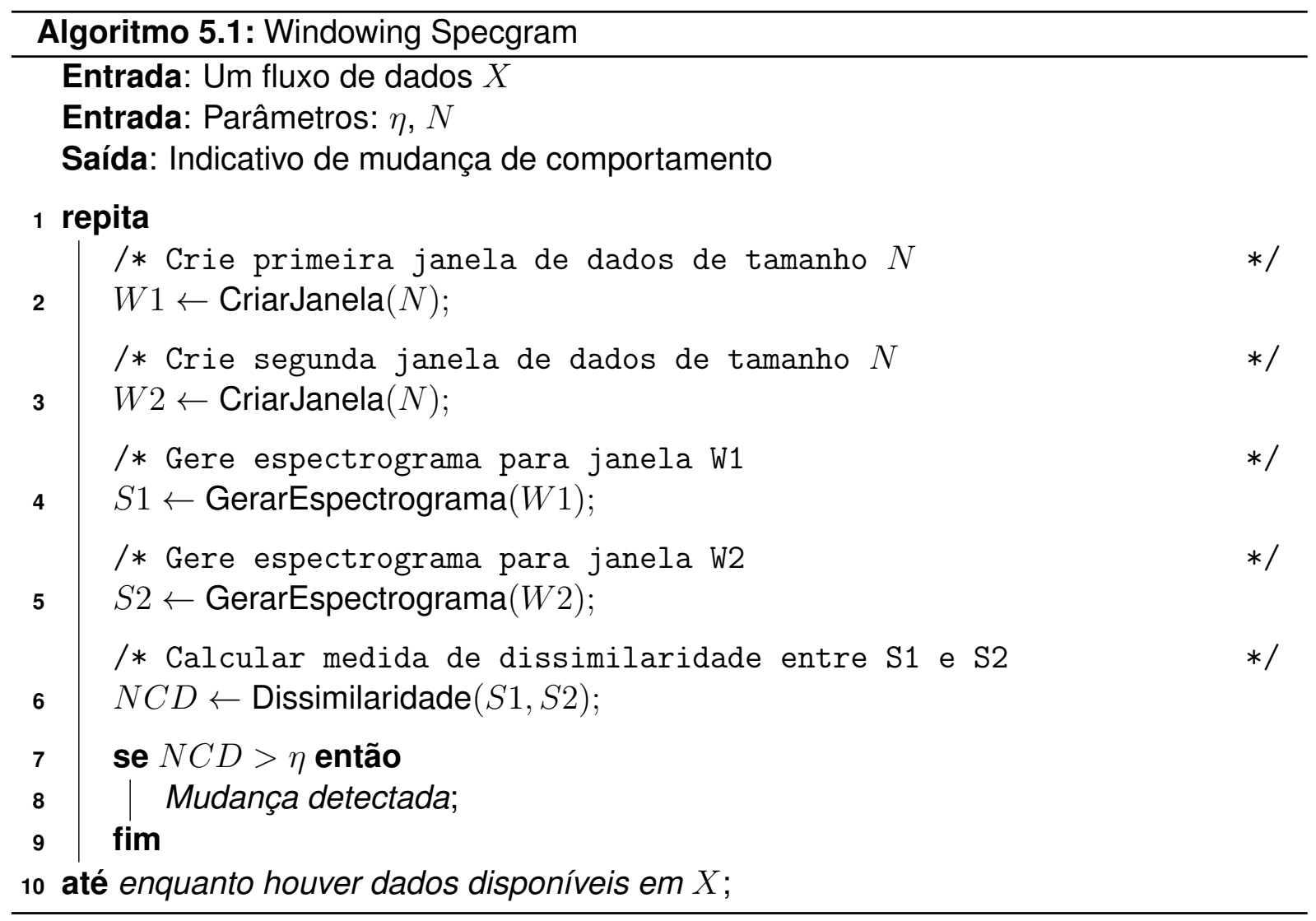

Inicialmente, duas janelas, $W 1$ e $W 2$, de tamanho $N$ são criadas. Em seguida, geramse dois espectrogramas, $S 1$ e $S 2$, referentes aos dados contidos nas janelas $W 1$ e $W 2$ respectivamente. O próximo passo é comparar os dois espectrogramas criados. Para isso, utiliza-se a medida NCD. Para cada um dos espectrogramas gerados, a matriz contendo 


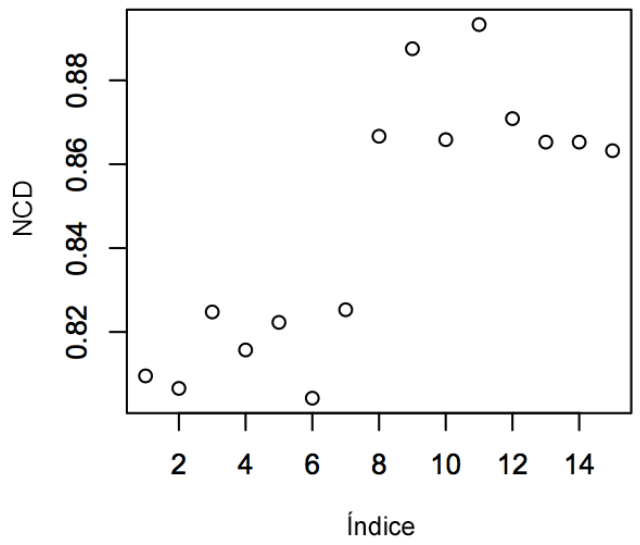

(a)

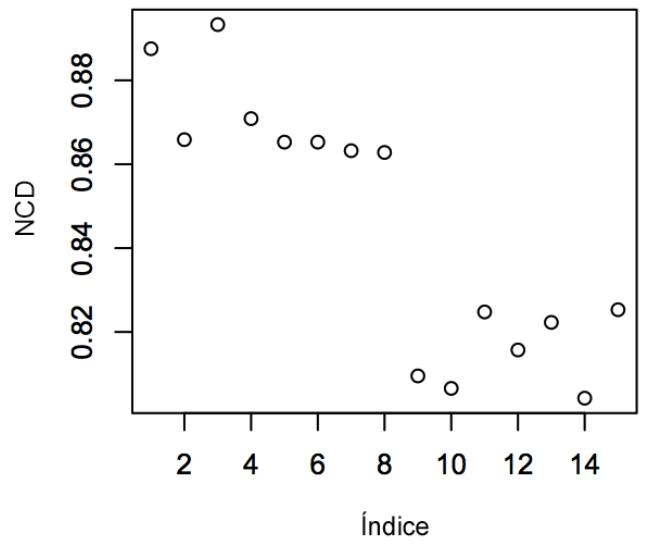

(b)

Figura 5.4: Gráfico com valores de NCD para duas ondas unidimensionais distintas.

seus dados é salva em um arquivo de texto. É também salvo um arquivo contendo as matrizes dos dois espectrogramas, cada um referente a uma janela de dados. Todos os três arquivos gerados são comprimidos por um algoritmo de compressão de dados $^{2}$ e os tamanhos dos arquivos resultantes são armazenados. Esses tamanhos são utilizados para o cálculo do NCD entre os dois espectrogramas, gerando um valor de distância entre eles.

Em seguida, $W 1$ é deslizada para a posição referente à $W 2$, enquanto que $W 2$ é deslizada para frente. O processo de geração de espectrogramas e cálculo da distância entre eles se repete. Por exemplo, se temos uma janela contendo $N=30$ exemplos, a primeira janela irá conter os exemplos de índices 1 a 30 e a segunda janela irá conter os exemplos de índices 31 a 60 . No próximo passo, a primeira janela conterá os exemplos de índices 31 a 60 e a segunda janela conterá os exemplos de índices 61 a 90 .

A Figura 5.4 apresenta um exemplo. A Figura 5.4 (a) apresenta os valores de NCD (eixo y) para a concatenação de uma curva seno de 258 a uma curva seno de $440 \mathrm{~Hz}$, enquanto que a Figura 5.4 (b) apresenta os valores de NCD para a concatenação inversa. Para a produção dos dados na Figura 5.4, foi utilizada uma janela contendo $N=50$ pontos. Observe que os valores de NCD, em ambos os gráficos, se localizam em duas porções distintas, devido à mudança na frequência da onda seno sendo processada.

Para determinar se uma mudança ocorreu, comparam-se dois valores de NCD consecutivos. Dessa forma, sejam $N C D_{i}$ o valor de NCD entre as janelas $W 1$ e $W 2$ e $N C D_{i+1}$ o valor de NCD obtido após ambas janelas serem deslizadas para frente. Se $N C D_{i+1}-$ $N C D_{i} \geq \eta$, uma mudança é indicada. Observe que é a diferença entre valores consecutivos de NCD que constitui uma mudança, e não valores únicos de NCD. Portanto, é necessário analisar pelo menos três janelas antes de decidir se uma mudança de compor-

\footnotetext{
${ }^{2}$ Neste trabalho, utilizou-se o algoritmo para compressão gzip.
} 
tamento está em curso. Caso, ao deslizar a segunda janela para frente, essa contenha somente dados referentes a um novo comportamento, a mudança será detectada com um atraso mínimo igual ao tamanho da janela empregado.

O valor $\eta \in[0,1]$ representa o limiar de separação. Esse valor é constante e estabelecido pelo usuário. Quanto menor o valor de $\eta$, maior o número de mudanças detectadas, porém ao custo de maior número de falsos positivos. Por outro lado, ao aumentar $\eta$ diminuise o número de falsos positivos ao custo de detectar menos mudanças.

\subsection{Experimentos Iniciais em Jogos}

\subsubsection{Configuração dos Experimentos}

Para avaliar a performance do algoritmo de detecção de comportamento proposto foram realizados vários experimentos utilizando os conjuntos de dados de FPS (gerados a partir das simulações realizadas com o algoritmo M-DBScan*) e RTS. Foram também realizados experimentos comparando ws com os algoritmos PHT e ADWIN. As implementações utilizadas foram as mesmas detalhadas no Capítulo 4. Todos os algoritmos avaliados foram comparados por meio da medida $F 1$, apresentada no Capítulo 4, e do atraso para detecção de mudanças. Para obtenção do número de VPs e FPs, foi empregada a mesma abordagem utilizada nos experimentos apresentados no Capítulo 4.

A implementação disponível no $\mathrm{R}$ para gerar espectrogramas permite utilizar um valor mínimo de Sampling Rate igual a 200. Considerando que ws é baseado em janelas de tempo, isso seria equivalente a utilizar uma janela contendo 200 exemplos, uma vez que os exemplos são armazenados na janela de dados antes de serem processados. Entretanto, uma janela de tamanho 200 poderia resultar em atraso mínimo para detecção de mudanças de aproximadamente 50 minutos de jogo nos dados de FPS e em 200 partidas nos dados de RTS, tornando a abordagem impraticável. Portanto, o parâmetro Sampling Rate foi fixado no valor mínimo, i.e., Sampling Rate $=200$, produzindo assim espectrogramas com frequências entre 1 e $100 \mathrm{~Hz}$, e o tamanho da janela foi determinado separadamente para os conjuntos de FPS e RTS.

Para os conjuntos de dados de FPS, o tamanho da janela adotado foi $N=30$, o que impõe um atraso mínimo para detecção de mudanças de aproximadamente 7,5 minutos. O número de pontos dentro de um intervalo onde será aplicada a FFT, ou Frame Size, foi configurado para o valor 8 e o limiar $\eta=0,007$. Os valores de parâmetros utilizados para os algoritmos PHT e ADWIN foram os mesmos apresentados nos experimentos do Capítulo 4.

Nos experimentos com os conjuntos de dados de RTS utilizou-se uma janela contendo $N=20$ pontos, correspondendo a um atraso mínimo para detecção de mudanças igual a 20 partidas. O valor de Frame Size foi o mesmo utilizado para os conjuntos de dados de FPS, i.e., FrameSize $=8$. O limiar entre distâncias NCD adotado foi $\eta=0.003$ para 
os 6 primeiros conjuntos e $\eta=0.0035$ para os 6 conjuntos restantes. Os valores de parâmetros utilizados para os algoritmos PHT e ADWIN foram os mesmos apresentados nos experimentos do Capítulo 4.

Todos os parâmetros utilizados foram obtidos através de avaliações empíricas, de modo que os valores aqui apresentados são as configurações que resultaram em melhor desempenho de cada um dos algoritmos investigados.

\subsubsection{Resultados}

Nesta seção são apresentados os resultados experimentais. A Tabela 5.1 apresenta os resultados utilizando a medida $F 1$ para cada um dos conjuntos de dados de FPS. A Tabela 5.2 apresenta os valores de VP e FP totais obtidos por cada algoritmo, calculados a partir da soma dos valores de VP e FP para cada conjunto de dados. Nessa tabela também é apresentado o valor de $F 1$ total para os conjuntos de dados de FPS, calculado de acordo com os valores totais de VP e FP. É ainda apresentado o atraso médio, em número de exemplos, para detecção de mudanças observado em cada algoritmo e os respectivos desvios padrão. Para obtenção dos atrasos médios foram considerados apenas os VPs.

Um exemplo de como ocorre a detecção de mudança de comportamento no algoritmo WS pode ser observado na Figura 5.5. No eixo y são representadas as diferenças entre valores de NCD consecutivos. Quando essa diferença é maior do que o limiar $\eta$, representado pela linha vermelha no gráfico, diz-se que uma mudança foi detectada. Nesse exemplo, pode-se observar claramente a detecção das três mudanças de comportamento existentes nos dados.

Os resultados em termos de $F 1$ para os conjuntos de dados de RTS são apresentados na Tabela 5.3. A Tabela 5.4 contém os valores de VP, FP e de $F 1$ totais obtidos nesses conjuntos de dados, assim como os atrasos médios para detecção de mudanças. Um exemplo, utilizando o décimo primeiro conjunto de dados, é apresentado na Figura 5.6.

\subsubsection{Análise dos Resultados}

Para os conjuntos de dados de FPS, os resultados apresentados nas Tabelas 5.1 e 5.2 mostram que o algoritmo ws apresenta os melhores resultados com respeito a medida $F 1$. 
Tabela 5.1: F1 obtida pelos algoritmos WS, PHT e ADWIN em cada um dos conjuntos de dados de FPS.

\begin{tabular}{lrrr}
\hline Conjunto & WS & PHT & ADWIN \\
\hline 1 & 0,8 & 0,46 & 0,22 \\
2 & 0,5 & 0,33 & 0,26 \\
3 & 0,8 & 0,4 & 0,24 \\
4 & 0,8 & 0,4 & 0,25 \\
5 & 0,8 & 0,5 & 0,25 \\
6 & 1 & 0,31 & 0,21 \\
7 & 1 & 0,4 & 0,22 \\
8 & 1 & 0,28 & 0,22 \\
9 & 1 & 0,375 & 0,22 \\
10 & 0,8 & 0,46 & 0,21 \\
11 & 0,5 & 0,28 & 0,23 \\
12 & 0,8 & 0,375 & 0,26 \\
13 & 0,5 & 0,33 & 0,26 \\
14 & 0,8 & 0,25 & 0,24 \\
15 & 1 & 0,33 & 0,21 \\
16 & 0,5 & 0,21 & 0,24 \\
17 & 0,5 & 0,54 & 0,21 \\
18 & 0,8 & 0,31 & 0,25 \\
19 & 0,5 & 0,57 & 0,19 \\
20 & 0,8 & 0,44 & 0,19 \\
21 & 0,8 & 0,28 & 0,23 \\
22 & 0,8 & 0,44 & 0,24 \\
23 & 0,8 & 0,54 & 0,21 \\
24 & 1 & 0,5 & 0,20 \\
\hline & & &
\end{tabular}

Tabela 5.2: Valores de VP, FP e F1 totais obtidos nos conjuntos de dados de FPS. A última coluna contém os atrasos médios para detecção de mudança, em número de exemplos, e respectivos desvios padrão.

\begin{tabular}{lrrrr}
\hline Algoritmo & VP & FPS & F1 & Atraso Médio \\
\hline WS & 48 & 0 & 0,80 & $46,15(15,15)$ \\
PHT & 59 & 183 & 0,37 & $36,9(28,56)$ \\
ADWIN & 72 & 490 & 0,23 & $5,65(4,34)$ \\
\hline
\end{tabular}

Tabela 5.3: F1 obtida pelos algoritmos WS, PHT e ADWIN em cada um dos conjuntos de dados de RTS.

\begin{tabular}{lrrr}
\hline Conjunto & WS & PHT & ADWIN \\
\hline 1 & 0,5 & 0,66 & 0,33 \\
2 & 0,66 & 0,66 & 0,66 \\
3 & 0,5 & 0,4 & 0,28 \\
4 & 0,8 & 0,8 & 0,33 \\
5 & 0,66 & 0 & 0,66 \\
6 & 0,8 & 0 & 0,33 \\
7 & 0,66 & 0,5 & 0,44 \\
8 & 1 & 0 & 0,28 \\
9 & 0,66 & 0,66 & 0,33 \\
10 & 0,66 & 0,66 & 0,33 \\
11 & 1 & 0,5 & 0,4 \\
12 & 0,66 & 0 & 0,44 \\
\hline
\end{tabular}




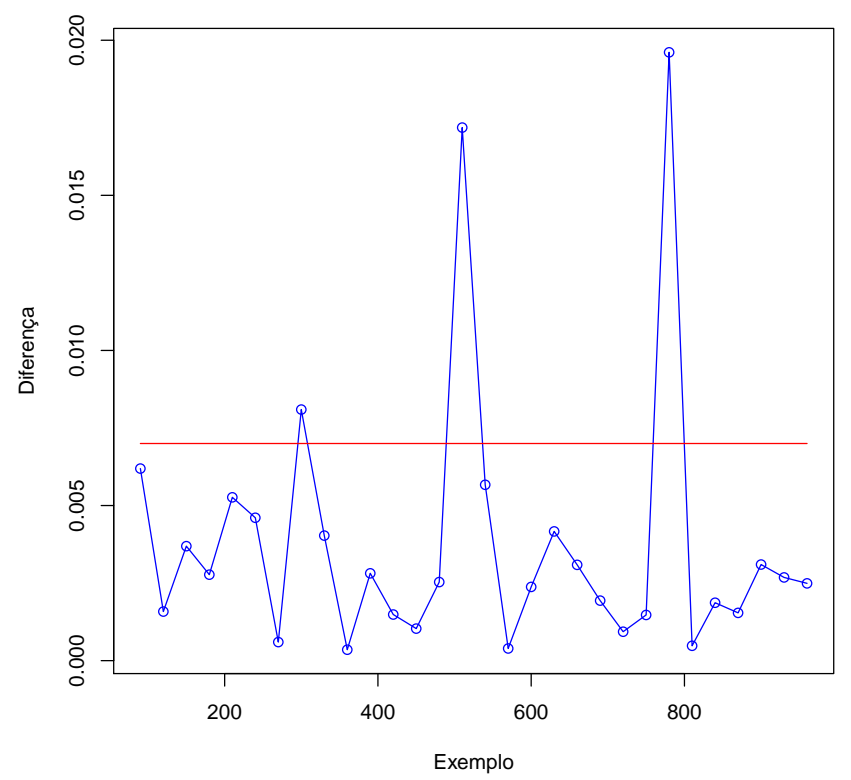

Figura 5.5: Diferenças entre valores de NCD consecutivos para o algoritmo wS no sexto conjunto de dados de FPS. A linha vermelha representa o limiar $\eta=0,007$ utilizado para sinalizar uma mudança de comportamento.

Tabela 5.4: Valores de VP, FP e F1 totais obtidos nos conjuntos de dados de RTS. A última coluna contém os atrasos médios para detecção de mudança, em número de exemplos, e respectivos desvios padrão.

\begin{tabular}{lcccc}
\hline Algoritmo & VP & FP & F1 & Atraso Médio \\
\hline WS & 16 & 4 & 0,72 & $22,5(6,8)$ \\
PHT & 9 & 10 & 0,42 & $65,1(24,69)$ \\
ADWIN & 16 & 39 & 0,40 & $57,9(26,15)$ \\
\hline
\end{tabular}

O melhor desempenho de ws nesses experimentos se deve a transformação dos dados de seu espaço original para uma série de valores de NCD no tempo, tornando necessário definir um único limiar de separação para indicar a ocorrência de mudanças. Como mencionado no Capítulo 4, para serem utilizados em dados multidimensionais, os algoritmos PHT e ADWIN necessitam ser aplicados por dimensão, o que exige a utilização dos mesmos valores de parâmetros para todas as dimensões ou a definição de múltiplos valores. Neste trabalho foi implementada a primeira opção. A utilização de valores de parâmetros idênticos para todas as dimensões acaba por prejudicar o desempenho geral desses algoritmos, pois esses parâmetros controlam o limiar de separação para detecção de mudanças. Além disso, a aplicação do detector de mudanças separadamente por dimensão acaba por elevar o número de FPs, pois uma mesma mudança é detectada em múltiplas dimensões em instantes de tempo distintos.

O atraso médio observado pelo algoritmo ws nos dados de FPS equivale a aproximadamente 11 minutos de jogo. Esse atraso está vinculado ao atraso mínimo que o algoritmo 


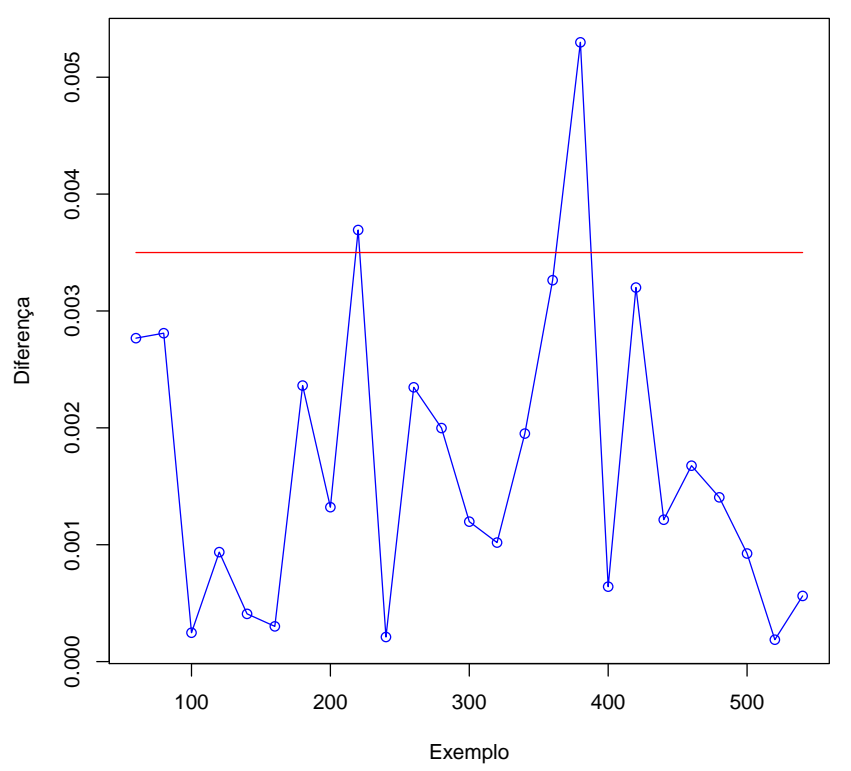

Figura 5.6: Diferenças entre valores de NCD consecutivos para o algoritmo wS no décimo primeiro conjunto de dados de RTS. A linha vermelha representa o limiar $\eta=0,0035$ utilizado para sinalizar uma mudança de comportamento.

pode apresentar nestes experimentos, que é dependente do tamanho da janela de dados utilizada. Para esses conjuntos de dados, o tamanho da janela empregado resulta em um atraso mínimo para detecção igual a 7,5 minutos. O algoritmo com menor atraso médio observado foi o ADWIN.

Para os conjuntos de dados de RTS, os resultados apresentados nas Tabelas $5.3 \mathrm{e}$ 5.4 mostram que, novamente, o algoritmo ws apresenta melhores resultados em termos de F1. As mesmas considerações realizadas para os conjuntos de FPS se aplicam para justificar esses resultados. Para esses conjuntos de dados, observou-se também que ws apresentou os menores níveis de atraso, com um atraso médio aproximadamente igual ao menor atraso que poderia ser obtido com o tamanho de janela utilizado.

Nos experimentos realizados, observou-se que o algoritmo ws apresentou dificuldade em detectar mudanças de comportamento quando os comportamentos são muito similares. Isso acontece particularmente nos conjuntos de dados de FPS, onde três dos quatro comportamentos presentes nos dados são bastante similares entre si. Para contornar essa situação em especial, foi proposta uma alteração na definição apresentada do algoritmo Ws. Os detalhes dessa alteração são apresentados na próxima seção.

\subsection{Detectando Comportamentos Similares}

Os resultados da Seção 5.4 mostraram a aplicabilidade do algoritmo ws em detectar mudanças de comportamento nos dados de FPS. Como já mencionado, três dos quatro com- 
portamentos implementados no jogo do gênero FPS apresentam um elevado grau de similaridade entre si. Em particular, para alguns desses comportamentos, uma das características que os distingue é a existência de um atributo nulo. Ou seja, uma das diferenças entre dois comportamentos muito similares $A$ e $B$ está na existência de um atributo não nulo em $B$ que era nulo em $A$, ou vice-versa.

A existência de um atributo nulo no conjunto de dados provoca a inclusão de uma faixa vertical branca no espectrograma gerado a partir desses dados. Isso ocorre pois, como explicado anteriormente, o espectrograma é criado levando-se em conta um atributo por vez. Dessa maneira, como o atributo é nulo, todo o espaço reservado no gráfico do espectrograma para representar as faixas de frequência em relação a este atributo é preenchido com a cor branca, pois não há, de fato, frequências distintas a serem representadas nesse caso. O fato é que a medida de distância NCD empregada não apresentou boa capacidade de distinguir entre esses espectrogramas, resultando em valores muito parecidos de NCD para dados de ambos os comportamentos e, portanto, não indicando mudança.

Para tentar resolver esse problema, uma modificação foi implementada no algoritmo WS. Essa modificação consiste em um passo adicional logo após o cálculo do NCD onde verificam-se as duas matrizes que representam os dois espectrogramas criados. Se as matrizes possuírem sequências de colunas anuladas distintas, adiciona-se um fator $\alpha \in$ $(0,1]$ ao valor calculado de NCD, gerando uma alteração mais significativa entre dois valores de NCD consecutivos. Observe que a adição de $\alpha$ altera o intervalo em que valores de NCD serão produzidos de $[0,1]$ para $[0,2]$.

Foi necessário incluir também uma leve alteração no passo seguinte de detecção de mudanças. Essa mudança consiste em verificar se duas detecções são indicadas em sequência e, em caso positivo, desconsiderar a segunda mudança. Ou seja, uma mudança detectada no instante $i$ só será considerada, se no instante $i-1$ não houve indicativo de mudança. Essa adição é necessária pois o efeito da adição de $\alpha$ somente altera um ponto na série de valores de NCD, afastando-o dos demais pontos já observados. Os pontos consecutivos, por sua vez, que representam todos um mesmo comportamento, apresentarão valores de NCD próximos entre si e aos valores apresentados pelo comportamento anterior. Isso se dá pois ambos comportamentos são muito parecidos. Assim, se não desconsiderarmos mudanças consecutivas, o algoritmo detectará sempre um FP para cada VP. Essa nova versão do algoritmo será referenciada como Windowing Specgram Extended (WSE) para diferenciar do algoritmo original WS.

Para o passo de detecção de mudanças do algoritmo foi proposta também uma segunda abordagem. Essa abordagem consiste em aplicar o algoritmo PHT aos valores de NCD consecutivos. O PHT busca por variações na média de uma série de valores e, dessa forma, irá indicar uma mudança sempre que os valores de NCD começarem a divergir de valores passados. Para diferenciar do algoritmo WSE, o algoritmo usando PHT será referenciado como Windowing Specgram Extended with PHT (WSE-PHT). 
Em seguida, são apresentados experimentos adicionais utilizando tanto WSE quanto WSE-PHT. Os resultados obtidos são então comparados àqueles observados anteriormente para WS, assim como para os algoritmos PHT e ADWIN.

\subsection{Experimentos Adicionais}

\subsubsection{Configuração dos Experimentos}

Foram realizados experimentos adicionais utilizando os dois novos algoritmos, WSE e WSEPHT. Os objetivos desses experimentos são: avaliar se a modificação proposta em WSE produz um aumento de desempenho, em termos de detecção de mudanças, em relação ao algoritmo ws original; determinar se a utilização do PHT nos valores obtidos de NCD é mais adequada do que comparar a distância entre valores consecutivos de NCD.

Além disso, para avaliar o desempenho obtido por ambas abordagens propostas, 0 desempenho dos algoritmos ADWIN e PHT foram utilizados para comparação. Tanto os conjuntos de FPS quanto os de RTS foram utilizados nos experimentos e seus resultados são apresentados separadamente.

Para os conjuntos de dados de FPS, Sampling Rate $=200$ e $N=30$ pontos foram utilizados. O número de pontos dentro de um intervalo onde será aplicada a FFT, ou Frame Size, foi configurado para o valor 8. O valor adicionado ao NCD foi de $\alpha=0,007$. Para a abordagem WSE, configurou-se o limiar $\eta=0,007$. Já para WSE-PHT, os valores de parâmetros utilizados foram $\delta_{W S E-P H T}=0,0001$ e $\epsilon_{W S E-P H T}=0,007$. Os valores de parâmetros utilizados para os algoritmos PHT e ADWIN foram os mesmos apresentados nos experimentos do Capítulo 4.

Nos experimentos com os conjuntos de dados de RTS utilizou-se Sampling Rate $=200$ e $N=20$. O número de pontos dentro de um intervalo onde será aplicada a FFT, ou Frame Size, foi configurado para o valor 8. O valor adicionado ao NCD foi $\alpha=0,02$. O limiar entre distâncias NCD adotado pela abordagem WSE foi $\eta=0,003$ para os 6 primeiros conjuntos e $\eta=0,0035$ para os 6 conjuntos restantes. Para o WSE-PHT utilizaram-se $\delta_{W S E-P H T}=$ 0,0001 e $\epsilon_{W S E-P H T}=0.002$. Os valores de parâmetros utilizados para os algoritmos PHT e ADWIN foram os mesmos apresentados nos experimentos do Capítulo 4.

Todos os parâmetros utilizados foram obtidos através de avaliações empíricas, de modo que os valores aqui apresentados são as configurações que resultaram em melhor desempenho de cada um dos algoritmos investigados.

\subsubsection{Resultados}

Os resultados na Tabela 5.5 representam a medida $F 1$ obtida em cada um dos conjuntos de dados de FPS. Nessa tabela estão incluídos os resultados dos algoritmos WSE, WSE-PHT, 
PHT e ADWIN. Foram também adicionados novamente os resultados obtidos pelo algoritmo WS, para facilitar a comparação. Em seguida, na Tabela 5.6, são apresentados os valores de VP, FP e F1 totais.

Tabela 5.5: F1 obtida pelos algoritmos WS, WSE, WSE-PHT, PHT e ADWIN em cada um dos conjuntos de dados de FPS.

\begin{tabular}{lrrrrr}
\hline Conjunto & WS & WSE & WSE-PHT & PHT & ADWIN \\
\hline 1 & 0,8 & 1 & 0,8 & 0,46 & 0,22 \\
2 & 0,5 & 1 & 0,5 & 0,33 & 0,26 \\
3 & 0,8 & 1 & 0,66 & 0,4 & 0,24 \\
4 & 0,8 & 0,8 & 0,66 & 0,4 & 0,25 \\
5 & 0,8 & 0,8 & 0,5 & 0,5 & 0,25 \\
6 & 1 & 1 & 0,66 & 0,31 & 0,21 \\
7 & 1 & 0,86 & 0,86 & 0,4 & 0,22 \\
8 & 1 & 0,86 & 0,66 & 0,28 & 0,22 \\
9 & 1 & 0,86 & 0,66 & 0,375 & 0,22 \\
10 & 0,8 & 0,86 & 0,86 & 0,46 & 0,21 \\
11 & 0,5 & 0,86 & 0,66 & 0,28 & 0,23 \\
12 & 0,8 & 0,86 & 0,66 & 0,375 & 0,26 \\
13 & 0,5 & 0,86 & 0,5 & 0,33 & 0,26 \\
14 & 0,8 & 0,66 & 0,5 & 0,25 & 0,24 \\
15 & 1 & 0,86 & 0,66 & 0,33 & 0,21 \\
16 & 0,5 & 0,86 & 0,66 & 0,21 & 0,24 \\
17 & 0,5 & 0,86 & 0,8 & 0,54 & 0,21 \\
18 & 0,8 & 0,66 & 0,66 & 0,31 & 0,25 \\
19 & 0,5 & 0,86 & 0,8 & 0,57 & 0,19 \\
20 & 0,8 & 0,86 & 0,86 & 0,44 & 0,19 \\
21 & 0,8 & 0,66 & 0,66 & 0,28 & 0,23 \\
22 & 0,8 & 0,66 & 0,66 & 0,44 & 0,24 \\
23 & 0,8 & 0,86 & 0,8 & 0,54 & 0,21 \\
24 & 1 & 0,86 & 0,86 & 0,5 & 0,20 \\
\hline
\end{tabular}

Tabela 5.6: Valores de VP, FP e $F 1$ totais obtidos nos conjuntos de dados de FPS. A última coluna contém os atrasos médios para detecção de mudança, em número de exemplos, e respectivos desvios padrão.

\begin{tabular}{lrrrr}
\hline Algoritmo & VP & FP & F1 & Atraso Médio \\
\hline WS & 48 & 0 & 0,80 & $46,15(15,15)$ \\
WSE & 66 & 18 & 0.86 & $43,6(15,05)$ \\
WSE-PHT & 48 & 16 & 0,70 & $30(0)$ \\
PHT & 59 & 183 & 0,37 & $36,9(28,5)$ \\
ADWIN & 72 & 490 & 0,23 & $5,65(4,36)$ \\
\hline
\end{tabular}

Como exemplo, a Figura 5.7 apresenta a detecção de mudança de comportamento nos algoritmos WS, WSE e WSE-PHT para o primeiro conjunto de dados de FPS.

Os resultados apresentados na Tabela 5.5 foram submetidos a um teste de hipóteses para verificar se existe diferença estatística significativa entre os resultados observados. Como diferentes algoritmos são avaliados e não se pode assumir uma distribuição Normal dos dados, foi escolhido o teste não paramétrico de múltiplas comparações de Friedman 
para comparar os resultados obtidos. No caso do teste de Friedman rejeitar a hipótese nula de que o desempenho dos algoritmos comparados é similar, utilizou-se o teste de Nemenyi para descobrir quais pares de algoritmos diferem entre si. Em todos os testes realizados um nível de confiança igual a $95 \%$ foi empregado.

A Tabela 5.7 apresenta os resultados obtidos com a aplicação do teste de hipótese. Como o teste de hipóteses entre dois algoritmos é simétrico, a Tabela 5.7 apresenta apenas a metade superior.

Tabela 5.7: Testes de hipótese entre pares de algoritmos considerando $F 1$ nos conjuntos de dados de FPS. O símbolo - é utilizado para comparações desconsideradas. O símbolo $=$ representa igualdade estatística entre os algoritmos considerados. Os símbolos $\wedge \mathrm{e}<$ são utilizados para representar existência de diferença estatística entre os algoritmos considerados e indicam, respectivamente, vantagem para o algoritmo da coluna e vantagem para o algoritmo da linha.

\begin{tabular}{lrrrrr}
\hline & WS & WSE & WSE-PHT & PHT & ADWIN \\
\hline WS & - & $=$ & $=$ & $<$ & $<$ \\
WSE & & - & $<$ & $<$ & $<$ \\
WSE-PHT & & & - & $<$ & $<$ \\
PHT & & & & - & $<$ \\
ADWIN & & & & & - \\
\hline
\end{tabular}

Os atrasos, em número de exemplos, para detecção de mudanças também foram calculados. A Tabela 5.8 apresenta estatísticas relacionadas aos atrasos obtidos. Para cálculo dessas estatísticas foram considerados apenas os VPs, ou seja, as mudanças verdadeiramente detectadas. Em seguida, na Figura 5.8 pode-se observar os boxplots para os atrasos obtidos por cada algoritmo investigado.

Tabela 5.8: Estatísticas sobre atrasos para detecção de mudanças nos conjuntos de dados de FPS: mínimo, primeiro quartil, mediana, média com desvio padrão, terceiro quartil e máximo.

\begin{tabular}{lrrrrrr}
\hline Algoritmo & Mínimo & Primeiro Quartil & Mediana & Média & Terceiro Quartil & Máximo \\
\hline WS & 30 & 30 & 60 & $46,15(15,15)$ & 60 & 60 \\
WSE & 30 & 30 & 30 & $43,6(15,05)$ & 60 & 60 \\
WSE-PHT & 30 & 30 & 30 & $30(0)$ & 30 & 30 \\
PHT & 7 & 15 & 27 & $36,9(28,5)$ & 41 & 111 \\
ADWIN & 1 & 2 & 5 & $5,65(4,36)$ & 7 & 18 \\
\hline
\end{tabular}

A Tabela 5.9 apresenta os valores de $F 1$ obtidos em cada conjunto de dados de RTS. Os valores de VP, FP e F1 observados nesses conjuntos são apresentados na Tabela 5.10. O resultado do teste de hipótese considerando F1 é apresentado na Tabela 5.11. 
Tabela 5.9: F1 obtida pelos algoritmos WS, WSE, WSE-PHT, PHT e ADWIN em cada um dos conjuntos de dados de RTS.

\begin{tabular}{rrrrrr}
\hline Conjunto & WS & WSE & WSE-PHT & PHT & ADWIN \\
\hline 1 & 0,5 & 0,66 & 0,5 & 0,66 & 0,33 \\
2 & 0,66 & 0,66 & 0 & 0,66 & 0,66 \\
3 & 0,5 & 0,66 & 0,5 & 0,4 & 0,28 \\
4 & 0,8 & 1 & 0,8 & 0,8 & 0,33 \\
5 & 0,66 & 0,66 & 0,5 & 0 & 0,66 \\
6 & 0,8 & 1 & 0,5 & 0 & 0,33 \\
7 & 0,66 & 0,66 & 0,8 & 0,5 & 0,44 \\
8 & 1 & 1 & 0,8 & 0 & 0,28 \\
9 & 0,66 & 0,66 & 0,66 & 0,66 & 0,33 \\
10 & 0,66 & 0,66 & 0,8 & 0,66 & 0,33 \\
11 & 1 & 1 & 0,8 & 0,5 & 0,4 \\
12 & 0,66 & 0,66 & 0,66 & 0 & 0,44 \\
\hline
\end{tabular}

Tabela 5.10: Valores de VP, FP e F1 totais obtidos nos conjuntos de dados de RTS. A última coluna contém os atrasos médios para detecção de mudança, em número de exemplos, e respectivos desvios padrão.

\begin{tabular}{lrrrr}
\hline Algoritmo & VP & FP & F1 & Atraso Médio \\
\hline WS & 16 & 4 & 0,72 & $22,5(6,83)$ \\
WSE & 16 & 0 & 0,8 & $22,5(6,83)$ \\
WSE-PHT & 16 & 10 & 0,64 & $27,5(14,37)$ \\
PHT & 9 & 10 & 0,42 & $65,1(24,69)$ \\
ADWIN & 16 & 39 & 0,40 & $57,93(26,15)$ \\
\hline
\end{tabular}

Tabela 5.11: Testes de hipótese entre pares de algoritmos considerando $F 1$ nos conjuntos de dados de RTS. O símbolo - é utilizado para comparações desconsideradas. O símbolo $=$ representa igualdade estatística entre os algoritmos considerados. Os símbolos $\wedge \mathrm{e}<$ são utilizados para representar existência de diferença estatística entre os algoritmos considerados e indicam, respectivamente, vantagem para o algoritmo da coluna e vantagem para o algoritmo da linha.

\begin{tabular}{lrrrrr}
\hline & WS & WSE & WSE-PHT & PHT & ADWIN \\
\hline WS & - & $=$ & $=$ & $<$ & $<$ \\
WSE & & - & $=$ & $<$ & $<$ \\
WSE-PHT & & & - & $=$ & $<$ \\
PHT & & & & - & $=$ \\
ADWIN & & & & & - \\
\hline
\end{tabular}

Como exemplo, a Figura 5.9 apresenta a detecção de mudança de comportamento nos algoritmos WS, WSE e WSE-PHT para o décimo primeiro conjunto de dados de RTS.

Novamente os atrasos para detecção de mudança foram armazenados. A Tabela 5.12 apresenta estatísticas relacionadas aos atrasos obtidos. Em seguida, na Figura 5.10 podese observar osboxplots para os atrasos obtidos por cada algoritmo investigado. 
Tabela 5.12: Estatísticas sobre atrasos para detecção de mudanças nos conjuntos de dados de RTS: mínimo, primeiro quartil, mediana, média com desvio padrão, terceiro quartil e máximo.

\begin{tabular}{lrrrrrr}
\hline Algoritmo & Mínimo & Primeiro Quartil & Mediana & Média & Terceiro Quartil & Máximo \\
\hline WS & 20 & 20 & 20 & $22,5(6,83)$ & 20 & 40 \\
WSE & 20 & 20 & 20 & $22,5(6,83)$ & 20 & 40 \\
WSE-PHT & 20 & 20 & 20 & $27,5(14,37)$ & 25 & 60 \\
PHT & 27 & 46 & 74 & $65,1(24,69)$ & 82 & 97 \\
ADWIN & 3 & 42 & 57 & $57,93(26,15)$ & 80 & 92 \\
\hline
\end{tabular}

\subsubsection{Análise dos Resultados}

Para os conjuntos de dados de FPS foi observado que a modificação proposta em WSE produziu um desempenho total superior ao que havia sido obtido por ws (Tabela 5.6). Essa melhoria se dá devido ao aumento no número de VPs detectados. O aumento no número de VPs trouxe consigo um consequente aumento no número de FPs em WSE. A explicação para o aumento no número de FPs está na existência de alguns exemplos ruidosos nos dados. Quando isso acontece, duas janelas contendo dados de um mesmo comportamento podem apresentar diferentes sequências de colunas anuladas na matriz que representa o espectrograma, levando à detecção de uma mudança equivocada. Entretanto, mesmo com o aumento em FPs, o F1 total de WSE ainda foi melhor do que WS. Esse é um indício de que a inclusão de $\alpha$ permite a detecção de comportamentos que não estavam sendo percebidos por WS, atingindo o objetivo esperado. Os testes estatísticos não apontaram diferenças entre os resultados obtidos por WS e WSE apesar da melhora observada no valor de F1 (Tabela 5.7).

Os resultados na Tabela 5.6 sugerem que WSE alcança melhores resultados que WSEPHT. O principal fator diferenciador entre os algoritmos WSE e WSE-PHT é a ocorrência de VPs, que foi bastante inferior no algoritmo WSE-PHT. Isso se dá principalmente porque o teste PHT utlizado é capaz de detectar apenas subidas no valor da média observada dos valores. Entretanto, os valores de NCD podem se diferenciar tanto por um aumento no valor de NCD quanto por uma diminuição. Para que o teste PHT fosse capaz de detectar ambas situações, seria necessário aplicar um segundo teste que considerasse descidas na média. Para os experimentos realizados, o teste estatístico utilizado indicou a existência de diferença significativa entre os valores de $F 1$ totais obtidos por WSE e WSE-PHT (Tabela 5.7).

Também é importante apontar que os algoritmos WS, WSE e WSE-PHT obtiveram melhores resultados do que $\mathrm{PHT}$ e ADWIN. Essa diferença foi confirmada pelos testes estatísticos realizados. Como já apontado anteriormente, o melhor desempenho de WS, WSE e WSEPHT ocorreu porque esses algoritmos transformam os dados de seu espaço original para 
uma série de valores no tempo, tornando necessário definir um único limiar de separação para indicar a ocorrência de mudanças.

No que diz respeito aos atrasos observados, o algoritmo ADWIN foi o que obteve meIhores resultados, com menor atraso médio (Tabela 5.8). Esse resultado também pode ser observado na Figura 5.8, onde os boxplots de cada algoritmo são apresentados. Entretanto, a mesma observação realizada no Capítulo 4 referente ao ADWIN continua válida. Analisando melhor os resultados do ADWIN concluiu-se que aproximadamente $30 \%$ dos VPs foram detectados por coincidência, o que contribuiu para que parte dos atrasos fosse inferior a 5 exemplos, explicando os valores para atraso mínimo e primeiro quartil apresentados na Tabela 5.8. Se não contabilizarmos esses VPs no total de detecções corretas do ADWIN, conclui-se que esse algoritmo detectou 48 das 72 mudanças ocorridas. Mesmo com essa consideração o atraso médio do ADWIN foi de aproximadamente 6 exemplos, o que o mantém como o algoritmo com menor atraso médio observado nesses experimentos. Dentre os algoritmos propostos neste capítulo, o que obteve melhores resultados em termos de atraso foi WSE-PHT. Entretanto, assim como ADWIN, essa abordagem não alcançou bom desempenho em termos de F1. O algoritmo WSE apresentou, em $50 \%$ dos casos, um atraso igual ao mínimo atraso que poderia ser obtido nesses experimentos.

Os resultados observados para os conjuntos de dados de RTS apontam para melhor desempenho, em termos de F1, do algoritmo wSE (Tabela 5.10). Embora os testes de hipótese, apresentados na Tabela 5.11, não tenham indicado diferenças entre os algoritmos WS, WSE e WSE-PHT, a $F 1$ total de WSE é nitidamente melhor que a $F 1$ dos algoritmos WS e WSE-PHT. Uma explicação para que os testes de hipótese não tenham indicado essa diferença é o tamanho da amostra utilizada que contém apenas 12 medidas para cada algoritmo. Os testes, entretanto, apontaram para melhor desempenho de WSE em relação aos algoritmos PHT e ADWIN, o que está de acordo com os resultados observados nos conjuntos de dados de FPS.

Os menores atrasos médios observados foram os dos algoritmos WS e WSE (Tabela 5.12). É interessante notar que $75 \%$ dos atrasos para detecção observados para o algoritmo WSE foram iguais a 20 exemplos, o que corresponde ao atraso mínimo imposto pelo algoritmo nesses experimentos.

\subsection{Considerações Finais}

Neste capítulo foi apresentado um algoritmo baseado em janelas, denominado de WSE, para detecção de mudanças de comportamento. Este algoritmo foi projetado para considerar todos os requisitos para detecção de mudanças relativos ao domínio dos jogos computacionais: trabalhar com dados multidimensionais, não realizar suposições a priori a respeito dos dados e ser robusto a outliers presentes no fluxo.

Os resultados obtidos nos experimentos realizados em conjuntos de dados provenien- 
tes de dois gêneros de jogos distintos mostraram a aplicabilidade do algoritmo wSE em detectar mudanças de comportamento. Nos conjuntos de FPS, WSE detectou aproximadamente $91 \%$ de todas as mudanças de comportamento. A ocorrência de FPs no algoritmo WSE foi decorrente da presença de ouliers no fluxo. Embora o algoritmo seja baseado em janelas, o que automaticamente reduziria a influência de eventos outliers no resultado final, a etapa de verificação de matrizes desse algoritmo ainda não é robusta a esse tipo de ruído nos dados.

Os resultados mostraram que $50 \%$ de todas as mudanças detectadas tiveram um atraso associado igual ao mínimo atraso imposto pelo algoritmo sob as configurações utilizadas, i.e., aproximadamente 7,5 minutos de jogo. Nos conjuntos de RTS, wSE detectou aproximadamente $67 \%$ das mudanças de comportamento, com um atraso médio de 20 exemplos, i.e., 20 partidas realizadas. É interessante notar que $75 \%$ de todas as detecções ocorreram com atraso igual ao mínimo atraso do algoritmo para os experimentos realizados.

Quando comparado aos algoritmos PHT e ADWIN, WSE alcançou os melhores resultados em termos da medida $F 1$. A vantagem do WSE reside no fato de que esse algoritmo transforma o problema de detecção de mudança em dados multidimensionais para uma série de valores de NCD. Assim, a detecção de mudança é realizada em uma única dimensão.

A principal desvantagem do algoritmo WSE é que ele apresenta um atraso mínimo igual ao tamanho da janela empregada quando a janela $W 2$ se inicia exatamente ao mesmo tempo que a mudança de comportamento. Essa característica do algoritmo pode torná-lo proibitivo em algumas situações, caso o tamanho da janela seja muito grande. Esse fato pode ser minimizado diminuindo-se o tamanho da janela empregado. O tamanho mínimo que uma janela pode assumir deve ser empiricamente calculado através de experimentos em dados do mesmo domínio, de modo a encontrar o tamanho que gere espectrogramas que ainda sejam diferenciáveis entre si, mesmo com um número reduzido de exemplos utilizados em sua geração. 


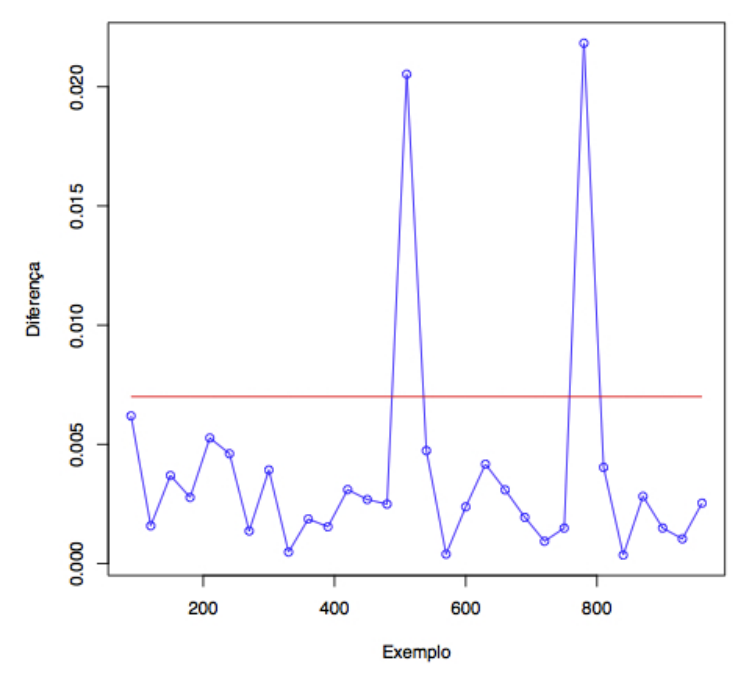

(a)

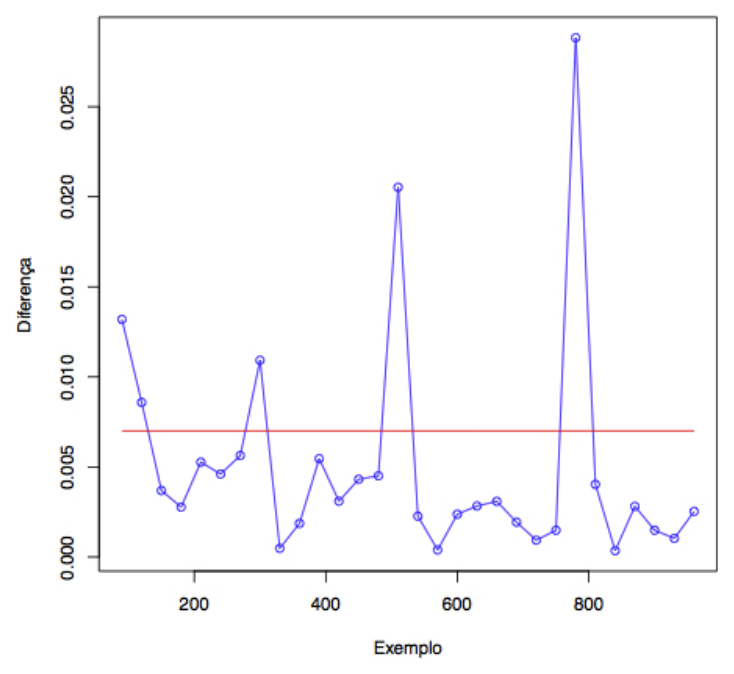

(b)

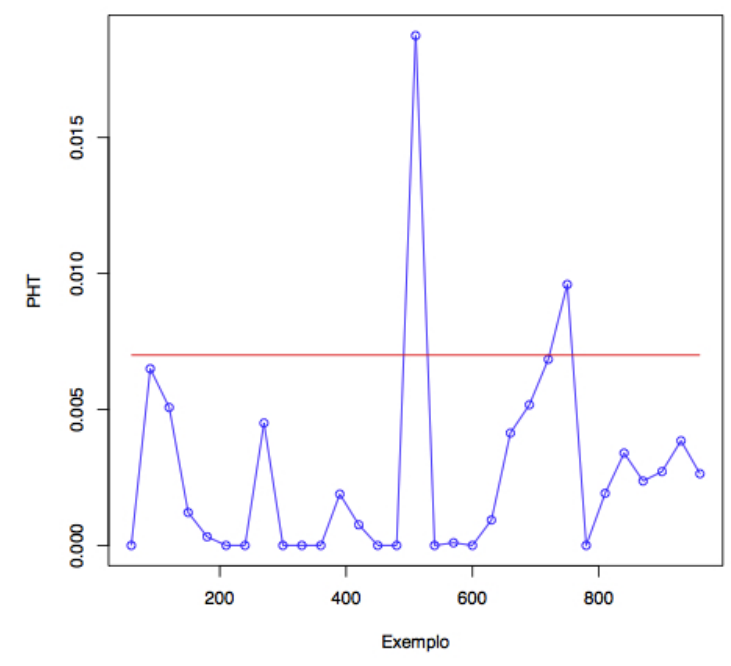

(c)

Figura 5.7: Detecção de mudança de comportamento no primeiro conjunto de dados de FPS. A linha vermelha representa o limiar utilizado para sinalizar uma mudança de comportamento. (a) Diferença entre valores de NCD consecutivos para o algoritmo WS. (b) Diferença entre valores de NCD consecutivos para o algoritmo WSE. (c) Valores para a estatística calculada pelo PHT para o algoritmo WSE-PHT. 

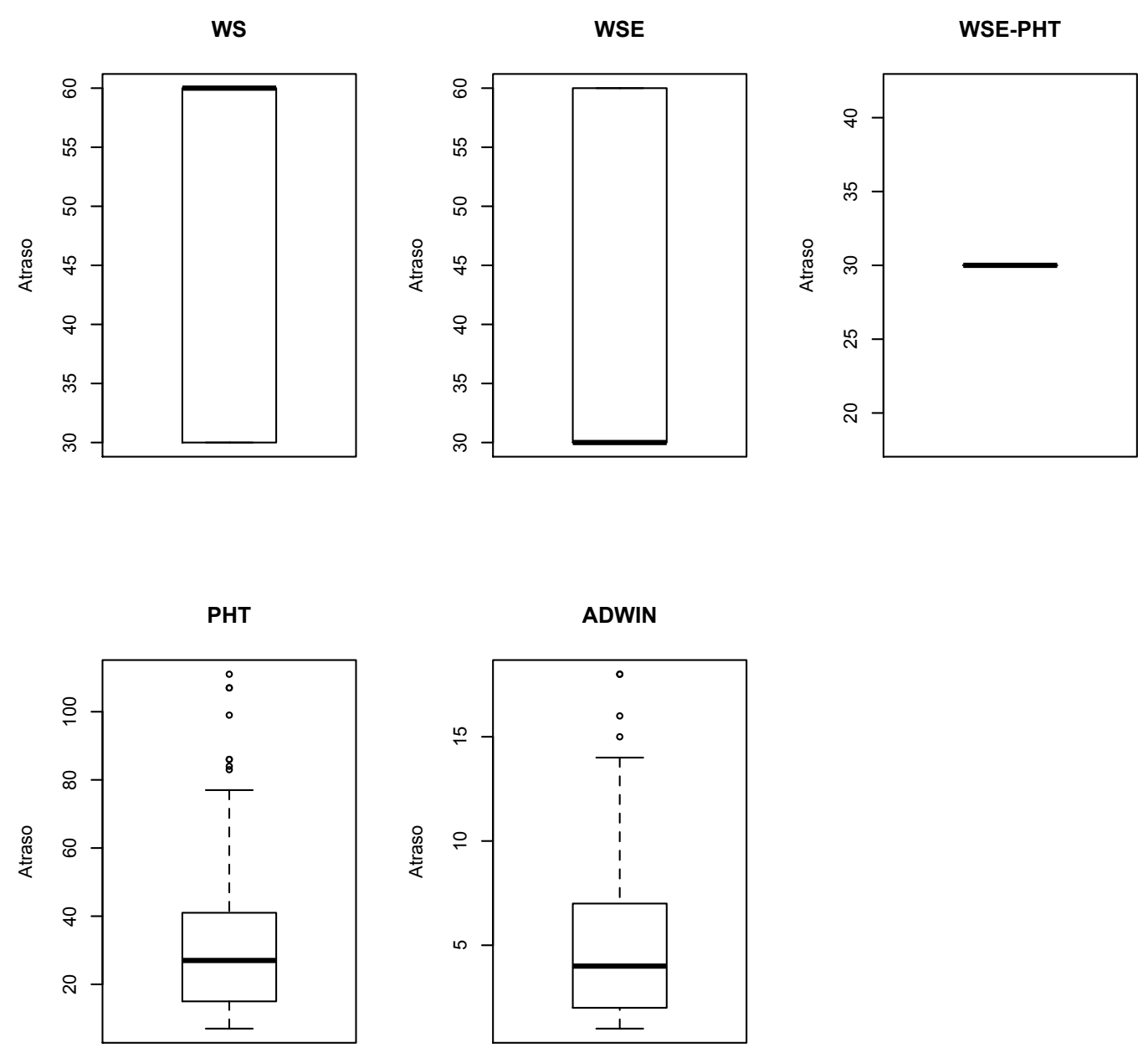

Figura 5.8: Boxplots para os atrasos obtidos nos conjuntos de dados de FPS por cada um dos algoritmos investigados. 


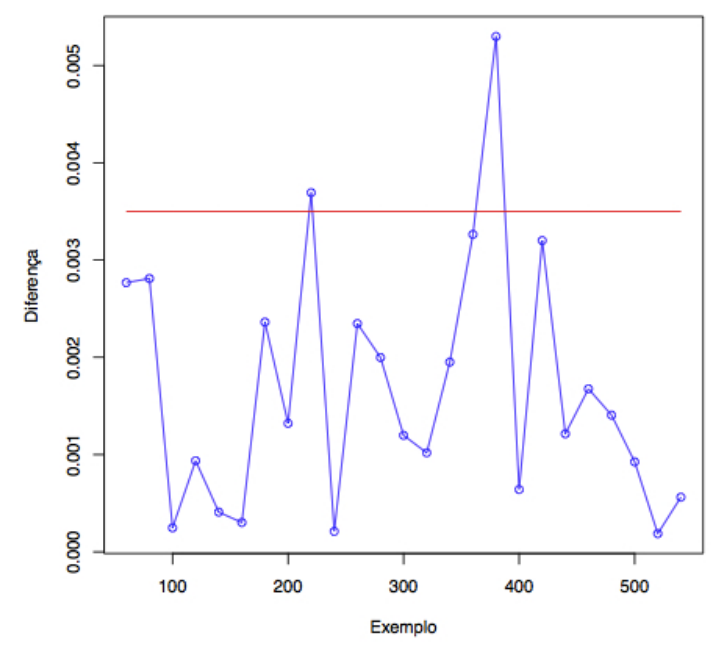

(a)

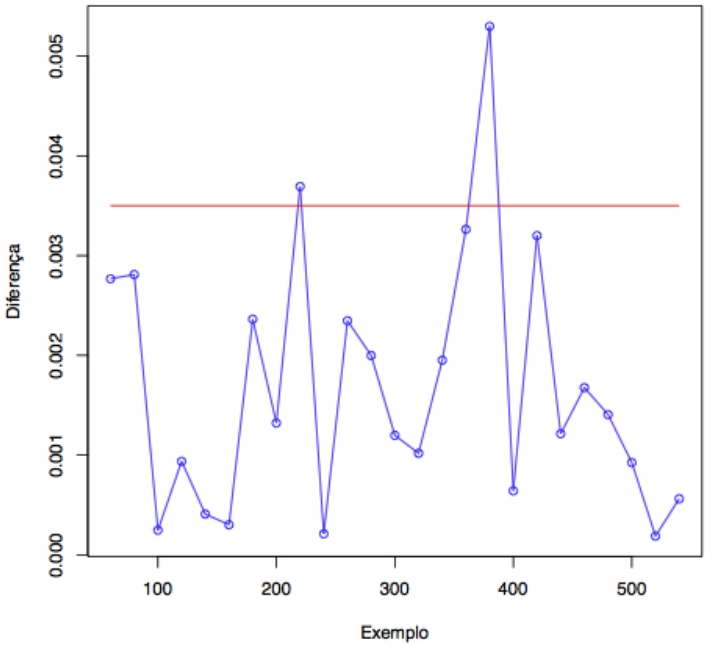

(b)

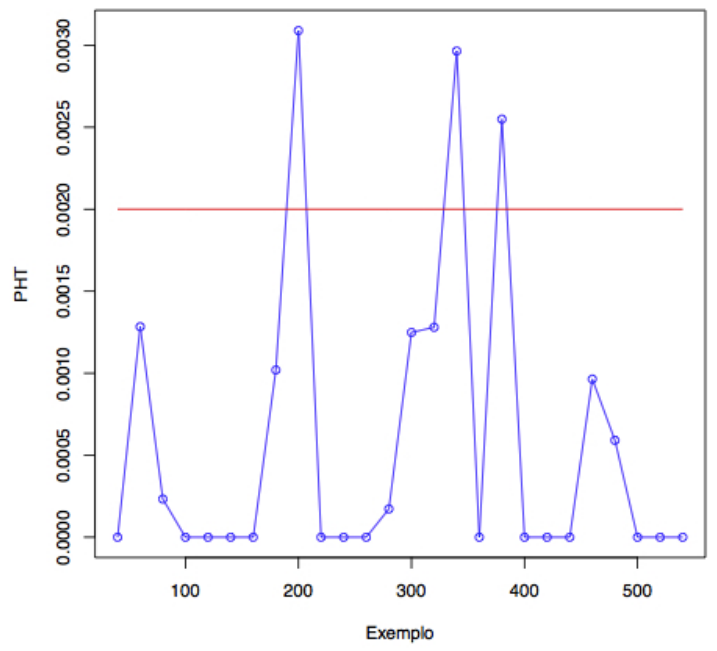

(c)

Figura 5.9: Detecção de mudança de comportamento no décimo primeiro conjunto de dados de RTS. A linha vermelha representa o limiar utilizado para sinalizar uma mudança de comportamento. (a) Diferença entre valores de NCD consecutivos para o algoritmo WS. (b) Diferença entre valores de NCD consecutivos para o algoritmo WSE. (c) Valores para a estatística calculada pelo PHT para o algoritmo WSE-PHT. 

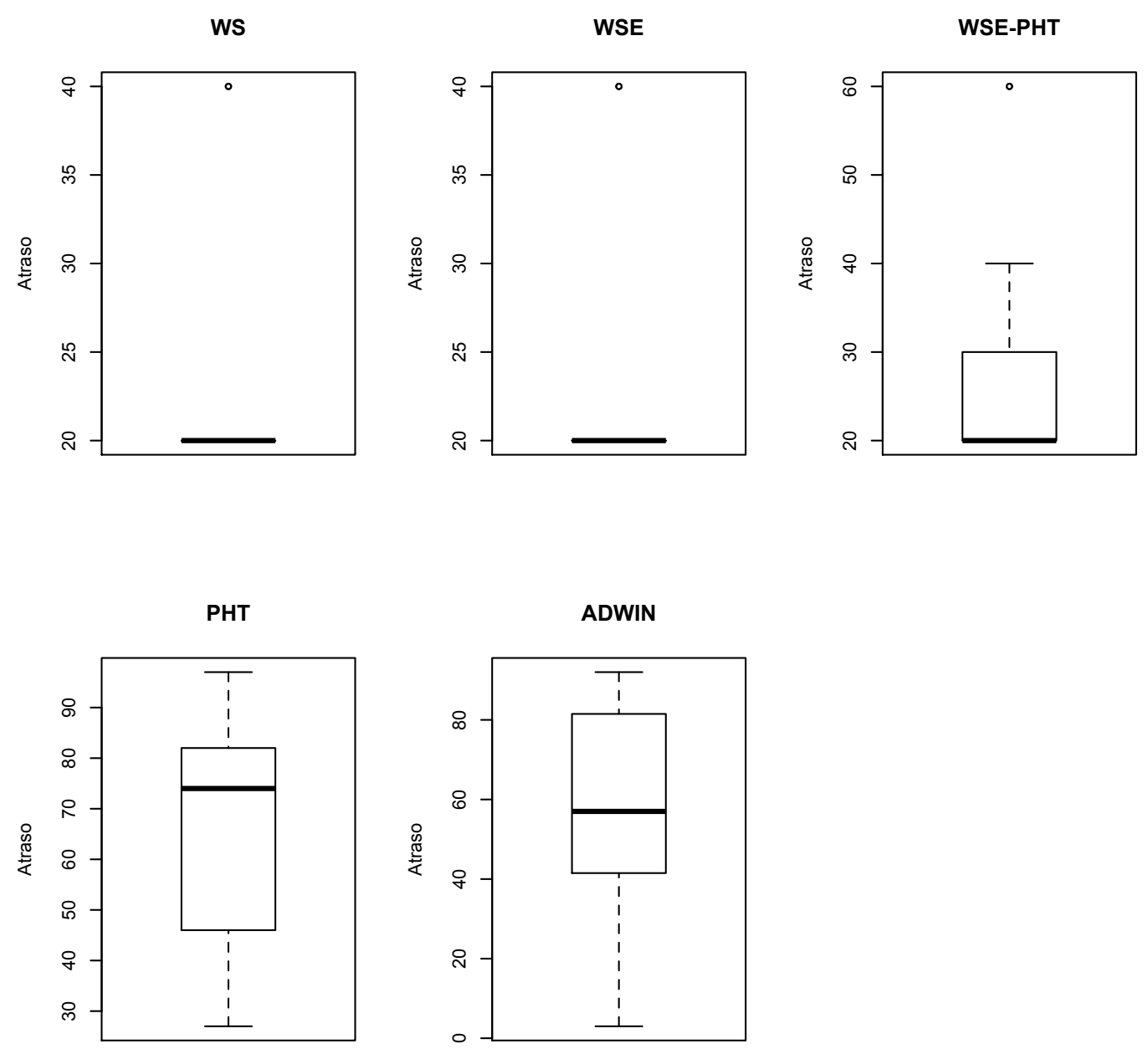

Figura 5.10: Boxplots para os atrasos obtidos nos conjuntos de dados de RTS por cada um dos algoritmos investigados. 


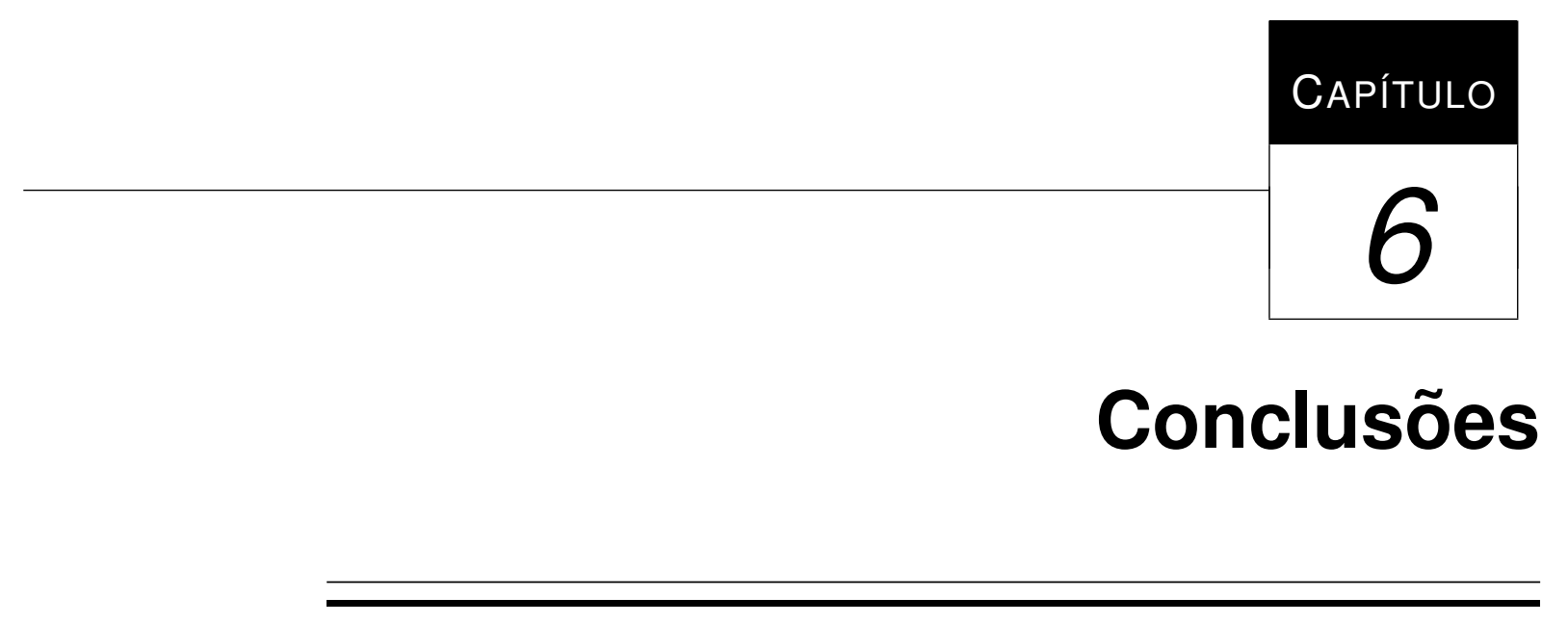

A aplicação de técnicas de IA e AM em jogos comerciais tem recebido uma crescente atenção por parte de pesquisadores em diferentes grupos de pesquisa. As simulações fornecidas pelos jogos comerciais modernos são tão realistas que servem como um excelente cenário de teste para estas técnicas, possibilitando o avanço das técnicas atuais e o surgimento de novos algoritmos. Embora existam atualmente diversos trabalhos dedicados ao estudo e aplicabilidade de algoritmos de AM no cenário de jogos, a maior parte das contribuições nessa área se dá através da análise offline de dados obtidos a partir da interação de jogadores com o software de jogo. Essas fontes de dados são muito úteis para, por exemplo, treinar algoritmos supervisionados para aprender controladores que se comportem de forma mais parecida com o comportamento humano. Esses controladores podem, em seguida, ser utilizados para controlar o comportamento de personagens do jogo. Uma outra utilização desses dados é no estudo das características dos jogadores, de modo a utilizar essa informação no projeto de jogos mais adequados para uma gama maior de usuários.

Umas das aplicações mais interessantes de algoritmos de aprendizado em dados de jogos é na obtenção de métodos capazes de adaptar o jogo atual para melhor se adequar às necessidades do jogador. A abordagem mais investigada na literatura é a que constrói modelos de aprendizado de comportamento de jogadores de modo offline, ou seja, dados de partidas completas de jogadores são utilizados para aprender modelos de decisão que informam o tipo (ou padrão) de jogador. O objetivo é identificar o padrão de jogador em novas partidas. A partir da identificação desse padrão, pode-se alterar algumas variáveis do jogo de modo a produzir uma interação mais adequada à este jogador. 
Essa abordagem considera que o comportamento de um novo jogador deve se encaixar em um dos padrões de comportamento previamente aprendidos. Essa hipótese restringe a aplicabilidade dessa abordagem na prática, pois é praticamente impossível construir um modelo de decisão que reconheça todos os possíveis comportamentos que os jogadores podem apresentar. Além disso, essas abordagens não consideram que o comportamento do jogador pode evoluir ou variar com o decorrer do tempo. Desse modo, abordagens que monitoram a evolução desse comportamento são bastante atraentes, embora ainda pouco exploradas.

Esta tese propôs o estudo de técnicas para detecção de variações comportamentais do jogador no decorrer de sua interação com o ambiente de jogo. Para atingir esse objetivo, foram estudadas diversas técnicas da área de pesquisa conhecida como MFCD.

A MFCD é uma área de pesquisa bastante atual que se preocupa em desenvolver algoritmos capazes de processar um fluxo contínuo de informações sendo geradas no tempo. Em oposição ao cenário de AM tradicional, em um fluxo os dados necessários para induzir um modelo de aprendizado não estão completamente disponíveis a priori, mas sim tornam-se disponíveis a medida que sejam gerados pela aplicação correspondente. Além disso, algumas aplicações geram dados a uma taxa muito elevada, tornando-se proibitivo armazenar todos os dados em memória. Por isso, algoritmos projetados para trabalhar no cenário de fluxos de dados impõem limites quanto a quantidade de memória disponível para utilização e, em geral, processam os dados uma única vez, descartando-os em seguida.

Uma importante característica dos fluxos é que, em alguns casos, não se pode assumir uma distribuição estacionária dos dados. Isso significa que, com o passar do tempo, a aplicação sendo monitorada pode alterar o seu comportamento, fato este que se refletirá nos dados. Os algoritmos de aprendizado para fluxos de dados devem, portanto, levar em consideração a possível mudança de comportamento nos dados durante o tempo. Assim, existem diversos algoritmos projetados especificamente para monitorar os dados em um fluxo e detectar alterações em suas características.

Devido às características encontradas nos algoritmos para aprendizado em fluxos de dados, este trabalho propôs o estudo e utilização dos conceitos aplicados por estes algoritmos na tarefa de detectar automaticamente mudanças de comportamento em jogos. Entretanto, devido às desvantagens particulares dos algoritmos disponíveis na literatura, sua aplicação direta ao domínio dos jogos se fez inviável. Assim, dois novos algoritmos foram projetados de modo a atender as necessidades da tarefa de detecção de mudança de comportamento em jogos computacionais.

O primeiro algoritmo proposto, M-DBScan*, utiliza um algoritmo de agrupamento para fluxos de dados baseado no DenStream e um mecanismo para detecção de novidades cuja inspiração surgiu do algoritmo da RNA SONDE. O M-DBScan* conta ainda com uma estratégia para detecção de mudanças de comportamento a partir de uma sequência de 
novidades detectadas. Assim, o algoritmo M-DBScan* não faz nenhuma suposição a priori sobre o número e o formato dos grupos que estarão presentes nos dados. Além disso, o M-DBScan* implementa um limiar dinâmico para separação entre eventos normais e novidades e também considera a diferenciação entre mudanças de comportamento de eventos outliers. Devido a essas características, o M-DBScan* se diferencia dos demais métodos disponíveis na literatura que abordam a detecção de mudança através de agrupamento de dados e detecção de novidades.

O M-DBScan* também se diferencia de algoritmos estatísticos, como PHT e ADWIN, pois transforma o problema de detecção de mudanças em um fluxo de dados multidimensional para uma série unidimensional. Dessa maneira, o M-DBScan* não precisa ser aplicado separadamente por dimensão, aliviando a complexidade do algoritmo (ver Apêndice A) assim como facilitando a definição de parâmetros que definem limiares.

Os resultados experimentais obtidos demonstram que o M-DBScan* é, de fato, capaz de detectar uma boa parte das mudanças de comportamento, com nível aceitável de FPs, mantendo um atraso para detecção das mudanças bastante razoável. Além disso, quando comparados aos resultados obtidos por outros métodos para detecção de mudanças disponíveis na literatura, os resultados alcançados pelo M-DBScan* foram visivelmente melhores na tarefa em questão.

Em trabalhos futuros, pretende-se investigar o desempenho dessa abordagem em simulações com seres humanos. Também deve ser alvo de investigação futura a implementação de um mecanismo de esquecimento a nível de macro-clusters, de modo que se possa impor limites quanto ao consumo de memória com o passar do tempo. Além disso, uma vez que uma mudança for detectada, a informação presente nos grupos formados poderá ser utilizada para conduzir a adaptação das respostas do jogo.

Os resultados obtidos durante o desenvolvimento deste algoritmo geraram as seguintes publicações:

- VALLIM, R. M. M.; ANDRADE, I. C.; CARVALHO, A. C. P. L. F. Player Modeling using Online Clustering and Novelty Detection. Proceedings of the $\mathrm{X}$ Brazilian Congress on Computational Intelligence, 2011, p. 1-8.

- VAllim, R. M. M.; ANDRADE FILHO, J. A.; CARVALHO, A. C. P. L. F.; GAMA, J. A Density-Based Clustering Approach for Behavior Change Detection in Data Streams. Proceedings of the Brazilian Symposium on Neural Networks, 2012.

- VAllim, R. M. M.; ANDRAde FILHO, J. A.; MELlO, R. F.; CARVALHO, A. C. P. L. F.; GAMA, J. Unsupervised Change Detection in Data Streams. A ser publicado no volume 18(2) da Revista Intelligent Data Analysis.

Além disso, o seguinte artigo foi submetido para a revista Expert Systems with Applications: 
- VAllim, R. M. M.; ANDRAde FILHO, J. A.; MELLO, R. F.; CARVALHO, A. C. P. L. F.; Online Behavior Change Detection in Computer Games.

O segundo algoritmo desenvolvido, WSE, baseia-se na utilização de janelas de dados. O WSE utiliza uma representação dos dados em um domínio de frequências, de modo a comparar janelas sucessivas sob essa nova representação. Para tanto, o algoritmo gera espectrogramas a partir dos dados contidos em cada janela e, em seguida, utiliza uma medida de dissiimilaridade para comparar essas representações gráficas. A partir dessa comparação, o WSE implementa uma estratégia simples de detecção de alterações na medida de dissimilaridade no tempo, indicando assim possíveis mudanças de comportamento presentes nos dados.

O algoritmo WSE, assim como o M-DBScan*, transforma o problema de detecção de mudanças em um fluxo de dados multidimensional para o de detecção em uma série unidimensional, apresentando, portanto, as mesmas vantagens previamente descritas. Além disso, o algoritmo WSE naturalmente desconsidera eventos outliers, graças a seu projeto utilizando janelas de tempo. Finalmente, WSE não faz suposições prévias a respeito dos dados, uma vez que a estratégia empregada apenas transforma os dados de seu domínio original para um domínio de frequências.

Uma característica interessante do WSE é a sua complexidade computacional invariável no tempo (ver Apêndice A), o que permite aplicar este algoritmo em fluxos de dados com alto Sampling Rate.

Os resultados obtidos pelo algoritmo WSE foram promissores em termos da medida $F 1$. Os resultados obtidos por WSE também foram melhores do que aqueles observados pelas outras técnicas para detecção de mudança utilizadas. A principal desvantagem desse algoritmo é que, em alguns casos, o atraso mínimo para detecção de mudanças pode ser igual ou maior que o tamanho da janela de dados utilizada.

Futuramente, também pretende-se aplicar essa abordagem em simulações reais com seres humanos. Um ponto interessante para trabalhos futuros está em considerar a existência de exemplos outliers nos dados na etapa de verificação de matrizes, reduzindo a incidência de FPs. Uma outra direção a ser investigada é a interpretação das informações presentes em um espectrograma, de modo a poder guiar a adaptação das respostas do sistema, nesse caso, do jogo.

Os resultados obtidos durante o desenvolvimento deste algoritmo geraram o seguinte artigo, que será submetido para uma revista internacional:

- VAlLiM, R. M. M.; MELlO, R. F.; CARVALHO, A. C. P. L. F.; GAMA, J. Windowing Specgram: a Spectrogram Based Approach to Behavior Change Detection.

Além dessas publicações, no início deste projeto foi investigada a aplicação de árvores de decisão para fluxos de dados no cenário de jogos. Embora essa abordagem não tenha 
sido levada adiante neste projeto, os resultados obtidos resultaram na seguinte publicação no SBGames de 2010.

- VAllim, R. M. M. ; CARVAlHO A. C. P. L. F. ; GAMA, J. . Data Stream Mining Algorithms for Building Decision Models in a Computer Role Playing Game Simulation. In: Brazilian Symposium on Computer Games and Digital Entertainment, 2010, Florianópolis. Proceedings of the IX SBGames, 2010. p. 106-112.

Este artigo foi premiado na respectiva conferência como um dos melhores artigos apresentados na trilha de Computação.

Além das contribuições acima, este trabalho também contribuiu com a criação de oito conjuntos de dados artificiais contendo diferentes tipos de mudança de comportamento segundo o ponto de vista de agrupamento de dados. Além desses conjuntos, foram também criados vinte e quatro conjuntos de dados a partir das simulações realizadas no FPS UT2004. Estes conjuntos de dados poderão, futuramente, ser utilizados por outros pesquisadores para desenvolvimento e teste de novos algoritmos e técnicas de aprendizado em fluxos de dados.

Finalmente, é importante ressaltar que, embora os algoritmos propostos nesta tese tenham visado a aplicação de jogos em particular, eles podem ser aplicados em outros cenários onde o objetivo seja monitorar o comportamento de um sistema gerando dados no tempo. Exemplos incluem aplicações que monitoram o tráfego em redes, aplicações monitorando um conjunto de sensores industriais e aplicações de monitoramento médico. 
Referências

AGGARWAL, C. C. A framework for diagnosing changes in evolving data streams. In: Proceedings of the 2003 ACM SIGMOD International Conference on Management of Data. [S.I.]: ACM, 2003. p. 575-586.

AGGARWAL, C.; HAN, J.; WANG, J.; YU, P. A framework for clustering evolving data streams. In: Proceedings of the Twenty-Ninth International Conference on Very Large Data Bases. [S.I.]: Morgan Kaufmann, 2003. p. 81-92.

ALBERTINI, M. K.; MELLO, R. F. A Self-Organizing Neural Network to Approach Novelty Detection. In: Intelligent Systems for Automated Learning and Adaptation: Emerging Trends and Applications. [S.I.]: IGI Global, 2010. p. 49-71.

BAKKES, S.; SPRONCK, P.; HERIK, J. van den. Rapid and reliable adaptation of video game ai. Transactions on Computational Intelligence and Al in Games, IEEE Press, v. 1, p. 93-104, 2009.

BECKMANN, N.; KRIEGEL, H. P.; SCHNEIDER, R.; SEEGER, N. The R*-tree: An Efficient and Robust Access Method for Points and Rectangles. In: Proc. ACM SIGMOD Int. Conf. on Management of Data. [S.I.: s.n.], 1990. p. 322-331.

BIFET, A.; GAVALDÀ, R. Learning from Time-changing Data with Adaptive Windowing. In: SIAM International Conference on Data Mining. [S.I.: s.n.], 2007. p. 443-448.

BOASHASH, B. Time-Frequency Signal Analysis and Processing: A Comprehensive Reference. [S.I.]: Oxford: Elsevier Science, 2003.

BRACEWELL, R. N. The Fourier Transform and Its Applications (3rd ed.). [S.I.]: Boston: McGraw-Hill, 2000.

BRIGHAM, E. O. The Fast Fourier Transform. [S.I.]: New York: Prentice-Hall, 2002. 
CAO, F.; ESTER, M.; QIAN, W.; ZHOU, A. Density-based clustering over and evolving data stream with noise. In: Proceedings of the SIAM Conference on Data Mining. [S.I.: s.n.], 2006.

CHARLES, D.; BLACK, M. Dynamic Player Modeling: A Framework for Player-Centric Digital Games. In: Proceedings of the International Conference on Computer Games: Artificial Intelligence, Design and Education. [S.I.: s.n.], 2004. p. 29 - 35.

CILIBRASI, R.; VITÁNYI, P. M. B. Clustering by compression. IEEE Transactions on Information Theory, v. 51(4), p. 1523-1545, 2005.

CORMEN, T. H.; LEISERSON, C. E.; RIVEST, R. L.; STEIN, C. Introduction to Algorithms. [S.I.]: The MIT Press, 2001.

DELALLEAU, O.; CONTAL, E.; THIBODEAU-LAUFER, E.; FERRARI, R. C.; BENGIO, Y.; ZHANG, F. Beyond Skill Rating: Advanced Matchmaking in Ghost Recon Online. To appear at IEEE Transactions on Computational Intelligence and Al in Games, 2011.

DEMSAR, J. Statistical Comparisons of Classifiers over Multiple Data Sets. The Journal of Machine Learning Research, v. 7, p. 1-30, 2006.

DRACHEN, A.; CANOSSA, A.; YANNAKAKIS, G. N. Player modeling using selforganization in tomb raider: Underworld. In: Proceedings of the 5th International Conference on Computational Intelligence and Games. [S.I.]: IEEE Press, 2009. p. 1-8.

DUDA, R.; HART, P.; STORK, D. Pattern Classification. [S.I.]: Wiley-Interscience, 2000.

Epic Games, Digital Extremes. Unreal Tournament 2004. 2004. Atari (Linux/Windows), Macsoft (MacOS), Midway.

ESTER, M.; KRIEGEL, H. P.; SANDER, J.; XU, X. A density-based algorithm for discovering clusters in large spatial databases with noise. In: Proceedings of the Second International Conference on Knowledge Discovery and Data Mining. [S.I.]: AAAI Press, 1996. p. 226-231.

FACELI, K.; LORENA, A. C.; GAMA, J. M. P.; CARVALHO, A. C. P. L. F. Inteligência Artificial - uma abordagem de Aprendizado de Máquina. [S.I.]: Rio de Janeiro: LTC, 2011.

FUNGE, J. D. Artificial Intelligence for Computer Games: An Introduction. [S.I.]: Peters Corp., 2004. ISBN 1568812083.

GALLI, L.; LOIACONO, D.; LANZI, P. Learning a context-aware weapon selection policy for unreal tournament iii. In: Proceedings of the Symposium on Computational Intelligence and Games. [S.I.]: IEEE, 2009. p. 310-316. 
GAMA, J. Knowledge Discovery From Data Streams. [S.I.]: CRC Press, 2010.

GAMA, J.; FERNANDES, R.; ROCHA, R. Decision trees for mining data streams. Intelligent Data Analysis, IOS Press, v. 10, p. 23-45, 2006.

GAMA, J.; MEDAS, P.; CASTILLO, G.; RODRIGUES, P. P. Learning with drift detection. In: Proceedings of the 17th Brazilian Symposium on Artificial Intelligence. [S.I.]: Springer, 2004. p. 286-295.

GAMA, J.; RODRIGUES, P. P. Data Stream Processing. In: Learning from Data Streams: Processing Techniques in Sensor Networks. [S.I.]: Springer, 2007. p. 25-38.

An Overview on Mining Data Streams. In: Studies in Computational Intelligence. [S.I.]: Springer Berlin/Heidelberg, 2009. p. 29-45. ISBN 978-3-642-01090-3.

GEMROT, J.; KADLEC, R.; M.BIDA; BURKET, O.; PIBIL, R.; HAVLICEK, J.; ZEMCAK, L.; SIMLOVIC, J.; VANSA, R.; STOLBA, M.; PLCH, T.; BROM, C. Pogamut 3 can Assist Developers in Building AI (not only) for their Video Game Agents. Lecture Notes in Computer Science: Agents for Games and Simulations, p. 1-15, 2009.

GOLDBERG, D. E. The Design of Innovation: Lessons from and for Competent Genetic Algorithms. [S.I.]: Kluwer Academic Publishers, 2002. ISBN 1-4020-7098-5.

HART, P. E.; NILSSON, N. J.; RAPHAEL, B. A Formal Basis for the Heuristic Determination of Minimum Cost Paths. IEEE Transactions on Systems Science and Cybernetics, v. 4, n. 2, p. $100-107,1968$.

HARTIGAN, J. A.; WONG, M. A. A k-means clustering algorithm. Journal of the Royal Statistical Society. Series C (Applied Statistics), v. 28, n. 1, p. 100-108, 1979.

HAYKIN, S. Advances in Spectrum Analysis and Array Processing. In: Prentice-Hall Signal Processing Series. [S.I.]: Prentice-Hall, 1991. p. 999. . Neural Networks - A Compreensive Foundation. New Jersey: Prentice-Hall, 1999.

HEFNY, A. S.; HATEM, A. A.; SHALABY, M. M.; ATIYA, A. F. Cerberus: Applying supervised and reinforcement learning techniques to capture the flag games. In: Proceedings of the Fourth Artificial Intelligence and Interactive Digital Entertainment Conference. [S.I.]: AAAI Press, 2008. p. 179-184.

HOULETTE, R. Player Modeling for Adaptive Games. In: Al Game Programming Wisdom II. [S.I.]: Charles River Media, 2004. p. 557-566.

HUNICKE, R.; CHAPMAN, V. Ai for dynamic difficult adjustment in games. In: Challenges in Game Artificial Intelligence AAAI Workshop. [S.I.: s.n.], 2004. p. 91-96. 
JAMES, J. F. A Student's Guide to Fourier Transforms (3rd ed.). [S.I.]: Cambridge University Press, 2011.

KNUTH, D. E. Seminumerical Algorithms. In: The Art of Computer Programming. [S.I.]: Addison-Wesley, 1998. p. 232.

KOHONEN, T. Self-organizing maps. [S.I.]: Springer Verlag, 1997.

LUCAS, S. M. Computational Intelligence and Al in Games: A New IEEE Transactions. IEEE Transactions on Computational Intelligence and Al in Games, v. 1, p. 1-3, 2009.

LUCAS, S. M.; KENDALL, G. Evolutionary Computation and Games. IEEE Computational Intelligence Magazine, v. 1, p. 10-18, 2006.

MARSLAND, S. On-line Novelty Detection Through Self-Organisation, With Application to Inspection Robotics. Tese (Doutorado) - University of Manchester, 2002.

MARSLAND, S.; SHAPIRO, J.; NEHMZOW, U. A self-organising network that grows when required. Neural Networks, v. 15, n. 8-9, p. 1041-1058, 2002.

MARTIN, B. Instance-Based Learning: Nearest Neighbor with Generalization. Dissertação (Mestrado) - University of Waikato, 1995.

MARTINEZ, H. P.; HULLETT, K.; YANNAKAKIS, G. N. Extending neuro-evolutionary preference learning through player modeling. In: Proceedings of the Symposium on Computational Intelligence and Games (C/G). [S.I.]: IEEE Press, 2010. p. 313-320.

PAGE, E. S. Continuous Inspection Schemes. Biometrika, v. 41, p. 100-115, 1954.

PRIESTERJAHN, S.; KRAMER, O.; WEIMER, A.; WEIMER, E.; GOEBELS, A. Evolution of reactive rules in multi player computer games based on imitation. In: Proceedings of the International Conference on Natural Computation. [S.I.]: Springer-Verlag, 2005. p. 744-755.

QUINLAN, J. R. C4.5: Programs for Machine Learning. Machine Learning, Springer Netherlands, v. 16, p. 235-240, 1993.

SEBASTIãO, R.; GAMA, J.; RODRIGUES, P.; BERNARDES, J. Monitoring incremental histogram distribution for change detection in data streams. In: Knowledge Discovery from Sensor Data. [S.I.]: Springer Berlin / Heidelberg, 2010, (Lecture Notes in Computer Science, v. 5840). p. 25-42.

SENETA, E. Non-negative Matrices and Markov Chains. Springer Series in Statistics, 2006. 
SHANNON, C. E. A mathematical theory of communication. Bell System Technical Journal, v. 27, p. $379-423$ and $623-656,1948$.

SMITH, A. M.; LEWIS, C.; HULLETT, K.; SMITH, G.; SULLIVAN, A. An Inclusive Taxonomy of Player Modeling. Santa Cruz, CA, 2011.

SPINOSA, E.; CARVALHO, A. C. P. L. F. de; GAMA, J. Olindda: a cluster-based approach for detecting novelty and concept drift in data streams. In: Proceedings of the 2007 ACM Symposium on Applied Computing. [S.I.: s.n.], 2007. p. 448 - 452.

TAN, P.; STEINBACH, M.; KUMAR, V. Introduction to Data Mining. [S.I.]: Addison Wesley, 2005. ISBN 0321321367.

THUE, D.; BULITKO, V.; SPETCH, M.; WASYLISHEN, E. Interactive Storytelling: A Player Modelling Approach. In: Proceedings of the AAAI Conference on Artificial Intelligence and Interactive Digital Entertainment. [S.I.]: Association for the Advancement of Artificial Intelligence (AAAl) Press, 2007. p. 43-48.

THUE, D.; BULITKO, V.; SPETCH, M.; WEBB, M. Socially Consistent Characters in PlayerSpecific Stories. In: Proceedings of the Sixth AAAI Conference on Artificial Intelligence and Interactive Digital Entertainment. [S.I.]: Association for the Advancement of Artificial Intelligence (AAAI) Press, 2011. p. 198-203.

THURAU, C.; BAUCKHAGE, C.; SAGERER, G. Combining self organizing maps and multilayer perceptrons to learn bot-behavior for a commercial computer game. In: Proceedings of GAME-ON (2003). [S.I.]: EUROSIS-EIT, 2003. p. 119-123.

TYCHSEN, A.; CANOSSA, A. Defining personas in games using metrics. In: Proceedings of the 2008 Conference on Future Play: Research, Play, Share. [S.I.]: ACM, 2008. p. 73-80.

University of Waikato. Weka wiki. 2012. Online. Disponível em: http://weka. wikispaces. com/.

VARSTA, M.; MILLáN, J. D. R.; HEIKKONEN, J. A recurrent self-organizing map for temporal sequence processing. In: Proceedings of the 7th International Conference on Artificial Neural Networks. [S.I.]: Springer Verlag, 1997. p. $421-426$.

WARD, J. H. J. Hierarchical Grouping to optimize an objective function. Journal of the American Statistical Association, v. 58, p. 236-244, 1963.

WEBER, B. G.; MATEAS, M. A data mining approach to strategy prediction. In: Proceedings of the 5th International Conference on Computational Intelligence and Games. [S.I.]: IEEE, 2009. p. 140-147. 
WIDMER, G.; KUBAT, M. Learning in the presence of concept drift and hidden contexts. Machine Learning, v. 23, p. 69-101, 1996.

YANNAKAKIS, G. N.; HALLAM, J. Real-time Game Adaptation for Optimizing Player Satisfaction. IEEE Transactions on Computational Intelligence and Al in Games, v. 1, p. 121-133, 2009.

YANNAKAKIS, G. N.; MARAGOUDAKIS, M. Player Modeling Impact on Player's Entertainment in Computer Games. Lecture Notes in Computer Science, v. 3538, p. 74-48, 2005.

ZANETTI, S.; RHALIBI, A. E. Machine learning techniques for fps in q3. In: Proceedings of the 2004 ACM SIGCHI International Conference on Advances in Computer Entertainment Technology. [S.I.]: ACM, 2004. p. 239-244.

ZHANG, T.; RAMAKRISHNAN, R.; LIVNY, M. BIRCH: An efficient data clustering method for very large databases. In: Proceedings of the 1996 ACM SIGMOD International Conference on Management of Data. [S.I.]: ACM Press, 1996. p. 103-114.

ZIV, J.; LEMPEL, A. A Universal Algorithm for Sequential Data Compression. IEEE Transactions on Information Theory, v. 23, n. 3, p. 337-343, 1977. 


\section{Complexidade Computacional dos Algoritmos Propostos}

Neste capítulo são realizadas algumas considerações sobre a complexidade computacional dos algoritmos M-DBScan* na configuração ISDR1R2 e WSE. Esses algoritmos foram analisados por terem apresentado os melhores resultados dentre todas as abordagens propostas neste trabalho. A metodologia empregada para análise da complexidade computacional considera o limite assintótico superior de uma função $g(n)$, expresso usando a notação $O(g(n))$. Uma vez que a notação $O$ descreve um limite superior no pior caso, tem-se automaticamente um limitante no tempo de execução do algoritmo para todas as possíveis entradas (CORMEN et al., 2001).

\section{A.1 M-DBScan*}

O M-DBScan* é um algoritmo incremental que pode ser dividido em três etapas: agrupamento, detecção de novidades e detecção de mudanças de comportamento. Cada exemplo disponível no fluxo deve passar, obrigatoriamente, por cada uma dessas etapas. Portanto, a complexidade do M-DBScan* é dada pela complexidade para processar um exemplo que, por sua vez, é expressa pelo somatório das complexidades associadas à cada uma das etapas do algoritmo. Como o número de dimensões presentes nos dados é invariável do início ao final do fluxo, esse fator não será considerado no cálculo da complexidade, uma vez que pode ser considerado como uma constante.

A etapa de agrupamento do M-DBScan* é dividida em duas fases: micro e macroagru- 
pamento. Na fase de microagrupamento, para cada exemplo de entrada, o M-DBScan* deve verificar se existe um p-micro-cluster para recebê-lo. Para tanto, é necessário calcular a distância entre o exemplo e o centro de cada $p$-micro-cluster. Se denotarmos por $n$ o número de $p$-micro-clusters existentes, então a complexidade da fase de microagrupamento é da ordem de $O(n)$ operações. Em seguida, na fase de macroagrupamento, aplica-se o algoritmo $D B S$ can sobre os $p$-micro-clusters existentes. A complexidade computacional do $D B S c a n$ é governada pelo número de vezes que se calcula a vizinhança de um ponto, de modo a determinar os pontos que são diretamente conectados por densidade. O cálculo da vizinhança pode ser implementado em $O(\log (n))$ operações utilizando-se métodos de acesso espacial, como as $R^{*}$-trees (BECKMANN et al., 1990). Como a vizinhança de um ponto é calculada uma única vez, então a complexidade do DBScan é $O(n *(\log (n)))$ (ESTER et al., 1996). Note que o número de pontos $n$ é igual ao número de p-micro-cluster existentes.

Assim, a complexidade da etapa de agrupamento do M-DBScan* $\left(C_{A}\right)$ é representada na Equação A.1.

$$
C_{A}=O(n)+O(n *(\log (n)))
$$

A etapa seguinte de detecção de novidades do M-DBScan* consiste, primeiramente, na atualização da medida de entropia espacial. Para cálculo da medida de entropia são necessárias $O(N)$ operações, onde $N$ é o número de macro-clusters gerados na etapa de agrupamento. Em seguida, o algoritmo atualiza a média móvel de entropias $(\Phi)$, o desvio padrão incremental $(\Omega)$ e o limiar dinâmico $(\tau)$. Essas operações são incrementais e, portanto, a complexidade é constante, i.e., $O(1)$.

A verificação de novidades pela restrição R1 é implementada por uma simples operação que verifica se a entropia atual é superior ao limiar $(\tau)$. A restrição $\mathrm{R} 2$ também é baseada em verificações implementadas de modo incremental. Portanto, a complexidade para ambas as restrições é $O(1)$. Assim, a complexidade da etapa de detecção de novidades do M-DBScan* $\left(C_{D N}\right)$ é governada pelo cálculo da medida de entropia e é portanto $O(N)$.

A etapa final do M-DBScan* verifica a ocorrência de uma mudança de comportamento a partir das novidades detectadas. Para tanto, o algoritmo utiliza uma janela deslizante, atualizada a cada ocorrência de novidade. Para verificar a ocorrência de uma mudança de comportamento, o M-DBScan* verifica o número de novidades ocorrendo dentro da janela. Essa verificação é incremental e, portanto, a complexidade para detecção de mudanças $\left(C_{D M}\right)$ usando a janela deslizante também pode ser considerada constante, ou seja, $O(1)$.

Dessa maneira, tem-se que a complexidade total do M-DBScan* é dada pela soma das complexidades em cada uma das três etapas. Essa complexidade é apresentada na Equação A.2. 


$$
C_{M-D B S c a n *}=C_{A}+C_{D N}+C_{D M}
$$

Incluindo-se as respectivas complexidades na Equação A.2 obtém-se a Equação A.3.

$$
C_{M-D B S c a n *}=O(n)+O(n *(\log (n)))+O(N)+O(1)
$$

Como o número de macro-clusters tende a ser menor do que o número de p-microclusters, ou seja, $N<n$ então pode-se considerar que a complexidade computacional do M-DBScan* é governada pelo termo $O(n)+O(n *(\log (n)))$ e, portanto, a complexidade final do algoritmo é $O(n *(\log (n)))$.

\section{A.2 WSE}

O algoritmo WSE pode ser dividido em quatro etapas sucessivas: cálculo da DFT para geração de espectrogramas, geração de valores de NCD, verificação das matrizes dos espectrogramas e detecção de mudanças. Portanto, a complexidade do WSE, assim como no caso do M-DBScan*, pode ser escrita como um somatório das complexidades associadas à cada etapa do algoritmo. Como o número de dimensões presentes nos dados é invariável do início ao final do fluxo, esse fator não será considerado no cálculo da complexidade, uma vez que pode ser considerado como uma constante.

A primeira etapa do algoritmo WSE é a aplicação da DFT aos dados contidos nas janelas $W 1$ e $W 2$. Uma vez que o algoritmo FFT é utilizado para calcular os coeficientes de Fourier, para cada janela tem-se uma complexidade de $O(N * \log (N))$ operações, onde $N$ é o tamanho da janela. Uma vez que duas janelas são utilizadas, tem-se uma complexidade total para essa etapa igual a $O(2 *(N * \log (N)))$. Como o termo 2 é constante, tem-se que a complexidade para esse passo do algoritmo $\left(C_{D F T}\right)$ é igual a $O(N * \log (N))$.

A segunda etapa de WSE gera um valor de NCD entre os espectrogramas construídos a partir dos coeficientes de Fourier. A complexidade computacional do cálculo de NCD $\left(C_{N C D}\right)$ é $O(f(n))$, onde $f(n)$ é o custo computacional associado à tarefa de compressão dos arquivos contendo as matrizes dos espectrogramas. Neste trabalho, o algoritmo compressor gzip foi utilizado. O gzip é baseado no algoritmo compressor LZ77 (ZIV; LEMPEL, 1977), cuja complexidade é $O(n)$, onde $n$ é o número de caracteres no arquivo. Assim, como o WSE comprime três arquivos, a complexidade é dominada pela compactação do maior arquivo. Se o maior arquivo contiver $n$ caracteres, então a complexidade é no máximo $O(n)$. Portanto, $O(f(n))=O(n)$.

O algoritmo WSE verifica, em seguida, a ocorrência de colunas nulas nas matrizes que representam os espectrogramas. Verificar quais colunas são nulas em uma matriz contendo $p$ linhas e $q$ colunas requer, no pior caso, $O(p * q)$ operações. Entretanto, se durante a geração da matriz for construído também um vetor de $q$ posições que armazena a soma 
dos elementos em cada coluna da matriz (o que pode ser feito de maneira incremental), então a verificação das colunas nulas $\left(C_{V M}\right)$ pode ser implementada em $O(q)$. Faz-se ainda necessário considerar que duas matrizes devem ser verificadas. Entretanto, isso não altera a complexidade obtida pois é equivalente à adição de um termo multiplicador constante.

A etapa final do algoritmo WSE compara valores de NCD consecutivos, indicando mudanças quando a diferença entre eles for maior do que $\epsilon$. Esse passo consiste em uma única operação de comparação realizada de modo incremental e, portanto, sua complexidade $\left(C_{D M}\right)$ é igual a $O(1)$.

Assim, a complexidade computacional total do algoritmo WSE, apresentada na Equação A.4, é dada pela soma das complexidades em cada etapa.

$$
C_{W S E}=C_{D F T}+C_{N C D}+C_{V M}+C_{D M}
$$

Incluindo-se as respectivas complexidades na Equação A.4 obtém-se a Equação A.5.

$$
C_{W S E}=O(N * \log (N))+O(n)+O(q)+O(1)
$$

Como o último termo é constante, pode-se simplificar a complexidade na Equação A.5 como na Equação A.6.

$$
C_{W S E}=O(N * \log (N))+O(n)+O(q)
$$

Segundo a Equação A.6, é possível observar que a complexidade do algoritmo WSE é dominada pelo cálculo da FFT e, portanto a complexidade final do WSE é $O(N * \log (N)))$. 